NATIONAL LABORATORY

MANAGED BY UT-BATTELLE

FOR THE DEPARTMENT OF ENERGY

\title{
Cracking and Corrosion of Composite Tubes in Black Liquor Recovery Boiler Primary Air Ports
}

\section{October 2006}

\section{Prepared by}

James R. Keiser, Douglas L. Singbeil, Gorti B. Sarma, Joseph R. Kish, Jerry Yuan, Laurie A. Frederick, Kimberly A. Choudhury, J. Peter Gorog, François R. Jetté, Camden R. Hubbard, Robert W. Swindeman, Preet M. Singh, and Philip J. Maziasz

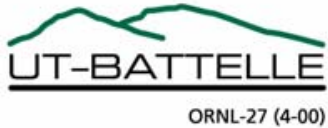




\section{DOCUMENT AVAILABILITY}

Reports produced after January 1, 1996, are generally available free via the U.S. Department of Energy (DOE) Information Bridge.

Web site http://www.osti.gov/bridge

Reports produced before January 1, 1996, may be purchased by members of the public from the following source.

National Technical Information Service

5285 Port Royal Road

Springfield, VA 22161

Telephone 703-605-6000 (1-800-553-6847)

TDD 703-487-4639

Fax 703-605-6900

E-mail info@ntis.gov

Web site http://www.ntis.gov/support/ordernowabout.htm

Reports are available to DOE employees, DOE contractors, Energy Technology Data Exchange (ETDE) representatives, and International Nuclear Information System (INIS) representatives from the following source.

Office of Scientific and Technical Information

P.O. Box 62

Oak Ridge, TN 37831

Telephone 865-576-8401

Fax 865-576-5728

E-mail reports@osti.gov

Web site http://www.osti.gov/contact.html

This report was prepared as an account of work sponsored by an agency of the United States Government. Neither the United States Government nor any agency thereof, nor any of their employees, makes any warranty, express or implied, or assumes any legal liability or responsibility for the accuracy, completeness, or usefulness of any information, apparatus, product, or process disclosed, or represents that its use would not infringe privately owned rights. Reference herein to any specific commercial product, process, or service by trade name, trademark, manufacturer, or otherwise, does not necessarily constitute or imply its endorsement, recommendation, or favoring by the United States Government or any agency thereof. The views and opinions of authors expressed herein do not necessarily state or reflect those of the United States Government or any agency thereof. 
ORNL/TM-2006/112

Materials Science and Technology Division

\title{
CRACKING AND CORROSION OF COMPOSITE TUBES IN BLACK LIQUOR RECOVERY BOILER PRIMARY AIR PORTS
}

\author{
James R. Keiser* \\ Douglas L. Singbeil ${ }^{\dagger}$ \\ Gorti B. Sarma \\ Joseph R. Kish \\ Jerry Yuan
}

\author{
Laurie A. Frederick ${ }^{\dagger}$ \\ Kimberly A. Choudhury ${ }^{*}$ \\ J. Peter Gorog ${ }^{\S}$ \\ François R. Jetté** \\ Camden R. Hubbard*
}

\author{
Robert W. Swindeman ${ }^{*}$ \\ Preet M. Singh ${ }^{\dagger \dagger}$ \\ Philip J. Maziasz
}

* Oak Ridge National Laboratory, Oak Ridge, Tennessee

${ }^{\dagger}$ Pulp and Paper Research Institute of Canada, Vancouver, British Columbia

*Process Simulations Limited, Vancouver, British Columbia

${ }^{\S}$ Weyerhaeuser Company, Federal Way, Washington

** Domtar Incorporated, Montréal, Quebec

${ }^{\dagger \dagger}$ Georgia Institute of Technology, Atlanta, Georgia

October 2006

\author{
Prepared by \\ OAK RIDGE NATIONAL LABORATORY \\ P.O. Box 2008 \\ Oak Ridge, Tennessee 37831-6283 \\ managed by \\ UT-BATTELLE, LLC \\ for the \\ U.S. DEPARTMENT OF ENERGY \\ under contract DE-AC05-00OR22725
}





\section{CONTENTS}

Page

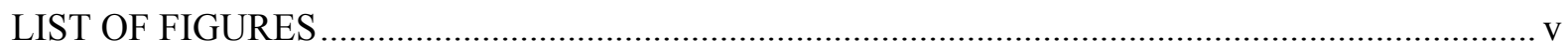

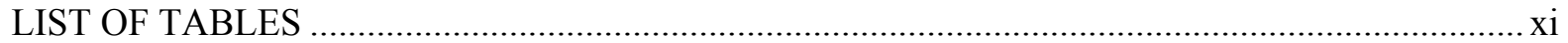

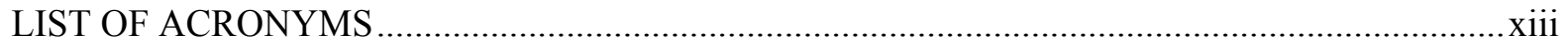

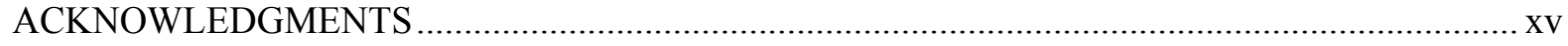

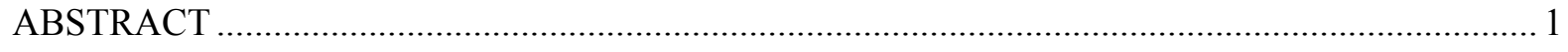

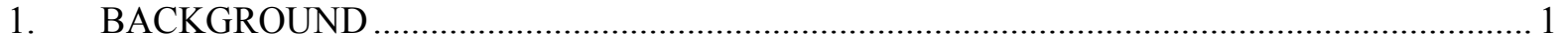

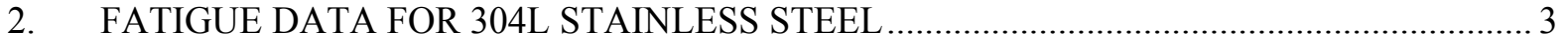

3. FIELD OBSERVATIONS OF CRACKING OF PRIMARY AIR PORT TUBES .................... 7

4. LABORATORY OBSERVATIONS OF CRACKED AIR PORT TUBES ............................. 9

5. ENVIRONMENT CHARACTERIZATION_-TEMPERATURE STUDIES .......................... 11

5.1 THERMOCOUPLE INSTALLATION AND POSITIONING .................................... 11

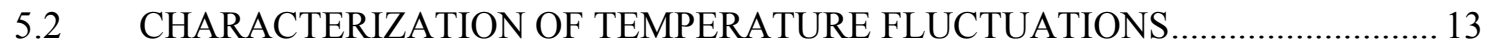

5.2.1 Count of "Time above a Critical Temperature" ............................................ 13

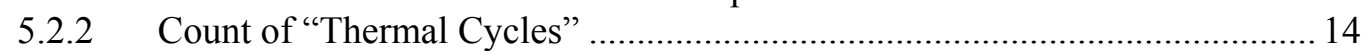

5.3 PRIMARY AIR PORT TEMPERATURE MEASUREMENTS …............................. 15

5.4 INITIAL OBSERVATIONS OF THE EFFECTS OF BOILER OPERATING

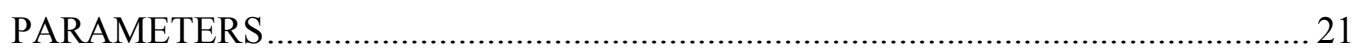

6. ENVIRONMENT CHARACTERIZATION—CAMERA STUDIES ….................................. 27

6.1 USING AN IN SITU VIDEO CAMERA TO DIAGNOSE THE CAUSE OF

TEMPERATURE FLUCTUATIONS ON AIR PORT TUBES IN KRAFT

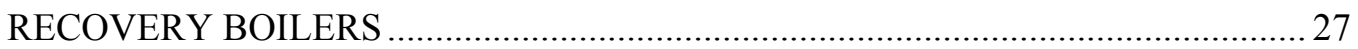

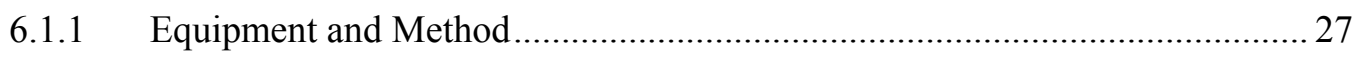

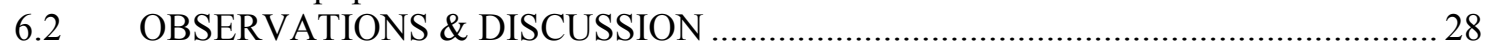

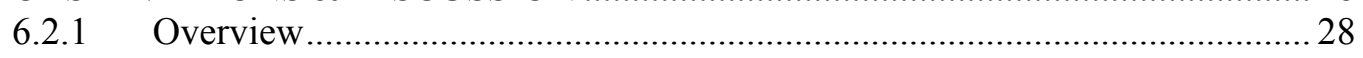

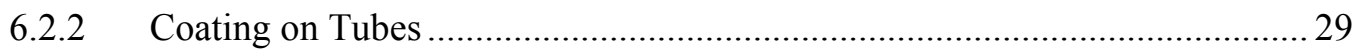

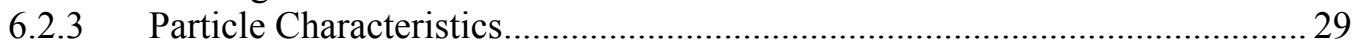

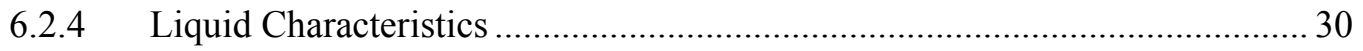

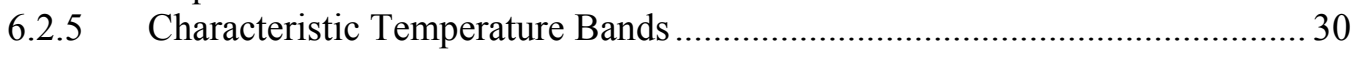

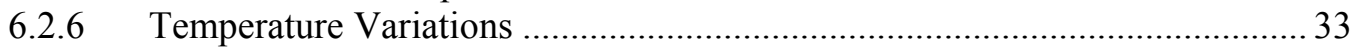

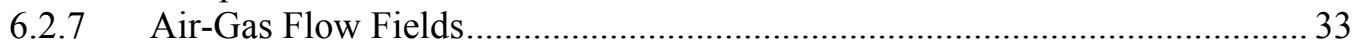

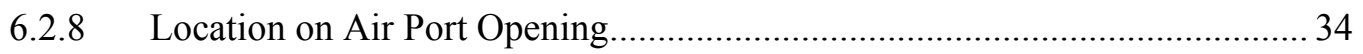

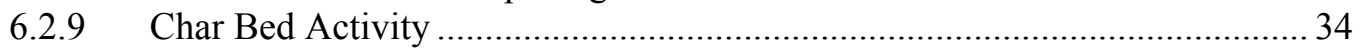

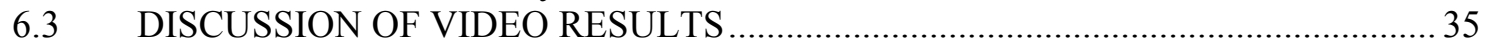

6.3.1 Discussion of Observed Conditions Associated with High Temperatures ..... 36

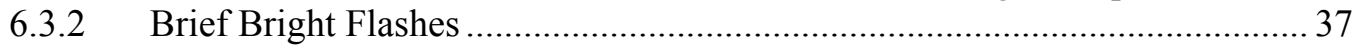

6.3.3 Initiation of a High Temperature Excursion .................................................... 37

6.3.4 Hot Liquid Smelt at Tube Bend Surfaces .................................................... 38

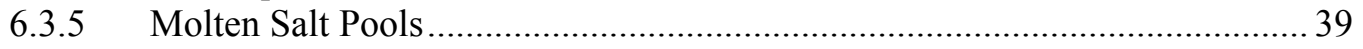

6.3.6 Comparison of Normal and High Temperature Conditions .............................. 39

6.3.7 Sulfate/Sulfide Redox Cycle ......................................................................... 41

6.3.8 Simultaneous Burning of Supplemental Fuel .............................................. 42

6.3.9 Lingering Evidence of High Temperature Conditions.................................... 43

6.3.10 Conditions at Bottom of Primary Air Ports ................................................. 44

6.4 SUMMARY 46 
7. COMPUTATIONAL FLUID DYNAMICS MODELING OF RECOVERY BOILERS

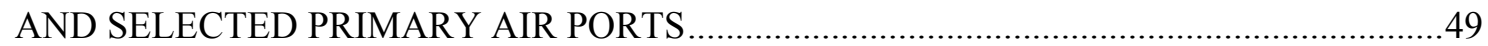

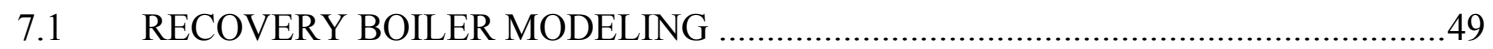

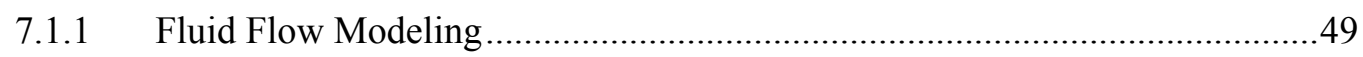

7.1.2 Black Liquor Combustion Modeling .........................................................49

7.1.3 Modeling of Selected Recovery Boilers .....................................................50

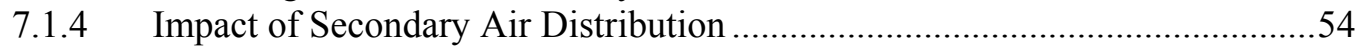

7.1.5 Modeling of Recovery Boiler-P and Recovery Boiler-A …...........................79

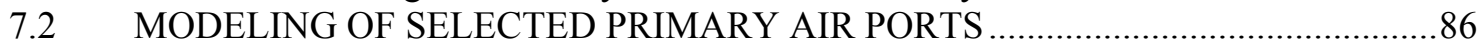

7.2.1 Comparison between Different Designs at Same Location .............................86

7.2.2 Comparison of Same Design between Different Locations .............................86

7.2.3 Comparison of Same Design under Different Operation Conditions ................97

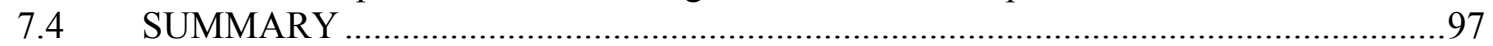

8. REDUCING THERMAL EXCURSIONS THROUGH CHANGES IN BOILER

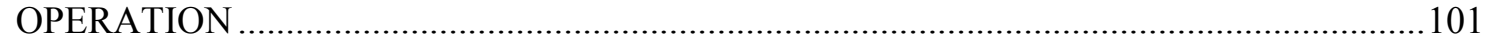

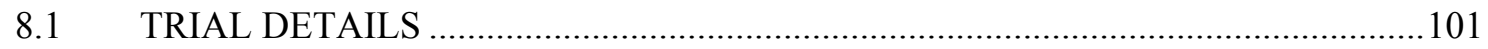

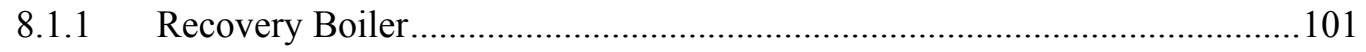

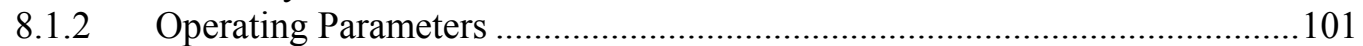

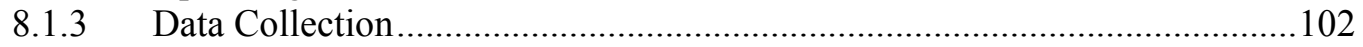

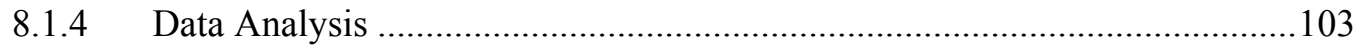

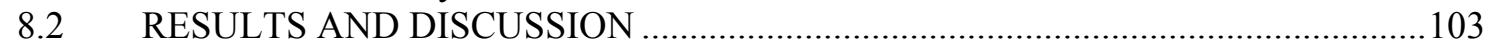

8.2.1 Operating Parameters and Thermal Fluctuations .........................................103

8.2.2 Critical Conditions for Thermal Fluctuations.................................................111

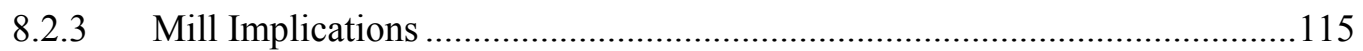

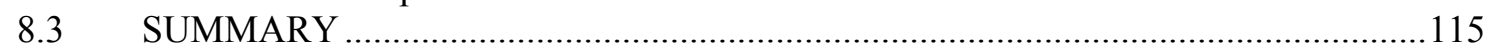

9. MODELING OF STRESSES IN PRIMARY AIR PORT COMPOSITE TUBES ....................117

9.1 MODELING OF HEAT FLUX REQUIRED TO CAUSE LOCALIZED

TEMPERATURE EXCURSIONS ....................................................................... 123

10. NEUTRON AND X-RAY DIFFRACTION MEASUREMENT OF RESIDUAL

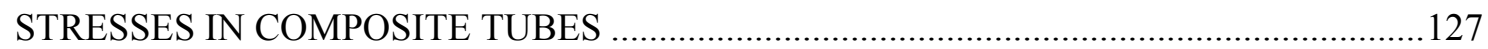

11. SCC RESISTANCE OF ALTERNATIVE COMPOSITE TUBE MATERIALS .....................131

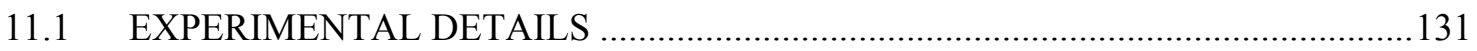

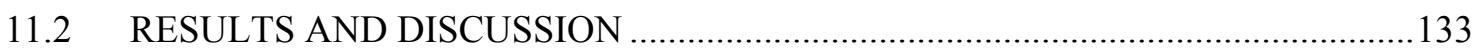

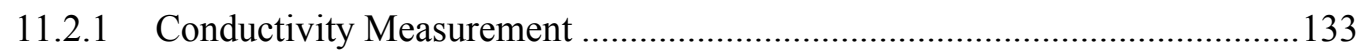

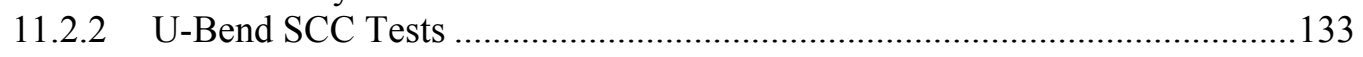

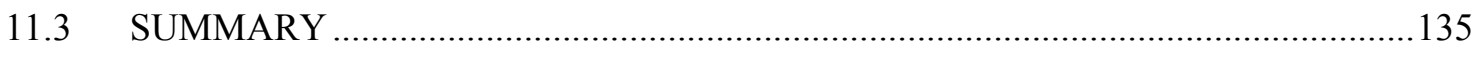

12. NORTH AMERICAN EXPERIENCE WITH ALTERNATIVE COMPOSITE TUBE

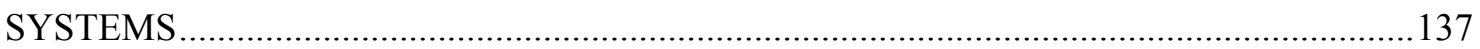

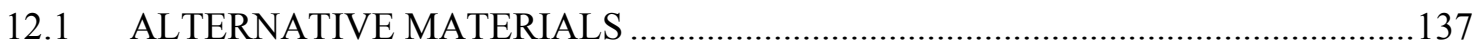

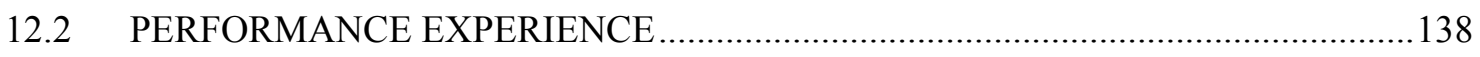

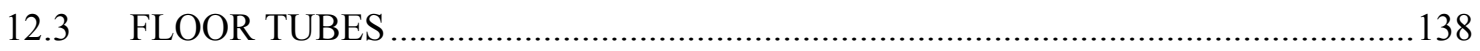

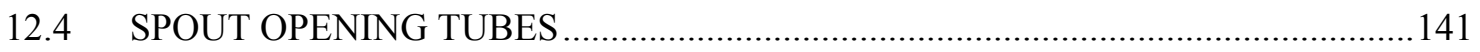

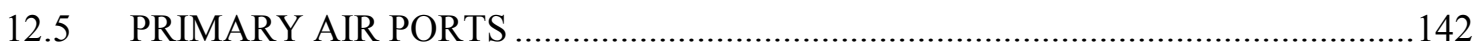

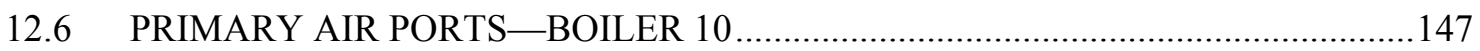

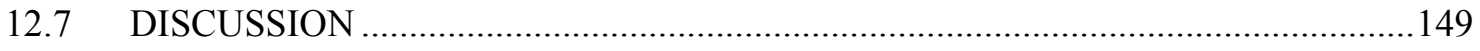

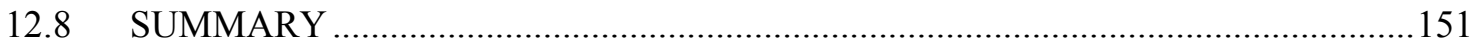

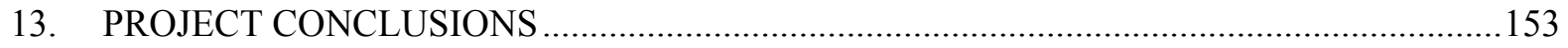

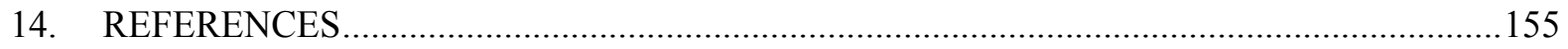




\section{LIST OF FIGURES}

Figure

Page

1

ASME fatigue design curve for 300 series stainless steels for $427^{\circ} \mathrm{C}$ 3 ASME fatigue design curve for 300 series stainless steels for $427^{\circ} \mathrm{C}$ with additional laboratory-generated data included 4 TEM examination of tube sample shows differences between spout opening tube, floor tube and air port tube

Examples of cracked primary air port opening tubes with (left to right) craze cracking, circumferential cracking, membrane cracking and cracking in the

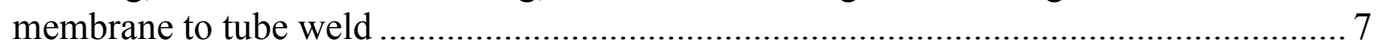

Cracks in 304L stainless steel clad tubes just below the air port opening ....................... 9

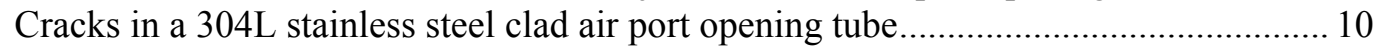

Cracks in an alloy 625 clad air port opening tube.

Thermocouples were mounted on the portion of air port opening tubes in the area where cracking was frequently observed .....

Examples of the thermocouple installations used in the first three boilers equipped with thermocouples on the primary air port tubes.

Data collected every 10 seconds plotted to show the rise and fall of a thermal fluctuation over a four minute time period recorded by thermocouples placed in a recovery boiler

Assembly used to compare performance of chordal versus surface thermocouples. ...... 13

Cycle count and ASTM "rainflow" method lead to almost identical variations in number of cycles

Plot of cycles and data points $>450^{\circ} \mathrm{C}$ for six North American recovery boilers for one year period

The numbered thermocouple positions shown above were used to observe temperature variations around the air ports in one mill.

Thermocouples record severe thermal activity on left hand side wall of a North

American black liquor recovery boiler.

Sketch showing the locations at which thermocouples were installed in one boiler to determine the variation in temperature patterns around the air port ....

Thermocouples in each monitored position surrounding boiler air ports are graphed to demonstrate activity displayed in individual positions

Plot of temperatures measured at two locations on the fireside of a primary air port tube (R24-1 and R24-5) and the temperatures measured at equivalent locations on the windbox side of the same tubes.

Data from three different mills show the difference in thermal fluctuations

between air ports with and without a history of cracking

Activity from two different air ports compared over a five day period

Plot of temperature versus time for two thermocouples on primary air port opening tubes in a boiler originally equipped with the longer, narrower air port design .....

Start-up procedures at four mills demonstrate the increase in thermal activity as black liquor is first sprayed into the boiler.

Plot demonstrates the volatility within the boiler as a sequence of high and low temperature black liquor is fired during a time trial..... 
Typical temperature fluctuations seen during operation on liquor with normal (left) and reduced (right) solids content.

Plot of temperatures measured by primary air port thermocouples on the right hand side wall and the front wall when the secondary air pattern was changed from 5 versus 5 to 3 versus 2 .

Cycles and excursions plotted for continuous in-service thermocouples over a five year period in one North American boiler .

Temperatures measured in secondary air ports of boiler with history of primary air port cracking ......

Plot of temperature vs time showing apparent effect on secondary air port

thermocouples of automatic secondary air port rodder operation at 20 minute

intervals.

Thermocouple measurements for thermocouples on the straight and bent tubes of a " $D$ " shaped primary air port opening on a boiler with $7.6 \mathrm{~cm}$ (3 in.) OD tubes on $10.2 \mathrm{~cm}$ (4 in.) centers

Camera probe inserted through primary air port opening shutdown; it records activities on the fireside of the primary air port.

Primary air port during shutdown; view gained looking down towards boiler floor with the boiler-view camera

Temperature measurements from thermocouples installed on tube bends at the bottom of a primary air port; expansion of data time scale assisted in the recognition of tow dominant temperature bands

Temperature measurements from thermocouples installed on tube bends at the bottom of a primary air port (a) example of characteristic temperatures in the upper temperature band and (b) example of characteristic temperatures in the lower temperature band

View of the air port opening tubes as seen by the boiler camera probe taken while

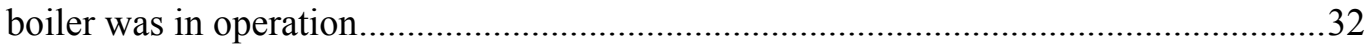

Primary air system of Boiler-Q......

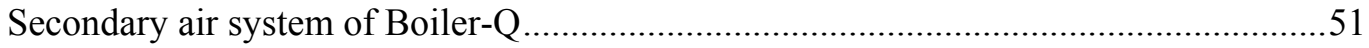

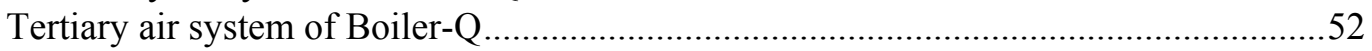

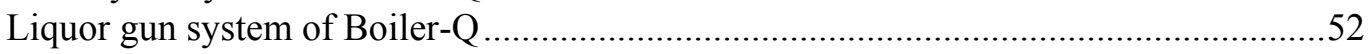

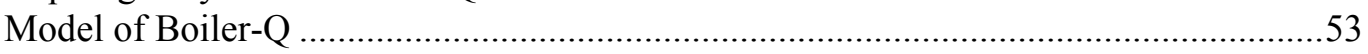

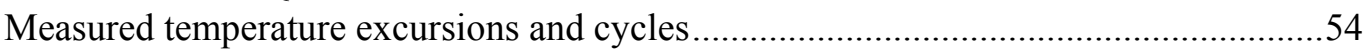

Predicted wall deposition in Case Before and Case After of Boiler-Q............................56

Predicted gas temperature near the walls in Boiler-Q ..................................................57

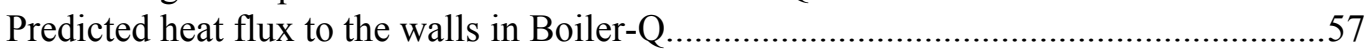

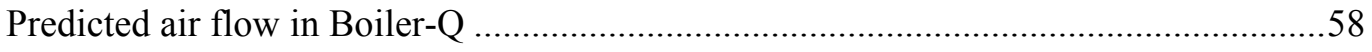

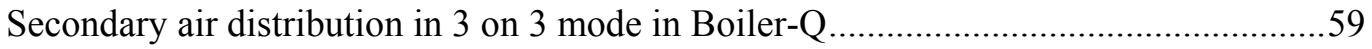

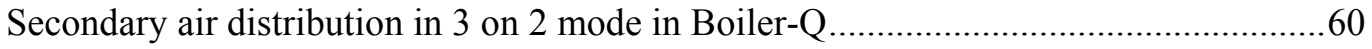

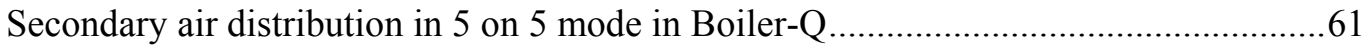

$\begin{array}{ll}48 & \text { Secondary air distribution in } 4 \text { on } 4 \text { mode in Boiler-Q ..............................................62 } \\ 49 \text { (a) } & \text { Gas temperatures under different secondary air distribution modes in Boiler-Q ..........64 }\end{array}$

49(b) Gas temperatures under different secondary air distribution modes in Boiler-Q ...........65

50(a) Vertical velocities under different secondary air distribution modes in Boiler-Q...........66

50(b) Vertical velocities under different secondary air distribution modes in Boiler-Q..........67

51(a) Heat flux under different secondary air distribution modes in Boiler-Q .......................68

51(b) Heat flux under different secondary air distribution modes in Boiler-Q .......................69

51(c) Heat flux under different secondary air distribution modes in Boiler-Q ........................70 
52(a) Trajectories of small droplets under different secondary air distribution modes in

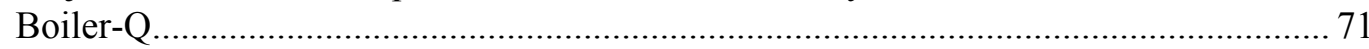

52(b) Trajectories of small droplets under different secondary air distribution modes in

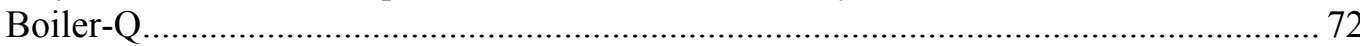

53(a) Trajectories of medium droplets under different secondary air distribution modes

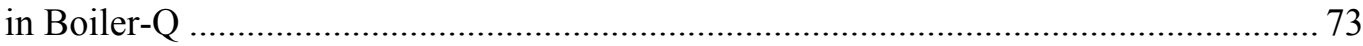

53(b) Trajectories of medium droplets under different secondary air distribution modes

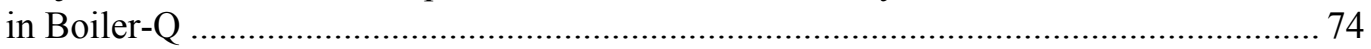

54(a) Air flow under different secondary air distribution modes in Boiler-Q ......................... 75

54(b) Air flow under different secondary air distribution modes in Boiler-Q........................ 76

54(c) Air flow under different secondary air distribution modes in Boiler-Q........................ 77

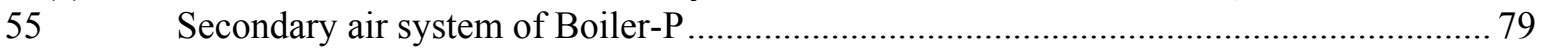

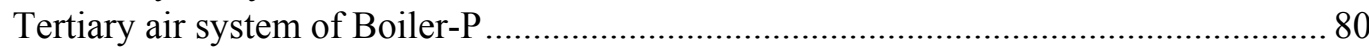

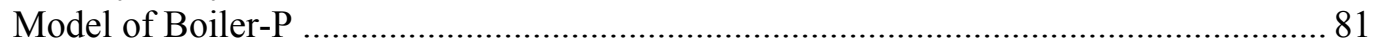

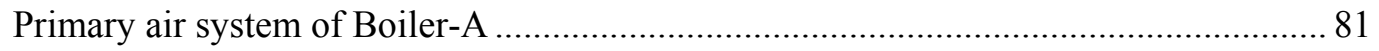

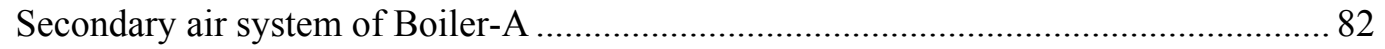

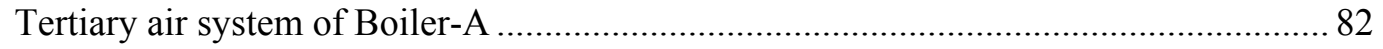

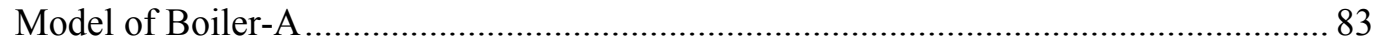

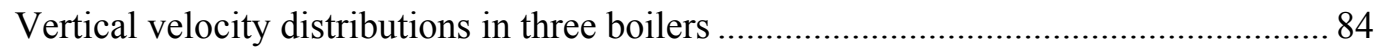

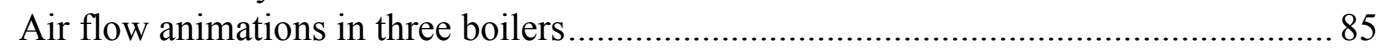

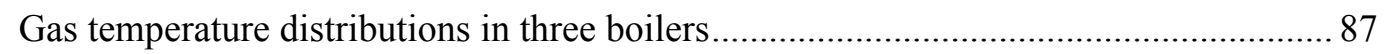

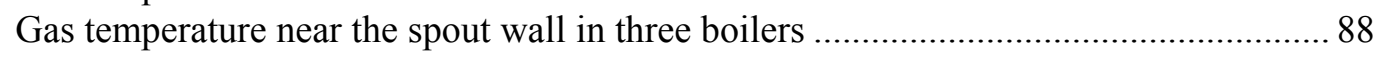

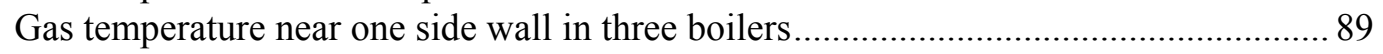

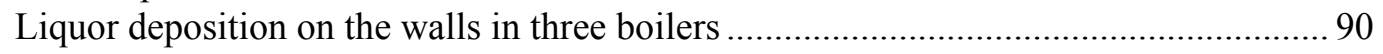

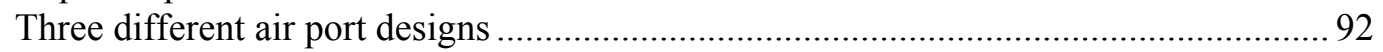

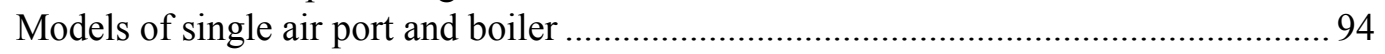

Comparison between Design A and Design B at same location ..................................... 95

Comparison between Design A and Design C at same location .................................. 96

Comparison of same design under different operation conditions ................................ 98

Comparison of Design A at different locations........................................................ 100

Schematic illustration showing primary air ports instrumented with thermocouples and their locations on tubes in and around primary air ports ..................................... 103

75 Plots comparing trend in cracking statistics with trend in thermal activity .................. 104

76 Plot of primary air jet momentum as a function of the windbox showing influence of combustion air changes made to optimize the system during Trials I and II............ 106

77 Plot of secondary air jet momentum as a function of the windbox showing influence of combustion air changes made to optimize system during Trials I

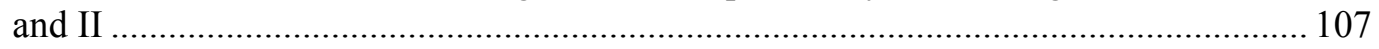

78 Plot comparing thermal activity for trial pairs showing the influence of burning soap in combination with black liquor for each nozzle type under study 108

79 Plot comparing thermal activity for trial pairs showing the influence of nozzle type under study with and without the burning of soap in combination with black liquor

80 Plot comparing thermal activity for trial pairs showing the combined additive influence of nozzle type and burning of soap in combination with black liquor

81 The three critical conditions required for the large thermal fluctuations associated with primary air port cracking: simultaneous char bed contacting the port tubes, a high flux of droplets contacting the port tube while pyrolysis and possibly dehydration is incomplete, and low primary air jet momentum. 
Schematic contour map of char bed shape and height around the time of the verification experiments

Schematic representation based on measurements (left) was used to generate a finite element mesh for one side of the primary air port (right)

Temperature $\left[{ }^{\circ} \mathrm{C}\right]$ contours on the outside (left) and inside (right) surface of the primary air port composite tubes under normal operating conditions

Variation of hoop and axial stresses during a normal operating cycle at the fireside surface (left) and at the inside surface (right), of a primary air port composite tube.....118 Temperature $\left[{ }^{\circ} \mathrm{C}\right]$ contours at the fireside surface of primary air port during localized heating

Stress variation at the fireside surface of the $304 \mathrm{~L}$ clad composite tube during normal operating cycle and during localized heating to $450^{\circ} \mathrm{C}$ (left) and $600^{\circ} \mathrm{C}$ (right)

Stress variation at the interface on the carbon steel side of the 304L clad composite tube during normal operating cycle and during localized heating to $450^{\circ} \mathrm{C}$ (left) and $600^{\circ} \mathrm{C}$ (right).

Stress variation at the inside surface of the $304 \mathrm{~L}$ clad composite tube during normal operating cycle and during localized heating to $450^{\circ} \mathrm{C}$ (left) and $600^{\circ} \mathrm{C}$ (right)

91 Stress variation at the fireside surface of the alloy 825 clad composite tube during normal operating cycle and during localized heating to $450^{\circ} \mathrm{C}$ (left) and $600^{\circ} \mathrm{C}$ (right)

Stress variation at the interface on the carbon steel side of the alloy 825 clad composite tube during normal operating cycle and during localized heating to $450^{\circ} \mathrm{C}$ (left) and $600^{\circ} \mathrm{C}$ (right).

Stress variation at the inside surface of the alloy 825 clad composite tube during normal operating cycle and during localized heating to $450^{\circ} \mathrm{C}$ (left) and $600^{\circ} \mathrm{C}$ (right).....

Heat flux $\left[\mathrm{W} / \mathrm{mm}^{2}\right]$ contours on the outside surface of primary air port showing region of increased heat flux on the lower portion of the bent tube Variation of heat flux (left) and corresponding temperature (right) during localized heating due to combustion of black liquor droplets on the primary air port tube surface. Variation of heat flux (left) and corresponding temperature (right) during localized heating due to oxidation of $\mathrm{Na}_{2} \mathrm{~S}$ in the smelt on the primary air port tube surface .......125

97 Change in temperature at the fireside surface of primary air port tubes due to increase in heat flux (left) and due to increase in the boiler temperature (right)....

98 Photo of a 304L stainless steel clad tube bent in the shape required for the most

common air port design used in North American boilers ....

99 Surface residual axial stresses measured (a) at selected locations along the tube and (b) at selected locations around the circumference of the tube.....

100 Results of neutron diffraction residual stress measurements showing stresses in both the 304L stainless steel and the carbon steel (ferrite) as a function of position along the tube.

101 Axial strain measured at several points through the wall thickness of a previously exposed 304L stainless steel/carbon steel tube. 
103 Change in voltage across a fixed resistor in the apparatus circuit and temperature of $75 \% / 25 \% \mathrm{Na}_{2} \mathrm{~S} / \mathrm{NaOH}$ molten hydrate mixture

104 Micrographs showing nature of cracking found in U-bends after exposure to $75 \% / 25 \% \mathrm{Na}_{2} \mathrm{~S} / \mathrm{NaOH}$ molten hydrate mixture at $180^{\circ} \mathrm{C}$ for 48 hours

105 Bar chart comparing influence of metallurgical condition on the maximum crack depth recorded in U-bends after exposure in to $75 \% / 25 \% \mathrm{Na}_{2} \mathrm{~S} / \mathrm{NaOH}$ molten hydrate mixture at $180^{\circ} \mathrm{C}$ for 48 hours

106 Cracks formed in weld-overlaid UNI309/CS composite floor tubes installed in Boiler 18 after 24 months of exposure

107 Cracks in weld-overlaid UNI625/CS composite floor membrane installed in Boiler 11 after 12 months exposure

108 Cracks in co-extruded SAN65/CS composite floor membrane installed in Boiler 11 after 12 months exposure

109 Cracks in co-extruded A625/CS composite tube installed in a spout opening after 48 months of exposure in Boiler 3

110 Pictures of the various primary air port designs under consideration in this study....... 143

111 Cracks in co-extruded SAN38/CS composite tube fabricated into primary air port installed in Boiler 1 after 42 months of service.

112 Cladding thickness of SAN38/CS composite tubes fabricated into Port B installed in Boiler 10 after 12 months of service

113 Photograph showing membrane-type cracking in primary air port comprised of weld-overlaid UNI625/CS composite opening tubes installed in Boiler 8 after 12 months of service

114 Overlay thickness of UNI625/CS composite tubes fabricated into Port B installed in Boiler 10 after one year service

115 Photograph showing tube and membrane cracks in upper crotch of a primary air port (Port B) comprised of GBEST/CS composite tubes installed in Boiler 10 after 36 months service.

116 Cracks found in SAN63/CS composite tubes fabricated into Port H installed in Boiler 20 after 12 months of service.

117 Cladding/Overlay thickness of "worse case" port tube from test panels installed in Boiler A. 



\section{LIST OF TABLES}

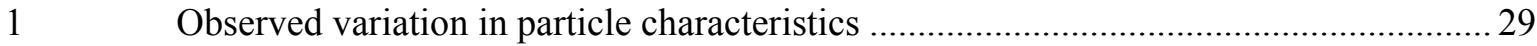

2 Observed features and activities associated with temperature decreases ....................... 33

$3 \quad$ Observed features and activities associated with temperature increases........................ 34

4 Observed sets of fireside conditions associated with known or inferred high tube surface temperatures, based on the temperature indicator listed ..................................... 36

$5 \quad$ Activities observed during high temperature conditions which might have caused the increased heat flux to the tube surfaces.................................................................... 38

6 Summary and interpretation of conditions for high temperature excursions .................. 44

$7 \quad$ Operational conditions of case before and case after of Boiler-Q................................55

$8 \quad$ Predicted process data of liquor combustion in Boiler-Q ............................................5 57

9 Simulation conditions of five cases with different secondary air distribution in

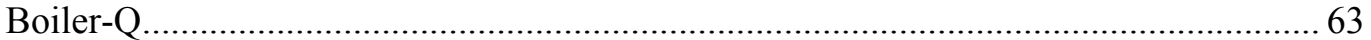

10 Summary of modeling predictions of five cases with different secondary air

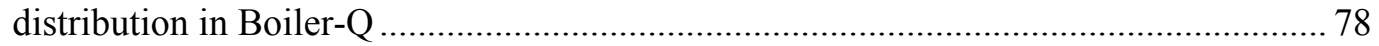

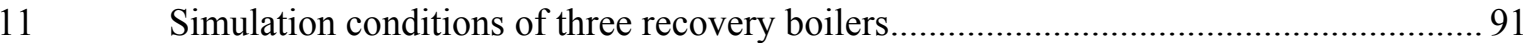

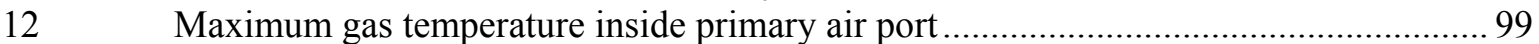

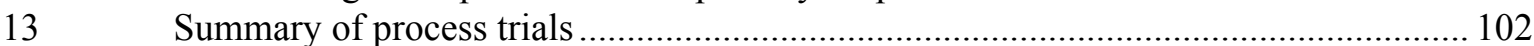

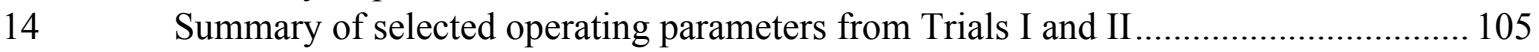

15 Summary of selected operating parameters from Trials III through VI ...................... 110

16 Overview of base material used to construct U-bends ............................................ 131

17 Summary of alternative composite tubes under study .............................................. 137

$18 \quad$ Summary of recovery boilers under study ........................................................... 138

19 Performance history of alternative composite floor tubes........................................ 139

$20 \quad$ Performance history of alternative composite spout opening tubes ............................ 141

21 Performance history of alternative composite primary air port opening tubes ............ 144

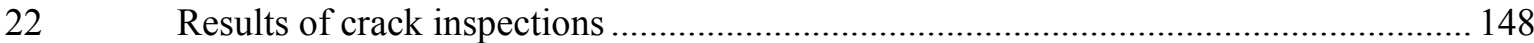

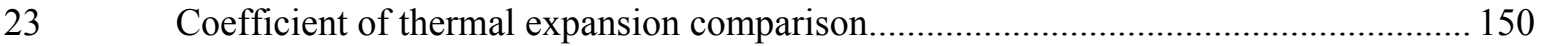





\section{LIST OF ACRONYMS}

ASME

ASTM

AW

BCO

BLS

CFD

CTE

CW

DCS

EAC

FD

LTB

MA

NIR

OD

ORNL

$\mathrm{S}$

SA

SCC

TCO

TEM

TMT

UTB
American Society of Mechanical Engineers

American Society for Testing and Materials

as-welded

bottom of the casting opening

black liquor solids

computational fluid dynamics

coefficient of thermal expansion

cold-worked

data collection system

environment-assisted cracking

forced draft

lower temperature band

mill-annealed

near infrared

outside diameter

Oak Ridge National Laboratory

sensitized

solution-annealed

stress corrosion cracking

top of the casting opening

transmission electron microscopy

top membrane termination

upper temperature band 



\section{ACKNOWLEDGMENTS}

The authors gratefully recognize the contributions of a number of individuals who contributed to the study including Blaine Anderson, Sarah Bailey, Thomas Ely, Ibrahim Karidio, Hu Longmire, Robert Prescott, Bostjan Taljat, Victor Uloth, Angela Wensley, and Xun-Li Wang. The authors also acknowledge the cooperation of a number of paper companies, including but not limited to, Weyerhaeuser Company; Domtar Incorporated; Georgia-Pacific Corporation; P. H. Glatfelter Company; Daishowa-Marubeni International, Ltd.; Blue Ridge Paper Company; and Bowater, Inc., who provided access to facilities, purchased and installed thermocouples, and - along with Alabama River Pulp, International Paper, Irving Pulp and Paper, Mead and Westvāco_- provided samples. Tube samples were provided by Sandvik Materials Technology, Welding Services Incorporated, and Sumitomo Metals, and metallic coupons for corrosion tests were provided by Haynes International, Rolled Alloys, Sandvik Materials Technology, Special Metals, and Sumitomo Metals. The equipment manufacturers Alstom Power (formerly Combustion Engineering), Andritz (formerly Ahlstrom Recovery, Inc.), Babcock \& Wilcox-Canada, Babcock \& Wilcox-U.S., and Kvaerner Pulping are recognized for their contribution of information and materials. Staff members at Åbo Akademi, VTT, ÅF IPK and University of Toronto participated in discussions and contributed information that was of value to this project. This work was sponsored by the U.S. Department of Energy, Office of Energy Efficiency and Renewable Energy, Industrial Technologies Program, Industrial Materials for the Future and the Forest Product Industries of the Future and was performed at the Oak Ridge National Laboratory managed by UT-Battelle, LLC under contract DE-AC05-00OR22725. 



\title{
CRACKING AND CORROSION OF COMPOSITE TUBES IN BLACK LIQUOR RECOVERY BOILER PRIMARY AIR PORTS
}

\author{
James R. Keiser, ${ }^{*}$ Douglas L. Singbeil, ${ }^{\dagger}$ Gorti B. Sarma, ${ }^{*}$ Joseph R. Kish, ${ }^{\dagger}$ \\ Jerry Yuan, ${ }^{\ddagger}$ Laurie A. Frederick, ${ }^{\dagger}$ Kimberly A. Choudhury, ${ }^{*}$ J. Peter Gorog,${ }^{\S}$ \\ François R. Jetté, ${ }^{* *}$ Camden R. Hubbard, Robert W. Swindeman, \\ Preet M. Singh, ${ }^{\dagger \dagger}$ and Philip J. Maziasz
}

\begin{abstract}
Black liquor recovery boilers are an essential part of kraft mills. Their design and operating procedures have changed over time with the goal of providing improved boiler performance. These performance improvements are frequently associated with an increase in heat flux and/or operating temperature with a subsequent increase in the demand on structural materials associated with operation at higher temperatures and/or in more corrosive environments. Improvements in structural materials have therefore been required. In most cases the alternate materials have provided acceptable solutions. However, in some cases the alternate materials have solved the original problem but introduced new issues. This report addresses the performance of materials in the tubes forming primary air port openings and, particularly, the problems associated with use of stainless steel clad carbon steel tubes and the solutions that have been identified.
\end{abstract}

\section{BACKGROUND}

Co-extruded 304L stainless steel/SA210 carbon steel tubes, hereafter referred to as composite tubes, were first used to make recovery boiler walls in Nordic countries in the early 1970s.

Experience quickly showed these tubes to have improved resistance to environments that sometimes caused severe thinning of carbon steel tubes [1]. Consequently, by the end of the decade, application of composite tubes had been extended to service in many boilers as floor tubes, as well as wall tubes. A similar pattern of implementation of composite tubes in recovery boilers occurred in North America, but offset by nearly a decade.

The increased operating experience gained with composite tubes in kraft recovery boilers soon led to the realization that these tubes could be subject to different corrosion problems and failure mechanisms than the carbon steel tubes they replaced. These included accelerated preferential corrosion of the stainless steel outer layer in recesses around port openings ("balding"), and cracking of the stainless layer in tubes that formed spout openings in some boilers. By the mid-1980s, cracking of the stainless steel layer of floor tubes was reported in the Nordic countries [2-5], and this was followed in the early-1990s by similar reports of cracking of the stainless steel cladding of floor tubes in North American boilers [6]. It was only a few years later that the first reports were received of cracking of 304L/SA210 composite tubes forming primary air port openings in some boilers [6].

\footnotetext{
*Oak Ridge National Laboratory, Oak Ridge, Tennessee

†Pulp and Paper Research Institute of Canada, Vancouver, British Columbia

Process Simulations Limited, Vancouver, British Columbia

${ }^{\S}$ Weyerhaeuser Company, Federal Way, Washington

${ }^{* *}$ Domtar Incorporated, Montreal, Quebec

${ }^{\dagger \dagger}$ Georgia Institute of Technology, Atlanta, Georgia
} 
As the widespread nature of the cracking problem in composite floor tubes first became apparent, a study funded primarily by the U.S. Department of Energy was undertaken to try to identify the cracking mechanism and to identify solutions. A second program was eventually begun to determine why cracking and corrosion were occurring at primary air port openings. Both projects were led by Oak Ridge National Laboratory (ORNL), and included the Pulp and Paper Research Institute of Canada (Paprican), the Institute of Paper Science and Technology (now affiliated with Georgia Institute of Technology) and Process Simulations Limited as direct contributors. Many North American pulp and paper companies, two tube suppliers, and five boiler manufacturers provided substantial assistance and in-kind support. Collaborations and information exchanges were also established with European engineering consulting firms and research laboratories, including Åbo Akademi and VTT in Finland, and ÅF-IPK in Sweden. This paper compiles the findings from these extensive research efforts.

During the latter stages of the study of composite floor tube cracking, a number of mills began reporting cracks in tubes forming some primary air port openings [7,8]. Both craze and circumferential cracks were reported, and in all cases, the cracks were limited to the lower portion of the air ports. Most frequently, the cracks were on or very near the bent portion of the tubes at the bottom of the port, but the cracks were sometimes seen some distance below this area. The most significant aspect of this cracking was that, unlike floor tube cracks, some of the cracks continued through the stainless/carbon steel interface into the carbon steel. This was reason for serious concern and an indication that this cracking was not totally like that seen on composite floor tubes.

Consequently, as the study of composite floor tubes reached a conclusion, the research efforts were directed toward determining the cause of, and solutions for, cracking of the primary air port tubes.

The approach used to investigate the problem of primary air port tube cracking was three-fold. One approach called for study of the possibility of changing boiler operating conditions to eliminate cracking. This required characterization of the environment of the air port tubes and the effects of various boiler operating parameters. The second approach was to search for a material alternative to 304L stainless steel for the outer layer of the composite tubes. This material would be required to resist the effects that cause cracking in the stainless steel. The third approach was to measure and model the stress state of the tubes in the vicinity of the air ports to determine what was happening that, under some conditions, cracks could advance into the carbon steel. If these conditions could be identified, then cracks could, at least, be restricted to the stainless steel layer and not threaten the integrity of the carbon steel, load-bearing portion of the tubes. 


\section{FATIGUE DATA FOR 304L STAINLESS STEEL}

Because of the significant difference in the thermal expansion coefficient between the components of composite tubing, 304L stainless steel and carbon steel, it is reasonable to expect that considerable stresses could develop when the tubing is subjected to thermal cycling. One of the more widely accepted ideas in the paper industry was that the floor tube and air port tube cracking were both due to thermal fatigue. To determine whether composite tube cracking could be attributed to thermal fatigue that was caused by thermal cycling, a review of 304L stainless fatigue data was undertaken and laboratory studies were conducted to generate fatigue data to provide more information on the behavior of this alloy. The ASME Code Section III, Subsection NH design curve provided information for coarse-grained 300 series stainless steels. Figure 1 shows this design curve for $427^{\circ} \mathrm{C}$ with mechanical and thermal fatigue data for $304 \mathrm{H}$ and $304 \mathrm{~L}$ stainless. The results of laboratory tests are shown in Fig. 2 added to the same design curve [9]. If thermal cycles from 300 to $450^{\circ} \mathrm{C}$ are considered, the cyclic strains would be about $0.25 \%$. According to the ASME design curves, the fatigue life for a composite tube subjected to cyclic strains of this magnitude would be expected to be at least 100,000 cycles. As discussed in a subsequent section of this report, there is no evidence that a composite air port tube experiences anywhere close to that number of thermal cycles.

Microstructural examination was also used to gain information about the mechanical and thermal cycling history of the tubes. The plastic deformation that occurs during exposure of an austenitic stainless steel, such as 304L, to severe thermal or mechanical cycling causes multiplication of microstructural line defects called dislocations. The back and forth movement of dislocations during any type of cycling provides opportunities for self-annihilation or dynamic recovery. Often, this recovery is manifested by development of a substructure in which walls of high dislocation density surround relatively dislocation-free areas. This substructure is unique to fatigue loading conditions and its presence is indicative of severe fatigue loading. Its absence could, but does not necessarily, indicate fatigue loading did not occur [7].

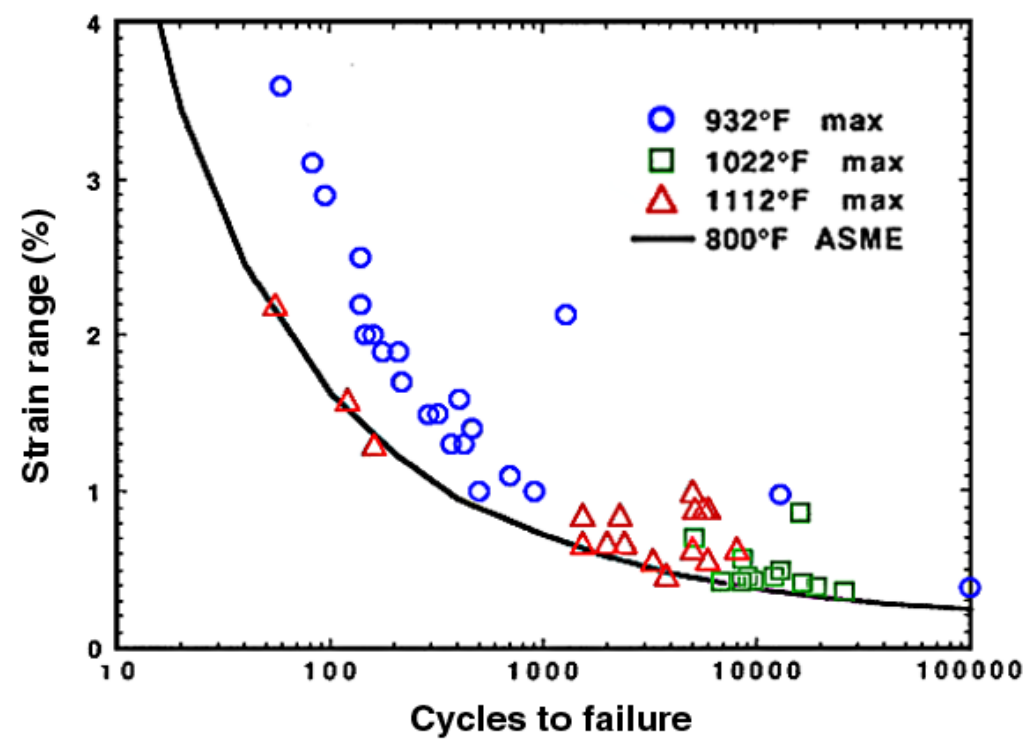

Fig. 1. ASME fatigue design curve for $\mathbf{3 0 0}$ series stainless steels for $427^{\circ} \mathrm{C}$. Additional data for $304 \mathrm{H}$ and $304 \mathrm{~L}$ have been added to the plot. 


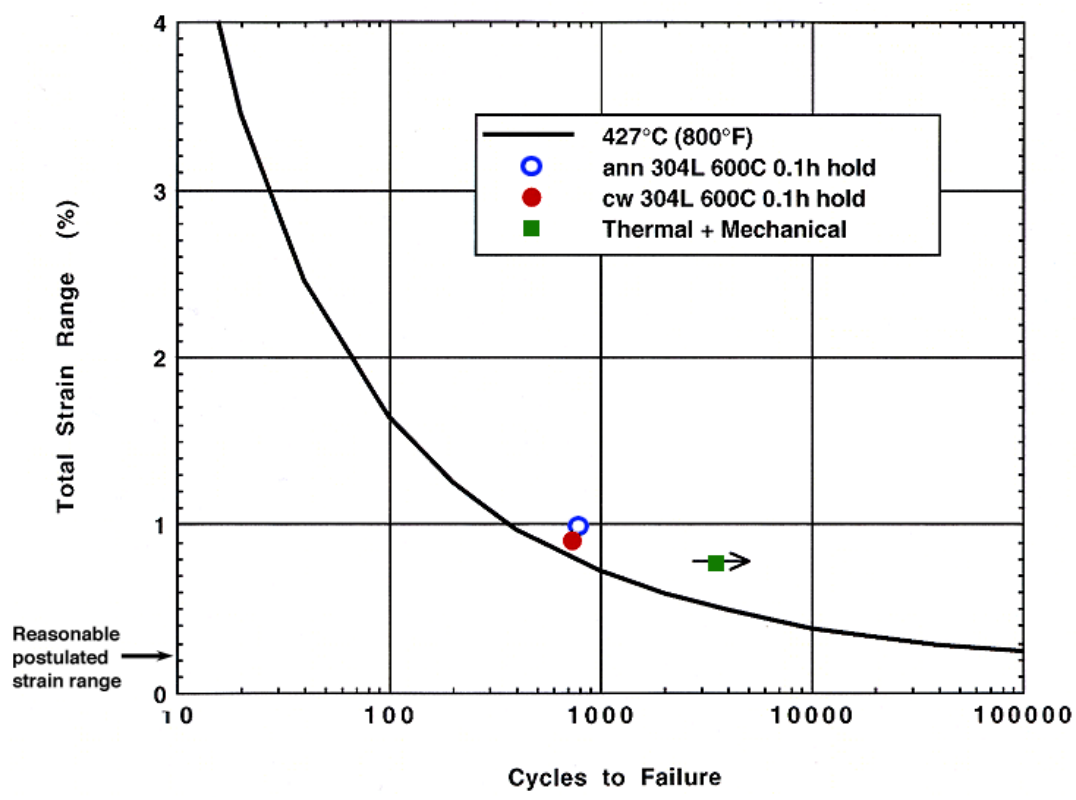

Fig. 2. ASME fatigue design curve for $\mathbf{3 0 0}$ series stainless steels for $427^{\circ} \mathrm{C}$ with additional laboratory-generated data included. Note that for cyclic strains of about $0.25 \%$, the fatigue life is predicted to be about 100,000 cycles.

In order to study these dislocation structures, a very high magnification technique, like transmission electron microscopy (TEM), must be used. Previous TEM studies of cracked floor tubes showed the stainless steel in these tubes did not develop microstructures characteristic of fatigue [7]. In contrast, specimens taken from cracked air port opening tubes showed more evidence of thermal cycling than floor tubes, though not as much as samples removed from spout opening tubes, which contained the same characteristic substructure as a laboratory-produced thermal fatigue sample (Fig. 3). These results were interpreted to indicate that the floor and air port opening tubes had been subjected to thermal cycling, but not enough to cause thermal fatigue cracking [7].

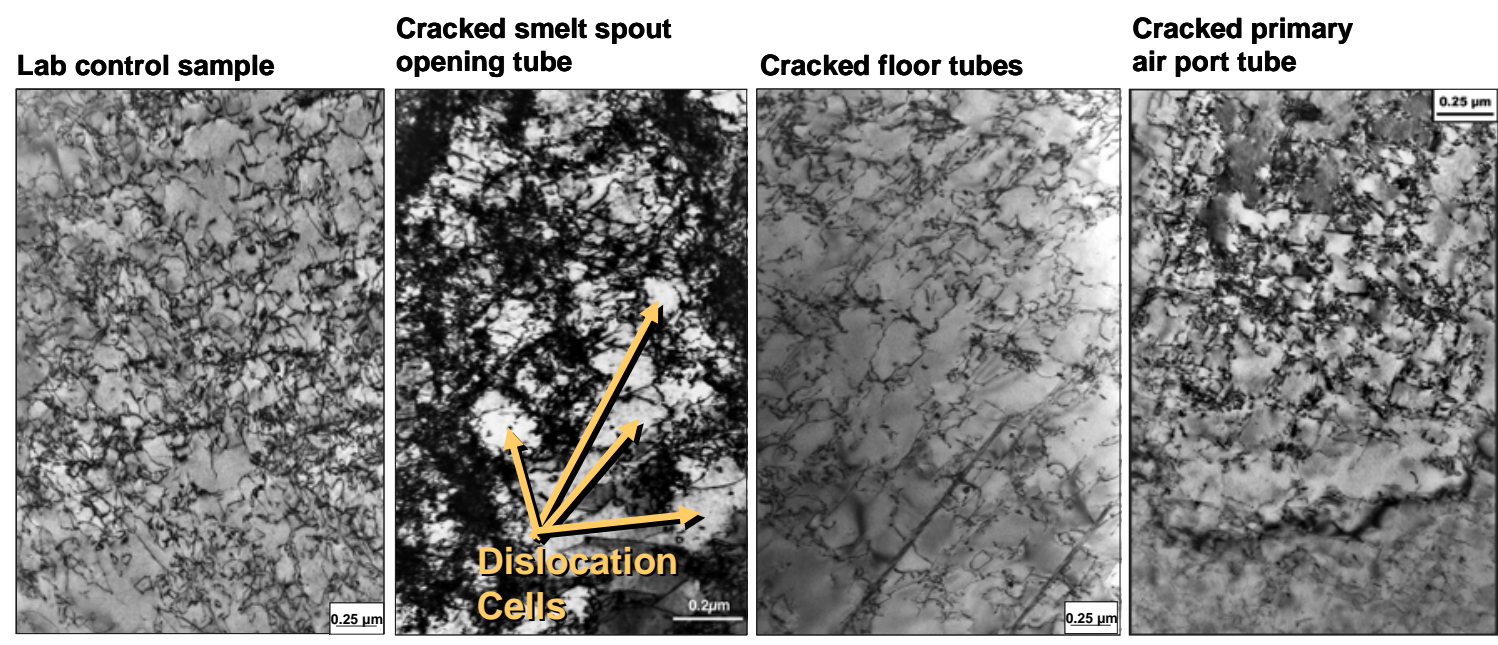

Fig. 3. TEM examination of tube sample shows differences between spout opening tube, floor tube and air port tube. The spout opening tube shows obvious evidence of thermal fatigue while the others only show evidence of thermal cycling. 
Since thermal fatigue was largely eliminated as a source of cracking for composite floor and primary air port tubes on the basis of this information, the research effort was directed toward determining the cracking mechanism and defining the thermal, chemical and mechanical state of the tubes and their immediate environment. In the following sections, detailed descriptions of these studies are presented. The descriptions first address the nature of the cracking observed both during field inspections and in the laboratory examinations. One of the first efforts in the study was to define the thermal environment of the tubes; the extent of the study and some of the results are described. Because of the observation of significant temperature fluctuations in fairly limited areas, an effort was made to determine the cause of these variations. To investigate the activities on the fireside surface of the air port tubes, a camera was built into a system that could be inserted through an air port so that the operator could view the surface of the tube. Modeling studies were also conducted to identify reactions that could be occurring on the tube surface and were capable of producing sufficient heat to cause the fluctuations that were measured.

In addition to characterizing the thermal and chemical environment of the air port tubes, another effort was directed toward understanding the mechanical environment of the tubes. This study included residual stress measurements on unexposed tubes and on tubes that had been exposed to operating conditions. Examination of exposed tubes was conducted primarily in the laboratory but in a few cases it was done on tubes in the boiler. Finite element modeling was also used to predict residual stresses, and the measurements provided a means to validate the modeling results.

Using the information obtained from characterization of the environment of the primary air port tubes, studies were conducted at several mills to determine the effect of changes in operating parameters on the temperature fluctuations observed in the boilers. Valuable information was obtained from each of the mills studied, but one mill particularly invested significant time and resources to help in the study of the effect of operating parameters. The results of these studies provided information, which when combined with the results of the other studies, enabled a recommendation on alternate materials and optimized operating parameters to be made. A review of the many components of this project is presented in the following sections. 



\section{FIELD OBSERVATIONS OF CRACKING OF PRIMARY AIR PORT TUBES}

Members of this research team visited many North American mills to observe the inspection of the composite tubes and particularly the tubes forming primary air ports. Cracking was seen on air port tubes for most boiler types utilized in North America. In Fig. 4, examples of craze and circumferential cracking are shown on air ports with cast inserts, and circumferential cracking is shown on air ports with welded sleeves. It is important to note that cracks in air port tubes were not always easy to detect. Cracks were most likely to be found if, prior to dye penetrant inspection, the surface corrosion products were removed from the tube by cleaning with a 120 (or smaller) grit "flapper wheel" until shiny metal could be seen $[10,11]$.
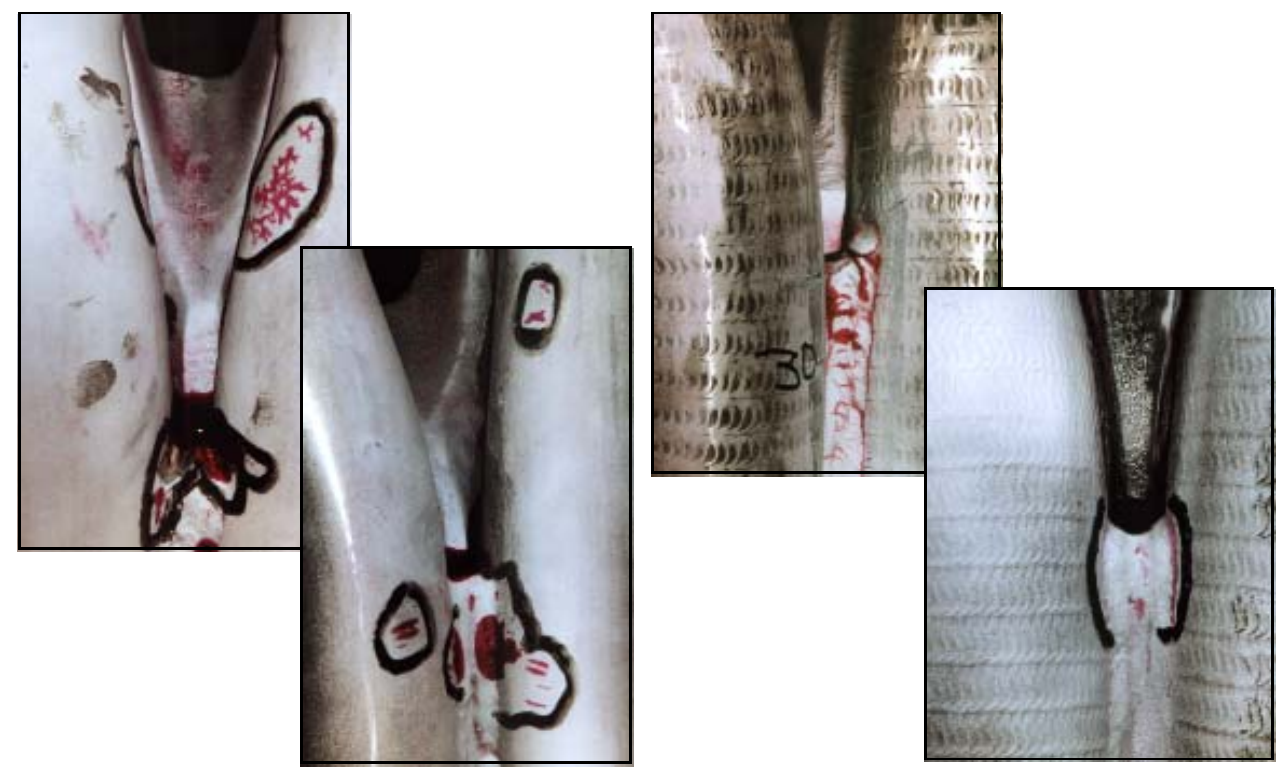

Fig. 4. Examples of cracked primary air port opening tubes with (left to right) craze cracking, circumferential cracking, membrane cracking and cracking in the membrane to tube weld. 



\section{LABORATORY OBSERVATIONS OF CRACKED AIR PORT TUBES}

A number of recovery boiler owners/operators have provided sections of boiler wall panels removed in order to replace primary air ports. These sections were subjected to a dye penetrant examination, then samples were removed from areas where crack indications were found. These samples were mounted so a cross section of the tube wall could be viewed. The samples were carefully ground and polished and when considered appropriate, etched with an acid solution to highlight microstructural features. Examination of these cross-sections provided information about crack characteristics and whether the cracks continued into the carbon steel. Any evidence of excessive heating of the tube would also be revealed by this examination.

Figures 5-7 show cracks in tubes revealed by dye penetrant inspection along with crosssectional views of cracks that were selected for inspection on the basis of the dye penetrant examination. The 304L stainless steel clad tube used for the primary air port opening shown in Fig. 5 had severe circumferential cracking just below the bottom of the air port. Metallographic examination of cross-sectioned samples revealed some of the cracks advanced into the carbon steel. The primary air port shown in Fig. 6 was taken from a different recovery boiler, but the opening tubes were also fabricated with 304L stainless steel. The cross sections of cracks shown in Fig. 6 reveal that cracks advanced to the stainless steel/carbon steel interface, but no significant penetration into the carbon steel occurred. Alloy 625 composite tubing was used to form the air port shown in Fig. 7, and as shown in the micrographs, significant cracking occurred in the tubes. The laboratory examination did not find any cracks that advanced into the carbon steel.

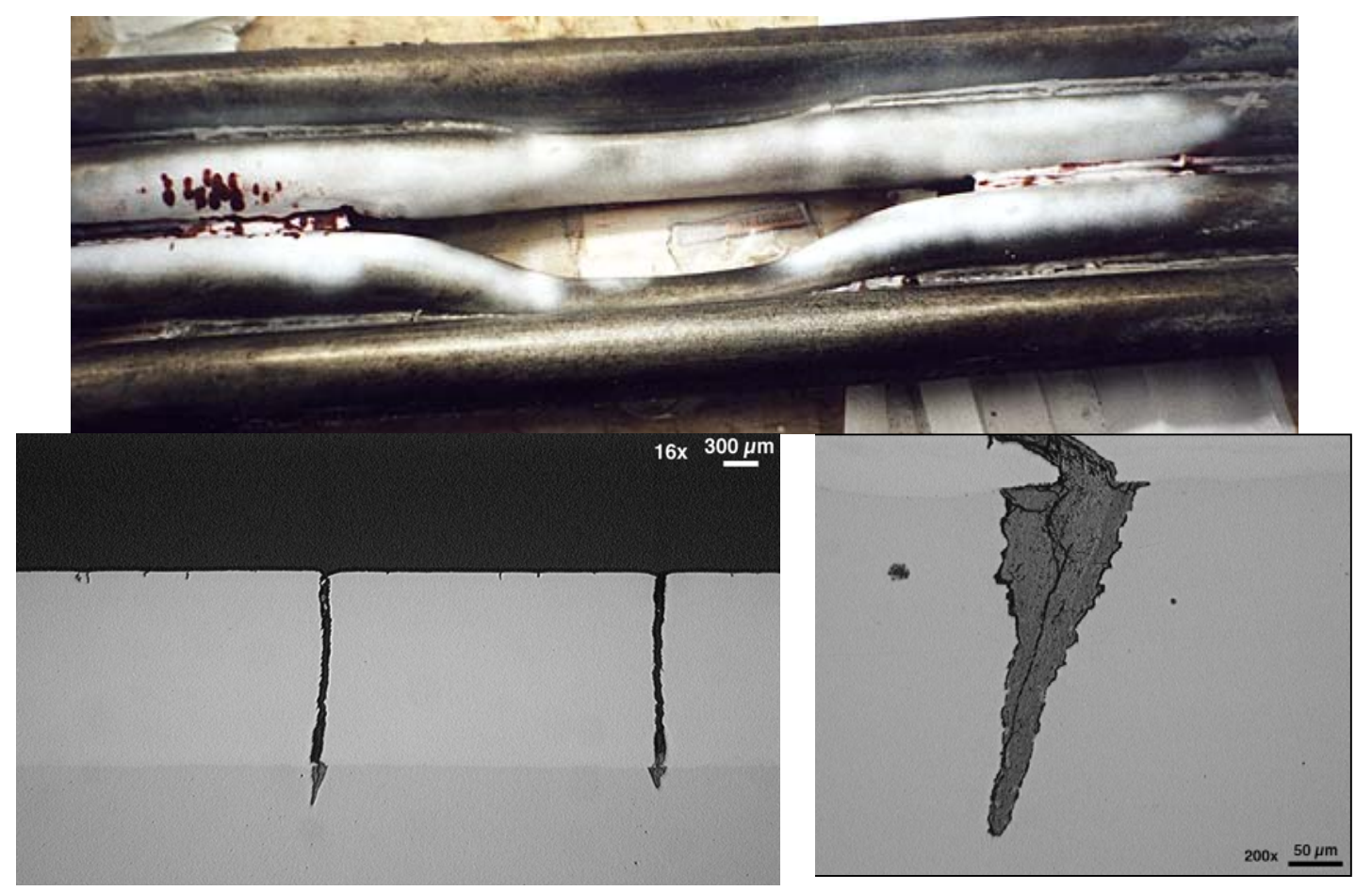

Fig. 5. Cracks in 304L stainless steel clad tubes just below the air port opening. Micrographs of the cross section of the tube show that these cracks penetrate into the carbon steel. 

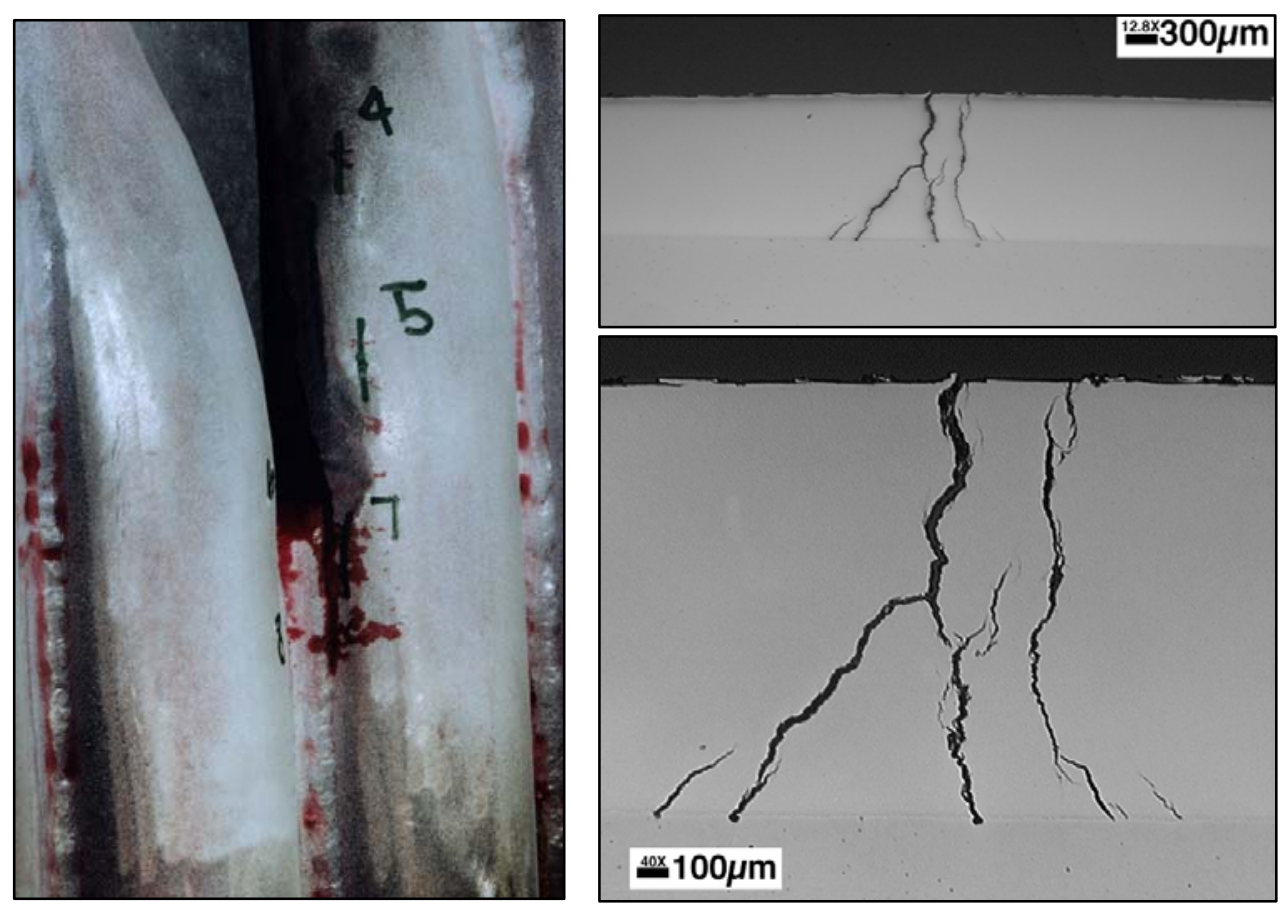

Fig. 6. Cracks in a 304L stainless steel clad air port opening tube. The cracks in location 4 are shown in cross section in the micrographs on the right. Note that many of these cracks terminate in a corrosion "pit" at the stainless steel/carbon steel interface.

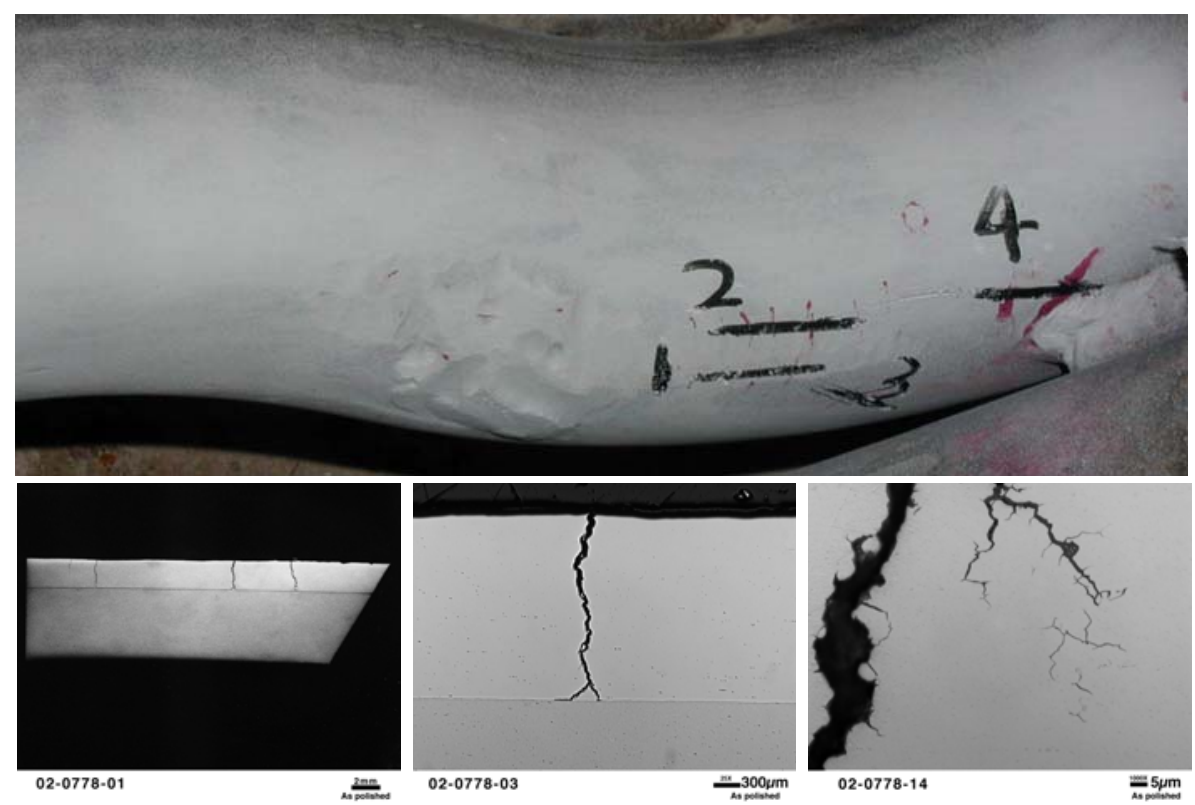

Fig. 7. Cracks in an alloy 625 clad air port opening tube. Many of these cracks continue through the alloy 625 layer to the interface. Note that the cracking is intergranular in nature. 


\section{ENVIRONMENT CHARACTERIZATION-TEMPERATURE STUDIES}

\subsection{THERMOCOUPLE INSTALLATION AND POSITIONING}

Since thermocouples were successfully used to obtain information on the temperature variations experienced by floor tubes, it was a logical extension to consider installing thermocouples on air port tubes. It was not clear that temperature variations should be expected, but it was initially decided to install thermocouples on primary air port tubes in three mills - two with a history of primary air port tube cracking and one new boiler nearly identical to one of the other two, but with no history of cracking.

Installation of thermocouples occurred during scheduled mill shutdowns. During recovery boiler inspections, members of this research team and mill employees worked together to install the thermocouples on the tubes and to bring the thermocouple leads to an instrument box that was mounted outside the boiler. The instrumentation in this box was connected to a remotely located computer and modem that were in a relatively clean, constant temperature environment. LabView software installed on each computer collected a temperature data point every ten seconds from each thermocouple and stored the data in a text file. Subsequently, ORNL staff members downloaded the data files using a phone modem. For the initial analysis, the raw data was plotted as a function of time, but only every third data point was used for this stage of the analysis.

Due to the delicate nature of the thermocouples and the requirement not to damage the integrity of the tube during installation of the thermocouples, a rigorous welding procedure was followed during installation. Nevertheless, depending on the skill and carefulness of the welders, an occasional thermocouple was damaged so severely during installation that it never provided useful data.

In the thermocouple installations on the first two boilers, thermocouples were mounted in the lower portion of an air port on the bent portion of the tubes in the general area where cracking was most often seen. The most frequently used installation arrangement is shown in Fig. 8 while several examples of typical thermocouple installations are shown in Fig. 9. In addition to the original three

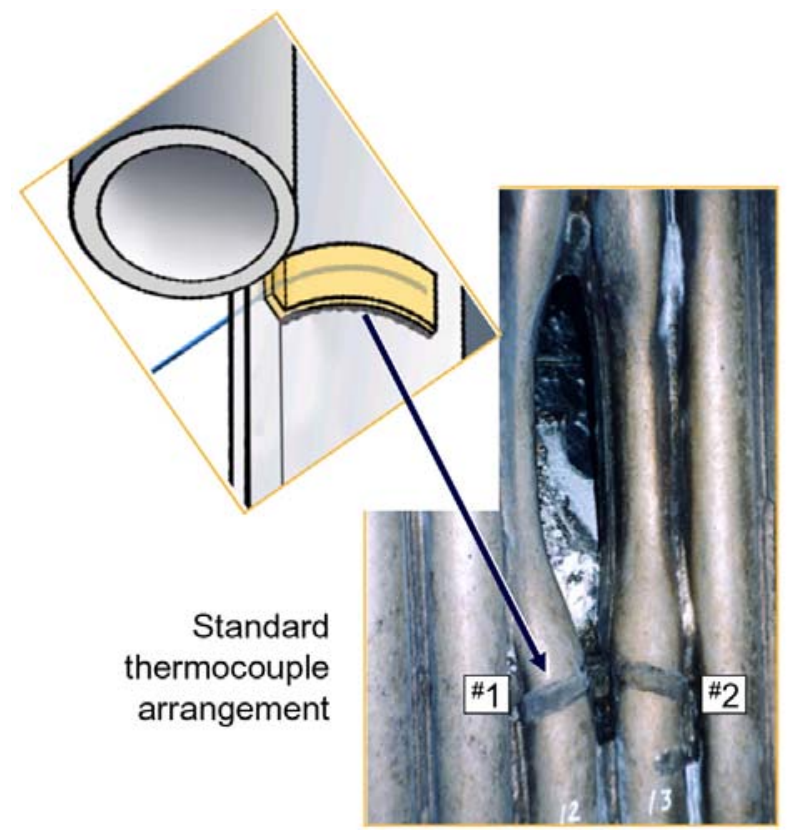

Fig. 8. Thermocouples were mounted on the portion of air port opening tubes in the area where cracking was frequently observed. 

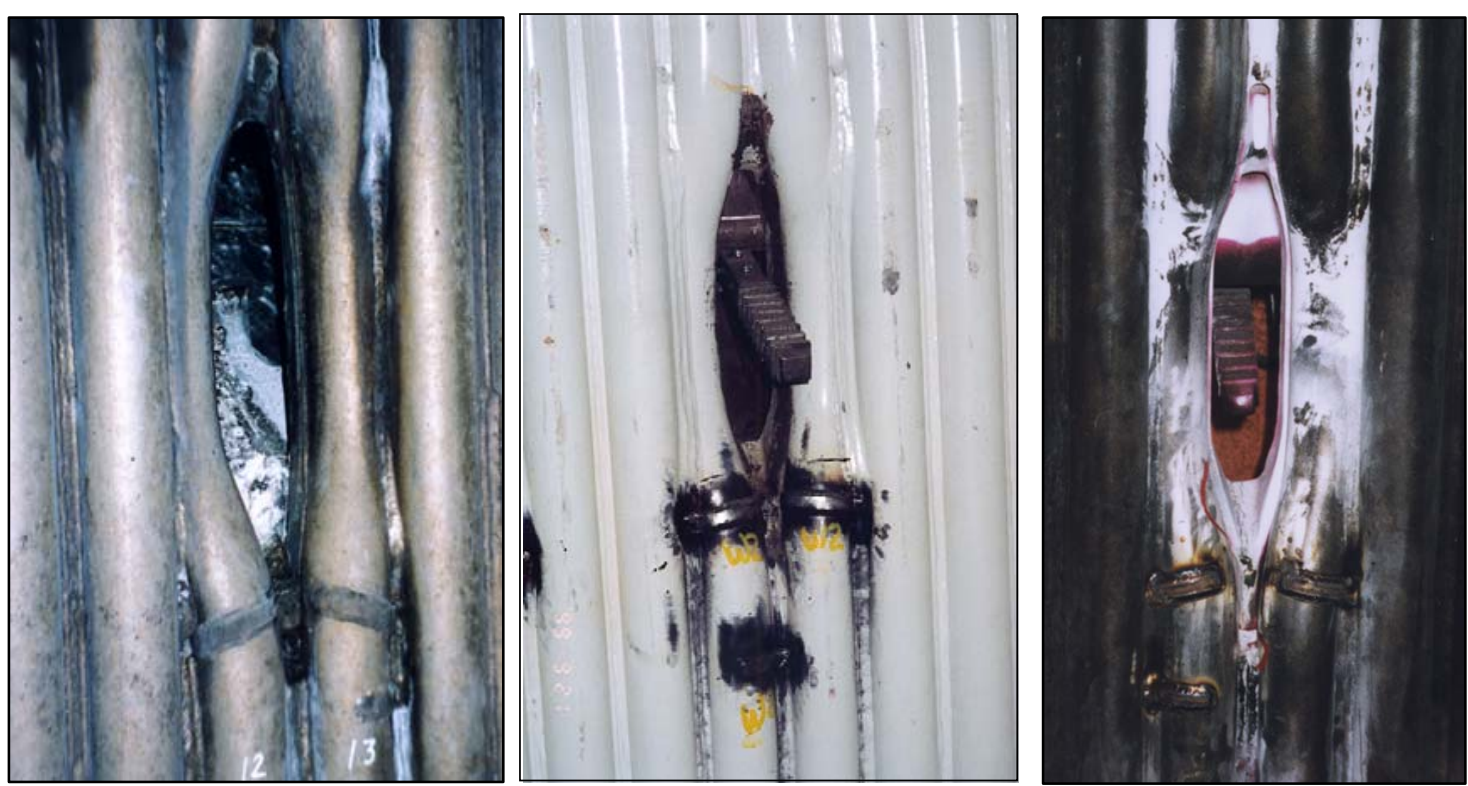

Fig. 9. Examples of the thermocouple installations used in the first three boilers equipped with thermocouples on the primary air port tubes.

mills, over the next five years eight more mills were instrumented with thermocouples and temperatures monitored.

To help establish some credibility for the temperature data, several issues had to be resolved. One issue concerned whether the measured temperature changes were real or electronic noise from the monitoring equipment. Figure 10 shows temperature versus time for a period in which a spike is seen to rise and fall back to a normal operating temperature. This expanded plot shows several

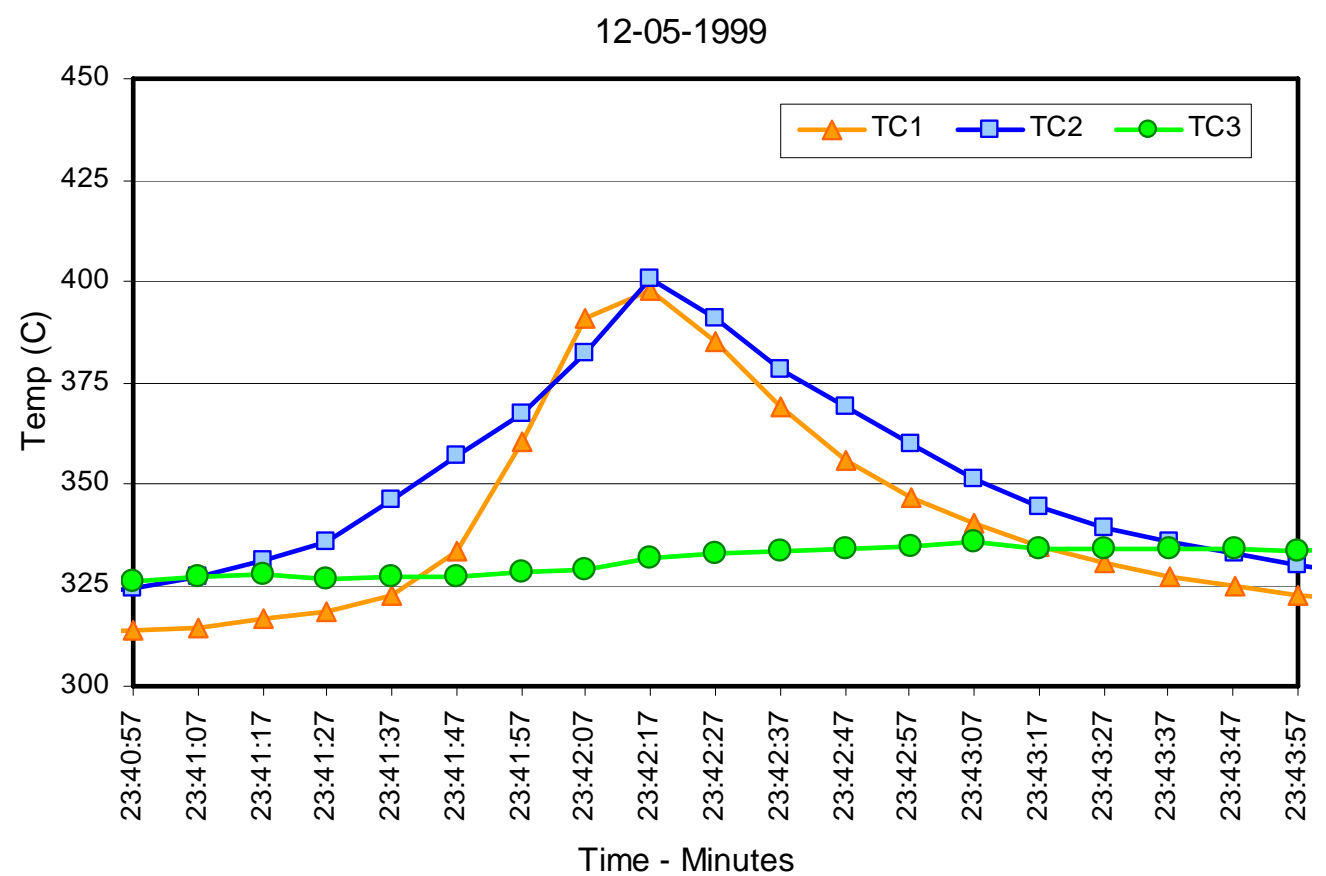

Fig. 10. Data collected every 10 seconds plotted to show the rise and fall of a thermal fluctuation over a four minute time period recorded by thermocouples placed in a recovery boiler. 
data points are involved in the temperature spike, and the pattern is consistent with a rapid heating and cooling event.

Another question was raised as to whether the temperatures being recorded were accurate considering the fact the thermocouples were not the conventional chordal type but instead were held firmly against the tube's surface by stainless steel strips welded to the tubes. To resolve whether the measured temperatures were truly representative of the temperatures at the tube surface, a tube with a modified version of chordal thermocouples was instrumented with thermocouples like those used on the air port opening tubes (Fig. 11). Since chordal thermocouples (which are embedded in the tube wall) are considered to give representative indications of tube wall temperatures, they were used as a reference for thermocouples mounted on the tube surface. The tube was air cooled while the surface was heated with high intensity lamps to simulate the sudden application of a heat pulse. Although the surface and chordal thermocouples did not record identical temperatures, the measured values were substantially equivalent and were considered representative of the actual tube surface conditions [12].

Analysis of the temperature data collected from the air port thermocouples has proven to be quite complex, as the relative severity at a given location is related not only to the magnitude of temperature experienced by the tube, but also the frequency and amplitude of fluctuations. A number of approaches have been used to analyze the data and facilitate meaningful comparisons between different locations at each air port, and also between air ports.

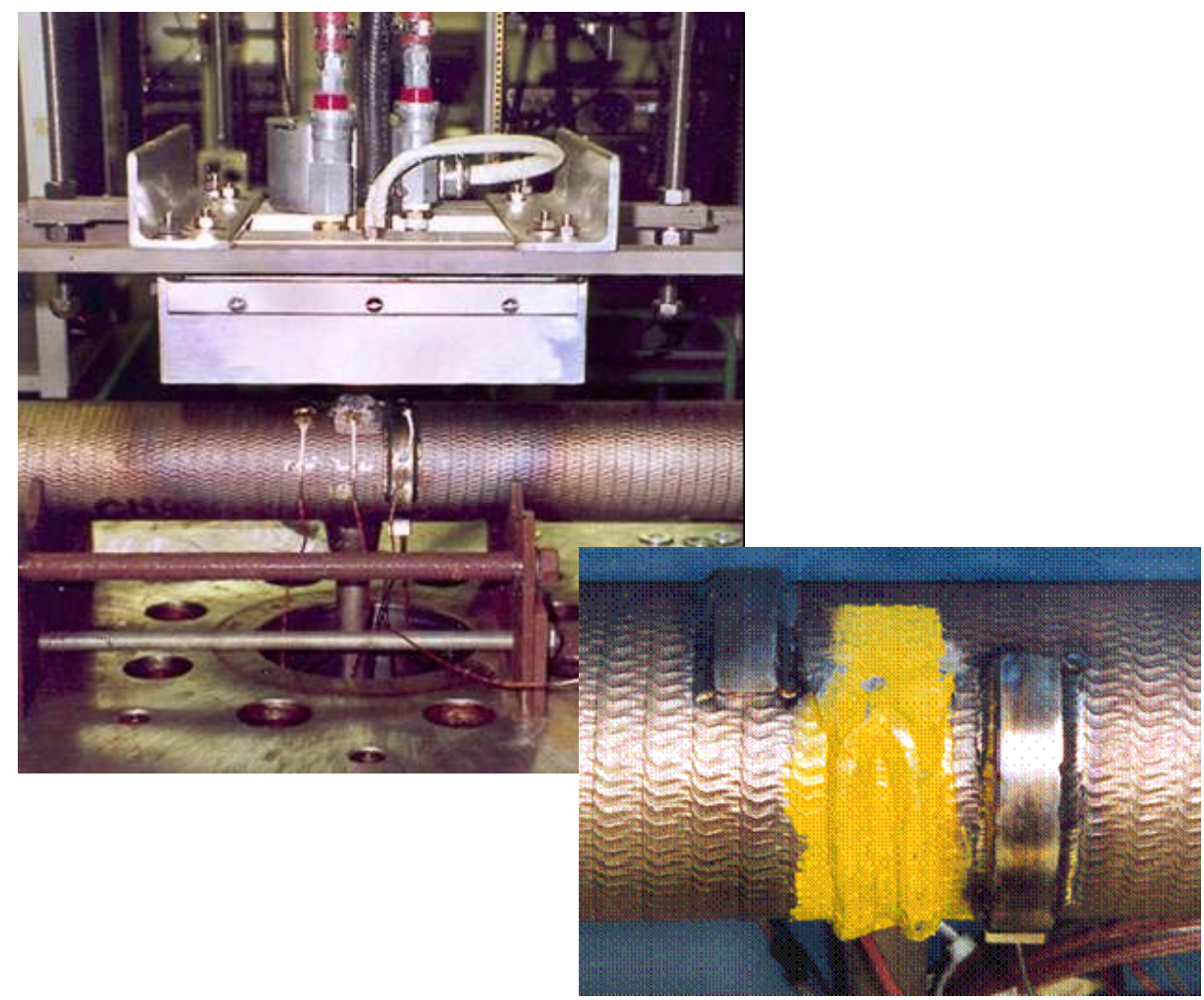

Fig. 11. Assembly used to compare performance of chordal versus surface thermocouples.

\subsection{CHARACTERIZATION OF TEMPERATURE FLUCTUATIONS}

\subsubsection{Count of "Time above a Critical Temperature"}

One of the simplest methods for judging the activity of a thermocouple is to count the number of data points above a critical temperature for a given location. Examination of data from several 
thermocouples during relatively calm periods indicated a representative "baseline" operating temperature was between 325 and $375^{\circ} \mathrm{C}$. Based on these data, any temperature value above $450^{\circ} \mathrm{C}$ was assumed to be detrimental, and a count of the number of such data points was made for each thermocouple.

Although this method does not measure the frequency of temperature fluctuations, it does indicate which locations are spending significant time at high temperatures. This can be detrimental to the tubes if one considers damage due to corrosion or the possibility that steam blanketing is present during these extended periods. Also, if a reduction in the time spent at high temperature could be correlated to some change in operating parameters, it could help in choosing operating conditions that minimize high temperature excursions.

\subsubsection{Count of "Thermal Cycles"}

Among the possible causes for cracking of primary air port tubes are thermal fatigue and corrosion fatigue, both of which require stress cycles. Consequently, it was important to estimate the number of thermal cycles experienced by a tube. Earlier work on modeling the cooling of floor tubes showed that a temperature change of about $75 \mathrm{C}^{\circ}$ is sufficient to cause the stress at the crown of a 304L composite tube to change from compressive to tensile yield, or vice-versa [7]. Based on this, a method to count the number of temperature cycles was devised. A half-cycle is defined as the increase or decrease in temperature by more than $75 \mathrm{C}^{\circ}$ from the previous lowest or highest value, respectively. Any fluctuations in temperature less than $75 \mathrm{C}^{\circ}$ are ignored, and the up- and down-cycles occur in sequence alternately. This procedure of counting cycles leads to results almost identical to the more rigorous ASTM "rainflow cycle" method (see Fig. 12) used widely to characterize mechanical fatigue [13-15]. The time consuming "rainflow" method needs to parse the data so the maximum value appears as the first data point. The cycle counting procedure used by ORNL provides a good indication of periods during which there are a large number of thermal fluctuations which could possibly be damaging from fatigue considerations. However, the cycle count does not contain any information regarding the time elapsed between successive cycles, which is a consideration in assessing corrosion issues.

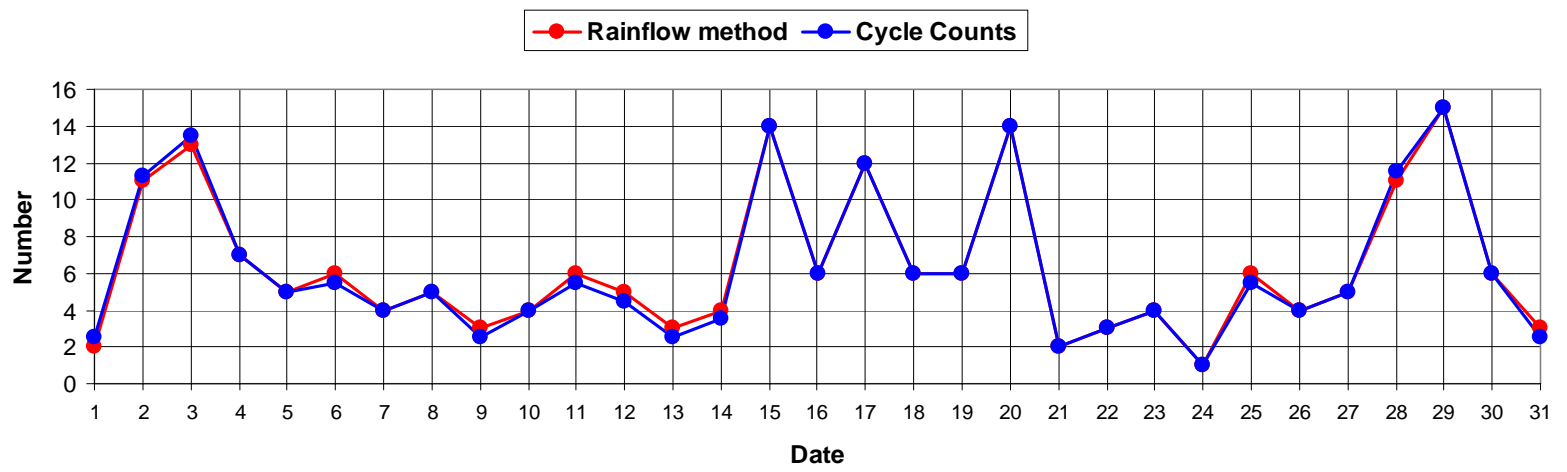

Fig. 12. Cycle count and ASTM “rainflow" method lead to almost identical variations in number of cycles. "Rainflow" method is more rigorous, but also more time consuming, and requires parsing of data to choose maximum value as first data point.

An example of the use of cycles and deviations to $\geq 450^{\circ} \mathrm{C}$ is shown in Fig. 13 where both of these parameters are plotted for six North American recovery boilers. This figure shows two of the boilers experienced considerably greater activity than the others, and one has much less than the others. It is probably not a coincidence that the first three boilers have experienced significant amounts of primary air port cracking while the sixth has experienced no cracking of primary air port tubes. 


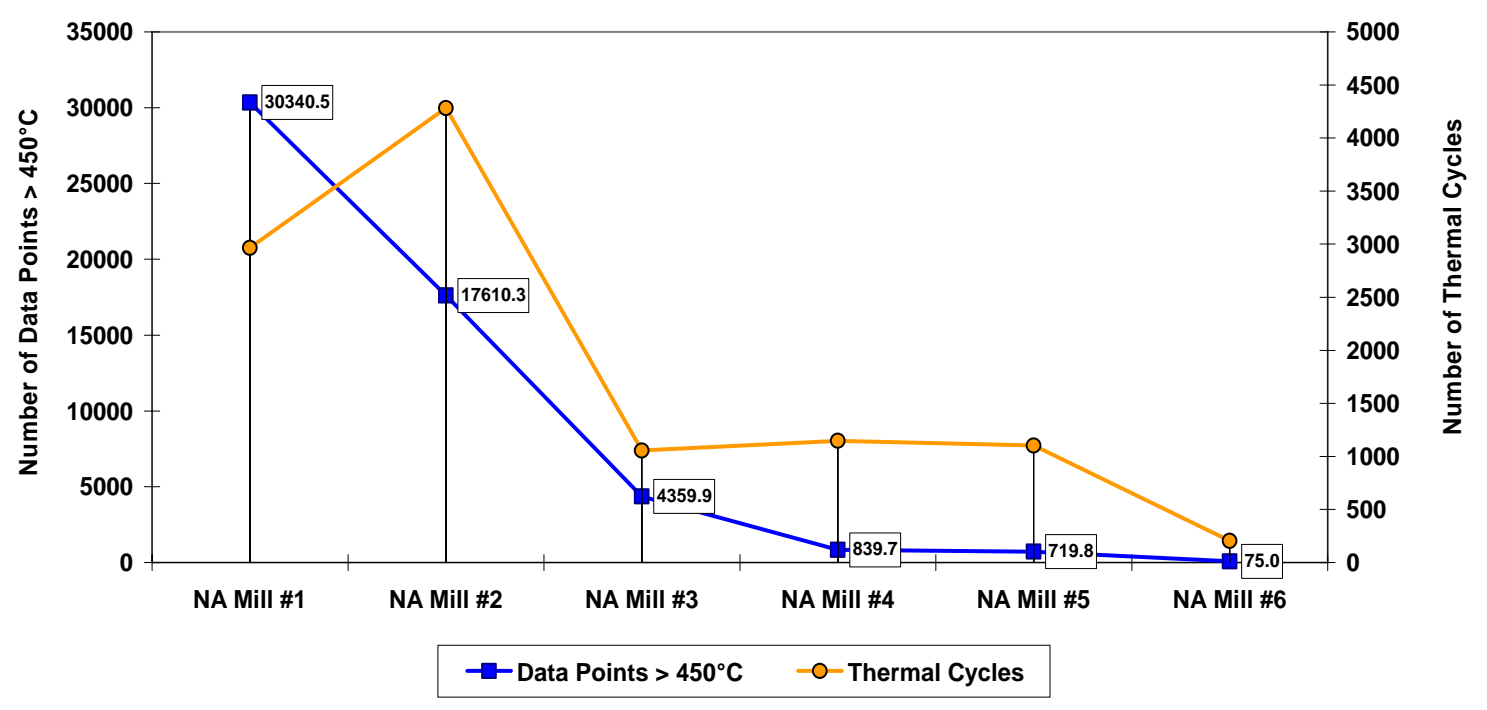

Fig. 13. Plot of cycles and data points $>450^{\circ} \mathrm{C}$ for six North American recovery boilers for one year period.

\subsection{PRIMARY AIR PORT TEMPERATURE MEASUREMENTS}

Originally, only two thermocouples were placed on the bottom fireside portion of cracking primary air ports at positions identified as \#1 and \#2 in Fig. 14. The thermocouples were mounted in the area of the lower tube bend where cracking was seen most frequently. Positions \#1 and \#2 were the most common positions installed in the monitored boilers. These two thermocouple positions,

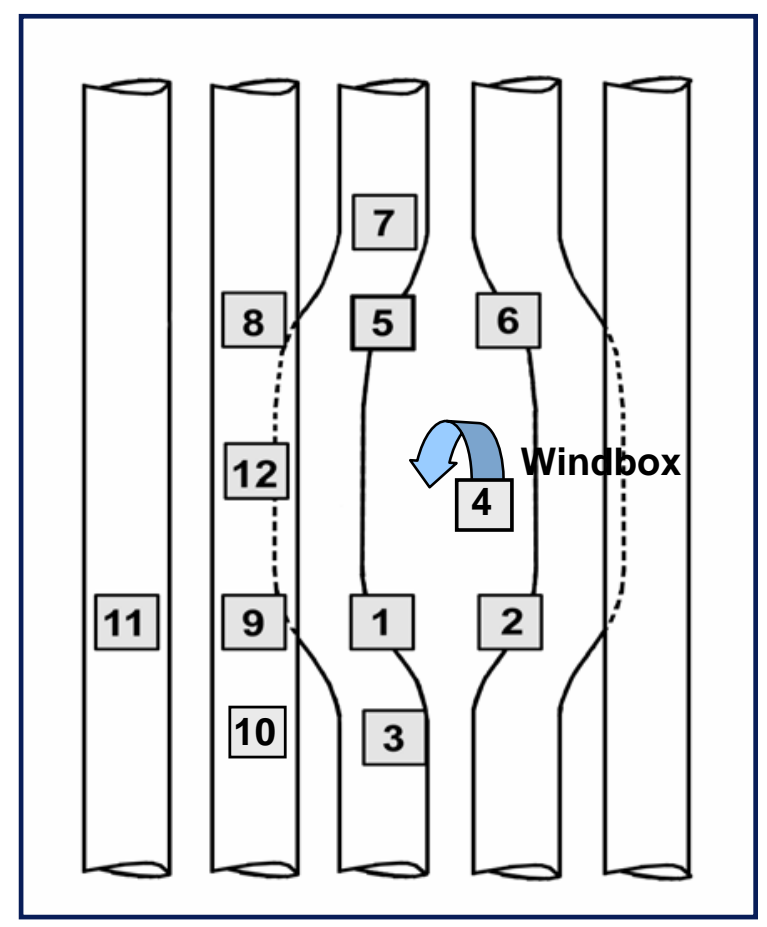

Fig. 14. The numbered thermocouple positions shown above were used to observe temperature variations around the air ports in one mill. Positions $\# 1$ and \#2 were used in all boilers in this study. No single air port was instrumented with all available positions. 
along with \#3 (directly below \#1), saw the greatest amplitude of spikes and the highest temperatures recorded at any of the thermocouple positions. Figure 15 shows an example of severe thermal cycling.

As the study progressed, more thermocouples were placed in various locations around the perimeter of selected primary air port openings to get a better understanding of the thermal conditions around the primary air ports. Position \#3, was added because cracking was noted in the area below the lower membrane termination at the bottom of some primary air ports. Because of an interest in determining if smelt was frequently splashing into the windboxes and causing fluctuations in the primary air temperature, thermocouples were installed in the wind boxes in two mills (position \#4). These temperatures rarely spiked and saw temperatures consistently $150 \mathrm{C}^{\circ}$ less than temperatures seen on the fireside portion of the tubes.

Thermocouples mounted in positions \#5-\#8, shown in Fig. 14, at the top of a few primary air ports, consistently recorded temperatures $\sim 50 \mathrm{C}^{\circ}$ higher but with considerably fewer cycles and fluctuations than thermocouples located at the bottom of the air ports. This was a consistent finding not only from air port to air port within the same boiler but also for different boilers. Unfortunately the two thermocouples placed at position \#6 never recorded accurate readings; it is expected that position \#6 would have produced temperatures very similar to those read by positions \#5, \#7, and \#8.

Adjacent straight tubes were fitted with thermocouples mounted at $90^{\circ}$ from the membrane. Thermocouples in positions \#9, \#11, and \#12 revealed fluctuations fewer in number and lower in magnitude than those seen by the lower portion of the air port. Shown in Fig. 16, the thermocouple placed approximately midway between the top and the bottom of the air port, position \#12, showed large fluctuations at times, similar to those in positions \#1 and \#2; at other times it would record data points similar to those at the top of the air port with higher temperatures but fewer oscillations.

Position \#11 in Fig. 16, located two full tubes away from the bottom of the air port opening, recorded the fewest fluctuations and lowest temperatures measured for any of the thermocouple

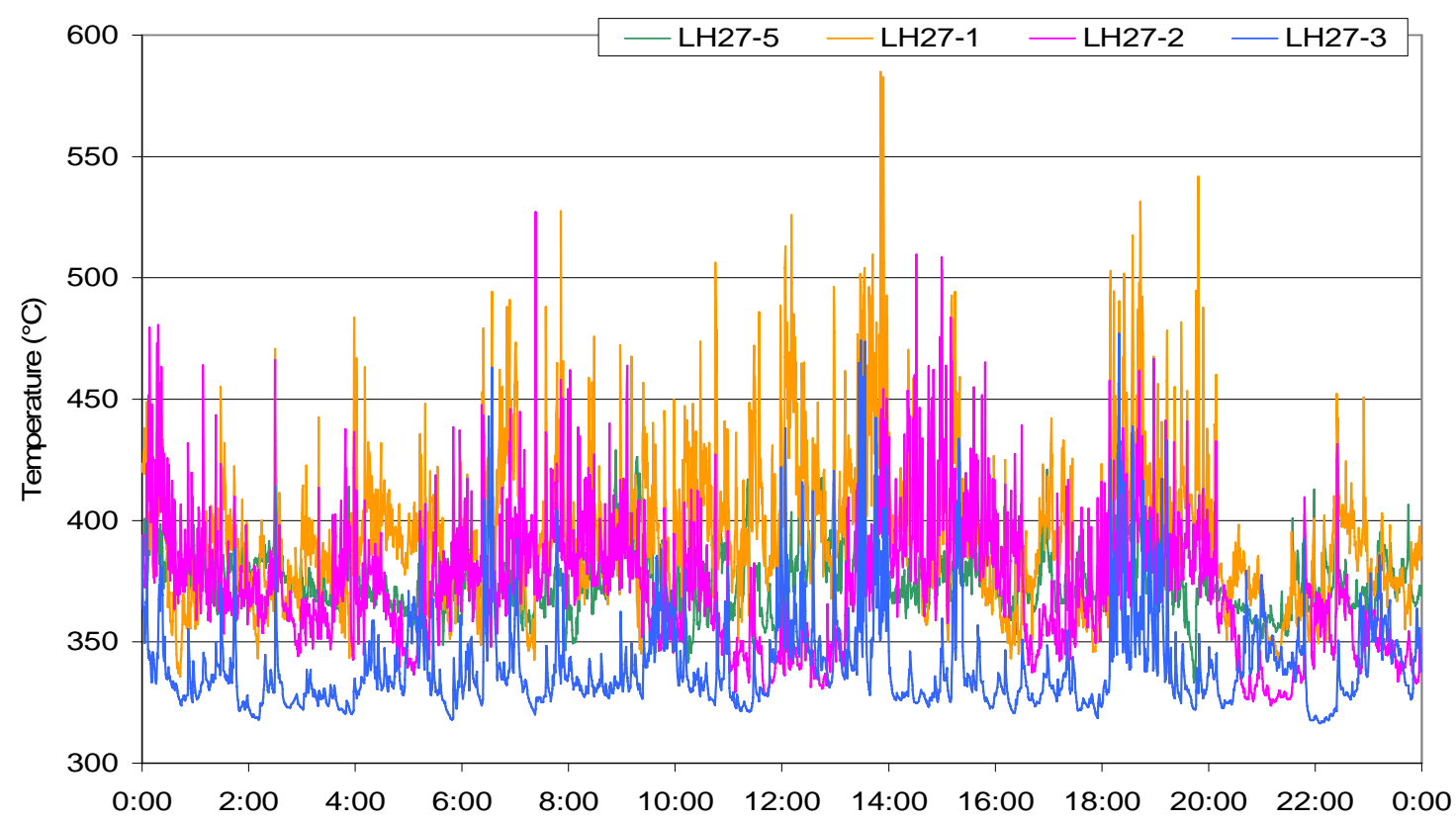

Fig. 15. Thermocouples record severe thermal activity on left hand side wall of a North American black liquor recovery boiler. 


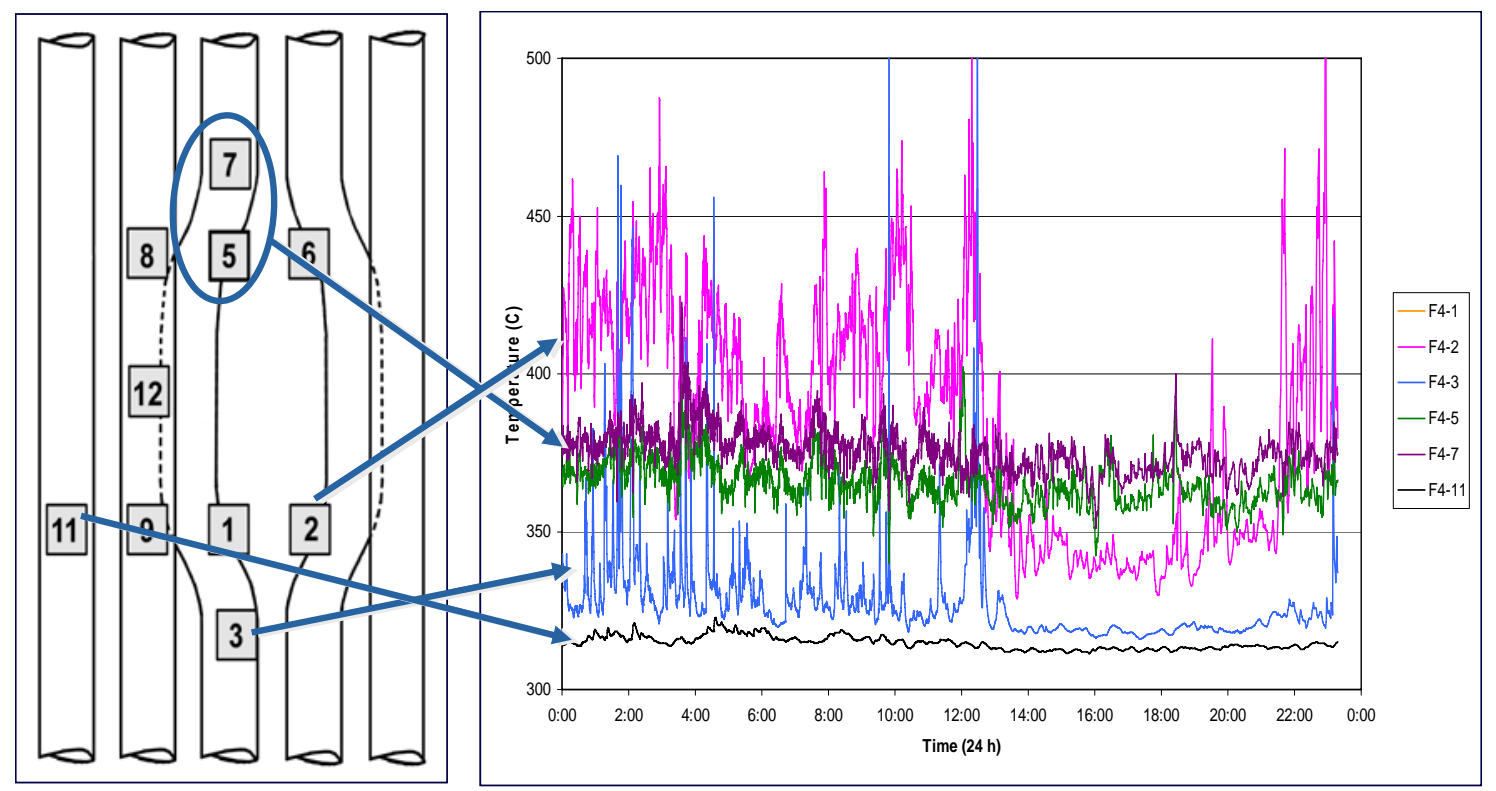

Fig. 16. Sketch showing the locations at which thermocouples were installed in one boiler to determine the variation in temperature patterns around the air port. Note that no air port had thermocouples installed at all the locations indicated. The plot on the right shows typical temperature patterns measured for the locations indicated.

positions. Figure 17 shows a period during which thermocouples located in most of the positions just described followed what would be considered to be typical behavior. As will be described in a subsequent section, it was determined this thermocouple was frequently covered by the bed, thus insulating it from the surrounding air movement and liquor distribution.

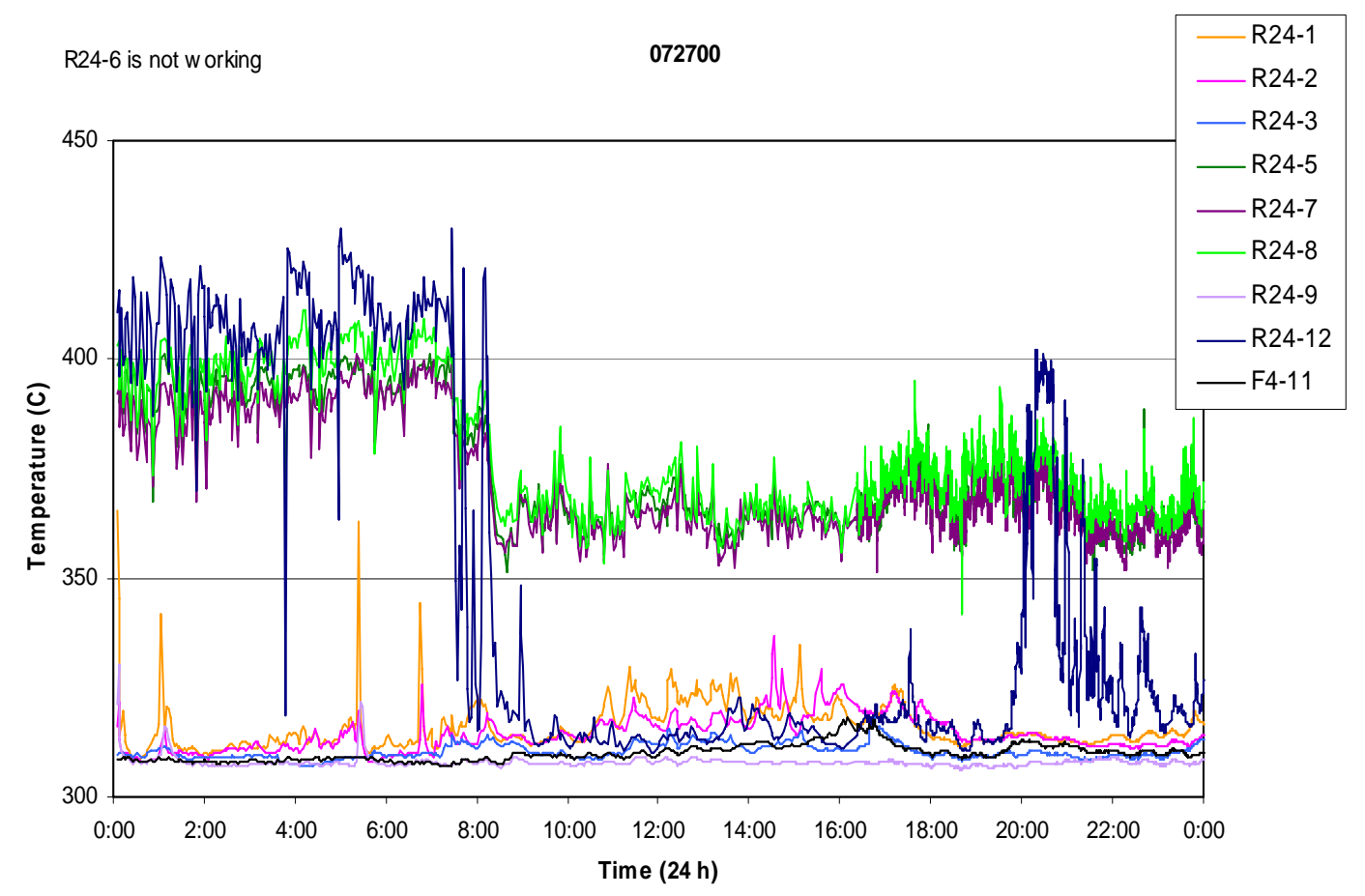

Fig. 17. Thermocouples in each monitored position surrounding boiler air ports are graphed to demonstrate activity displayed in individual positions. 
Thermocouples were also attached to the back of air port tubes in two locations; directly behind positions \#1 and \#5 on one primary air port in a single boiler. As shown in Fig. 18, these thermocouples showed very few fluctuations, particularly when compared to the thermocouples in the same relative positions but on the fireside.

May 9, 2003

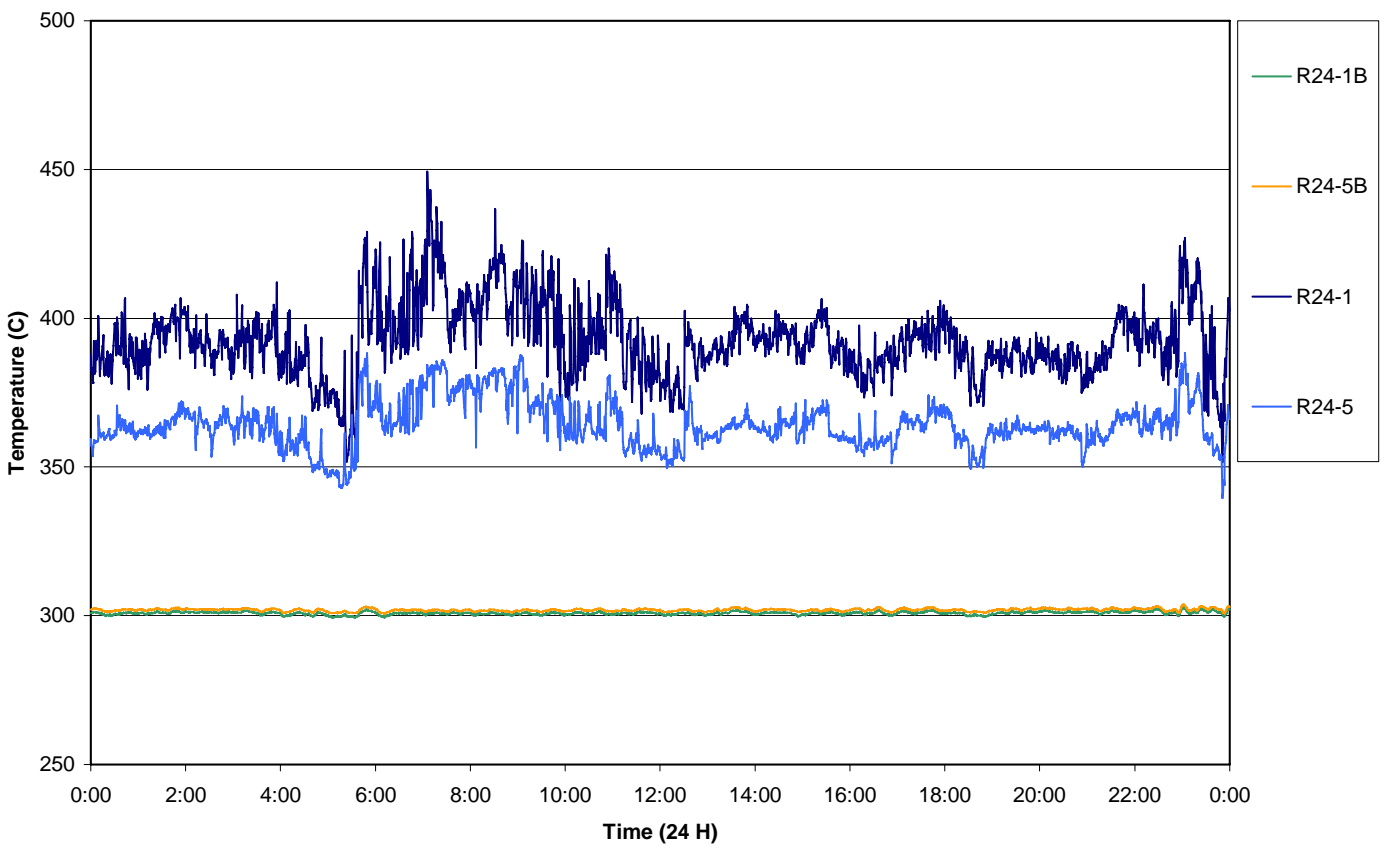

Fig. 18. Plot of temperatures measured at two locations on the fireside of a primary air port tube (R24-1 and R24-5) and the temperatures measured at equivalent locations on the windbox side of the same tubes. Note that negligible fluctuations were measured on the windbox side of the tubes.

Monitoring of all these areas provided a tremendous amount of data and, eventually, a basic understanding of the thermal activity seen by the bottom, top, and sides of the air port openings. It must be noted that no single air port in any of the eleven mills studied had thermocouples installed at all the positions shown in Fig. 14.

Several air port openings with no history of cracking were instrumented in different mills to serve as a reference for data comparison. As shown in Fig. 19, air ports with no history of cracking revealed minimal temperature spiking compared to the severe thermal fluctuations seen on the primary air ports with a history of cracking. The extreme temperatures seen by the tubes with a history of cracking indicate an intense heat source. Figure 20 demonstrated the intensity and frequency of amplitude one cracking air port saw over a five day period compared to another noncracking air port within the same mill. Although it was determined that thermal fluctuations did not have a role in initiating air port tube cracking, it is thought the thermal cycles likely play an important role in the propagation of cracks. Further observations, as will be described in more detail, led to the conclusion that boiler operating parameters play a significant roll in producing the thermal fluctuations seen by the primary air ports. 

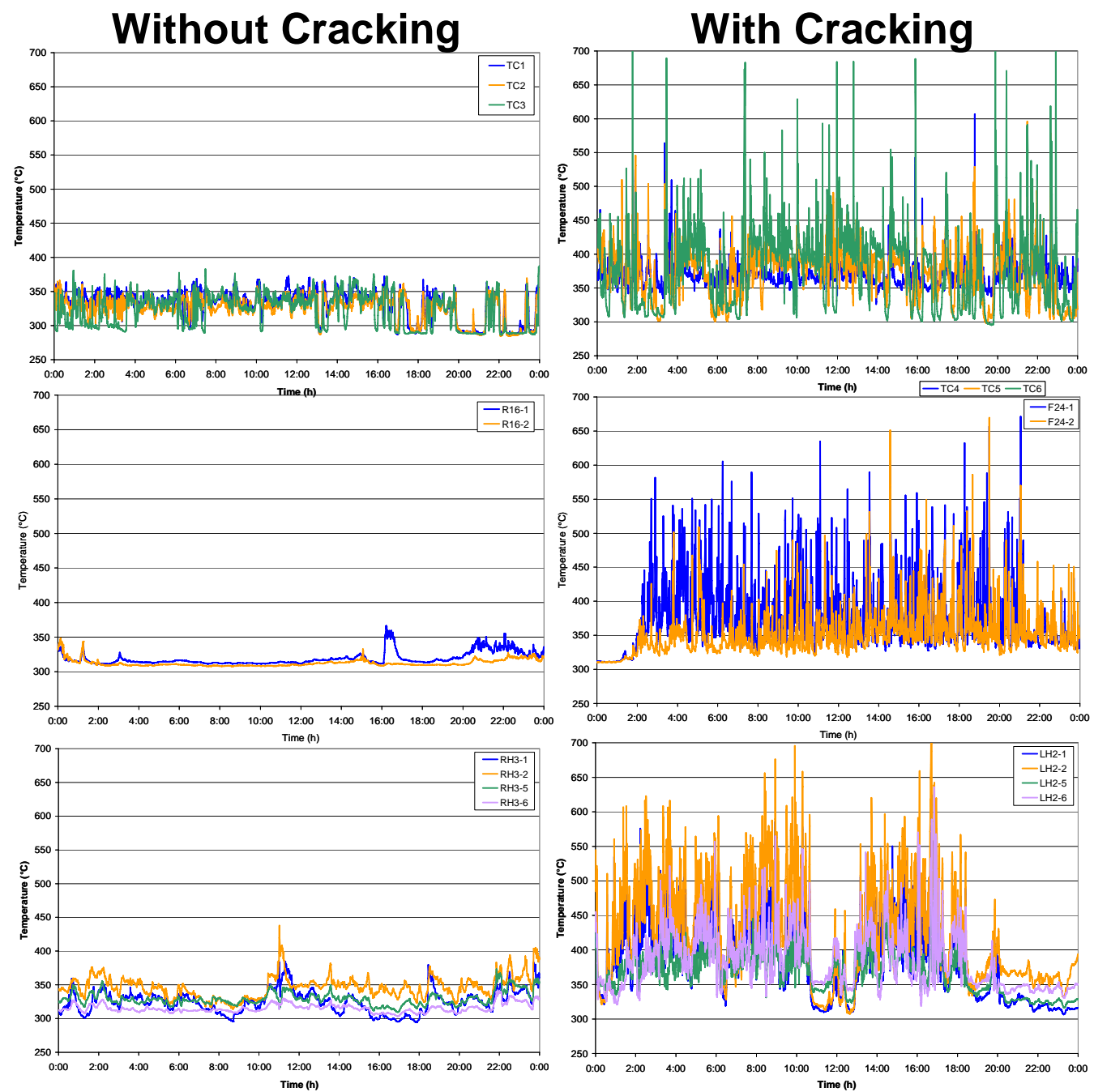

Fig. 19. Data from three different mills show the difference in thermal fluctuations between air ports with and without a history of cracking. 
PAP LW\#2 has previously exhibited cracking.

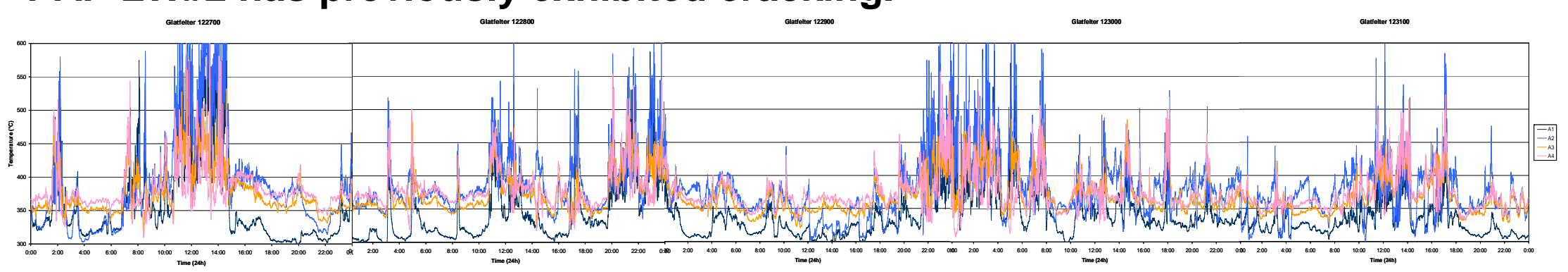

\section{PAP RW\#3 has exhibited no cracking.}

\section{catatrater 127200}

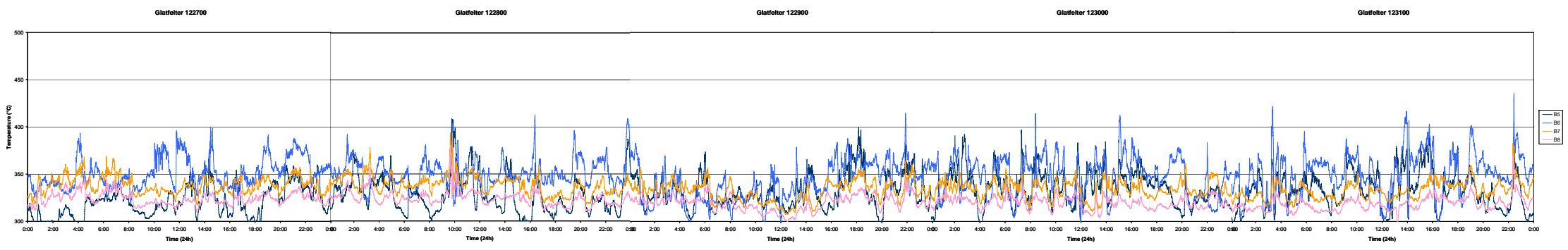

Fig. 20. Activity from two different air ports compared over a five day period. The primary air port with no history of cracking exhibits much less thermal activity over the extended period of time. 
A limited study was conducted in one boiler of a design in which there had been no reports of air port tube cracking in any North American boiler. This boiler design employs primary air ports that are longer and narrower than most of those found in North America, so there was a question as to whether this design might offer some advantage for preventing air port cracking. This boiler design has a number of other differences from the majority of boilers in North America in that it uses a four wall non-interlaced secondary air system as well as some other features that make the design unique. Thermocouples were mounted on single tubes of several primary air ports in this particular boiler, and the temperature behavior was monitored. Figure 21 shows a plot of the temperature data collected, and it is apparent that essentially no temperature excursions occurred during the time period monitored. Because of the lack of temperature fluctuations observed, the option of air port design was added to the list of possible means to prevent cracking of primary air port tubes.

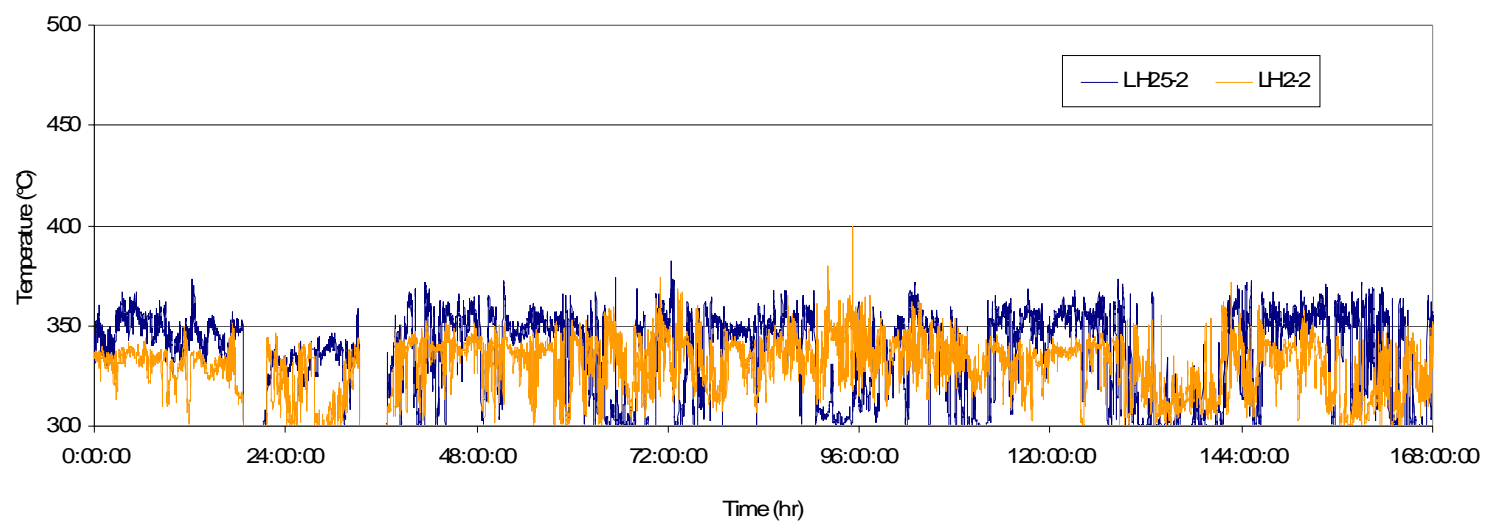

Fig. 21. Plot of temperature versus time for two thermocouples on primary air port opening tubes in a boiler originally equipped with the longer, narrower air port design.

Some mills have provided access to boiler operating parameters, supplementing the temperature information collected by the research team. These have included liquor firing schedules, liquor viscosity, liquor temperature, soap burning schedule, rodder schedules, bed size/placement/shape, etc. Monitoring temperature fluctuation patterns during periods when operating parameters were changed made it possible to identify some conditions that can significantly change the magnitude of temperature fluctuations.

\subsection{INITIAL OBSERVATIONS OF THE EFFECTS OF BOILER OPERATING PARAMETERS}

As data collection continued, it became apparent that a number of boiler operating parameters played very important roles in what temperatures were seen by the recovery boiler thermocouples. As can be seen in Fig. 22, a boiler operating on auxiliary fuel does not experience temperature fluctuations; however, liquor firing has an immediate effect on the temperatures measured on primary air port tubes.

Data from time trials testing liquor temperature in a North American boiler produced changes in temperature readings for primary air port thermocouples. Increases in liquor temperature corresponded to fewer thermal fluctuations seen by the thermocouples; these results are clearly visible in Fig. 23. Similarly, liquor viscosity, as determined by solids content, was also tested and shown to have an influence on thermal activity; Fig. 24 demonstrates the difference in fluctuations seen during operation on liquor with (a) normal solids content and (b) reduced solids content. Changes in secondary air distribution were also seen to have an effect on thermocouple activity. For example, 

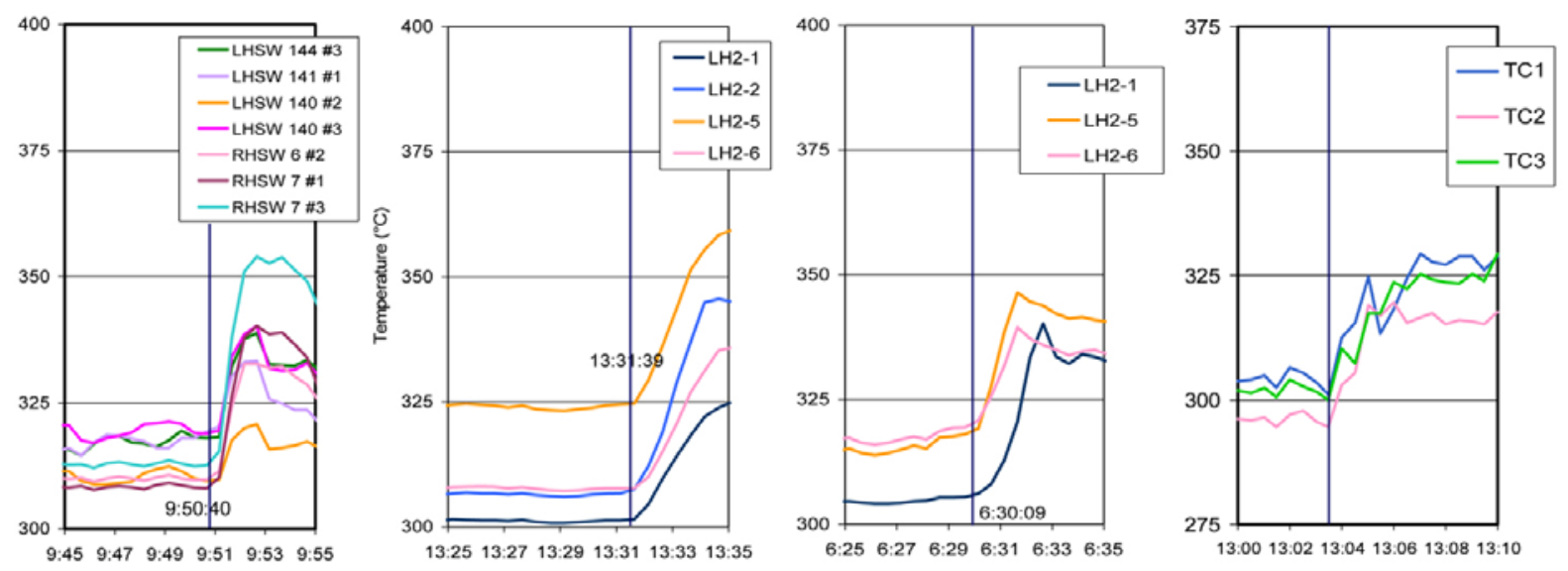

Fig. 22. Start-up procedures at four mills demonstrate the increase in thermal activity as black liquor is first sprayed into the boiler. The vertical lines indication initiation of black liquor spraying.

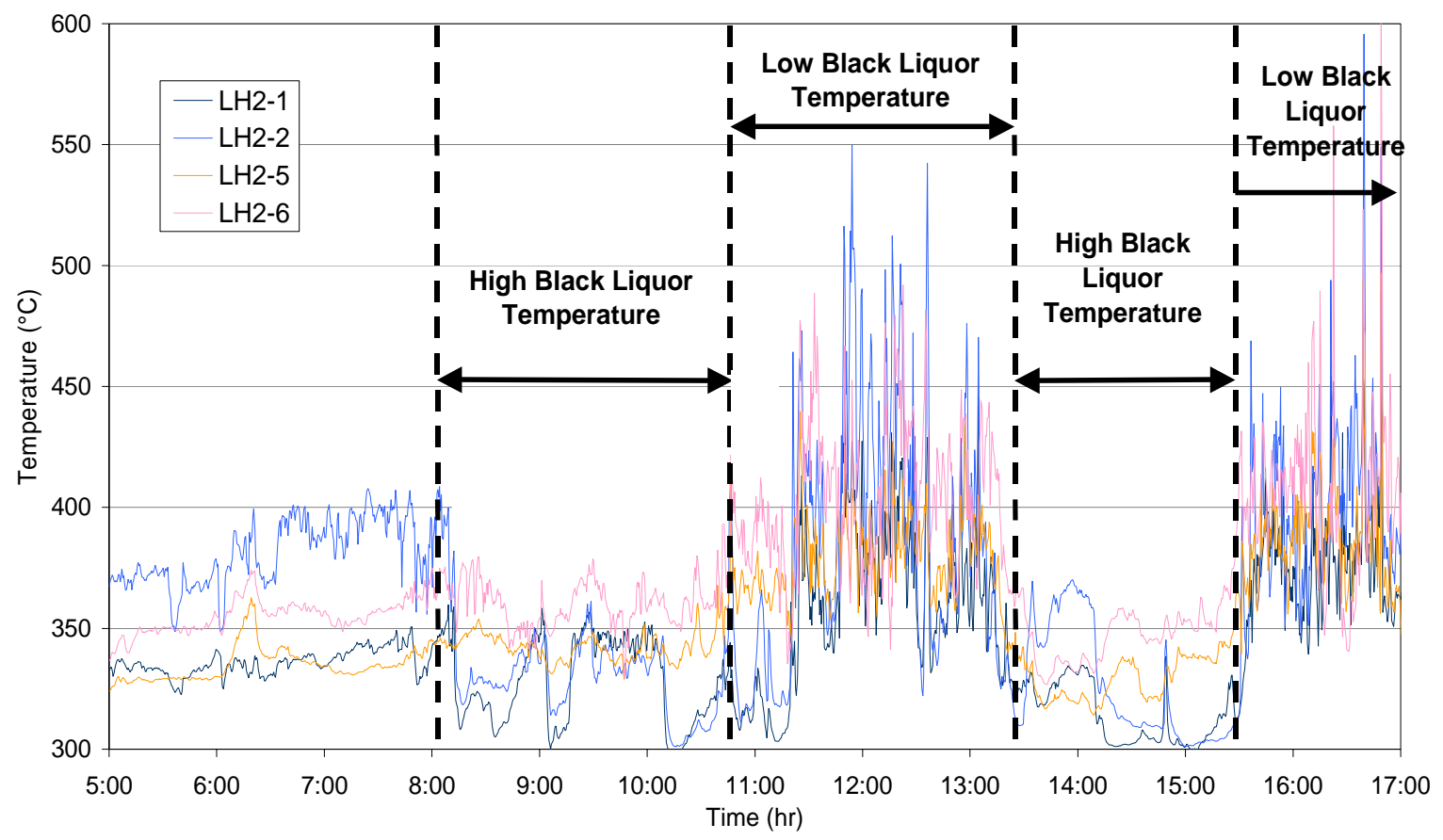

Fig 23. Plot demonstrates the volatility within the boiler as a sequence of high and low temperature black liquor is fired during a time trial. 


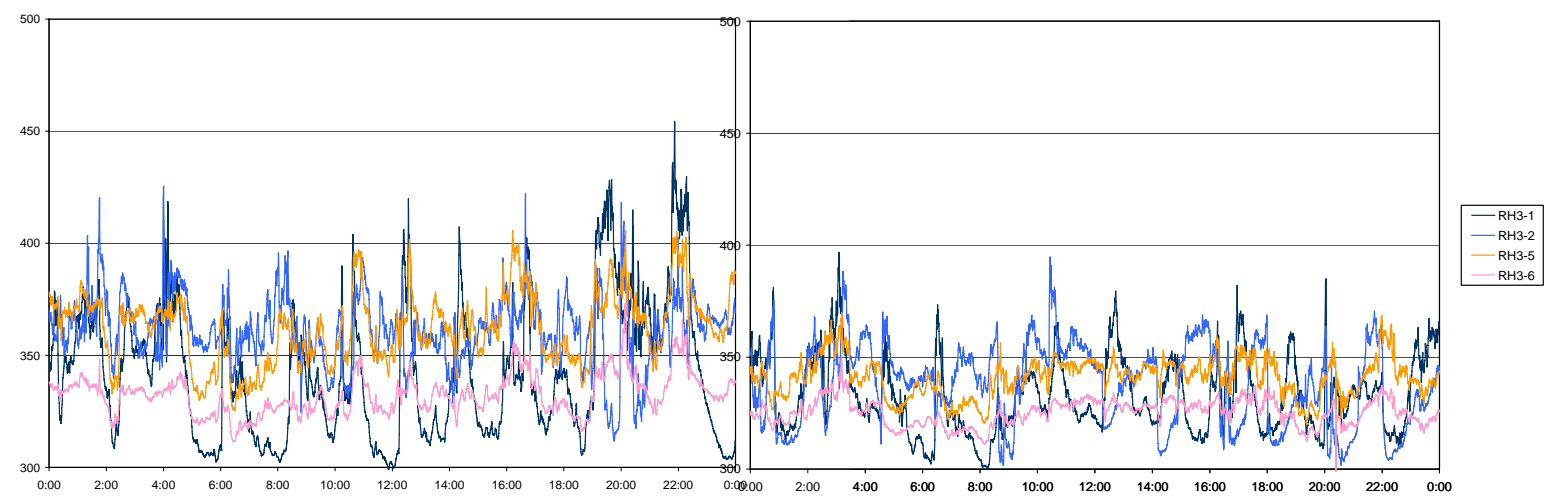

Fig. 24. Typical temperature fluctuations seen during operation on liquor with normal (left) and reduced (right) solids content.

Fig. 25 shows temperature fluctuations measured on the side wall thermocouples decreased slightly, while those on the front wall saw little change when operators switched from a 5 versus 5 interlaced arrangement to a 3 versus 2 interlaced mode.

After several years of collection of primary air port temperature data from one mill that initially had a very severe air port cracking problem, the frequency of cycles and excursions was plotted as a function of time. As is shown in Fig. 26, activity decreased significantly after May 2000. The fact that several operating changes were made around that time led to a decision to conduct a well-controlled investigation of the effects of those changes on temperature fluctuations. A much more extensive and systematic study of the effect of boiler operating parameters was subsequently conducted, and the results of this study are described later in this report.

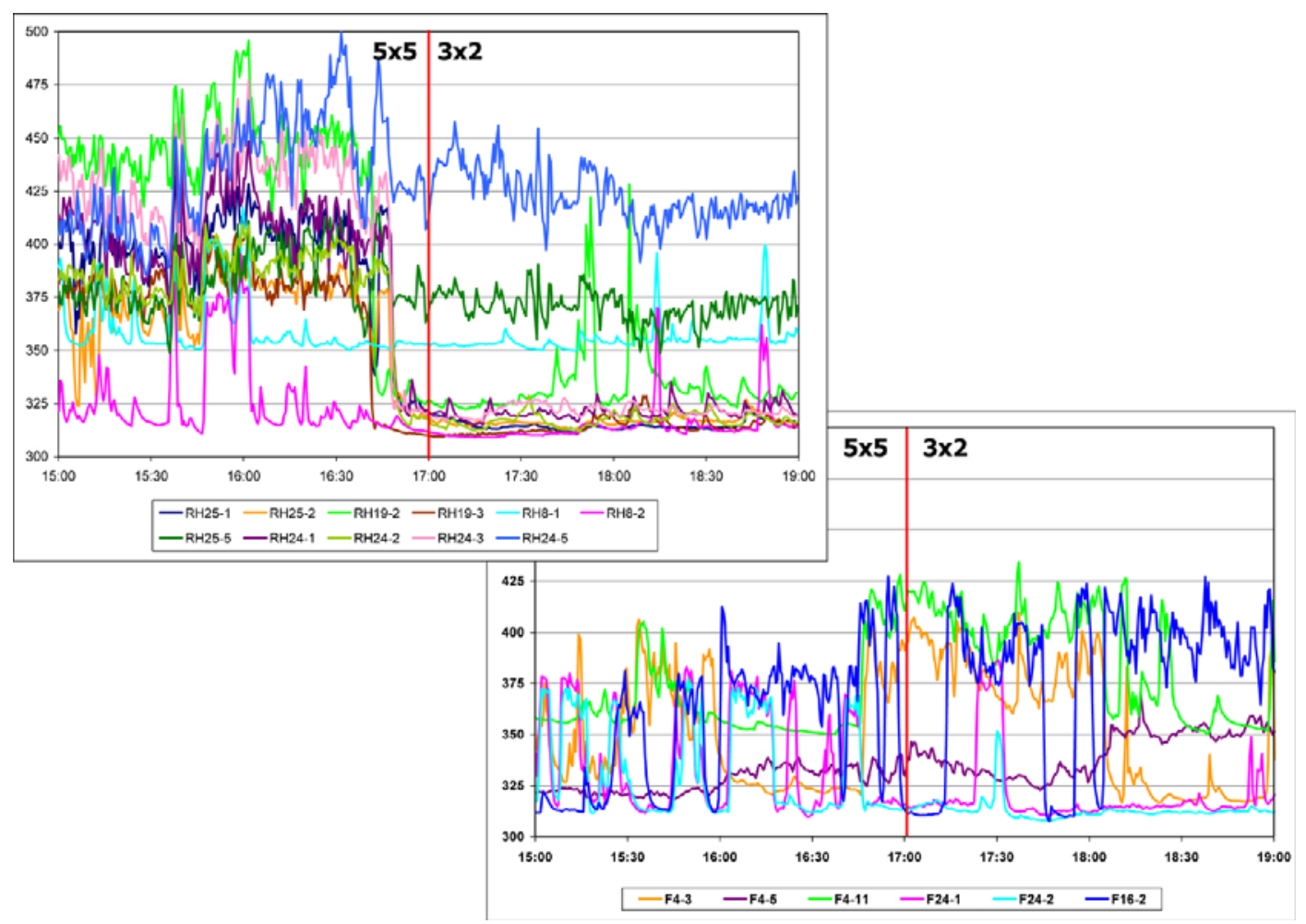

Fig. 25. Plot of temperatures measured by primary air port thermocouples on the right hand side wall and the front wall when the secondary air pattern was changed from 5 versus 5 to 3 versus 2 . 


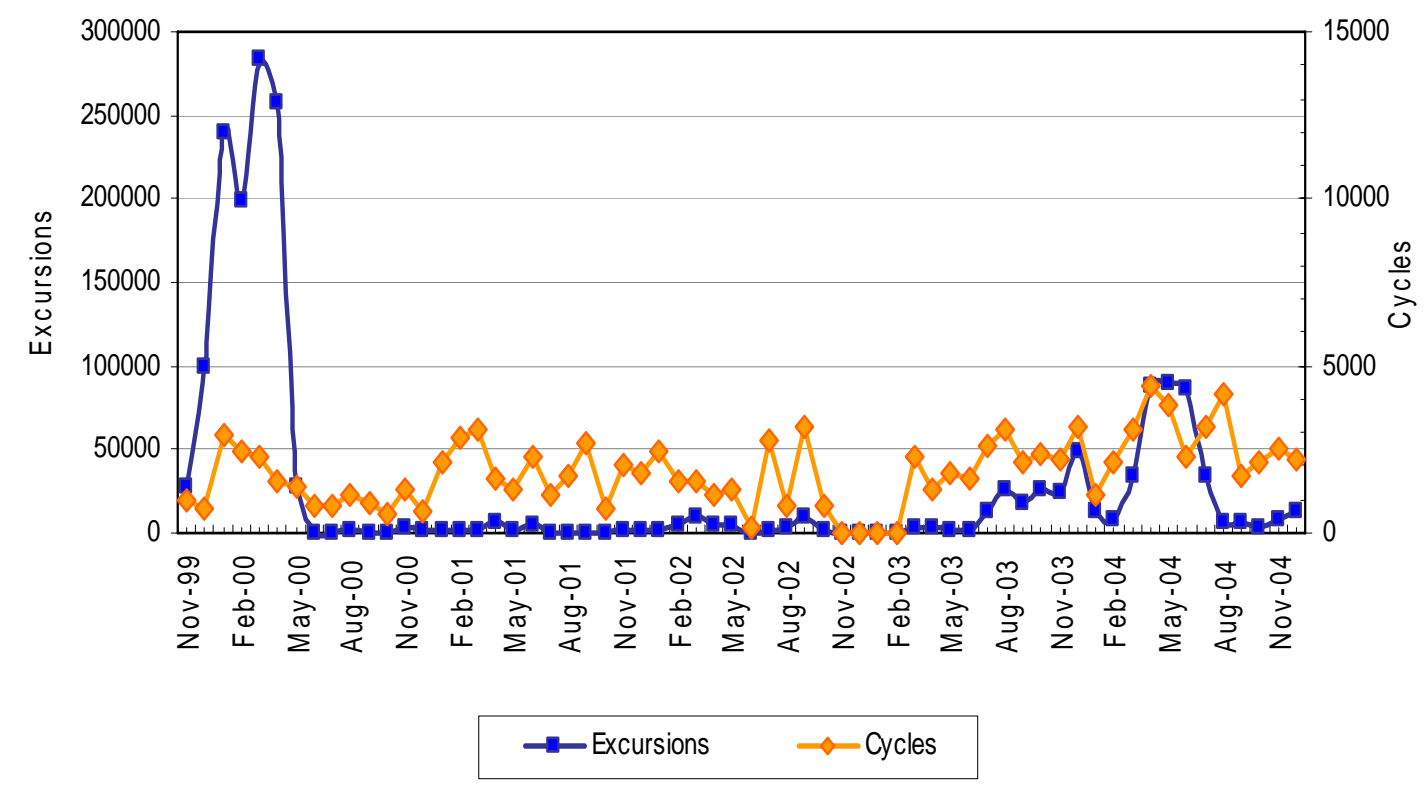

Fig. 26. Cycles and excursions plotted for continuous in-service thermocouples over a five year period in one North American boiler.

Additional studies have included monitoring thermocouples at the secondary air port level in a mill with a history of extensive primary air port cracking and monitoring thermocouples mounted on both sides of a "D" shaped primary air port opening in a boiler with $7.6 \mathrm{~cm}$ ( 3 in.) OD tubes on $10.2 \mathrm{~cm}$ (4 in.) centers. Figures 27 and 28 show the temperature patterns seen on secondary air ports,

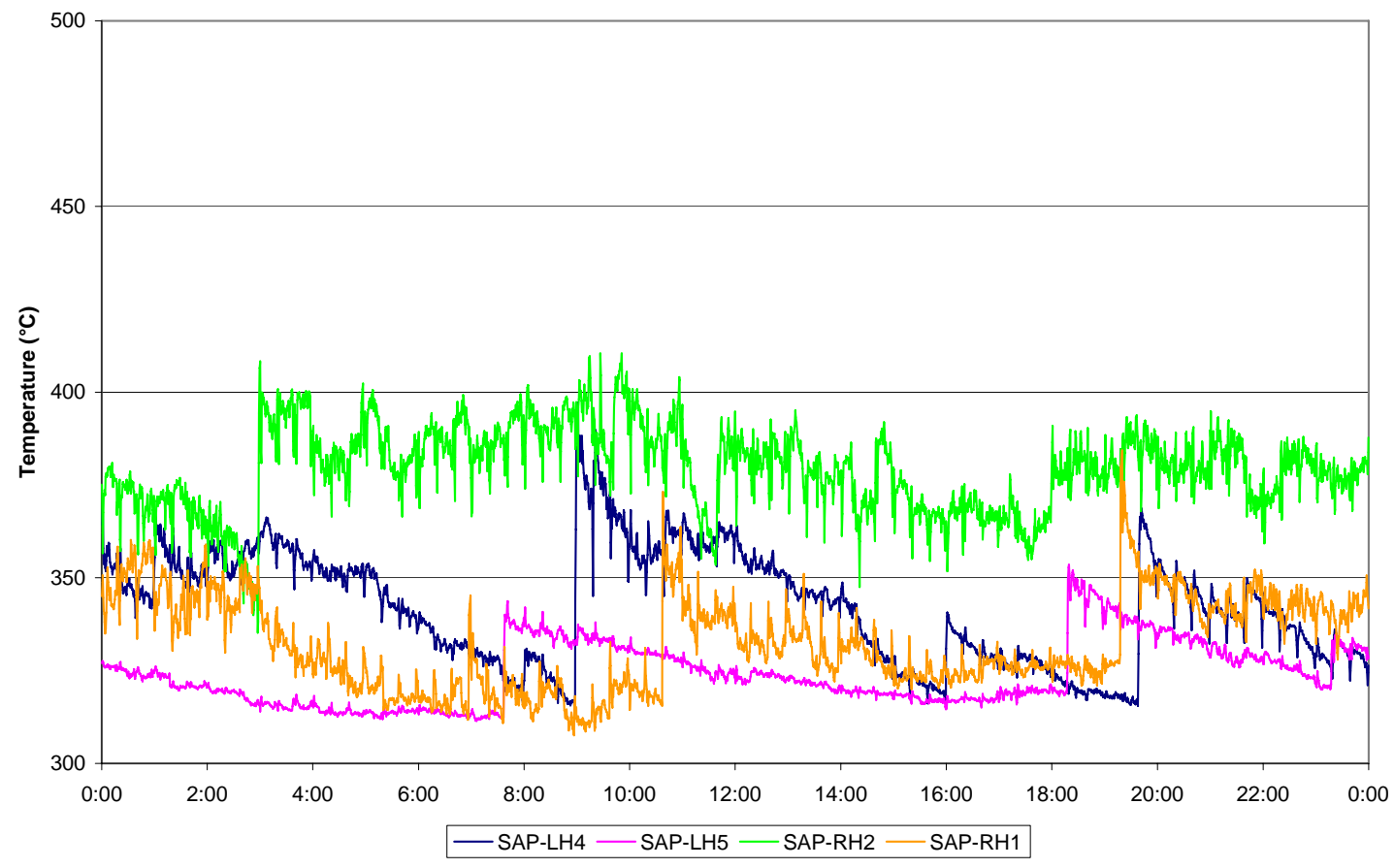

Fig. 27. Temperatures measured in secondary air ports of boiler with history of primary air port cracking. 
and these show minimal cycles and excursions. The cyclic pattern, shown clearly in Fig. 28, is associated with the automatic air port rodders. Figure 29 shows no significant difference in temperatures measured on the straight tube and the bent tube of a primary air port suggesting tube shape has no effect on the likelihood of temperature fluctuations.

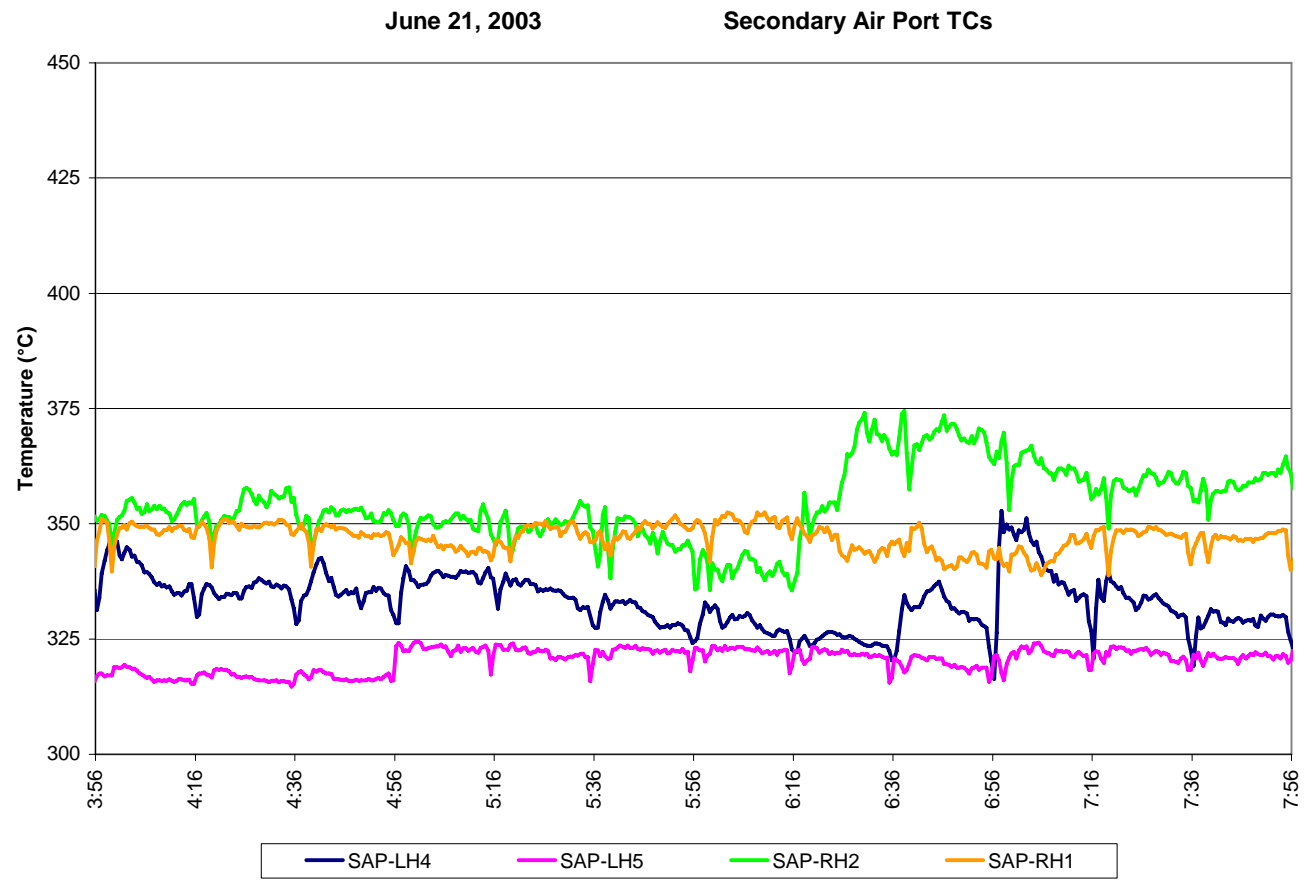

Fig. 28. Plot of temperature vs time showing apparent effect on secondary air port thermocouples of automatic secondary air port rodder operation at 20 minute intervals.

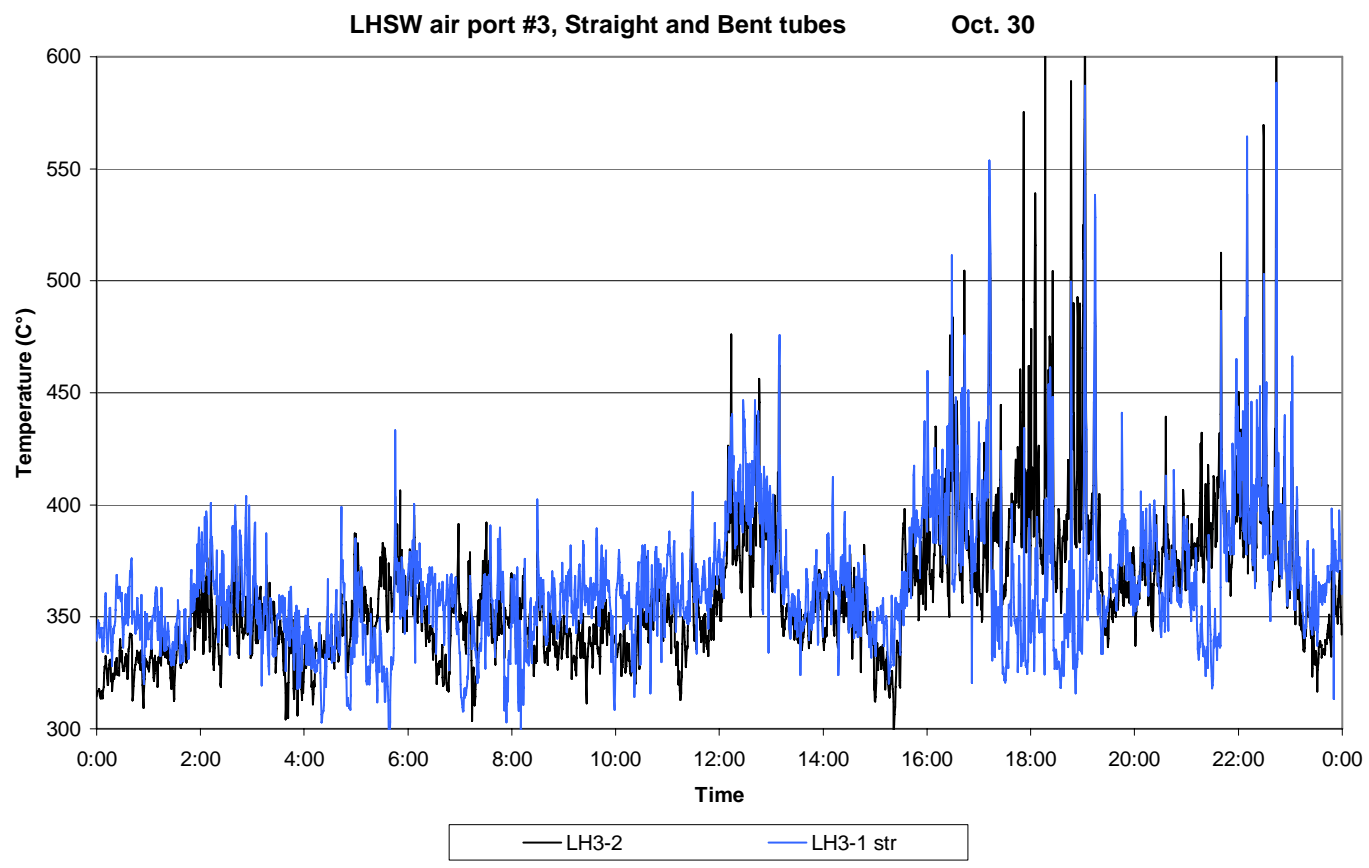

Fig. 29. Thermocouple measurements for thermocouples on the straight and bent tubes of a " $D$ " shaped primary air port opening on a boiler with $7.6 \mathrm{~cm}$ (3 in.) OD tubes on $10.2 \mathrm{~cm}(4 \mathrm{in}$.) centers. 



\section{ENVIRONMENT CHARACTERIZATION-CAMERA STUDIES}

\subsection{USING AN IN SITU VIDEO CAMERA TO DIAGNOSE THE CAUSE OF TEMPERATURE FLUCTUATIONS ON AIR PORT TUBES IN KRAFT RECOVERY BOILERS}

\subsubsection{Equipment and Method}

Paprican developed an air-cooled video camera probe that can be inserted through recovery boiler primary air ports, or other openings in the boiler (Fig. 30). A number of configurations were built, with different sensors, viewing angles, and direction of view to provide as much information as possible about events occurring in the vicinity of the primary air port opening tubes. For standardized comparisons, a configuration was chosen with the camera lens mounted on the side of the probe, to look down the wall as if viewing from inside the boiler. Video captured with this "boiler-view" configuration provided a good view of the tube bends at the bottom of the primary air port (Fig. 31). Typical lens-to-tube bend distances resulted in a 75 to $150 \mathrm{~mm}$ (3" to 6") wide field of view and allowed particles from 0.5 to $1 \mathrm{~mm}(1 / 64$ " to $1 / 32$ ") to be resolved. This version of the camera probe, used most frequently, was $38 \mathrm{~mm}$ (1.5") diameter and of adjustable length, had a working distance of approximately $75 \mathrm{~mm}$ (3”) to infinity, a $63^{\circ}$ field of view, 420 line sensor resolution and sensitivity to a narrow wavelength band in the near infrared (NIR).

Five trials with the camera probes have been conducted in three boilers. The observations presented in this section come largely from trials conducted in a single boiler at Mill C, with a significant cracking problem, $63.5 \mathrm{~mm}$ (2.5") diameter tubes on $76.2 \mathrm{~mm}$ (3") centers and previously instrumented with thermocouples on 15 of 130 air port openings. The thermocouples were located, as previously described, on the area of the tube bends where the worst cracking occurred, and at several other places surrounding the primary air port openings. On some occasions rapid temperature change was documented on the surface of the boiler tubes, of up to $50 \mathrm{C}^{\circ}$ in 10 seconds, during these periods.

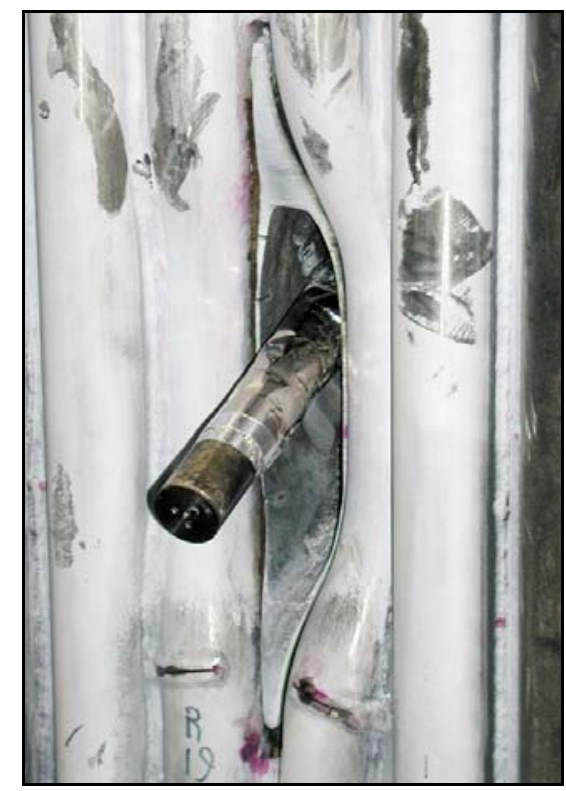

Fig. 30. Camera probe inserted through primary air port opening during a shutdown; it records activities on the fireside of the primary air port. 


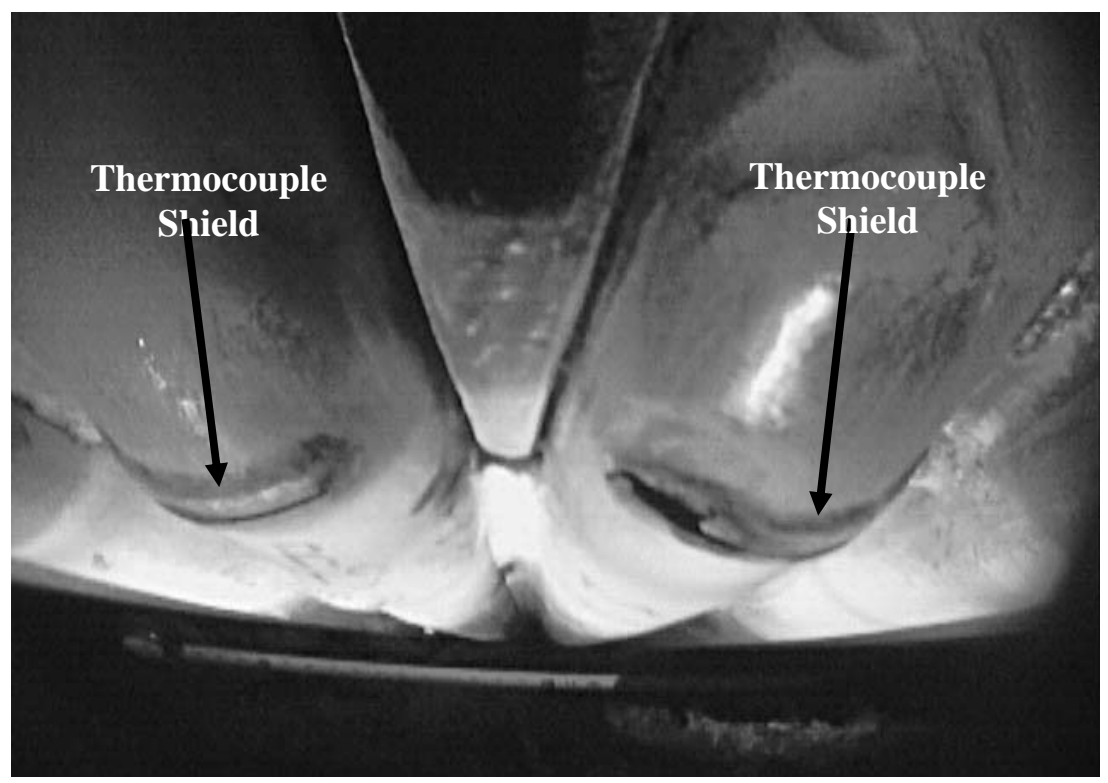

Fig. 31. Primary air port during shutdown; view gained looking down towards boiler floor with the boiler-view camera. A thermocouple shield can be seen on each of the tubes forming the air port opening, and a tape measure is visible on the boiler floor under the opening.

To acquire the video images, the camera probe was inserted through an external view port into the windbox, over the tip of the port rodders, and into the air port opening. Guillotine type velocity dampers on each port within the selected windbox were fully retracted before insertion and while the camera was in place. The field of view generally included the lower tube bends (including the thermocouple shields when present) and the intersection of the char bed with the wall. The camera was periodically rotated to one side or the other to provide information about the height of the ridges in the char bed between the air ports and the amount of particulate in the atmosphere. As long as the window for the camera lens remained clean, the camera was left in a given air port for up to 70 minutes at a time. Both primary and secondary rodding at adjacent air ports were observed to influence tube surface temperatures, and consequently, it was considered advantageous to leave the camera probe in place for longer than the longest port rodding cycle.

\subsection{OBSERVATIONS \& DISCUSSION}

\subsubsection{Overview}

Captured video was edited down to approximately thirty hours of useful footage, twenty-three of which came from Mill C. Detailed analysis was very time consuming due to the complexity of the image content and requirement for accurate matching of video and temperature time scales. However, features and activities which could be correlated to thermal behavior on the surface of the tubes or which reflected the degree of black liquor particle combustion at the time of deposition have been identified. Included in the initial observations, and described more fully below, was a coating on the interior surfaces, wide variation in deposited particulate morphology and flux, two characteristic temperature bands, smelt production and flow patterns and indications of air-gas flow fields. 


\subsubsection{Coating on Tubes}

When a boiler is firing liquor, a thin, continuous coating appears to cover all fireside surfaces of the tubes that were examined. This coating appeared to be one to two $\mathrm{mm}$ thick and quite adherent at the primary air port level. It appeared smooth, uniform and generally white (higher temperature) in the NIR region examined. The surface frequently became darkened by thin deposits which either washed away or slowly turned white. The coating is thought to be formed of condensed vapor, adherent fume, ejecta, and frozen smelt. Initial evidence for the existence of this coating came when the coating was disturbed. During one period, a high flow rate of clear liquid washed over the surface of the tubes. Subsequently, one small area of the washed coating peeled back from a primary port tube due to impingement of the camera cooling air, indicating that the coating may have been softened in that location. At the secondary level in another boiler, an approximately $8 \mathrm{~cm}$ long blister formed in the coating on the tube beside the air port, before it eventually spalled off in a brittle fashion. When the tubes were examined during a break in liquor firing, a bright white surface was evident over the entire visible boiler interior, with the exception of areas near the air port openings where lifting and spalling of the coating had occurred, revealing a dark grey surface beneath. When liquor firing recommenced, the dark surface rapidly lightened, even before significant visible particulate appeared or liquid flowed.

Based on these observations, there seems little likelihood that bare metal on the tube surface is directly exposed to radiation from hot gases in the boiler for any significant periods of time.

\subsubsection{Particle Characteristics}

When liquor was being fired in the boilers, particles were observed depositing near the air ports in a wide range of size, shapes and flux to the surface. The majority of particles stuck to the wall where they landed. No particles were observed to bounce off, though some would slide down the wall. They were most likely to slide if they were small and landed in the middle of a rapidly flowing liquid stream, and least likely to slide if the surface of the coating on the tubes was roughened by previous deposits.

Particles were observed to land on the surface of the coating and shrink, or less often to swell then shrink, both cases producing a clear liquid and frequently depositing a dark solid residue. This deposit usually fragmented into fines and was carried down the tube by the general flow of liquid, if voluminous enough. Shrinking of the particles is consistent with the process of char combustion, particle coalescence and melting previously described [16,17]. If so, the products would consist of molten inorganic salts or liquid smelt and unconsumed char carbon or black fines. Local particle accumulation on the walls, as is the case for the bed, appears to be primarily related to the speed of shrinkage (carbon conversion and salt melting) versus deposition rate, with the added factor of landing-surface roughness influencing location.

Geometry and physical behavior of the particles could be loosely related to their approximate size (Table 1). Particle brightness ranged from dark grey to bright white.

Table 1. Observed variation in particle characteristics

\begin{tabular}{lllllll}
\hline \multirow{2}{*}{$\begin{array}{l}\text { Size estimation } \\
\text { (long axis, }\end{array}$} & \multicolumn{2}{c}{ mm) } & Hollow? & & \multicolumn{2}{c}{ Swelling? } \\
\cline { 6 - 7 } & No & Yes & & No & Yes \\
\hline Large & 25 to 50 & & $\mathrm{X}$ & & $\mathrm{X}$ & \\
Medium & 12 to 25 & & $\mathrm{X}$ & & $\mathrm{X}$ & $\mathrm{X}$ \\
Small & 4 to 12 & $\mathrm{X}$ & $\mathrm{X}$ & & $\mathrm{X}$ & $\mathrm{X}$ \\
Tiny & 0.5 to 4 & $\mathrm{X}$ & & & $\mathrm{X}$ & \\
Black fines & $\sim 0$ to 2 & $\mathrm{X}$ & & & $\mathrm{X}$ & \\
\hline
\end{tabular}


When particle swelling occurred, as is expected during the devolatilization phase [16], the particles frequently elongated. Swelling values, estimated with video as the increase in maximum dimension, were less than 10 times and usually less than 5 times. Some swelling may already have occurred before deposition and measurement. Values for swelling or volume expansion of kraft black liquor under simulated furnace conditions have been reported as great as 100 times, but more typically 20 to 50 times [16]. A more recent survey of lab tests indicated the bulk of as fired sulfate liquors had a swelling range of 12 to $35 \mathrm{~cm}^{3} / \mathrm{g}$ BLS [18].

\subsubsection{Liquid Characteristics}

Liquid was observed flowing down the fireside of the tube walls at the secondary level and below. Liquid trails tended to flow from the crown of the tubes diagonally down to the membrane valleys between tubes, and continue there. Flow patterns varied with increasing volume as follows:

Low $=$ Liquid trails down membrane valleys

Medium $=$ Liquid trails down tube crowns and membrane valleys

High $=$ Liquid washing over tube crowns

The liquid normally appeared clear and colorless, but occasionally the liquid trails would appear dark. This could usually be explained by observation of a high concentration of entrained black fines, but may also have resulted from a thickening of the fluid layer or increased IR absorbance related to a change in chemistry. Temperatures measured on the lower tube bends in the coated state did not appear to be affected by the presence or absence alone of clear colorless liquid flowing over the thermocouple.

The major effects of liquid detected in the video are:

1. High clear liquid flow rates tended to keep particulate from building up on the tubes. An increase in liquid flow tended to remove previously deposited particulate.

2. The path of liquid flow determined the deposit patterns of the black fines. Dark deposits reaching up membrane valleys just above the bed, and mounds of deposited black fines at the intersection of the tube wall and bed seem associated with heavy local particle deposition rates at the primary air level.

3. High liquid flow rates may be associated with a softening of the coating on the tubes.

\subsubsection{Characteristic Temperature Bands}

Careful examination of thermocouple data over short time intervals revealed two dominant temperature bands (Fig. 32). Further examination of the corresponding video, during the longest and most stable of these temperature events, revealed two extremes in the density of accumulated char particles.

Conditions associated with the upper and lower temperature bands are described more fully below:

Upper temperature band-The thermocouple shields were exposed, except for the usual white coating on the surface. No particulate was landing on the surface of the thermocouple shields, the char bed was more than roughly $30 \mathrm{~cm}$ ( 1 foot) from the bottom of the primary air port, and very steady temperatures $\left( \pm 5^{\circ} \mathrm{C}\right)$ were recorded, typically for periods of about 15 minutes (Fig. 33a). The actual temperature measured within the upper band appeared to vary with location of the thermocouple relative to the port and the port's location around the boiler. For Mill C's boiler, the temperature band was generally 380 to $420^{\circ} \mathrm{C}$. 

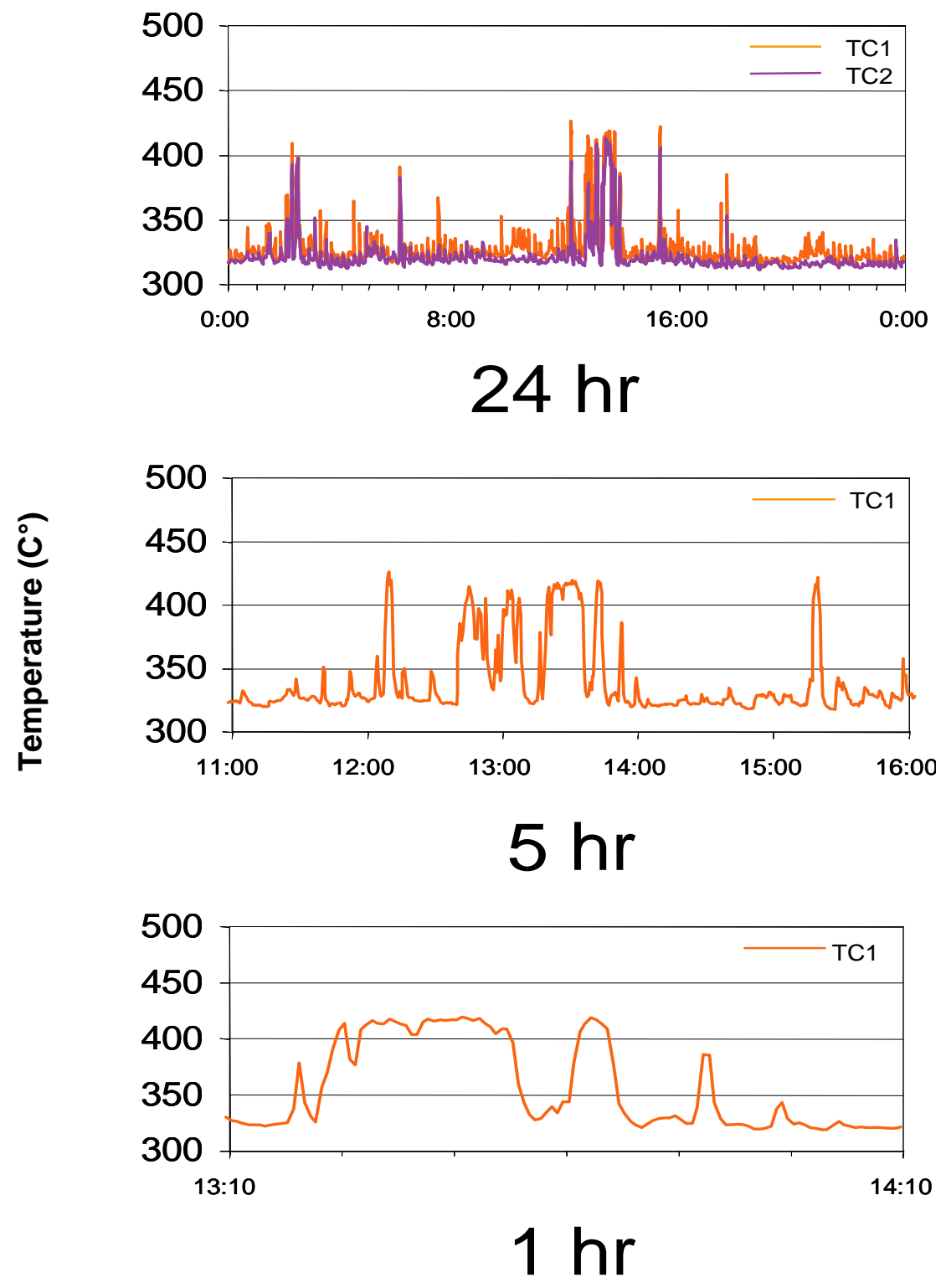

Fig. 32. Temperature measurements from thermocouples installed on tube bends at the bottom of a primary air port; expansion of data time scale assisted in the recognition of two dominant temperature bands. 


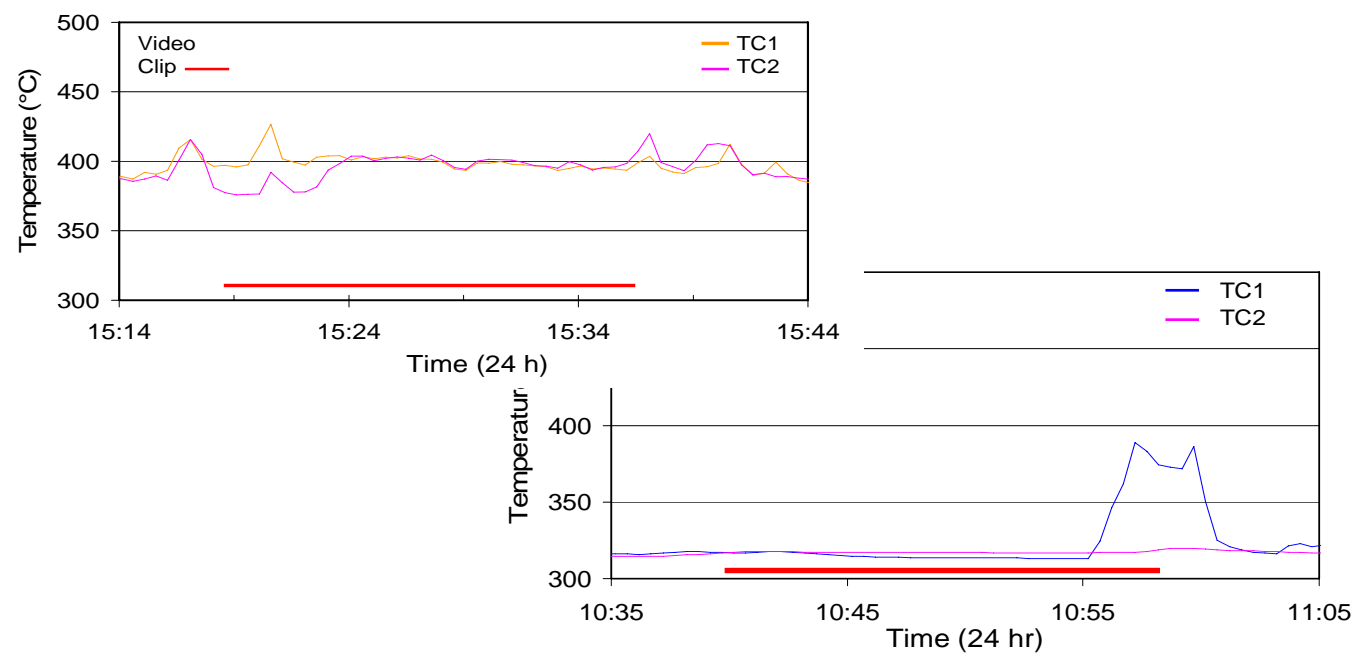

Fig. 33. Temperature measurements from thermocouples installed on tube bends at the bottom of a primary air port (a-upper left) example of characteristic temperatures in the upper temperature band and (b-lower right) example of characteristic temperatures in the lower temperature band.

Lower temperature band - A high char bed at the tube walls submerged the coated thermocouple shields beneath a compact layer of medium sized white or grey char particles. This results in very steady temperatures close to that of the water in the wall tubes, and can last for several hours at a time. The char bed over the tubes was continuously renewed by light particle deposition as combustion occurred, and appeared stable and dense enough to protect the coated thermocouple shields from exposure to radiation, hot combustion gas or air interaction. Exclusion of oxygen would allow endothermic reduction reactions to dominate [17]. It's possible that such a cooling effect could contribute to the stability of the temperature on tube surfaces submerged under the char bed. The temperature measured at the bottom of the primary air ports under this condition in Mill C's boiler was typically $320 \pm 5^{\circ} \mathrm{C}$ (Fig. 33b).

Examples of what is seen with the video camera are shown in Fig. 34. Figure 34 shows photos taken by the camera when a) the bed is low and when b) the bed is high.

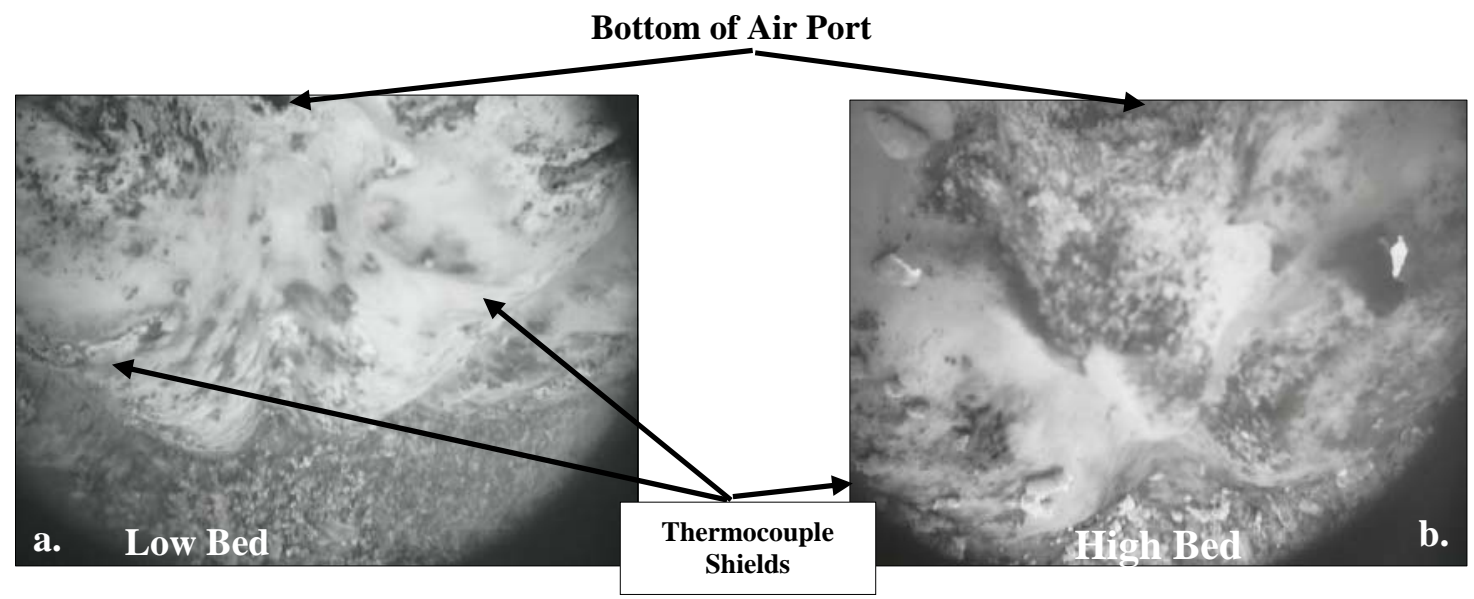

Fig. 34. View of the air port opening tubes as seen by the boiler camera probe taken while boiler was in operation. (a) The bed is low, and can be seen at the base of the tubes. Thermocouple shields are barely visible on both the left and right hand tubes, and (b) similar camera view of the air port. The bed at this point is much higher and may be obscuring view of the thermocouple shields. While not obvious in this still photograph, streams of transparent liquid are flowing down the smooth light gray surface on either tube. 


\subsubsection{Temperature Variations}

The upper temperature band appears to be the product of a balance between radiant heating and tube water cooling effects. On rare occasions, changes to the velocity or windbox dampers of the port being examined were seen to have an impact on the thermocouple temperatures. These changes could not be readily attributed to changes in char deposits. This indicates that injected air may also have an effect on the energy balance.

Decreases in the tube surface temperature from the upper band were frequently associated with deposition of material, with the lower band temperature being the limit of temperature reduction locally. Increase in temperature above the upper band was not as readily associated with isolated features or activities. Temperatures most frequently observed during filming generally varied between the upper and lower temperature bands as material was deposited on or removed from the thermocouple shields on the tube bends. It was noted that temperatures above $500^{\circ} \mathrm{C}$ were never observed when conditions approached that associated with steady, upper band temperatures.

Tables 2 and 3 document features or activities that were observed during video capture to correlate with decreases or increases in measured temperature on the tube bends at the bottom of the primary air ports.

\subsubsection{Air-Gas Flow Fields}

The flow and flow variation of injected air and hot boiler gases forming the boiler atmosphere had an impact on the temperatures measured on tube surfaces at the bottom of the primary air ports. Temperature changes corresponding to either primary or secondary air port damper changes have been correlated with activities B, D, F, G, H, and L listed in Tables 2 and 3, and more correlations may still be found. As well, observations of liquid flow across the tube surfaces give an indication of atmospheric influences, such a liquid trail flowing horizontally across the crown of the tube bend

Table 2. Observed features and activities associated with temperature decreases

\begin{tabular}{|c|c|c|c|}
\hline & Feature or activity & $\begin{array}{l}\text { Temperature } \\
\text { change }\end{array}$ & Observation \\
\hline $\mathrm{A}$ & $\begin{array}{l}\text { Char bed particulate surface level } \\
\text { rose to cover TCs }\end{array}$ & $\begin{array}{l}\text { Drop to LTB and } \\
\text { hold }\end{array}$ & $\begin{array}{l}\text { Temperature stepped down; Compact, } \\
\text { stable bed had greatest effect }\end{array}$ \\
\hline $\mathrm{B}$ & $\begin{array}{l}\text { Large transient increase in } \\
\text { deposition of particulate }\end{array}$ & Negative spike & $\begin{array}{l}\text { Particles were swelling grey to hollow } \\
\text { white in character; Particulate } \\
\text { blocked radiant energy }\end{array}$ \\
\hline $\mathrm{C}$ & $\begin{array}{l}\text { Opening of primary velocity } \\
\text { damper }\end{array}$ & $-70 \mathrm{C}^{\circ}$ below UTB & $\begin{array}{l}\text { TCs at top of port @UTB and not } \\
\text { affected; Little liquid; Light tiny } \\
\text { particle deposition }\end{array}$ \\
\hline $\mathrm{D}$ & $\begin{array}{l}\text { Increase in clear colorless liquid } \\
\text { flow over both bends }\end{array}$ & $\begin{array}{l}-30^{\circ} \text { to }-50 \mathrm{C}^{\circ} \text { below } \\
\text { UTB }\end{array}$ & $\begin{array}{l}\text { Associated with secondary air port } \\
\text { rodding cycle (possible air/gas flow } \\
\text { field shift?) }\end{array}$ \\
\hline $\mathrm{E}$ & $\begin{array}{l}\text { Liquid \& char carbon flow } \\
\text { increase when bed just } \\
\text { covering TCs }\end{array}$ & $-20^{\circ}$ to $-40 \mathrm{C}^{\circ}$ & $\begin{array}{l}\text { Flow increase not enough to lower bed } \\
\text { surface }\end{array}$ \\
\hline $\mathrm{F}$ & $\begin{array}{l}\text { Transient change in particle } \\
\text { deposition rate or particle } \\
\text { characteristics }\end{array}$ & $\begin{array}{l}-20^{\circ} \text { to }-30 \mathrm{C}^{\circ} \text { below } \\
\text { UTB }\end{array}$ & $\begin{array}{l}\text { May indicate a shift in gas flow (gusts); } \\
\text { the shift may bring a change in: } \mathrm{O}_{2} \text { or } \\
\text { volatile content, gas temperature, } \\
\text { particle content; frequently associated } \\
\text { with port rodding cycles }\end{array}$ \\
\hline
\end{tabular}

$\mathrm{TCs}=$ thermocouples; $\mathrm{UTB}=$ upper temperature band; LTB $=$ lower temperature band 
Table 3. Observed features and activities associated with temperature increases

\begin{tabular}{|c|c|c|c|}
\hline ID & Feature or activity & $\begin{array}{c}\text { Increase } \\
\left({ }^{\circ} \mathrm{C}\right)\end{array}$ & Comment \\
\hline $\mathrm{G}$ & $\begin{array}{l}\text { Transient change in particle deposition } \\
\text { rate or particle characteristics }\end{array}$ & $\begin{array}{l}\text { Smallest } \\
\text { effect }\end{array}$ & $\begin{array}{l}\text { May have indicated a shift in gas flow (gusts) } \\
\text { and change in } \mathrm{O}_{2} \text { or volatile content, gas } \\
\text { temperature, particle temperature }\end{array}$ \\
\hline $\mathrm{H}$ & $\begin{array}{l}\text { Increase in flow of clear dark liquid } \\
\text { over TCs }\end{array}$ & & Temperature rose above UTB \\
\hline I & All primary velocity dampers closed & & Firing on oil only \\
\hline $\mathrm{J}$ & $\begin{array}{l}\text { Liquid flow removing minor deposits } \\
\text { from TC surface }\end{array}$ & & Temperature rose to UTB \\
\hline $\mathrm{K}$ & $\begin{array}{l}\text { Char bed particulate surface level } \\
\text { dropped beneath TCs; Char particle } \\
\text { layer or black fines layer spalled off }\end{array}$ & & $\begin{array}{l}\text { On occasion, temperature spiked up then } \\
\text { settled back after } 1 \text { to } 3 \text { minutes to UTB }\end{array}$ \\
\hline $\mathrm{L}$ & $\begin{array}{l}\text { High liquid volume washed over } \\
\text { tubes; black fines appeared to coat } \\
\text { tubes deposited from liquid flow or } \\
\text { from rapid particle melting; heavy } \\
\text { deposition of white particles } \\
\text { shrinking very rapidly }\end{array}$ & $\begin{array}{l}\text { Largest } \\
\text { effect }\end{array}$ & $\begin{array}{l}\text { Liquid appeared dark on occasion, but it was } \\
\text { not apparent whether as a result of color } \\
\text { change, increased thickness/viscosity or fine } \\
\text { black particle content; temperatures well } \\
\text { above UTB observed on occasion }\end{array}$ \\
\hline
\end{tabular}

$\mathrm{TCs}=$ thermocouples; $\mathrm{UTB}=$ upper temperature band; LTB $=$ lower temperature band

(then turning $90^{\circ}$ down when intercepted by the air flow field from the primary air port), probably indicating a low pressure zone adjacent to the port.

A white fog has been observed at the bottom of the primary air ports when the char bed was high, and appeared as an elongated cloud projecting from the primaries when viewed from above or to the side at a distance. The fog is thought to be caused primarily by light scattered by aerosol particles at the air jet interface with furnace gases. Some contribution from increased broad band radiation at the interface is also possible, due to elevated temperatures produced by combustion of volatiles and ejecta (1 to 100 micron char fragments) [19-22].

\subsubsection{Location on Air Port Opening}

Cracks in composite tubes are almost never found in the upper half of primary air port openings. Despite the obvious desire to make comparisons between the top and bottom of air port openings, much fewer video observations have been made of the top of the air ports because of an increased rate of fume deposition on the camera window when looking up. However, the views that were obtained indicate that liquid can flow in a rapid wash over the upper tube bends and particles do not tend to build up on the surface there.

On some occasions, it seemed that particles did not land, though present in the nearby boiler atmosphere. At other times, particles were seen to slide down the tubes past the upper end of the port. If particles do not accumulate at the top of the port in the form of a bed or layer, then temperature cycling will not be produced by its removal and re-accumulation.

\subsubsection{Char Bed Activity}

It has been reported by Tran et al. [22] that an increase in char bed accumulation near primary air ports was considered to have a high probability of association with the cracking problem. As well, they reported that when temperature excursions occurred, the char bed was either observed to touch the tubes or the conditions at the ports were extremely turbulent. Based on our observations, the char bed surface rises to the primary port level during times of heavy deposition of particles. However, even while deposition continues, the surface of the char bed is observed to recede and grow again, over a range of several centimeters, which is enough to uncover and recover the lower tube bends. 
This is likely the result of slight variations in the balance between particle deposition and char carbon consumption. Observed activities such as gusts in the atmosphere causing particles to roll across the bed surface, heavy deposition of particulate particularly while still swelling, evolution of gases from below the surface of a somewhat molten bed, and char particles floating on the disturbed surface of a pool of liquid smelt, could all be described as turbulent and may be associated with the conditions reported.

\subsection{DISCUSSION OF VIDEO RESULTS}

Video recordings of the boiler interior at the primary air port level have demonstrated that the air port opening tubes exist in a very dynamic environment, with strong associations between the atmospheric flow, liquid flow, char particle deposition and accumulation and temperatures on the surface of tubes at the bottom of the primary air ports. Despite the wide range of conditions, a thin smooth layer or coating of adherent material appeared present on all observed boiler interior surfaces during operation. Two characteristic temperature bands were identified on the surface of the tube bends. Temperatures in the lower band were found when the coated thermocouple shields were thoroughly submerged beneath the char bed, and were close to that of the water in the wall tubes. Temperatures in the upper band were found when the coated thermocouple shields were not influenced by char particulate. Temperatures measured within the upper band appeared to vary with the port's location around the boiler on occasion. Multiple activities and features have been observed to cause rapid deviations from the upper temperature band, none of which caused temperatures to exceed $450^{\circ} \mathrm{C}$ on their own. No temperature excursions above $500^{\circ} \mathrm{C}$ occurred when the particulate deposition rate on the tube bends was low and the surface of the bed was well below the bottom of the primary air ports.

The observations have been listed in isolation from each other, and correlations with other activities have not yet been fully characterized. For example, further analysis is required to determine if the changes which occur in air/gas flow fields during air port rodding result in larger measured temperature changes when: (a) the tube bends are wetted, (b) the liquid appears darker, (c) the bed surface is close to the bottom of the ports and piled to either side, or (d) when deposits have accumulated on the tubes.

A set of physical observations has been associated with temperatures rising above $450^{\circ} \mathrm{C}$, but further analysis is required to identify the key components, interactions and synergies among the features present. Additional testing would be required to confirm the composition of the observed black fines and identify the change in composition associated with the darkening appearance of the liquid and deposits. Both might help to identify the mechanism responsible for temperature excursions above $450^{\circ} \mathrm{C}$.

The sulfate/sulfide redox cycle is capable of producing a large net exotherm [23]. That process is described in more detail later in this report (See Sulfate/Sulfide Redox Cycle). Flowing molten smelt was frequently observed in intimate contact with finely divided residual char on the coated tube surfaces, and yet no temperature increase above the characteristic UTB was ever attributed to those conditions. An assumption that the oxygen content would be relatively high in the boundary layer beside the air ports would seem to indicate that, at the temperatures found on the surface of the white coating under normal conditions, the sulfate reduction process was relatively slow [23-25] in producing sulfide in situ and was the rate limiting step in the redox cycle.

On the basis of these multiple observations, it was concluded that wide ranging combinations of physical features and activities may be present on the fireside of primary air port tubes [26] which constitute "normal" operation of the boiler, and that these conditions do not, by themselves, lead to tube surface temperatures rising above $450^{\circ} \mathrm{C}$. 


\subsubsection{Discussion of Observed Conditions Associated with High Temperatures}

Observations of excessive temperature excursions $\left(>450^{\circ} \mathrm{C}\right)$, on tubes instrumented with thermocouples, proved difficult to obtain. This was largely because the first target boiler for the video work had recently taken remedial measures that proved to quell the measured temperature cycling and excursions [27]. With the addition of video collected at two other mills with severe, ongoing localized cracking and corrosion problems at their primary air ports, it became possible to identify high tube surface temperature conditions, either by observation during temperature measurement $[26,28]$ or by repeated observation of similar conditions at inferred high temperature locations, based on:

1. A history of measured high temperatures (plus rapid thermocouple shield corrosion), and/or

2. Severe localized corrosion and composite tube cracking, both of which have previously been related to high tube surface temperatures [29-31].

See Table 4 for a description of the fireside conditions associated with high tube surface temperatures, and the tube surface temperature indicators used to identify them.

Table 4. Observed sets of fireside conditions associated with known or inferred high tube surface temperatures, based on the temperature indicator listed

\begin{tabular}{|c|c|c|}
\hline ID & Observed fireside condition & $\begin{array}{l}\text { Tube temperature } \\
\text { indicator }\end{array}$ \\
\hline A & 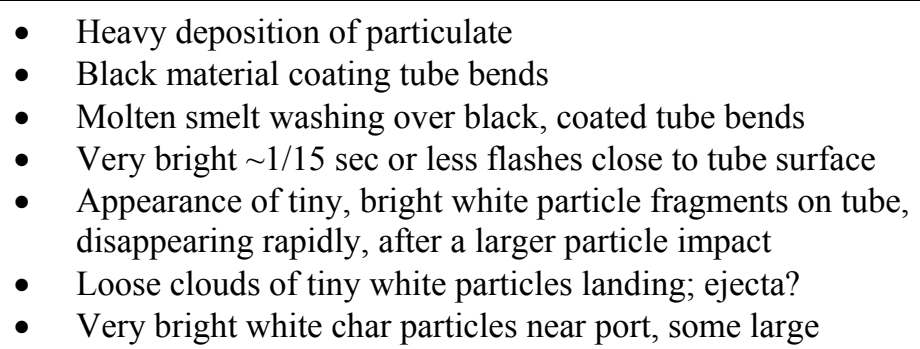 & $\begin{array}{l}\text { - Thermocouple } \\
\text { excursions above } 450^{\circ} \mathrm{C} \\
\text { during observation } \\
\text { - Composite tube cracking } \\
\text { location }\end{array}$ \\
\hline $\mathrm{B}_{1}$ & $\begin{array}{l}\text { Tar-like material in tube valleys and at the char bed surface, } \\
\text { up against the tube wall }\end{array}$ & $\begin{array}{l}\text { - Seen in locations where } \\
\text { TC read }>450^{\circ} \mathrm{C} \text { recently }\end{array}$ \\
\hline $\mathrm{B}_{2}$ & $\begin{array}{l}\text { - A thick, smooth, irregular, tar-like black deposit formed on } \\
\text { the tube crowns and bends } \\
\text { - Some liquid smelt flowing over the black deposit } \\
\text { - Frequently associated with very bright char particles }\end{array}$ & $\begin{array}{l}\text { - History of severe air port } \\
\text { composite tube cracking }\end{array}$ \\
\hline $\mathrm{C}$ & $\begin{array}{l}\text { White swollen particles "melting" to form bubbling, light } \\
\text { grey molten globules at the bottom of an air port opening } \\
\text { Patches in the bed which bubble like porridge indicating } \\
\text { that the char particles are molten enough to stick together } \\
\text { and restrict the flow of escaping gasses from below the } \\
\text { surface }\end{array}$ & $\begin{array}{l}\text { - History of severe } \\
\text { localized corrosion } \\
\text { and/or cracking } \\
\text { - History of high tube } \\
\text { surface temperatures }\end{array}$ \\
\hline $\mathrm{D}$ & $\begin{array}{l}\text { Pool of molten smelt below primary air port, with the } \\
\text { surface at the level of the tube bends or higher, and } \\
\text { frequently covered with a single-particle-thick layer of } \\
\text { freshly deposited char particles; molten pool agitation } \\
\text { caused by rising bubbles } \\
\text { - On occasion, conditions similar to example A observed on } \\
\text { tube coating just above the surface of the smelt pool }\end{array}$ & $\begin{array}{l}\text { History of severe } \\
\text { localized corrosion } \\
\text { and/or cracking }\end{array}$ \\
\hline
\end{tabular}

Note: The phrase "high temperature conditions" will be used to make reference to the fireside conditions listed in Table 4, except the inactive condition, $\mathrm{B}_{1}$. 


\subsubsection{Char bed height}

During all of the high temperature conditions observed, the char bed surface was within $15 \mathrm{~cm}$ (6 in.) of the bottom of the port opening.

Close proximity of the bed surface does not always result in high tube surface temperatures, as shown by many examples of stable dense beds resulting in stable characteristic LTB temperatures, or oscillating bed surfaces around the lower tube bend level associated with oscillating temperatures below $450^{\circ} \mathrm{C}$.

\subsubsection{Tar-like layer}

In some instances associated with rapid burning of particles, the black fines residue appeared to stick and form a tar-like layer over the coated tube bends at the location of particle impact. On other occasions, tar-like deposits were observed in shapes and locations similar to "mud slide" deposits of fines, described under normal conditions. Several observations have shown the black layer to be coherent and several patches of the black deposit have been observed releasing from the tube wall, leaving an undisturbed white coating beneath. One observation of a thin, smooth patch of tar spalling off a tube bend thermocouple shield coincided with a slight increase $\left(<20 \mathrm{C}^{\circ}\right)$ in temperature.

The coherent nature of the tar-like deposits seemed to indicate that the residual carbonaceous material became hotter than normal during deposition and softened to its sticky point. The measured increase in tube surface temperature when the thin black patch spalled off indicated that it had a net insulating value. (See also "Comparison of Normal and High Temperature Conditions.")

\subsubsection{Brief Bright Flashes}

Slow motion replay of white fogs observed at the bottom of the air ports during high temperature conditions showed the fogs to be dominated by bright explosions, which appeared or disappeared in the duration of one to two frames. These bright flashes were frequently associated with the disappearance of a large char particle and the appearance of small white fragments embedded in a dark tar like layer on the tube bend surface. This left the impression that the large particle had shattered on the tube bend surface, leaving a tar-like layer and glowing char fragments.

A white fog had been reported previously [26], which was thought to be caused primarily by light scattered by aerosol particles, with some contribution from increased temperatures due to combustion of volatiles and ejecta. Slow motion replay of video captured during high temperature excursions has since revealed that the white fog was not a steady state phenomenon. Single frame advance through video of fogs under normal conditions showed what appeared to be wisps of smoke which changed from frame to frame (1/30th second per frame). The explosive flashes of light during high temperature conditions would seem to indicate a greater amount of material being burned and/or a higher fuel to oxygen ratio.

\subsubsection{Initiation of a High Temperature Excursion}

Though multiple examples of high temperature conditions have been collected, Example A (Table 4), which produced measured tube surface temperatures just above $600^{\circ} \mathrm{C}$, was the only example where initiation of the conditions was observed. The excursion was created with the assistance of an engineer, by closing the windbox dampers of both the primary air port examined and the secondary air port immediately above. The temperature of one of the lower tube bends had been slowly decreasing from $330^{\circ} \mathrm{C}$ to $318^{\circ} \mathrm{C}$ over the preceding 80 minutes. When the secondary port damper was closed, the tube bend surface temperature rose $\sim 10^{\circ} \mathrm{C}$ over the next $\sim 5$ minutes. About one minute after the primary damper was closed, some swelling particles appeared along with an increase in burning rate and molten smelt in the char bed which covered the bends. The hollow, 
medium sized particles burned away over approximately the next minute, leaving a dark grey, cohesive deposit with a granular surface appearance over the thermocouples, $\sim 5-6 \mathrm{~mm}$ thick. A hole in the rough grey layer showed a small gap between it and the white coating beneath $(<1 \mathrm{~mm})$. Though the bulk of the insulating particulate had burned away, the tube surface temperature didn't start to rise dramatically for another minute. At that point, an increased molten smelt flow, containing a great deal of black fines, washed down the tubes over the granular grey deposit, washing some away. Shortly thereafter, there was a dramatic increase in the local deposition rate of bright white particles, a few being very large. The fog over the surface also increased in intensity. The gray granular layer was replaced by finely divided residual char particles, which subsequently formed a smooth, dark film. The very thin tar-like layer seemed to partially disintegrate and then reform with varying particle deposition rates. At that time, the temperature rose at a rate of up to $65^{\circ} \mathrm{C}$ in 10 seconds, peaking at $\sim 600^{\circ} \mathrm{C}$.

It is believed that the shift in air flow fields, brought on by the change in damper settings, resulted in a spray of particles, containing young liquor, moving closer to the air port. The change in the balance between material deposition and combustion rate resulted in the bed surface dropping, but the rough grey layer remaining continued to insulate the white coated tube surface. The lack of measured temperature increase at that point indicates that the increase in emissivity of the deposit was not as significant as the thermal insulation provided by the rough, dry, fairly dense char residue in poor contact with the surface. That layer seemed to be removed and replaced with a very thin black layer of softened char residue, by the subsequent increase in molten smelt flow over the tubes and the deposition of glowing, swollen particles. The removal of the insulating grey layer alone, would only be expected to result in an increase in temperature from the characteristic lower band to the upper band, therefore some other factor or factors contributed to the increased heat flux to the surface.

\subsubsection{Hot Liquid Smelt at Tube Bend Surfaces}

In the above example, when high temperature conditions first formed, particle deposition was rapid, the deposit was washed with molten smelt and darkened by the tar-like layer, and the white coating could be seen intermittently as the dark layer broke up and reformed. However, as the peak tube surface temperatures were approached, evidence of the white tube coating could no longer be seen.

Observations of the coating thickness at primary air ports have always indicated an estimated thickness of 1-2 mm, though evidence of softening has appeared. If the heat flux to the coating was large enough, it would be expected to increase its liquid content, soften and thin. Temperature excursions of $300^{\circ} \mathrm{C}$ and more above the characteristic UTB have been recorded [32], possibly indicating either a loss of cooling on the tube water side [33] or a large increase in fireside heat flux. Either would result in a rise in the deposit temperature and a thinning of the coating, which would exacerbate the heat flux to the tube metal surface. Under any of the active high temperature conditions listed in Table 5, when the tubes appeared darkest, it would have been possible for the normal white tube coating to have melted away under the tar-like layer, without that being identifiable within the video.

Table 5. Activities observed during high temperature conditions which might have caused the increased heat flux to the tube surfaces

\begin{tabular}{cl}
\hline ID & \multicolumn{1}{c}{ Activities which may contribute to increased heat flux to tubes } \\
\hline a & Removal of insulating char particles from the surface \\
b & Increased flux of sulfide containing particles to a high $\mathrm{O}_{2}$ environment \\
c & Increased deposition of carbonaceous fuel to the tube surfaces in a high $\mathrm{O}_{2}$ environment \\
d & Increase in deposit surface emissivity \\
e & The combination of increased heat flux and deposit surface emissivity, \\
f & Increased smelt flow over a hotter deposit, consisting of carbonaceous matter \\
g & Presence of a molten salt pool at the bottom of the primary air port \\
\hline
\end{tabular}




\subsubsection{Molten Salt Pools}

- As found in the examples described in Table 4, Items C \& D, when heavy deposition was occurring, associated with rapid shrinking of depositing particles and formation of a tar-like layer on the lower tube bends, the surface of the bed at the bottom of the air port was frequently observed in one of the following conditions:

- The particles in the bed close to the air port appeared to soften and start to agglomerate, appearing as bubbling porridge or developing into erupting lava pits

- Liquid smelt was observed flowing in trails across the char bed surface

- Molten smelt pools were observed that had a bright white froth at the surface and appeared to be agitated either by air from the port or by rising bubbles; Bright white particles floated on the pool surface to varying extents

- Just below the lower tube bends, tube surface temperatures above $425^{\circ} \mathrm{C}$ have been measured on eight video documented occasions, seven with temperatures above one or both of the tube bend temperatures, seven with the bed recognizably at or just below the ports and five of the eight with the appearance of high smelt flow rates down the tubes.

When the molten salt to char ratio increased initially, the bed acquired the appearance of boiling porridge, presumably as volatile gasification products rose to the surface, hindered by the molten salts. If the heavy deposition under high temperature conditions continued for an extended, though unknown period, the liquid salt runoff from the tube wall and surrounding bed ridges would appear to combine and eventually accumulate at the bottom of the air port. In a normal char bed, the chemically active layer is not deep [30] due to:

- The endothermic nature of the sulfate reduction reaction, which cools the bed

- The slowing of gasification processes with reduction of temperature

- The insulating nature of swollen char particulate with a hard, carbonaceous shell [34]

However, heat transfer into the bed below the surface would presumably increase with increased heat flux to the surface and increased molten salt presence between the swollen, insulating particles. It follows that the active gasification layer would increase in depth, producing more combustible gasses to rise and burn at the bed surface in the presence of oxygen, further increasing the bed surface temperature [30]. This process, if continued, would produce a pool of molten smelt at the bottom of the air port, with gasification of the char surrounding the pool volume continuing to produce combustible gasses. These would bubble to the pool surface as has been observed, and burn in the air jet, further heating the molten pool surface. Sulfide produced by the reduction of sulfate in the char particulate surrounding and kept hot by the molten pool, would diffuse to the surface of the liquid pool and oxidize exothermically, escalating the temperature of the surface salts even further. (See Sulfate/Sulfide Redox Cycle, below.)

\subsubsection{Comparison of Normal and High Temperature Conditions}

Detailed examination of the features and activities present during the high temperature conditions listed in Table 4 and comparison with extensive examples of normal heavy deposition of liquor char particles when temperatures did not exceed $450^{\circ} \mathrm{C}$, showed the following differences in the high temperature conditions:

- A tar like coating appeared to be formed by a softening of residual carbonaceous material, and was generally present in patches over the white coated tube surfaces

- Char particles, which were generally brighter than usual, shrank or disappeared more rapidly, frequently associated with a higher molten salt to residual char ratio: 
- Under normal conditions, swelling liquor appears to form rigid, dry hollow shells which appear to be eaten away by growing holes.

- In high temperature conditions, char appears to progress from individual particles melting and bubbling, to particle agglutination, to the formation of molten pools

- Rapidly swelling particles or the largest particles observed to date were seen repeatedly among the particles deposited on the char bed and tubes during high temperature conditions, and not significantly at other times

- Large particles were observed, in slow motion replay, to fracture on or just above the tube bend surface associated with a bright luminous flash and appeared to leave bright white fragments on the tube deposit surface

The difference in emissivity in the NIR region observed, between the black tar-like film and the white coating of condensed or frozen salts is unknown, but the magnitude of the increase may be roughly estimated from the literature. The total emissivity of a mixed sodium sulphate/sodium carbonate deposit of fume and carryover, produced by combustion of black liquor, was reported as ranging from 0.45 to 0.35 between 750 to $1000^{\circ} \mathrm{C}$ [35] and the emissivity of a fume deposit at $25^{\circ} \mathrm{C}$ was close to 0 between 1-2 $\mu \mathrm{m}$ [36]. The emissivity of solid carbon was given as $0.8-0.93$ and of soot on a solid as $0.94-0.91$ from 50 to $1000^{\circ} \mathrm{C}$ [37]. Black liquor char at $\sim 1 \mu \mathrm{m}$ and $25^{\circ} \mathrm{C}$ was reported as $\sim 0.89$ [36]. Therefore the emissivity of the tar-like layer may be roughly estimated as double that of the white coating. Doubling the deposit surface emissivity would result in twice the absorption of any incident radiant flux.

Observation of an increased rate of char burning, combined with the softening of the residual carbonaceous material on the coated tube surfaces, seemed to indicate the presence of an increased heat flux to the area, either by radiation, convection or both. The brightness of the particulate was an indicator of the local furnace temperature for three reasons (1) The faster the particle burned the hotter the particle surface would become and (2) The emissivity of black liquor and char only varies within a small range (see above). (3) Spectral radiant intensity increases dramatically with increasing temperature in the near infrared wavelength region observed [38,39]. Light from the particle to the camera would consist of both emitted and reflected radiation. Assuming the shutter speed of the camera was already maximized, the brighter the particle observed, the hotter the particle and the furnace temperature was likely to be.

The appearance of larger particles and the luminous flash produced on their breakup seemed to indicate that younger particles than usual were being deposited on or near the bottom of the air ports during high temperature conditions. The shattering of large particles would allow the sudden heating of material which had been insulated within the particle interior, and result in pyrolysis and faster char burning [30], with both contributing to an increased heat flux to the tubes. Independent observations reported elsewhere would seem to corroborate the relationship between heavy deposition of particles, evidence of an increased radiant flux and an increase in molten salts at the bottom of an air port with high tube surface temperature [40].

The reasons that the deposition of young liquor could be responsible for an increase in radiant flux to the local tube $\&$ char bed surfaces are:

- About $60-70 \%$ of the original oxygen demand and heating value of the black liquor solids is present in the volatiles (released during the pyrolysis stage) $[23,41]$.

- Increasing the fraction of organic matter which is burned in a sooty flame during pyrolysis serves to increase the fraction of total combustion energy which is released by radiation from that flame [38,39].

- The proximity of the combustion to the surface would result in the radiant energy from that event dominating the radiant flux to the surface, due to the high peak temperatures reached locally from 
the rapid pyrolysis gas combustion [30,38], the increased radiant intensity associated with those temperatures and the large solid angle subtended

Heat may also be transferred by convection from the combustion of the volatiles close to the tubes but it plays a smaller role in heat transfer at the temperatures encountered [42]. Evidence of low pressure regions to the side or below an air port has been detected on several occasions due to the motion of liquid or clouds of fine particulate, possibly ejecta [26,43,44]. Modeling has shown the potential for convection from hot gases, potentially over $1000^{\circ} \mathrm{C}$, to enter a port to one side of the primary air flow [45].

The surface of the tar-like layer will be hotter than the surface of the white coating beneath it due to both the increase in total insulation from the cooled tube and the concurrent increase in emissivity. However, as mentioned before, the darkening of the surface deposits alone does not account for the increased heat flux to the tubes (See "Tar-like Layer" above).

When molten salts pool, a temperature gradient would form through the pool as a result of the volatile combustion and exothermic oxidation of sulfide at the surface and the endothermic sulfate reduction and gasification processes below the surface (See Sulfate/Sulfide Redox Cycle, below). A salt pool would be likely to have a higher surface temperature than a normal char bed because of the increased heat flux associated with its formation, the diffusion of sulfide to the surface for oxidation and the larger chemically active volume below the surface, producing combustible gasses (See Molten Salt Pools, above). The liquid of the pool could also be expected to be a better conductor of heat to the tube coating surface than the porous solids of a normal char bed. The smelt pools were continually agitated by bubbles rising and the primary air jet flow across the surface. If the tidal zone of a hot molten salt pool was just at the level of the lower tube bend, it would likely contribute to tube temperature cycling to various degrees, depending on the relative liquid, gas and tube temperatures and the proportion of incident radiant energy absorbed by the liquid when it covered the tubes. If the molten salt pool surface became hot enough to thin the white coating layer, the distance below the port opening that the over-heating occurred would be limited by the steepness of the temperature gradient down through the pool.

Though all of the first four activities in Table 2 were potentially involved in the high temperature conditions, they had also been observed during normal conditions with tube surface temperatures below $450^{\circ} \mathrm{C}$. It has not been possible to separate the affect of (e) combined heat flux and surface emissivity increases from (f) increased smelt flow over a hotter carbonaceous deposit; to date, the two sets of conditions have appeared at the same time. Molten salt pools $(\mathrm{g})$ have not always been present when tube bend surfaces rose well above $450^{\circ} \mathrm{C}$.

\subsubsection{Sulfate/Sulfide Redox Cycle}

Previous discussion had indicated that the exothermic re-oxidation of sulfide to sulfate was suspected of being the chief contributor to an increased heat flux to the tube surfaces, but as already discussed above, in "normal" conditions the sulfide in deposited particles or smelt flowing over the tubes at the primary air ports appeared to be either too low in content to create a noticeable exotherm or already re-oxidized. Finely divided residual char particles (black fines) contained in the flow did not appear to significantly impact the sulfide content. However if active, the sulfate reduction sulfide oxidation cycle could produce a net exotherm, increasing in magnitude with increasing temperature $[23,25,30]$.

The ingredients required for the presence and acceleration of the sulfate/sulfide reduction/oxidation (redox) cycle seem present in the elements of the high temperature activities listed in Table 2: (e) combined heat flux and surface emissivity increases and (f) increased smelt flow over a hotter carbonaceous deposit. The sulfate/sulfide redox cycle is capable of producing a large net exotherm. The process consists of the endothermic reduction of $\mathrm{Na}_{2} \mathrm{SO}_{4}$ to $\mathrm{Na}_{2} \mathrm{~S}$ by carbon and the $\mathrm{Na}_{2} \mathrm{~S}$ being oxidized in turn back to $\mathrm{Na}_{2} \mathrm{SO}_{4}$, releasing two to six times more heat on oxidation of a mole of $\mathrm{Na}_{2} \mathrm{~S}$ than was required to reduce a mole of $\mathrm{Na}_{2} \mathrm{SO}_{4}$ in the first place. The process was 
initially discussed in the context of a char particle burning in flight, where the combustion of volatiles around the surface heated the particle to accelerate the sulfate reduction, while oxygen was mass transfer limited, resulting in reasonable reduction efficiencies.

The reactions and associated heats of reaction are quoted below. The endothermic reduction of sulfate to sulfide at $930^{\circ} \mathrm{C}$ is as follows:

$$
\begin{array}{cc}
\mathrm{Na}_{2} \mathrm{SO}_{4}+2 \mathrm{C} \mid \mathrm{Na}_{2} \mathrm{~S}+2 \mathrm{CO}_{2} & \mathrm{H}=+518 \mathrm{Btu} / \mathrm{lb} \mathrm{Na}_{2} \mathrm{SO}_{4}(1205 \mathrm{~kJ} / \mathrm{kg}) \\
\mathrm{Na}_{2} \mathrm{SO}_{4}+4 \mathrm{C} \mid \mathrm{Na}_{2} \mathrm{~S}+4 \mathrm{CO} & \mathrm{H}=+1539 \mathrm{Btu} / \mathrm{lb} \mathrm{Na} \mathrm{SO}_{4}(3580 \mathrm{~kJ} / \mathrm{kg})
\end{array}
$$

However, the heating value quoted for the oxidation of sulfide to sulfate is $5550 \mathrm{BTU} / \mathrm{lb} \mathrm{Na} 2 \mathrm{~S}$, which is considerably larger than either endotherm. The reaction is given as follows:

$$
\mathrm{Na}_{2} \mathrm{~S}+2 \mathrm{O}_{2} \mid \mathrm{Na}_{2} \mathrm{SO}_{4} \quad \mathrm{H}=-5550 \mathrm{Btu} / \mathrm{lb} \mathrm{Na} \mathrm{Na}_{2} \mathrm{~S}(12,900 \mathrm{~kJ} / \mathrm{kg})
$$

In the case of a falling film of smelt over a hot carbonaceous layer, oxygen has access to the smelt and will oxidize the sulfide as fast as it can reach it [30]. Therefore, the speed of the reduction reaction will probably be the rate limiting factor, and determine the number of times the same molecule of $\mathrm{Na}_{2} \mathrm{~S}$ can complete the redox cycle and produce a net heat release as it passes by the air ports. Reduction of sulfate by carbon, producing sulfide, $\mathrm{CO}$ and $\mathrm{CO}_{2}$, is known to double every 40 $60^{\circ} \mathrm{C}[23,30]$. Experimentation has shown that it does not produce a measurable amount of sulfide at $700^{\circ} \mathrm{C}$ and becomes rapid by $900^{\circ} \mathrm{C}$ [25]. An increase in smelt temperature of $200-250^{\circ} \mathrm{C}$ above $750^{\circ} \mathrm{C}$ would increase the reaction rate roughly $16-32$ times, effectively making available many times more sulfide for oxidation.

The fact that smelt is largely transparent in the visible-near infrared region [36] would allow the increased radiant flux from nearby combustion to pass through the smelt flow and continue to heat the tar-like layer over the white tube coating. The hot tar-like layer would not only supply the carbon required for the sulfate reduction but would heat the thin, smelt sheet flowing over it by both convection and conduction.

The above observations seem to indicate that an increase in radiant and possibly convective heat transfer, in conjunction with a heavy deposition of carbonaceous matter, could result in acceleration of the sulfate/sulfide redox cycle, producing the additional heat flux required to heat tube surface temperatures above $450^{\circ} \mathrm{C}$.

\subsubsection{Simultaneous Burning of Supplemental Fuel}

If the deposition of large amounts of any black liquor solids in combination with a significant increase of radiant flux produces the problematic heat flux increase, then other sources of increased radiant energy in conjunction with heavy older particle deposition should produce high tube surface temperature excursions as well. Three examples of video collected close to a supplemental fuel burner, while liquor was still fired, have been acquired. One, which has been included in examples of high temperature conditions, had originally been discarded as an artifact, but became of interest again with the later acquisition of Examples C and D (Table 1), which had very similar appearances.

\subsubsection{Observations during supplemental fuel burning}

When supplemental fuel (bunker oil) was being burned close to the port examined, while a reduced number of liquor guns were still firing, the camera probe temperatures were noted to rise higher and faster than normal, and tube surface temperatures above $450^{\circ} \mathrm{C}$ were noted on three occasions. The fireside conditions noted, ranged between the following: 
- On camera probe entry, particle deposition was not heavy, smelt flow was light and both swollen white and fine granular dark grey particles were observed sticking to the white tube coating. The air from the camera appeared to clear the larger particles from the surface, revealing a patch of tar-like material in a membrane valley below the port. Several flurries of particles impacted on a tube bend producing a flow of molten smelt over a smooth, dark deposit, which approximately corresponded to the measured temperature increasing to $510^{\circ} \mathrm{C}$. When the camera was rotated to the side, the white coating at the side of the port opening was seen to peel off the tube, from the impact of the camera air, appearing to expose bare metal beneath.

- Bubbling molten salts mixed with very bright white particles were observed pooled in the bottom of the port on cam-probe entry. Considerable tar-like material was on the tubes to the sides of the port. Viscous molten material was seen flowing down the surface of the char bed ridges between the ports. The measured tube surface temperature increased to $650^{\circ} \mathrm{C}$. Three hours later when oil was off and all four liquor guns were firing, the same port still appeared to have high temperature conditions, but the same thermocouple was registering less than $510^{\circ} \mathrm{C}$. That temperature was still $\sim 70^{\circ} \mathrm{C}$ above the characteristic upper temperature band (UTB) for that thermocouple (as observed four hours later).

When particle deposition was fairly light, the increased stickiness of the particles, the softening of the white tube coating, and the tendency of the camera to overheat indicated that burning of supplemental fuel nearby had increased the heat flux to the primary air port area, even when thermocouples were not in place. Where smelt flow was light, the stickiness of the particles even allowed a layer to form which shielded the tubes beneath, and resulted in characteristic lower temperature band (LTB) temperatures. The highest temperatures were measured, however, when deposition of liquor was associated with a darkening of the deposit surface and an increase in smelt flow.

In the example given, the high temperatures at the tube bend surfaces continued after the supplemental fuel was turned off, but at a lower level. It is not known whether the lingering high temperatures were due to the ongoing heavy deposition of young liquor or if the molten smelt pool which had formed would have maintained elevated temperatures for some time, even without continued deposition (see Molten Smelt Pools).

The examples of locally combined supplemental fuel and liquor burning captured so far have not answered the questions:

1. Would heavy deposition of older particles in combination with increased heat flux from nearby supplemental fuel burning also produce the problematic heat flux?

2. Does the composition of the organic matter and therefore it's age (time at temperature), also play an important role outside of its ability to rapidly release volatiles?

In light of all of the observations and analysis shown above, Table 6 was created to provide a brief interpretation of the conditions observed in association with high temperature conditions and outlining a mechanism for creation of tube surface temperatures above $450^{\circ} \mathrm{C}$.

\subsubsection{Lingering Evidence of High Temperature Conditions}

In the presence of heavy particle deposition, the appearance of large patches of thin, tar-like deposits on the surface of the normal white tube coatings or the presence of a molten pool at the bottom of the port have been taken as indicators of potential high tube temperature conditions. Either of these indicators may linger for awhile after the "active" problematic conditions have ceased. In the 
Table 6. Summary and interpretation of the conditions for high temperature excursions

\begin{tabular}{|c|c|}
\hline Observation & Interpretation \\
\hline $\begin{array}{l}\text { Very heavy deposition of moderate to } \\
\text { large particles, without the tube bends } \\
\text { becoming shielded by the char bed }\end{array}$ & $\begin{array}{l}\text { 1. Increased radiant heat flux to the tubes and char bed, } \\
\text { either from nearby combustion of pyrolysis gases or } \\
\text { supplemental fuel, or both } \\
\text { 2. Faster char burning and rapid melting of particles } \\
\text { resulting in molten salts flowing down tubes and } \\
\text { washing away most particle accumulations }\end{array}$ \\
\hline $\begin{array}{l}\text { A thin, smooth tar-like layer formed over } \\
\text { the white tube coating under a high flow } \\
\text { volume of molten salt }\end{array}$ & $\begin{array}{l}\text { 3. Heating \& softening of carbonaceous char residuals } \\
\text { had occurred; Deposit surface emissivity } \\
\text { approximately doubled; Black layer heats which heats } \\
\text { molten salts further }\end{array}$ \\
\hline $\begin{array}{l}\text { Tube surface temperature rises above } \\
450^{\circ} \mathrm{C} \text {, rapidly }\end{array}$ & $\begin{array}{l}\text { 4. Increase in sulfate reduction rate lead to an increased } \\
\text { exotherm from the accelerated sulfate/sulfide redox } \\
\text { cycle; Heat flux from sulfide oxidation combined with } \\
\text { that from nearby combustible burning } \\
\text { 5. Heating, softening and thinning of the white coating } \\
\text { layer on the lower tube bends as a result }\end{array}$ \\
\hline $\begin{array}{l}\text { Bed becomes more molten, first bubbling } \\
\text { like porridge then forming molten salt } \\
\text { pools }\end{array}$ & $\begin{array}{l}\text { 6. Increased heat transfer via liquid smelt to char below } \\
\text { the surface, extending active sulphate reduction and } \\
\text { gasification volume; Sulfide diffuses to the pool } \\
\text { surface and oxidizes; Combustible gases bubble up and } \\
\text { burn at the pool surface; Both heat pool surface which } \\
\text { further heats coated tube surface }\end{array}$ \\
\hline
\end{tabular}

case of the tar-like layer, the decrease in incident radiant flux would reduce the layer's temperature and therefore the rate of gasification. In the case of a molten pool with a large enough volume, it seems likely that the heat produced by the combustion of volatiles and oxidation of sulfide at the surface of the pool would help to maintain the pool temperature and therefore the liquid smelt to char ratio for a period of time (see Molten Salt Pools, above). Eventually, further deposition of older particulate would cover and insulate the pool surface.

\subsubsection{Conditions at Bottom of Primary Air Ports}

Thermocouple measurements of tube surface temperatures have shown that significantly more temperature cycles and high temperature excursions occur on the bends at the bottom of the air ports than elsewhere $[32,46]$. This may be due to some or all of the following factors:

\subsubsection{Proximity of the bed}

- When char deposition is heavy and builds the bed up against the wall, air from a primary port carves a long groove in a moderate char bed or forms a pit around the port when the bed is very high. Where the bed meets the tube wall between the ports, peaked ridges are formed, and these shield the tubes between the ports from the boiler activity. The higher the general bed level was approaching the wall, and the farther apart the spacing of the primary air ports, the larger the ridge and the higher up the wall it reached.

- On occasion, solidified smelt has been observed forming in ridges beneath the char that builds up between primary air ports and particularly between wind boxes, where the ports are further apart. 
Those sloped solids, which echo the shape of the char buildup over them, may serve to funnel the flow of molten salt towards the bottom of the air port.

- Under normal conditions, pits are less likely to form around the ports because the char particulate doesn't stick to anything and is readily blown away from directly in front of the port opening, even if it tumbles down from the ridge beside the port. Under high temperature conditions, the particulate becomes stickier and is not blown away so easily. The tube bends at the bottom of the port become exposed to radiant energy because of rapid char burning and large flows of molten smelt down the tubes, but that is not a stable condition. Eventually however, the volume of molten salts increases, molten material flows down the tubes and from the surrounding ridges of particulate and a pool of smelt forms below the port opening (see also Formation of Smelt Pools, above).

- The bends at the top of the port have never been observed to accumulate char particulate, and are unlikely to be exposed to pooled molten smelt.

It has been previously reported [46] that, in comparison to the temperature fluctuations on the bends at the bottom of the port, the magnitude of the cycles at the top of the port is much smaller, and those on the straight tube beside the bent port tube are both smaller in magnitude and frequency. As well, where an extra wall tube has been inserted between air ports at the breaks between windboxes, temperatures measured almost always show the lowest level of fluctuations (magnitude and frequency) of any tube at the primary air port level. With an understanding of the contributors [26] to characteristic upper and lower temperature band (UTB \& LTB) temperatures, as related above under normal conditions, it becomes possible to relate the fireside conditions listed above to the reported temperature characteristics. The tubes beneath piled char particulate will have a surface temperature in the characteristic LTB, with little variation, while the surfaces at the top of the port will typically be in the UTB with relatively infrequent drops in temperature as particulate occasionally impacts or slides past [26]. In contrast, the bends at the bottom of the port are in the least stable position in the balance between particle deposition, removal, combustion rate and smelt accumulation and therefore the most susceptible to temperature cycling.

\subsubsection{Slope of the tubes}

Brief observations indicated that particulate did not seem to accumulate at the tops of the ports. Particles appeared less likely to hit the tube bends at the top, where the tubes sloped away from the predominant direction of particle flow [26]. Particles were observed impacting and appearing to shatter at the bottom of the ports where the tubes are angled back.

A lack of particle accumulation and impact would result in little cycling between the characteristic temperature bands, below $450^{\circ} \mathrm{C}$. It may be that the angle of impact affects the likelihood of particle breakup and the resultant combustion rate. If the dominant source of radiant energy is above the level of the lower primary air port tube bends, the angling back of the tubes at the bottom of the port would tend to bring the surfaces closer to being perpendicular to the incident radiation, and therefore increase the radiant flux density by reducing the area over which the incident flux is distributed.

\subsubsection{Air flow fields}

- It has been noted previously that char particulate was observed falling close to the top and sides of the air ports without actually impacting the surface.

- Particles usually appear to land from above and to the sides of the bottom of the air ports, sometimes with a markedly heavier deposition on one side than the other. On relatively few 
occasions, particles appear to rise from below the port. One such instance brought a single swollen particle, estimated to be two inches long, to the bottom tip of the port casting. It remained there for over 20 seconds, slowly rolling upwards towards the air port opening as it shrank, relatively slowly.

- When liquid smelt flows down the tube walls, crusts of frozen smelt have routinely been observed to form in small ridges at the sides of the openings at what appears to be the edge of the air flow field from the ports. The shape of the crust varies with the combination of port and casting design. When smelt flow is heavy and prolonged, almost horizontal "stalactites" of frozen smelt have formed and in $\sim$ two cases, large hoods were observed over the tops of the ports. These smelt crusts redirect the continued flow of liquid and affect the path followed by smelt over the bends at the bottom of the port.

The reduced level of particle deposition at the top of the ports and the direction of particle approach will be the combined result of local air flow fields and the particle size and density [30], as well as the slope of the tubes. Modeling has indicated that backflow of furnace gases into the port, resulting under certain air injection conditions, would increase convection to tubes from hot combustion gases [45]. Backflow may contribute volatiles, which can't be seen with the current equipment, as well as particulate for combustion at the tube bends by sweeping both towards the base of the air jet. Shattering of hot swollen particles, in some cases with rigid outer shells, was mentioned above in the list of differences between high temperature and normal conditions and under the heading "Slope of the Tubes". The relatively cooler temperatures or the higher velocity of the primary air jets [30] may also have contributed to the particle shattering, which sometimes resulted, when they appeared to intersect the air jets near the tube bends.

\subsection{SUMMARY}

High tube surface temperature excursions above $450^{\circ} \mathrm{C}$ have previously been related to the cracking of composite tubes at the lower bends of primary air ports in kraft recovery boilers. In this work, comparison between fireside observations has lead to isolation of a set of activities or conditions associated with all known or inferred high tube surface temperatures to date, and normal and high temperature conditions have been defined. Conditions observed at the bottom of primary air ports have been related to experimental and modeling work found in the literature. Simultaneous increase in irradiance and heavy deposition of carbonaceous material on the air port opening tubes, has been inferred from the video and thermocouple data as required for creation of tube surface temperatures above $450^{\circ} \mathrm{C}$. A mechanism has been outlined which reconciles the significant exothermic oxidation of sulfide, originally expected at the air ports, with the in situ observations.

The seminal event of high temperature cycling, peaking above $450^{\circ} \mathrm{C}$, is the heavy deposition of young black liquor, on or very near the primary air ports. The resultant chain of events includes:

- Pyrolysis of carbonaceous material and combustion of the volatiles, close to the tube bends

- An increased heat flux to surfaces surrounding the primary port, not necessarily of itself enough to generate an excursion

- Increased rate of char burning and an increased ratio of molten salt to carbonaceous solid

- Softening of finely divided residual char on the deposit surfaces and formation of a tar-like layer with at least twice the emissivity of the normal white tube coating

- Increased rate of sulfate reduction on the tube deposit surfaces, as the hot tar-like layer heats the increased volume of flowing smelt, effectively producing more sulfide for oxidation

- Sulfide is oxidized to sulfate exothermically, as fast as oxygen can reach it 
- On occasion, molten salt pools form at the bottom of the primary air ports, in contact with the tubes, which have the potential to escalate in temperature at the surface due to pyrolysis gas combustion and sulfide oxidation

- When the normal white coating on the tube surface is exposed to an increase in heat flux, over and above that which produces characteristic UTB temperatures, an increase in deposit temperature, liquid fraction, softening and thinning would result, exacerbating the heat flux to the tube surfaces.

The burning of supplemental fuel near an area with young liquor deposition was implicated in increasing the maximum temperature reached at the tube surface during an excursion. What has not been shown is whether the combination of older liquor deposition with similar near by burning would also result in tube surface temperatures above $450^{\circ} \mathrm{C}$.

Altering boiler operation to prevent the deposition of liquor, on or near the primary air ports is recommended to avoid the creation of thermal cycling of the tube surfaces. Particular care should be given to prevent young liquor from depositing on the primary air port tubes. Frequent firing of supplemental fuel without also reducing the deposition of liquor on the port tubes near the fuel burner, should also be avoided. Both may result in the increase of tube surface temperatures at the lower bends of primary air ports above $450^{\circ} \mathrm{C}$, thereby increasing the risk of composite tube cracking.

An in-depth systematic study of the effect of boiler operating parameters on the conditions that result in air port temperature fluctuations is described in Chap. 8 of this report. 



\section{COMPUTATIONAL FLUID DYNAMICS MODELING OF RECOVERY BOILERS AND SELECTED PRIMARY AIR PORTS}

The temperature fluctuation data gained from the air port tube thermocouple measurements along with the understanding of boiler conditions developed from the in-situ camera studies provided considerable information about what was happening in the boiler during operation. Two other studies that were conducted as part of this project helped to identify the operating parameters that most strongly influenced the distribution of liquor and the creation of the temperature fluctuations. Using software developed at the University of British Columbia and Process Simulations Limited, computational fluid dynamics (CFD) was used to model boilers with and without air port tube cracking in an effort to identify the critical parameters responsible for the temperature fluctuations. In coordination with the modeling, systematic changes in operating parameters were conducted in one boiler to collect experimental data to determine which parameters actually affected the temperature fluctuations. In this section, the CFD studies will be summarized followed by a section describing the mill studies of the effect of operating parameter changes.

With regard to the cracking of the primary air port tubes, one of the most important clues found so far is the tube surface temperature fluctuations. Extensive measurements of tube surface temperature around primary air ports in many recovery boilers have clearly established that significant variations occur in the temperature of the tubes at the bottom of the primary air ports. As described in the previous section on temperature measurements, it has been shown that adjusting a number of operating parameters can change the temperature fluctuation pattern. In addition, it has also been noted that air port design may have some relationship to cracking of air port tubes. However, there is a question as to whether this relationship is due to air port design or to one or more of the other differences in boiler operating conditions. Consequently, the CFD studies also addressed the conditions around primary air ports of different designs.

\subsection{RECOVERY BOILER MODELING}

\subsubsection{Fluid Flow Modeling}

The three dimensional turbulent reacting flow in the recovery boiler is simulated by solving the fully three-dimensional Reynolds-averaged transport equations of mass, momentum energy, and chemical species. A two-equation turbulence model is used, in which equations for the turbulent kinetic energy " $\mathrm{k}$ " and its dissipation rate " $\mathrm{e}$ " are solved [47]. The gas phase combustion of $\mathrm{CH}_{4}, \mathrm{H}_{2}$, and $\mathrm{CO}$ is modeled by the Magnusson model, in which the chemical reactions are controlled by the turbulent diffusion rate [48]. The ray tracing method is adopted to simulate the radiation heat transfer. Rays are emitted in prescribed directions from points distributed over the domain boundary. A ray is defined by its point of origin, its direction and the band of the wavelength spectrum that it represents. Along each ray, an energy equation is solved, accounting for the energy emission from the gas, and the absorption and scattering by fine particulate and by $\mathrm{H}_{2} \mathrm{O}$ and $\mathrm{CO}_{2}$ in the gas.

\subsubsection{Black Liquor Combustion Modeling}

Black liquor undergoes three stages after injection into the boiler, namely evaporation, devolatilization, and char combustion/gasification. The moisture in black liquor evaporates when the droplets absorb enough heat from the flue gases. The devolatilization follows after the evaporation, and the volatile matter is released when sufficient heat is transferred to the droplet. The evolved volatiles contain $\mathrm{CH}_{4}, \mathrm{CO}, \mathrm{CO}_{2}$, and $\mathrm{H}_{2}$, and their fractions are calculated from the black liquor properties. The Magnusson combustion model simulates the turbulent combustion process of $\mathrm{CH}_{4}$, $\mathrm{H}_{2}$, and $\mathrm{CO}$ in the gas phase. The char combustion starts after all volatiles are released. Three heterogeneous reactions between carbon and $\mathrm{CO}_{2}, \mathrm{H}_{2} \mathrm{O}$, and $\mathrm{O}_{2}$ are included, and their reaction rates 
are controlled by turbulent diffusion. Those droplets that stick on the wall and drop down onto the bed have all the moisture evaporated and all volatiles released; and the remaining carbon reacts with $\mathrm{CO}_{2}, \mathrm{H}_{2} \mathrm{O}$, and $\mathrm{O}_{2}$ if these species can reach the wall and/or the bed. All droplets swell during the evaporation and the devolatilization, and shrink during the char combustion.

The black liquor droplet spray is assumed to have a log normal distribution of the diameter with specified minimum, maximum and mean values.

Typically, the CFD program requires thousands of iterations to obtain a converged solution. The post-processing software visualizes the data generated by the CFD code. Results are presented by either animated movies or figures in the form of vector fields and contours of variables.

\subsubsection{Modeling of Selected Recovery Boilers}

Three recovery boilers were selected for the modeling in this program. Boiler-Q has experienced extensive cracking of primary air port tubes. Boiler-P is the same type of boiler as Boiler Q with some differences in air system design. Boiler $\mathrm{P}$ has no report of primary air port tube cracking. Boiler-A is from a different manufacturer and has a completely different air system. Boiler- A has not experienced cracking. The purpose of the boiler modeling was to correlate primary air port cracking with boiler design, air system design, and boiler operation conditions.

\subsubsection{Modeling of recovery Boiler-Q}

This recovery boiler is a high-pressure (design pressure: $10.6 \mathrm{MPa}$ (1525 psig); current operating pressure: $8.8 \mathrm{MPa}$ (1260 psig)) recovery boiler, which began operation in June 1997. The boiler has a three level air system. Primary and secondary air flows are introduced below the liquor gun level by two separated forced-draft (FD) fans, whereas the tertiary air flow is introduced above the liquor gun level by its own FD fan.

The primary air system consists of 130 ports in total, with 33 ports on the left and right walls and 32 ports on the front and rear walls, as shown in Fig. 35. Each air port has a width of $\sim 6.4 \mathrm{~cm}(2.5$ in.), a measured flow area of $0.0149 \mathrm{~m}^{2}$, and a $5^{\circ}$ sloped bottom. The secondary air system, shown in Fig. 36, has 5 ports on each of the side walls and a $3 \times 2$ opposing ports on the front and rear walls. The tertiary air system is shown in Fig. 37, has 4 ports on the front wall and 3 on the rear. There are 3 liquor gun ports on each wall (Fig. 38); the number of liquor guns in operation depends on the boiler load and the gun size. Figure 39 shows the CFD model of Boiler-Q.

\subsubsection{Modeling of two boiler trials}

Extensive tube cracking of a primary air port was found in Boiler-Q before 2000. A number of trials were conducted on this boiler in an effort to find some adjustments that would reduce the tube cracking. Tube temperature measurements show that the number of temperature excursions was significantly reduced after the boiler adjustment in March 2000, as shown in Fig. 40. To understand why the temperature fluctuation were reduced, the CFD model was used to model the operations before (referred to as "Case Before") and after the changes (referred to as "Case After") in operating parameters. Table 7 lists operational conditions before and after the changes. There are three major differences between the two cases: air split, nozzle type, and soap addition. The secondary air ratio was reduced from $45.5 \%$ to $35.7 \%$; the air split between the primary and the tertiary was reduced, and the liquor nozzle was changed from wedge to a conventional splash plate. Soap was added into the liquor which increased the calorific value and reduced the mean droplet diameter. 


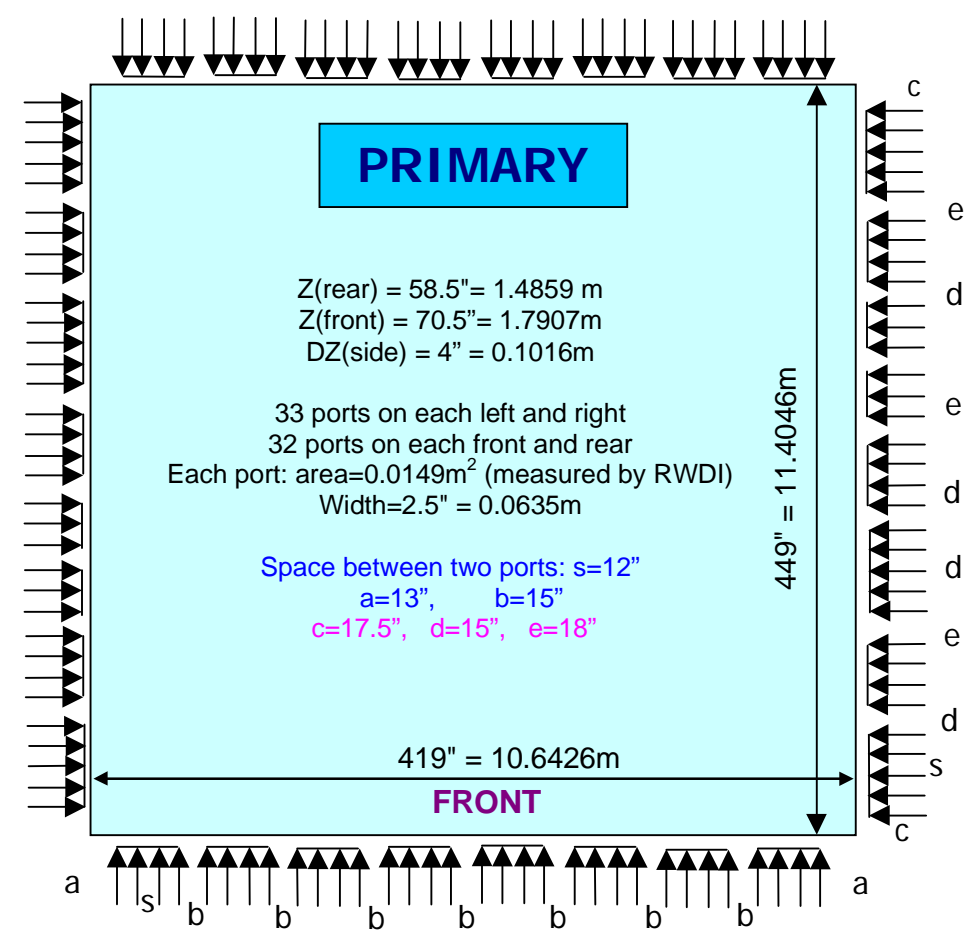

Fig. 35. Primary air system of Boiler-Q.

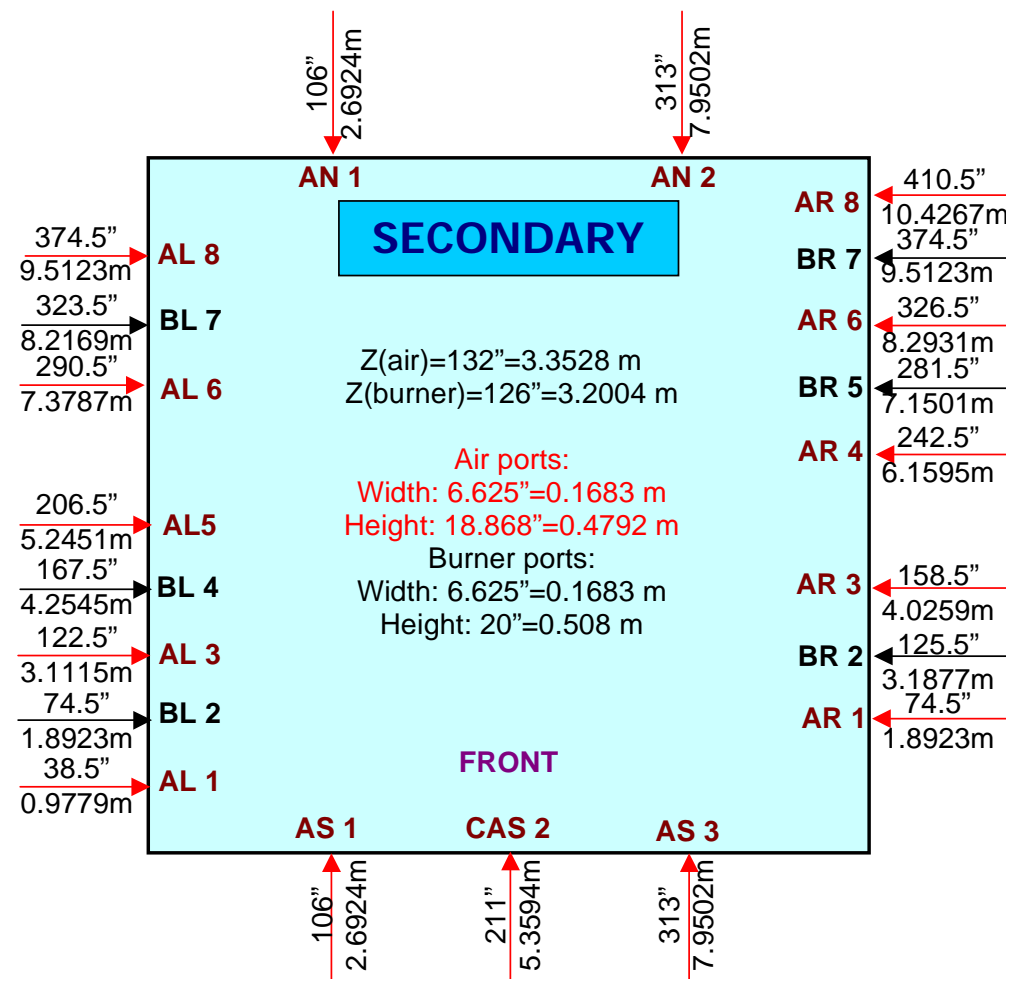

Fig. 36. Secondary air system of Boiler-Q. 


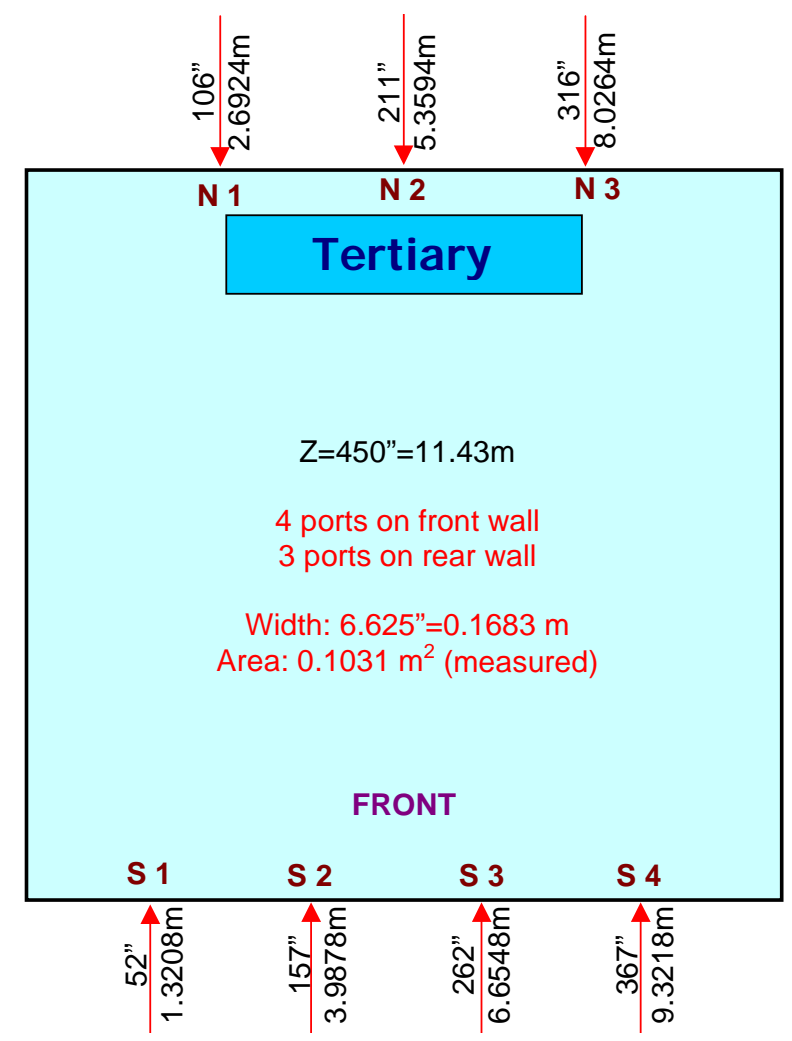

Fig. 37. Tertiary air system of Boiler-Q.

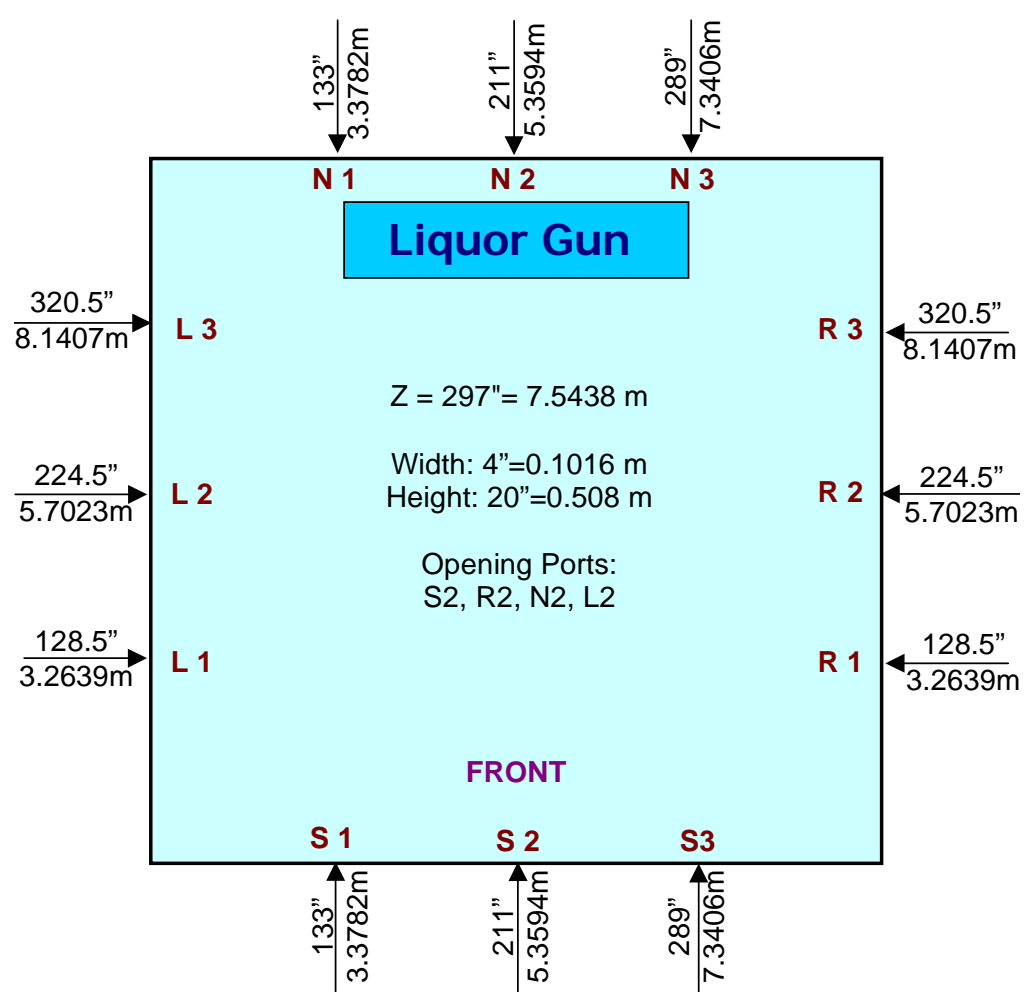

Fig. 38. Liquor gun system of Boiler-Q. 


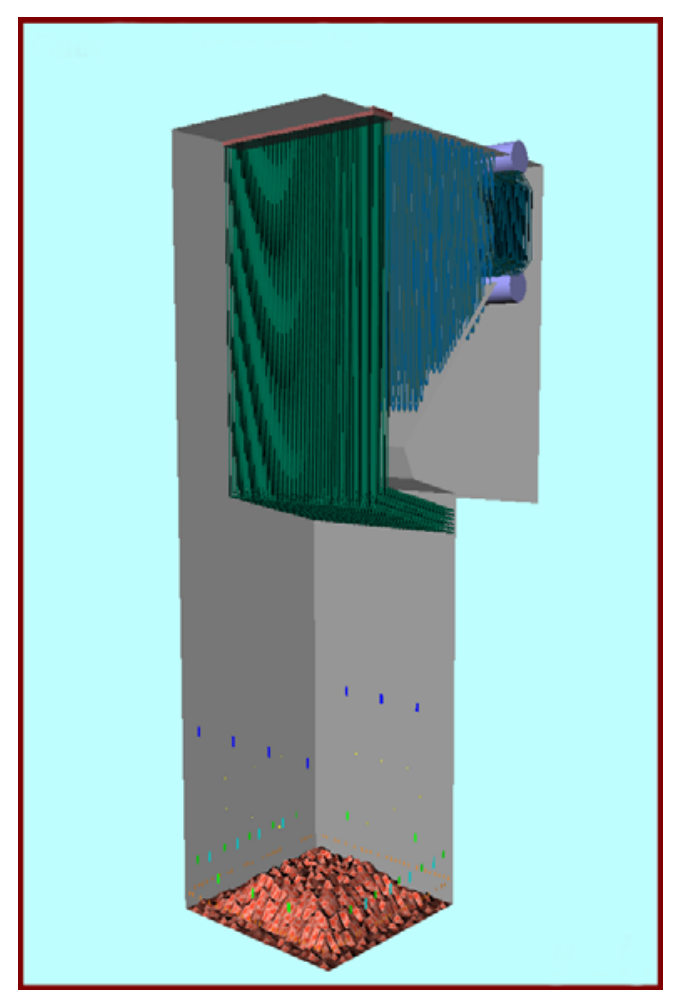

Fig. 39. Model of Boiler-Q.

The modeling of the two cases has shown some differences in the boiler performance, which are believed to be associated with tube temperature excursions. The liquor deposition on the walls is one of the major differences. As shown in Fig. 41 and listed in Table 8, the total liquor deposition on the walls decreases from $65.2 \%$ to $45.5 \%$ after the changes. Moreover, the volatiles remaining in the liquor when it sticks on the walls decrease by about half and the moisture remains more than half. It means that in "Case Before" there are twice as many liquor droplets burning on the walls comparing to "Case After". As discussed above, burning droplets on the walls could provide heat sources for tube temperature excursions. The decrease of wall deposition in "Case After" is considered a result of liquor nozzle change. A wedge nozzle spreads more liquor towards edges than a splash plate nozzle does. Finer droplets in "Case After" are more easily burned in flight; therefore fewer burning droplets hit the walls.

The heat fluxes to the walls and the gas temperatures near the walls show differences between the two cases. Figure 42 presents the gas temperature near the walls in the lower and mid furnace. In "Case Before," the gas temperature around primary air ports on the front and the right walls is higher than that in "Case After". Higher gas temperature reveals stronger combustion and contributes higher radiation heat to the walls around primary air ports. As shown in Fig. 43, the heat fluxes on the front and the right walls are higher in "Case Before" than in "Case After."

The flow pattern in the boiler shows a significant difference between the two cases. Figure 44 shows a picture of the flow animation of each case. In "Case Before," secondary air jets have strong collisions in the boiler center and form a strong upward flow in a limited area. A strong recirculation is formed above the secondary air. Although the modeling could not predict the flow instability quantitatively, the predicted flow pattern is believed highly unstable. Any disturbance in the operational conditions could change the pressure differences between the upward flow and the recirculating flow and promote upward flow in the furnace. The tube temperature excursion is believed to be strongly associated with the flow instability in the furnace. In comparison, the flow 
pattern in "Case After" shows less collisions of secondary air jets, more uniform flow across the furnace and smaller recirculation above the secondary air. The flow in "Case After" is believed more stable than in "Case Before". The difference of the flow pattern and the flow instability is considered a result of different air splits in the two cases. The ratio of secondary air is significantly reduced in "Case After," which consequently reduces the momentum of secondary air jets and therefore the collision of the jets.

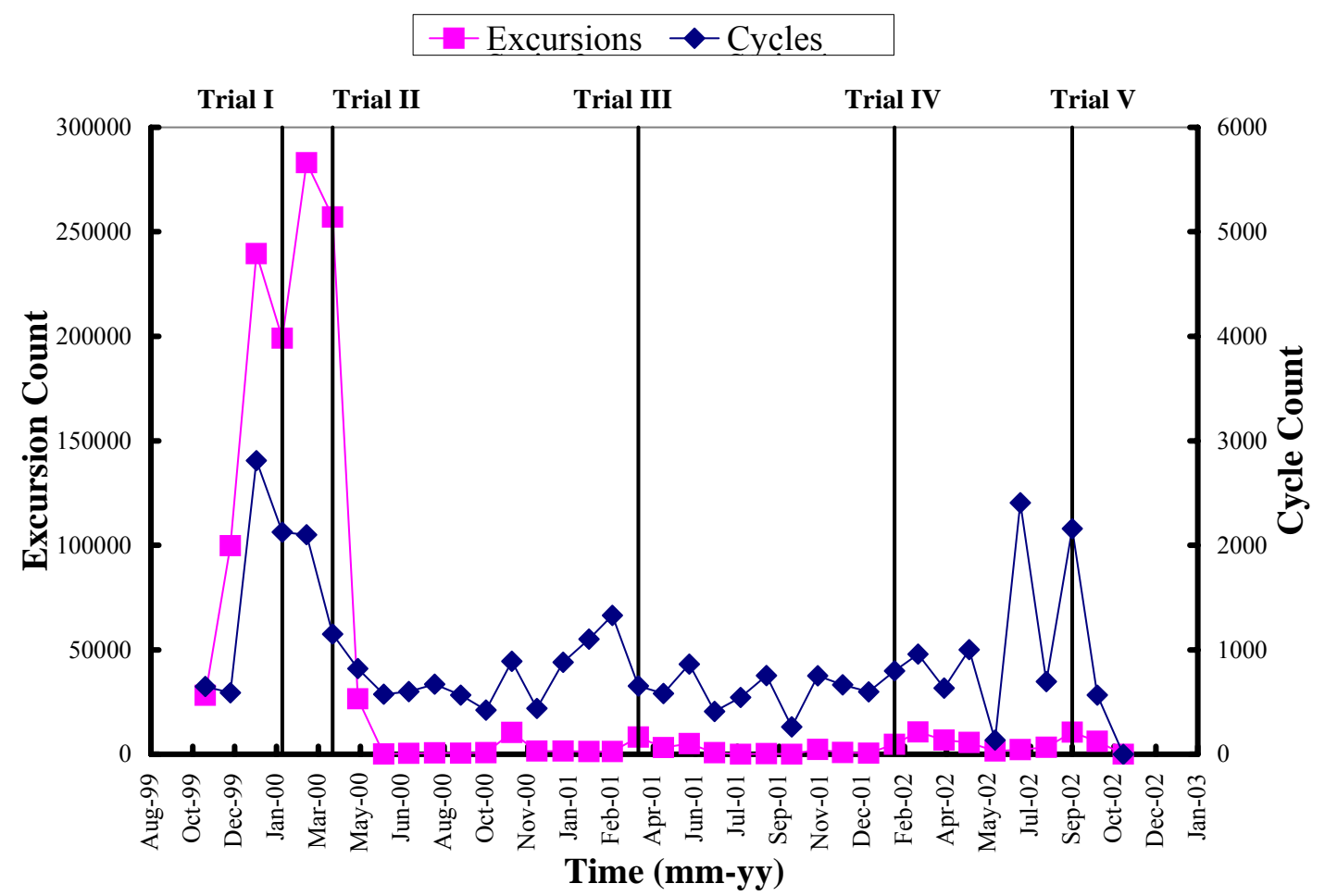

Fig. 40. Measured temperature excursions and cycles.

The modeling of the two trials indicates that reducing liquor deposition on the walls and improving flow instability in the furnace can reduce the tube temperature excursion.

\subsubsection{Impact of Secondary Air Distribution}

The secondary air system of this boiler (Q) was not appropriately designed. The above modeling has shown the collision of secondary air jets creates some flow instability in the furnace. Although reducing the amount of secondary air reduces the collision of the air jets and to some extent eliminate flow instability, the flow pattern stills needs to be improved. Redistributing secondary air among existing ports might improve the flow pattern and reduce the tube temperature excursions. Four different ways of secondary air distribution were modeled. 
Table 7. Operational conditions of case before and case after of Boiler-Q

\begin{tabular}{l|l|c|cc|}
\hline CASE BEFORE DATA \\
\begin{tabular}{l|c|ccc|}
\hline Primary & $31.5 \%$ & $32.25 \mathrm{~kg} / \mathrm{s}$ & 116,099 & $\mathrm{~kg} / \mathrm{hr}$ \\
\hline Secondary Flow & $45.5 \%$ & $46.60 \mathrm{~kg} / \mathrm{s}$ & 167,745 & $\mathrm{~kg} / \mathrm{hr}$ \\
\hline Tertiary & $22.5 \%$ & $23.01 \mathrm{~kg} / \mathrm{s}$ & 82,825 & $\mathrm{~kg} / \mathrm{hr}$ \\
\hline Leakage Air & $0.6 \%$ & $0.57 \mathrm{~kg} / \mathrm{s}$ & 2,069 & $\mathrm{~kg} / \mathrm{hr}$ \\
\hline Total Air & $100.0 \%$ & $102.43 \mathrm{~kg} / \mathrm{s}$ & $368,738 \mathrm{~kg} / \mathrm{hr}$ \\
\hline
\end{tabular}
\end{tabular}

CASE AFTER DATA

\begin{tabular}{l|c|c|cc|}
\hline Primary & $35.8 \%$ & $34.05 \mathrm{~kg} / \mathrm{s}$ & 122,564 & $\mathrm{~kg} / \mathrm{hr}$ \\
\hline Secondary Flow & $35.7 \%$ & $33.89 \mathrm{~kg} / \mathrm{s}$ & 121,999 & $\mathrm{~kg} / \mathrm{hr}$ \\
\hline Tertiary & $27.9 \%$ & $26.50 \mathrm{~kg} / \mathrm{s}$ & 95,389 & $\mathrm{~kg} / \mathrm{hr}$ \\
\hline Leakage Air & $0.6 \%$ & $0.57 \mathrm{~kg} / \mathrm{s}$ & 2,069 & $\mathrm{~kg} / \mathrm{hr}$ \\
\hline Total Air & $100.0 \%$ & $95.01 \mathrm{~kg} / \mathrm{s}$ & 342,021 & $\mathrm{~kg} / \mathrm{hr}$ \\
\hline
\end{tabular}

CASE BEFORE

\begin{tabular}{|c|c|l|}
\hline \multicolumn{3}{|c|}{ Black Liquor Properties } \\
\hline flowrate (base) & 19.725 & $\mathrm{kgDS} / \mathrm{s}$ \\
solids & $73.8 \%$ & \\
temperature & 120 & ${ }^{\circ} \mathrm{C}$ \\
Pressure & 296 & $\mathrm{kPa}$ \\
density & 1360 & $\mathrm{~kg} / \mathrm{m}^{3}$ \\
Nozzle Number & 4 & $\mathrm{~mm}$ \\
Nozzle diameter & 20.32 & $\mathrm{~mm}$ \\
Injection velocity & 15.15 & $\mathrm{~m} / \mathrm{s}$ \\
Nozzle type & Wedge & \\
Calorific Value & 13.724 & $\mathrm{MJ} / \mathrm{kg}$ \\
\hline Soap Addition & $\mathrm{No}$ & \\
\hline Mean Diameter & 2.5 & $\mathrm{~mm}$ \\
\hline
\end{tabular}

CASE AFTER

Black Liquor Properties

\begin{tabular}{|c|c|l|}
\hline \multicolumn{3}{|c|}{ Black Liquor Properties } \\
\hline flowrate (base) & 18.716 & $\mathrm{kgDS} / \mathrm{s}$ \\
solids & $73.8 \%$ & \\
temperature & 120 & ${ }^{\circ} \mathrm{C}$ \\
Pressure & 296 & $\mathrm{kPa}$ \\
density & 1360 & $\mathrm{~kg} / \mathrm{m}^{3}$ \\
Nozzle Number & 4 & $\mathrm{~mm}$ \\
Nozzle diameter & 20.32 & $\mathrm{~mm}$ \\
Injection velocity & 14.38 & $\mathrm{~m} / \mathrm{s}$ \\
Nozzle type & Splash & \\
Calorific Value & 14.464 & $\mathrm{MJ} / \mathrm{kg}$ \\
\hline Soap Addition & Yes & \\
\hline Mean Diameter & 2.0 & $\mathrm{~mm}$ \\
\hline
\end{tabular}



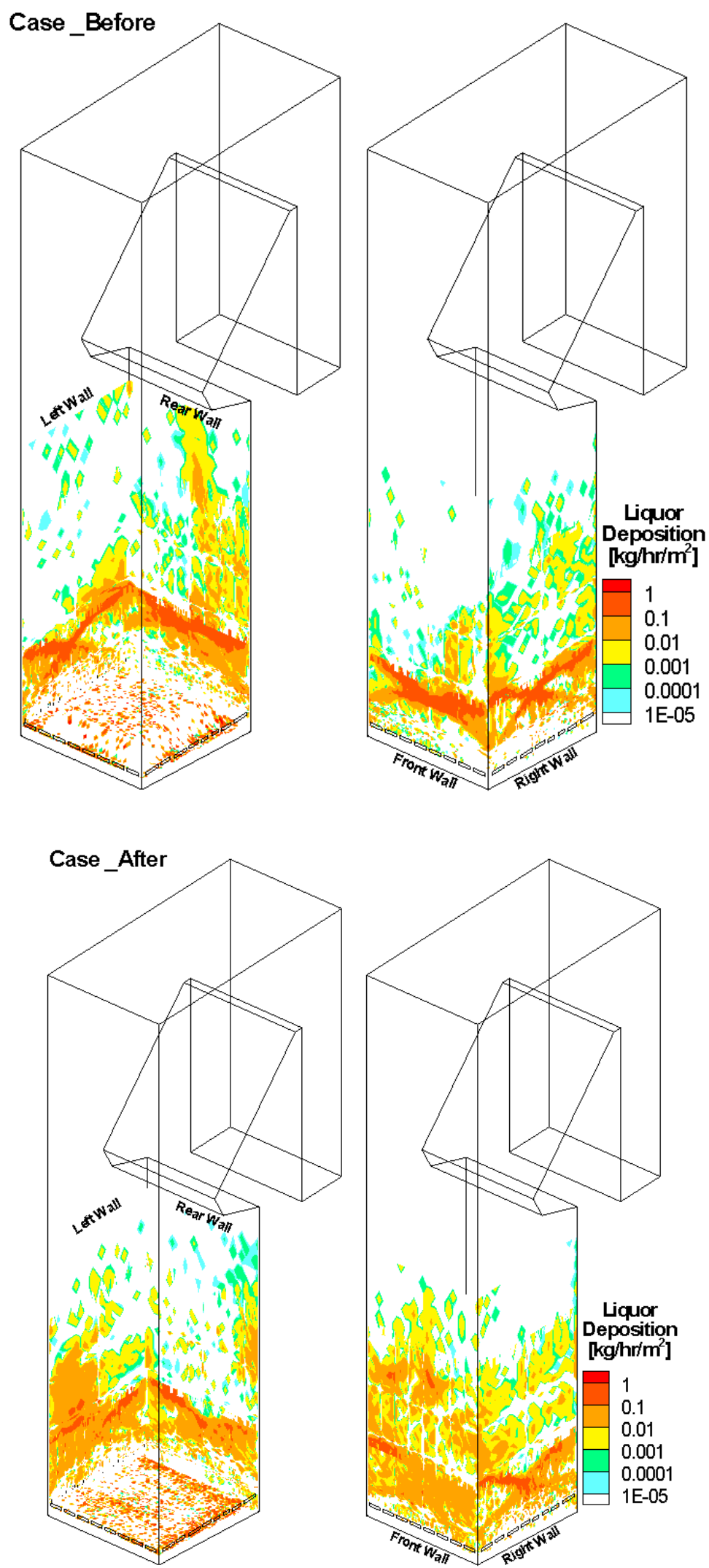

Fig. 41. Predicted wall deposition in Case Before and Case After of Boiler-Q. 
Table 8. Predicted process data of liquor combustion in Boiler-Q

\begin{tabular}{|c|c|c|c|c|c|}
\hline \multicolumn{6}{|c|}{ Case Before } \\
\hline$\% \mathrm{BL}$ & In Flight & Bed & & Carryover & Total \\
\hline Water & 18.998 & 0.015 & 7.187 & 0.000 & 26.200 \\
\hline Volatile & 10.834 & 0.436 & 24.255 & 0.000 & 35.525 \\
\hline Char & 1.660 & 0.228 & 5 & 0.000 & 7.736 \\
\hline Smelt & 0.000 & 2.575 & 27.888 & 0.076 & 30.539 \\
\hline Total & 31.492 & 3.254 & 65.178 & 0.076 & 100.000 \\
\hline \multicolumn{6}{|c|}{ Case After } \\
\hline$\% \mathrm{BL}$ & In Flight & $\mathrm{Be}$ & & ar & Total \\
\hline Jater & 23.419 & 0.013 & 2.768 & 0.000 & 26.200 \\
\hline Volatile & 20.894 & 0.572 & 12.786 & 0.000 & 34.252 \\
\hline Char & 4.159 & 0.449 & -4.400 & 0.000 & 9.008 \\
\hline & 0.000 & 4.921 & 25.590 & 0.029 & 30.540 \\
\hline ta & 48.472 & 5.955 & 45.544 & 0.029 & 100.00 \\
\hline
\end{tabular}
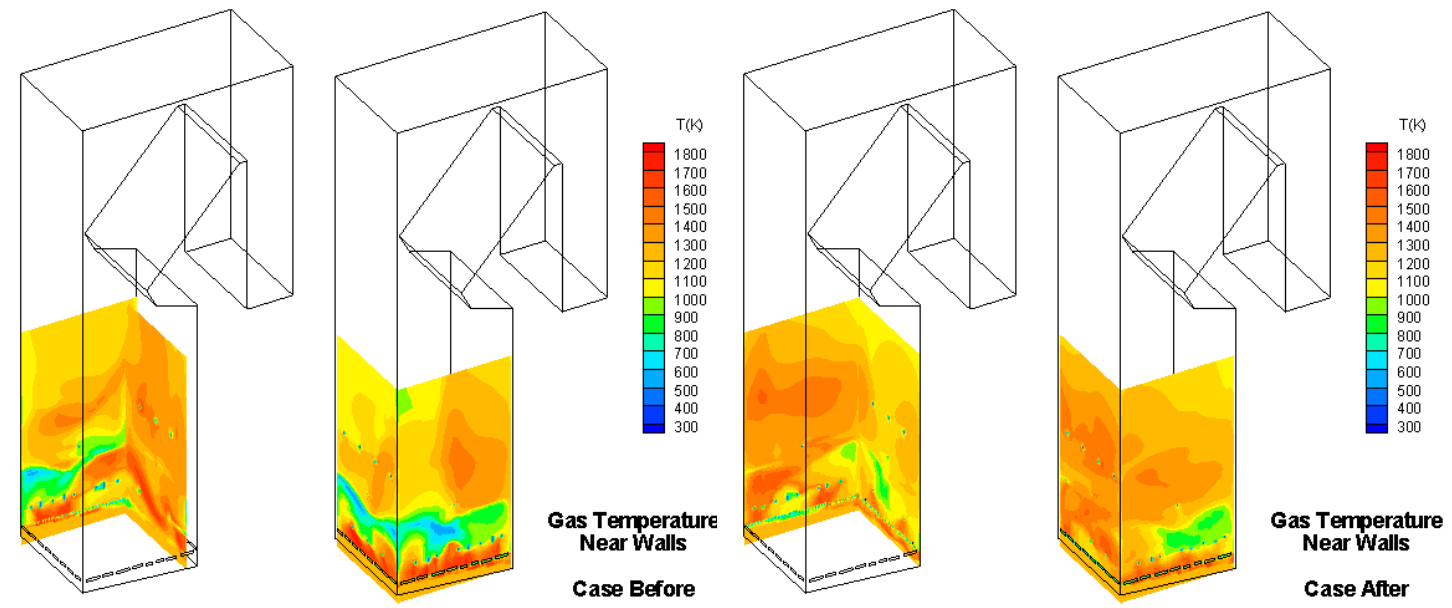

Fig. 42. Predicted gas temperature near the walls in Boiler-Q.
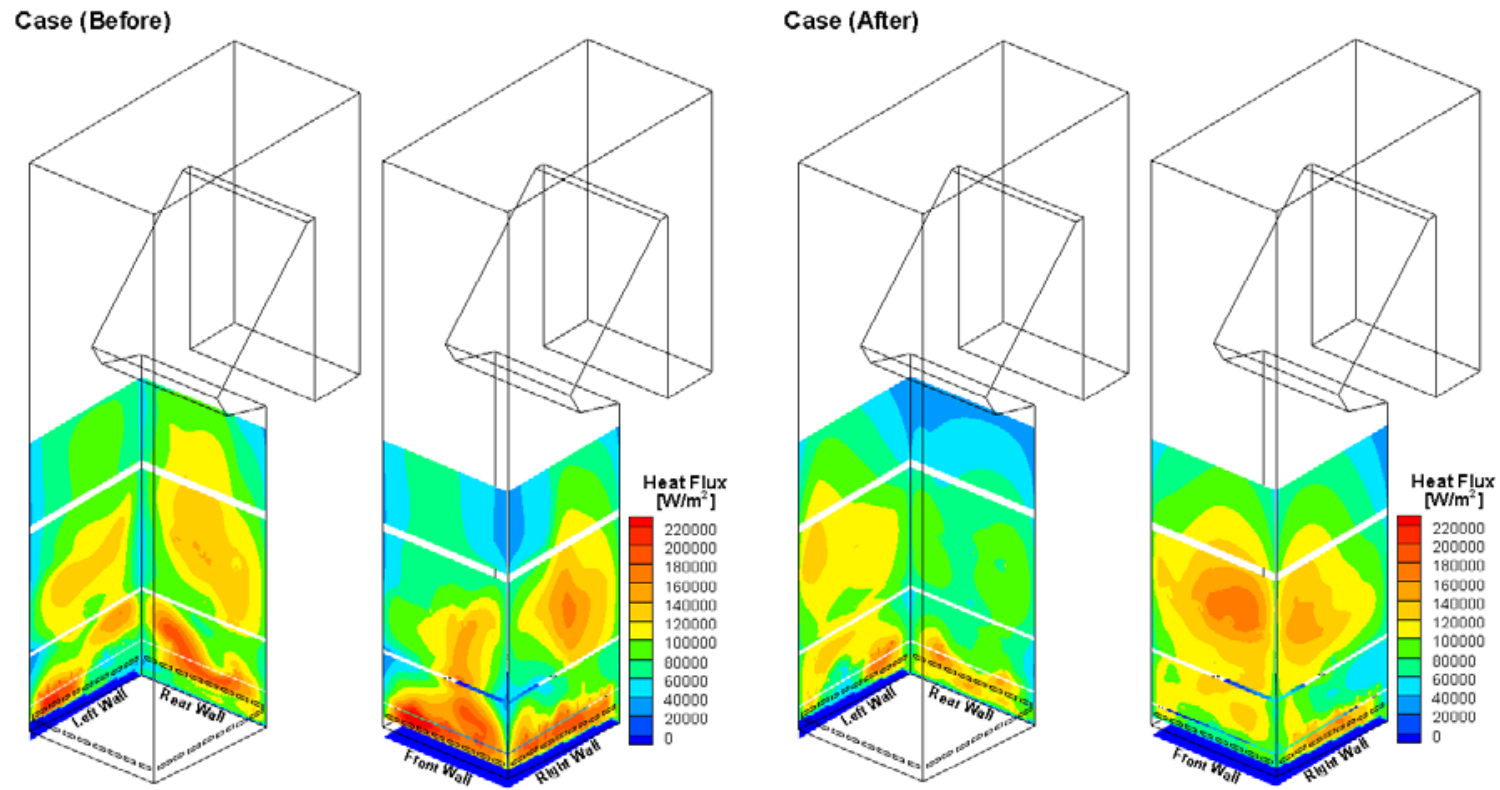

Fig. 43. Predicted heat flux to the walls in Boiler-Q. 

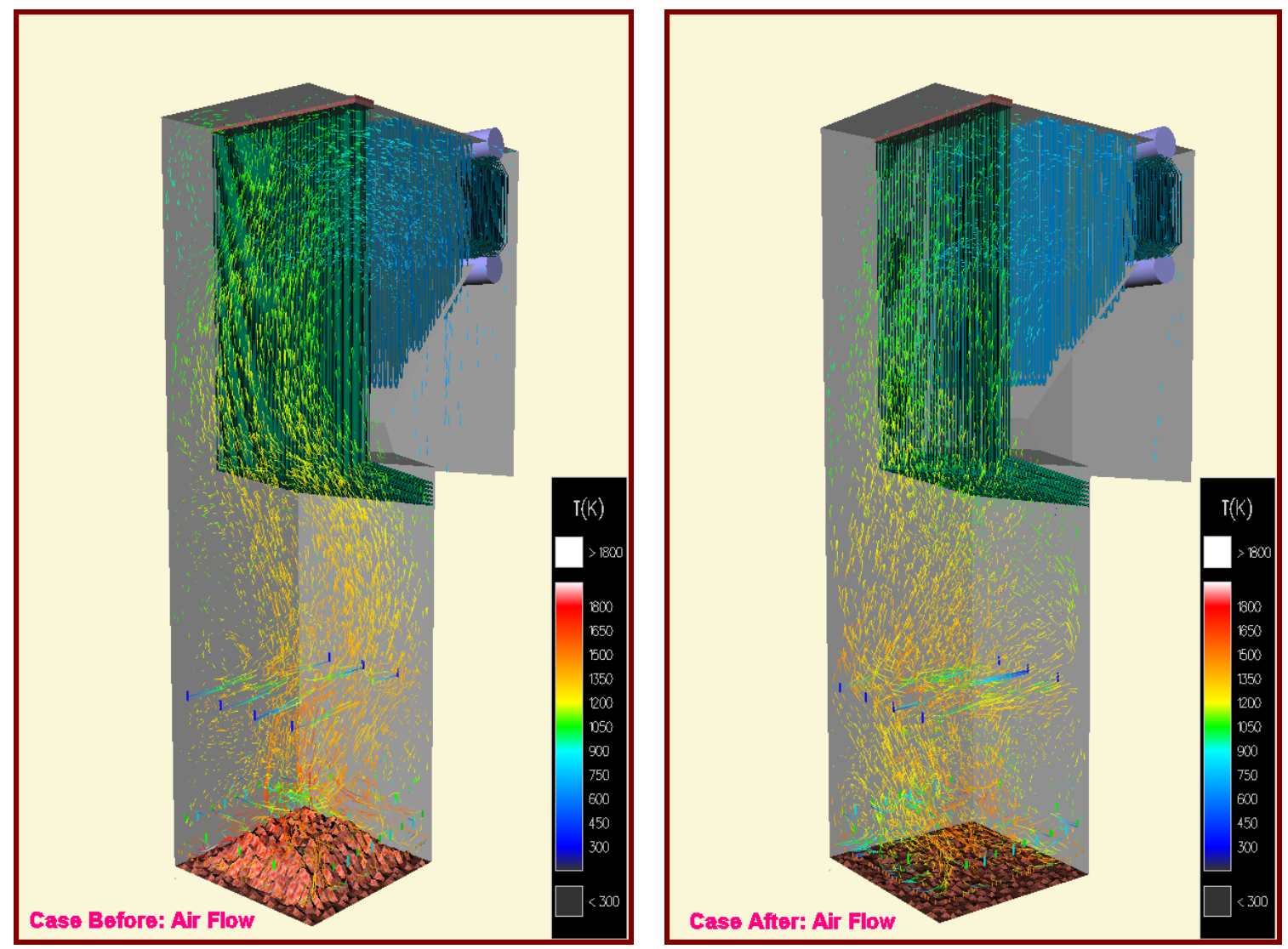

Fig. 44. Predicted air flow in Boiler-Q.

As shown in Fig. 36, there are five secondary airports on each side wall and two on each front and rear wall. In order to avoid jet collisions, it is better to form interlaced jets. There are four different ways to form interlaced jets by changing port openings on the side walls. Figure 45 shows a 3 on 3 mode of secondary air distribution; 3 ports on each side wall are largely open and the remaining ports are almost closed. Figure 46 shows a 3 on 2 mode; 3 ports on the left wall and 2 ports on the right wall are largely open. The other two modes, 5 on 5 and 4 on 4 are shown in Figs. 47 and 48. These four different modes of secondary air distribution were modeled; the major operational conditions are listed in Table 9. The only difference between the four cases is the secondary air distribution. The air split and the nozzle type are the same as "Case After" in the previous section.

In addition to the four cases, one more case was modeled, in which the existing secondary and tertiary air system was replaced by a new air system. The purpose of modeling this case was to see if a new air system could make any changes in boiler performance.

The modeling results of the five cases are illustrated in Figs. 49 to 53, which include the distributions of gas temperature, vertical velocity, liquor droplet trajectories, and heat flux to the walls. Figure 54 presents pictures of flow animation of the cases. The model predictions are also summarized in Table 10. 


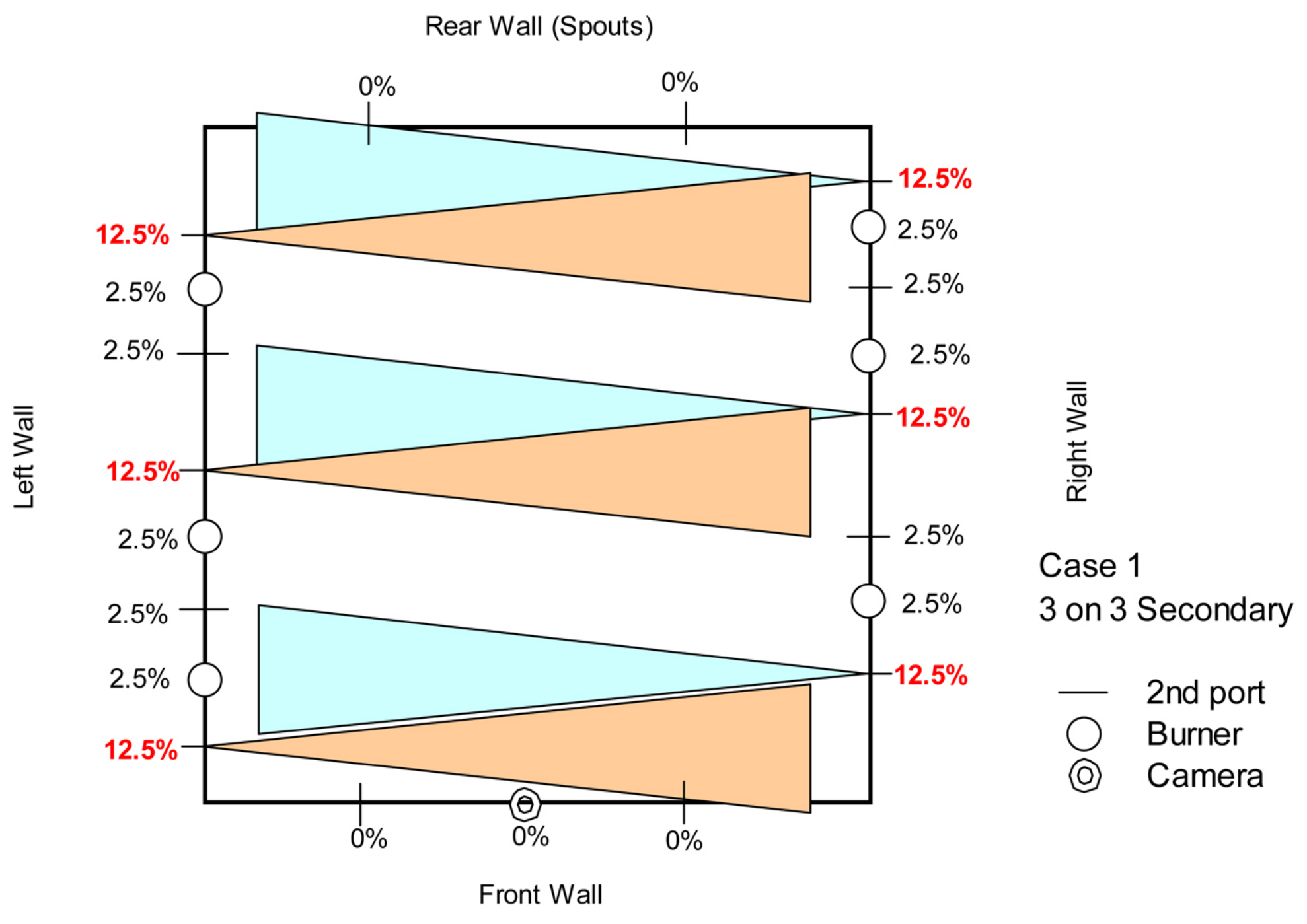

Fig. 45. Secondary air distribution in 3 on 3 mode in Boiler-Q. 
Rear Wall (Spouts)

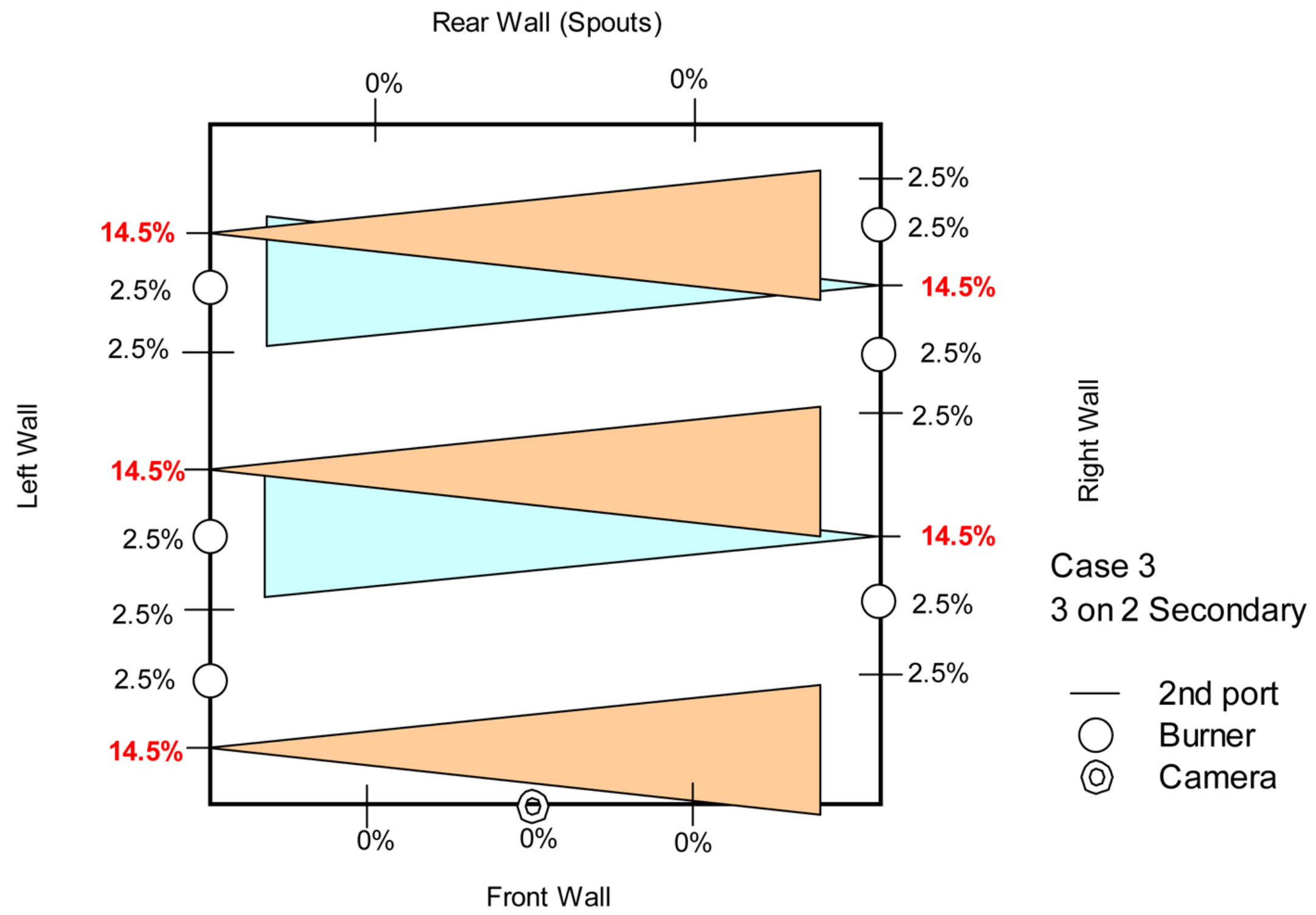

Fig. 46. Secondary air distribution in 3 on 2 mode in Boiler-Q. 


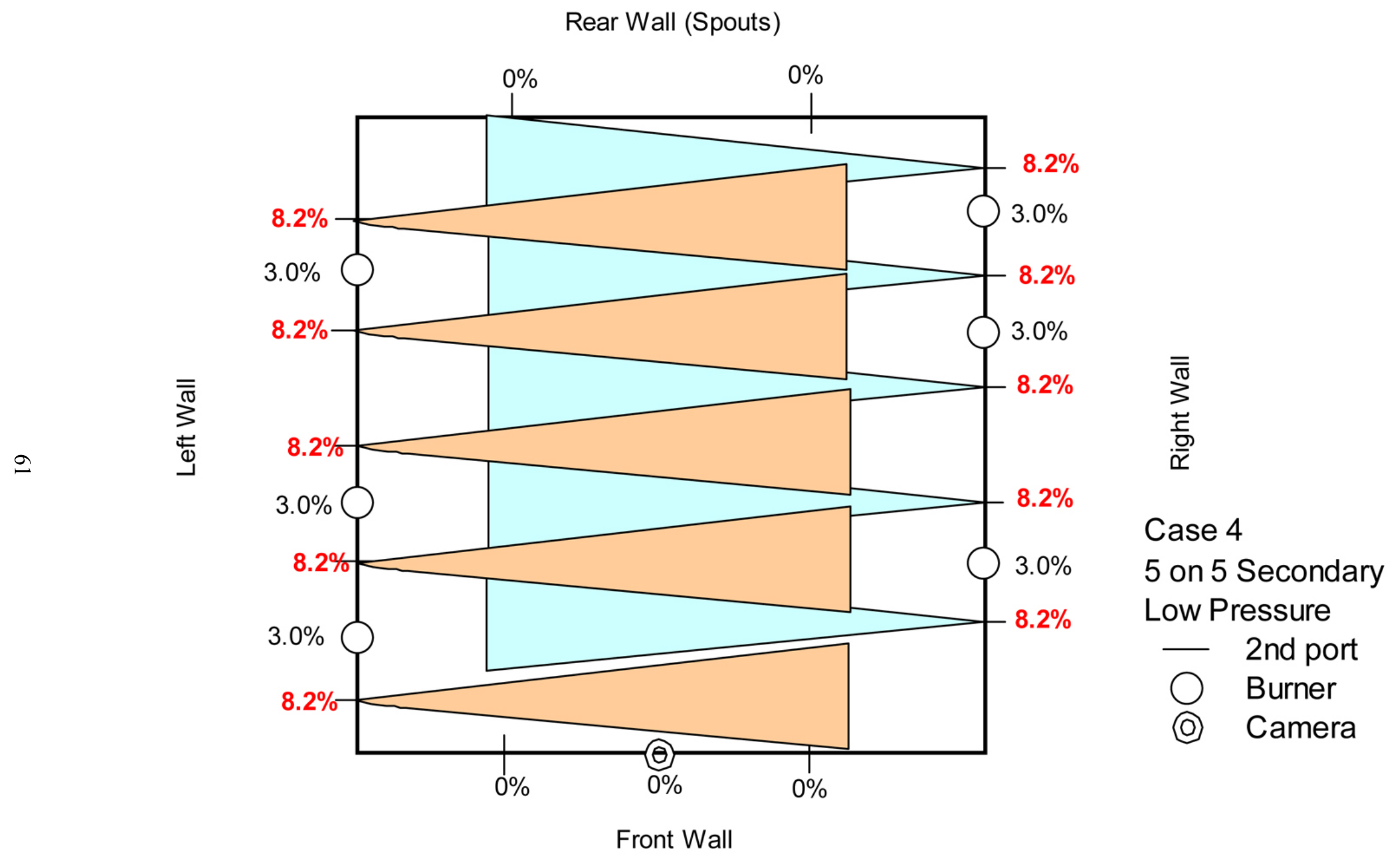

Fig. 47. Secondary air distribution in 5 on 5 mode in Boiler-Q. 
Rear Wall (Spouts)

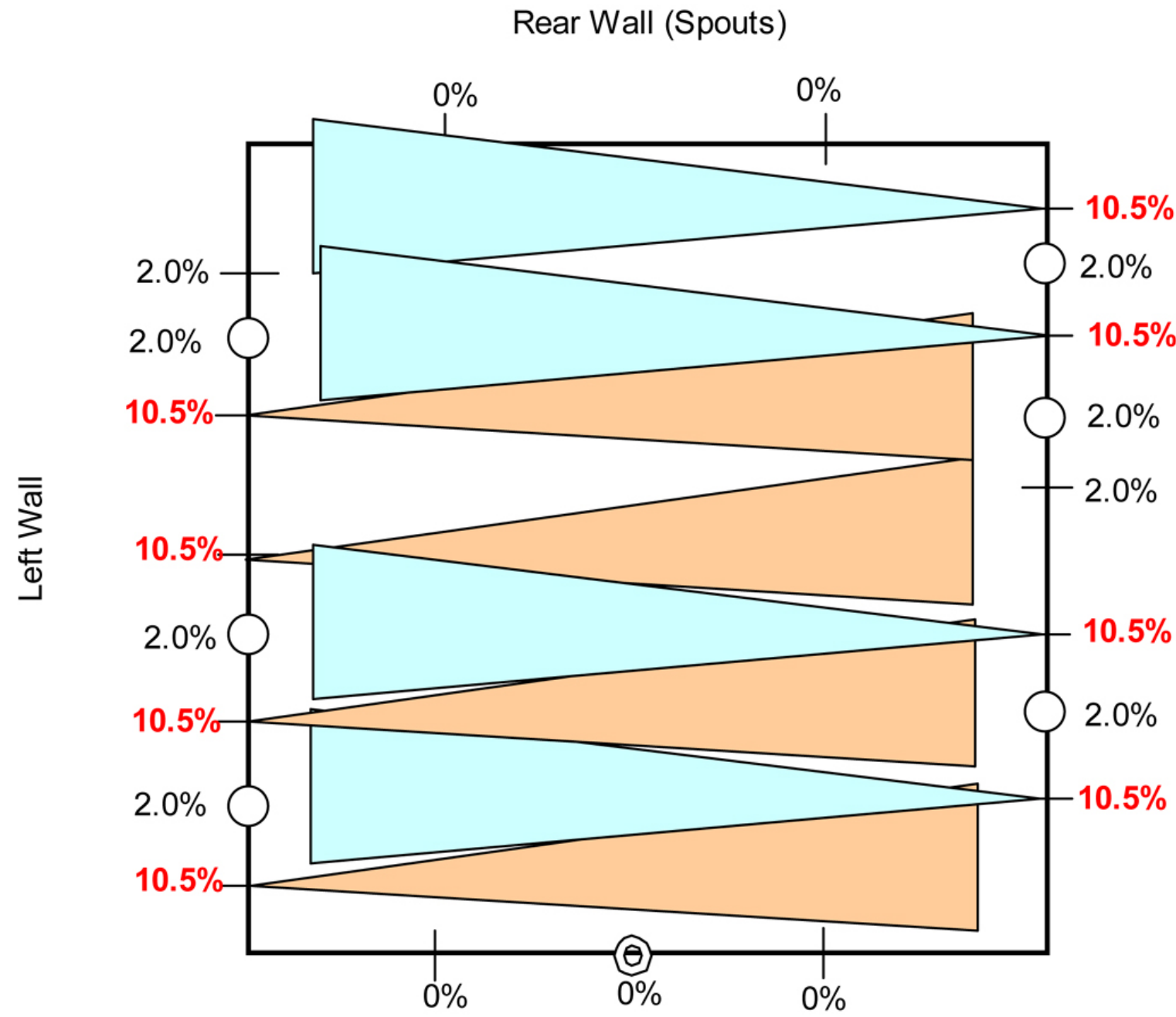

$\overline{\bar{\pi}}$
3
$\frac{1}{0.0}$
$\frac{1}{1}$

Case 5

4 on 4 Secondary

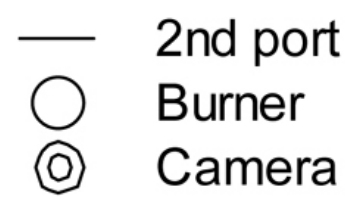

Front Wall

Fig. 48. Secondary air distribution in 4 on 4 mode in Boiler-Q. 
Table 9. Simulation conditions of five cases with different secondary air distribution in Boiler-Q

\begin{tabular}{|c|c|c|c|c|c|c|}
\hline Secondary air distribution & & $\begin{array}{l}\text { Case } 1 \\
3 \text { on } 3\end{array}$ & $\begin{array}{c}\text { Case } 2 \\
2(3 \text { on } 3)\end{array}$ & $\begin{array}{l}\text { Case } 3 \\
3 \text { on } 2\end{array}$ & $\begin{array}{l}\text { Case } 4 \\
5 \text { on } 5\end{array}$ & $\begin{array}{l}\text { Case } 5 \\
4 \text { on } 4\end{array}$ \\
\hline Char bed & & Low & Low & Low & Low & Low \\
\hline Liquor gun number & & \#28 & \#28 & \#28 & \#28 & \#28 \\
\hline Mean droplet size & $\mathbf{m m}$ & 2.5 & 2.5 & 2.5 & 2.5 & 2.5 \\
\hline Total forced air flow & kg/hr & 383,599 & 383,599 & 383,599 & 383,599 & 383,599 \\
\hline Primary air flow & kg/hr & 135,232 & 135,232 & 135,232 & 135,232 & 135,232 \\
\hline Primary air ratio of forced air & $\%$ & $35.3 \%$ & $35.3 \%$ & $35.3 \%$ & $35.3 \%$ & $35.3 \%$ \\
\hline Primary air temperature & ${ }^{\circ} \mathrm{C}$ & 150 & 150 & 150 & 150 & 150 \\
\hline Secondary air flow & kg/hr & 143,705 & 134,260 & 143,705 & 143,705 & 143,705 \\
\hline Secondary air ratio of forced air & $\%$ & $37.5 \%$ & $35.0 \%$ & $37.5 \%$ & $37.5 \%$ & $37.5 \%$ \\
\hline Secondary air temperature & ${ }^{\circ} \mathrm{C}$ & 150 & 150 & 150 & 150 & 150 \\
\hline Tertiary air flow & kg/hr & 104,662 & 114,107 & 104,662 & 104,662 & 104,662 \\
\hline Tertiary air ratio of forced flow & $\%$ & $27.3 \%$ & $29.7 \%$ & $27.3 \%$ & $27.3 \%$ & $27.3 \%$ \\
\hline Tertiary air temperature & ${ }^{\circ} \mathrm{C}$ & 30 & 30 & 30 & 30 & 30 \\
\hline Total air leakage & kg/hr & 3,156 & 3,156 & 3,156 & 3,156 & 3,156 \\
\hline Liquor gun port air leakage & kg/hr & 3,154 & 3,154 & 3,154 & 3,154 & 3,154 \\
\hline Smelt spout air leakage & kg/hr & 2 & 2 & 2 & 2 & 2 \\
\hline Air temperature & ${ }^{\circ} \mathrm{C}$ & 30 & 30 & 30 & 30 & 30 \\
\hline Total air flow rate & kg/hr & 386,755 & 386,755 & 386,755 & 386,755 & 386,755 \\
\hline Excess air ratio & $\%$ & $28.9 \%$ & $28.9 \%$ & $28.9 \%$ & $0.0 \%$ & $0.0 \%$ \\
\hline $\begin{array}{l}\text { Black liquor feed rate } \\
\text { Black liquor nozzle type }\end{array}$ & kgDS/hr & $\begin{array}{l}77,099 \\
\text { Splash }\end{array}$ & $\begin{array}{l}77,099 \\
\text { Splash }\end{array}$ & $\begin{array}{l}77,099 \\
\text { Splash }\end{array}$ & $\begin{array}{l}77,099 \\
\text { Splash }\end{array}$ & $\begin{array}{l}77,099 \\
\text { Splash }\end{array}$ \\
\hline Number of liquor guns & & 4 & 4 & 4 & 4 & 4 \\
\hline Steam generation & $\mathrm{kg} / \mathrm{hr}$ & 250,000 & 250,000 & 250,000 & 250,000 & 250,000 \\
\hline Operation pressure & $\mathbf{k P a}$ & 8,690 & 8,690 & 8,690 & 8,690 & 8,690 \\
\hline Operation temperation & ${ }^{\circ} \mathrm{C}$ & 480 & 480 & 480 & 480 & 480 \\
\hline
\end{tabular}



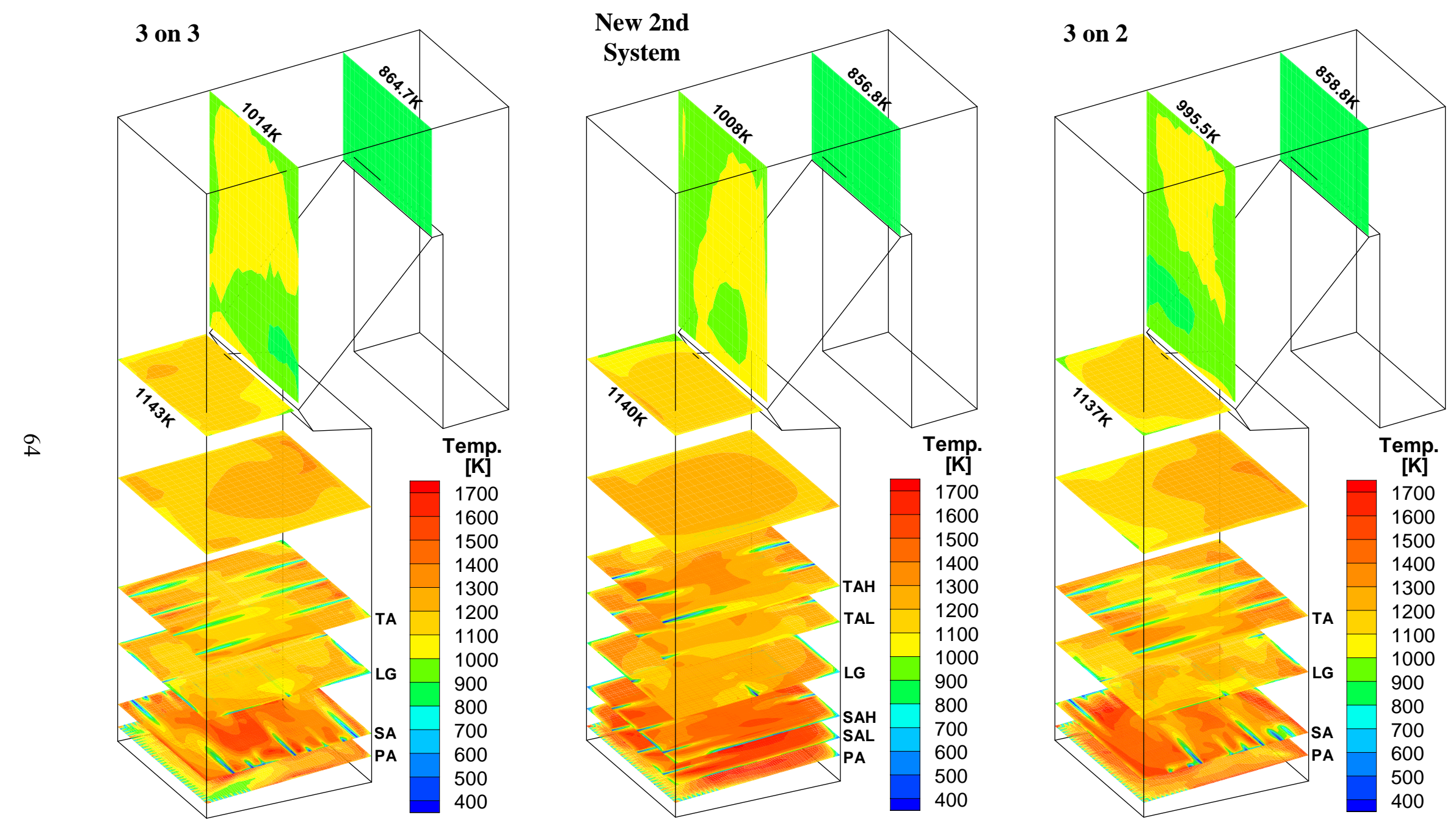

Fig. 49(a). Gas temperatures under different secondary air distribution modes in Boiler-Q. 

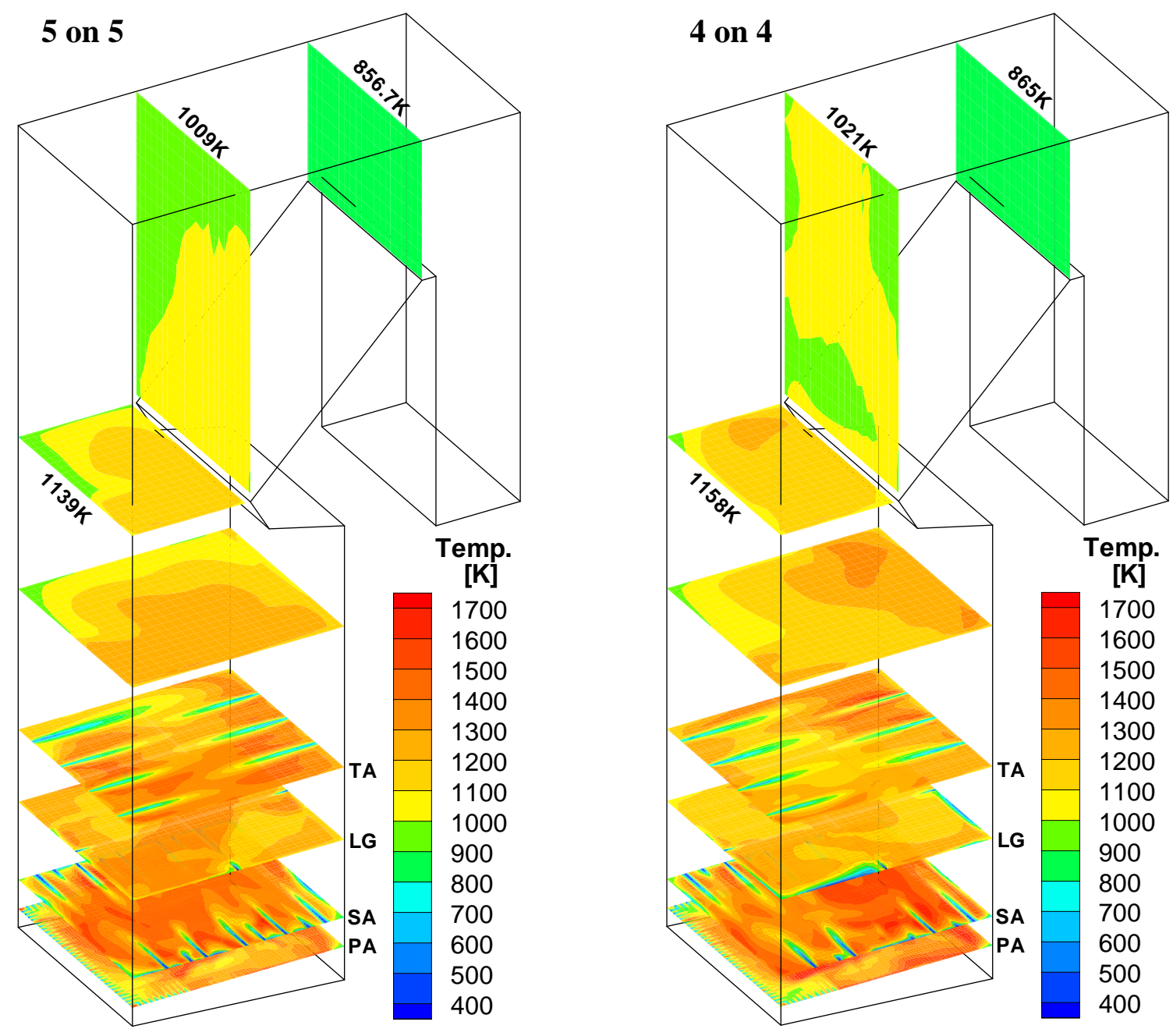

Fig. 49(b). Gas temperatures under different secondary air distribution modes in Boiler-Q. 

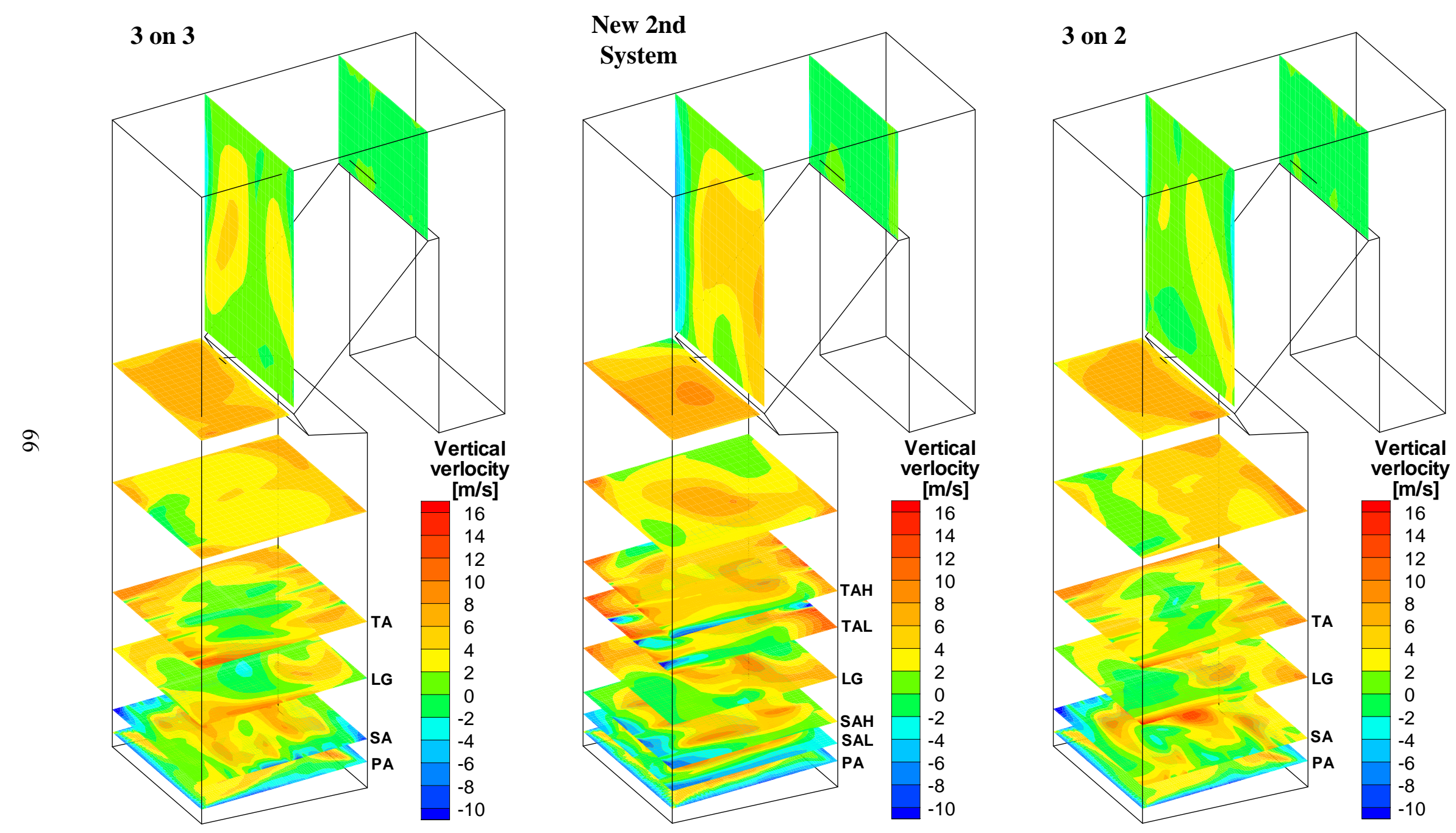

Fig. 50(a). Vertical velocities under different secondary air distribution modes in Boiler-Q. 

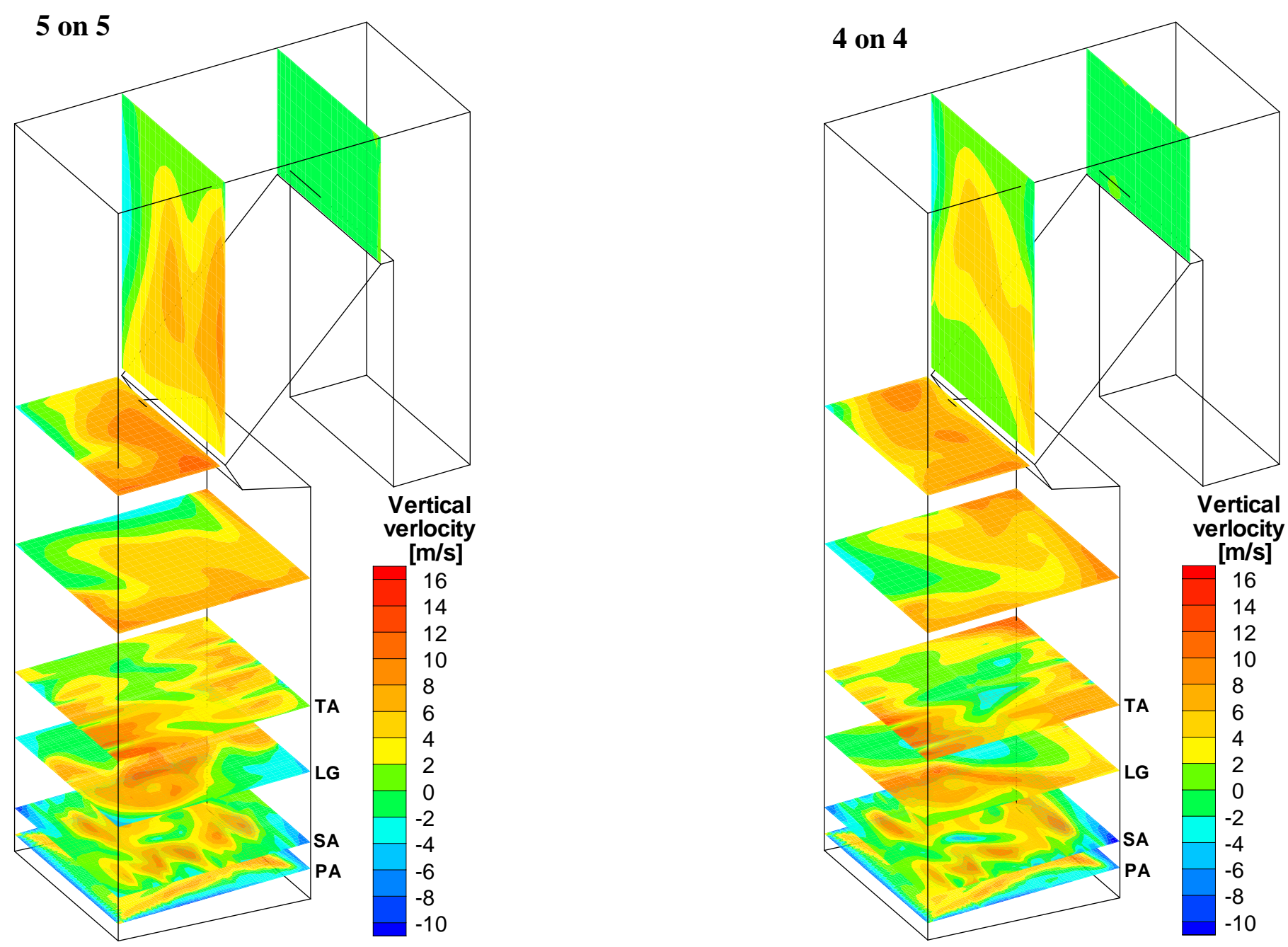

Fig. 50(b). Vertical velocities under different secondary air distribution modes in Boiler-Q. 

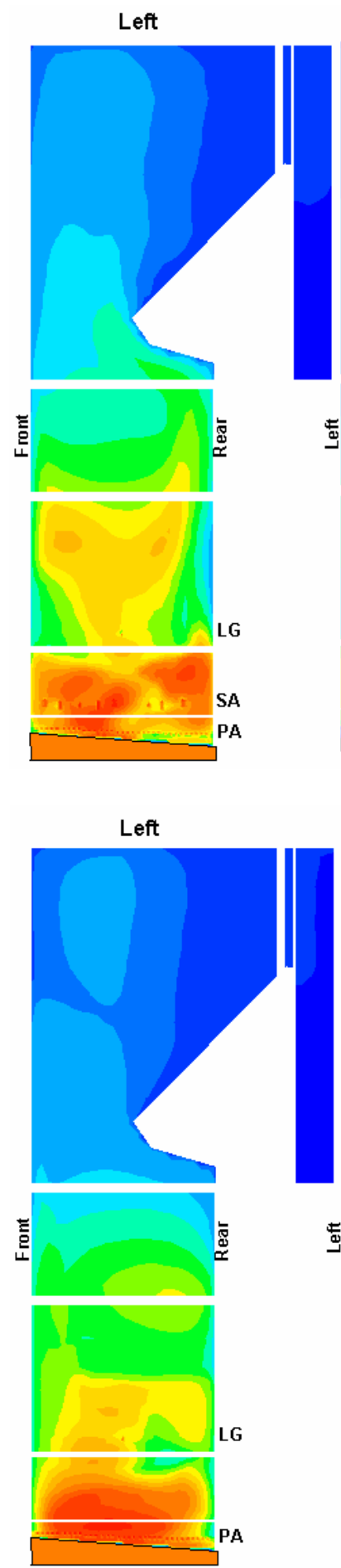

Front
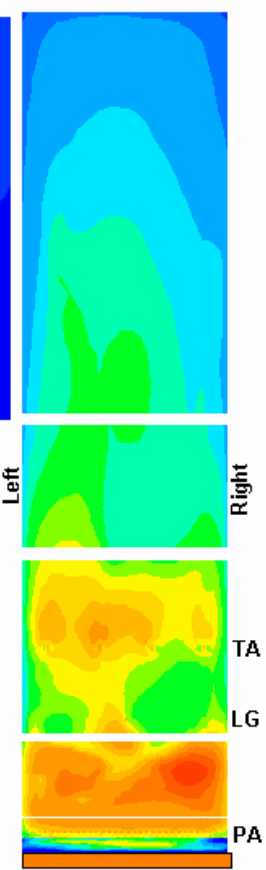

Front

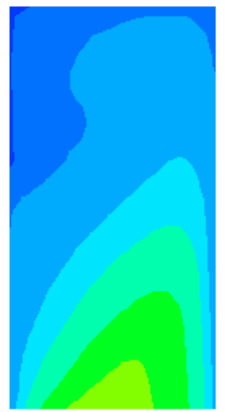

5
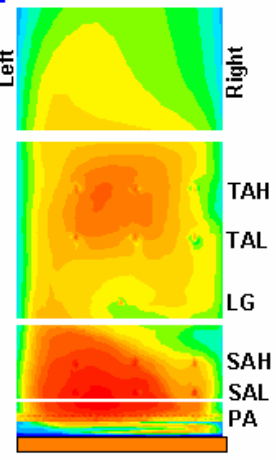

Right
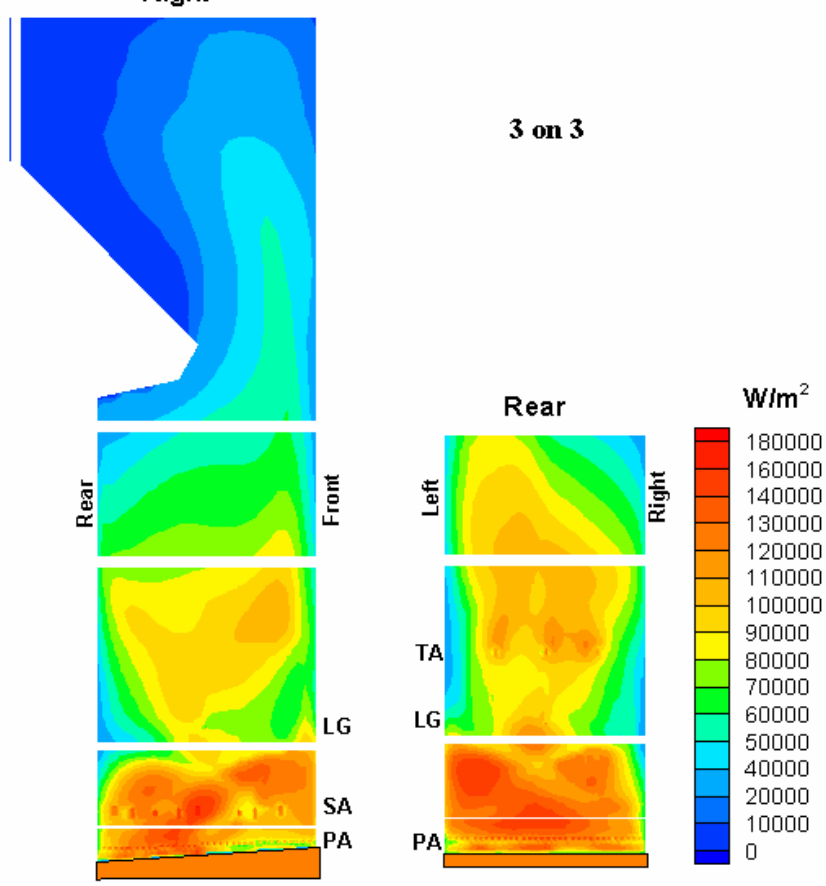

New Air

System

3 on 3
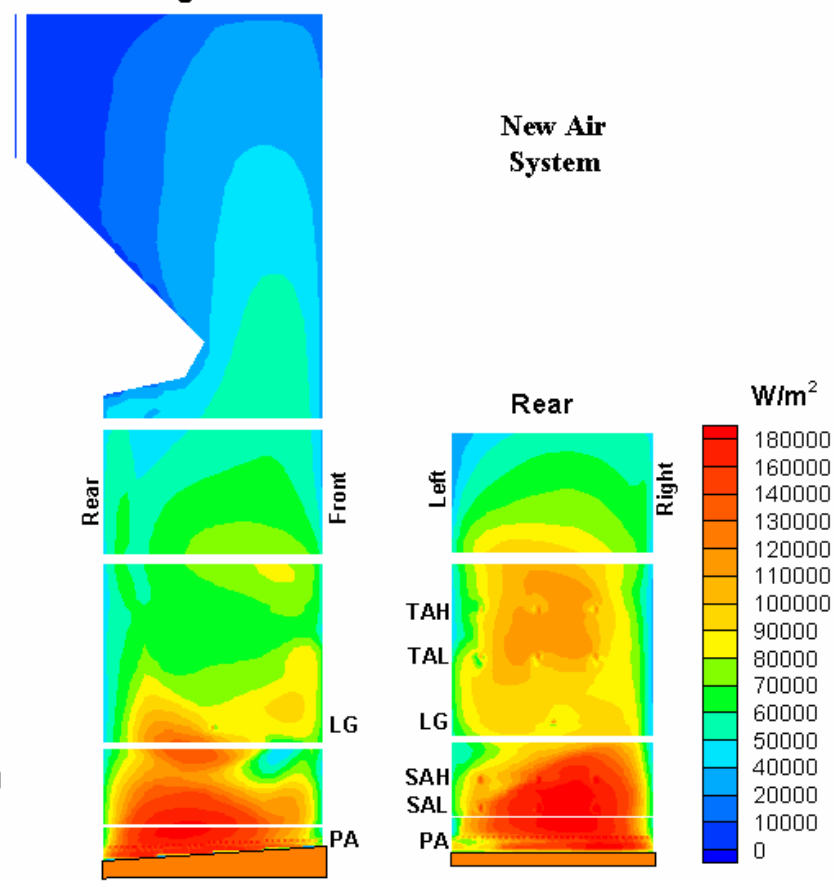

Fig. 51(a). Heat flux under different secondary air distribution modes in Boiler-Q. 


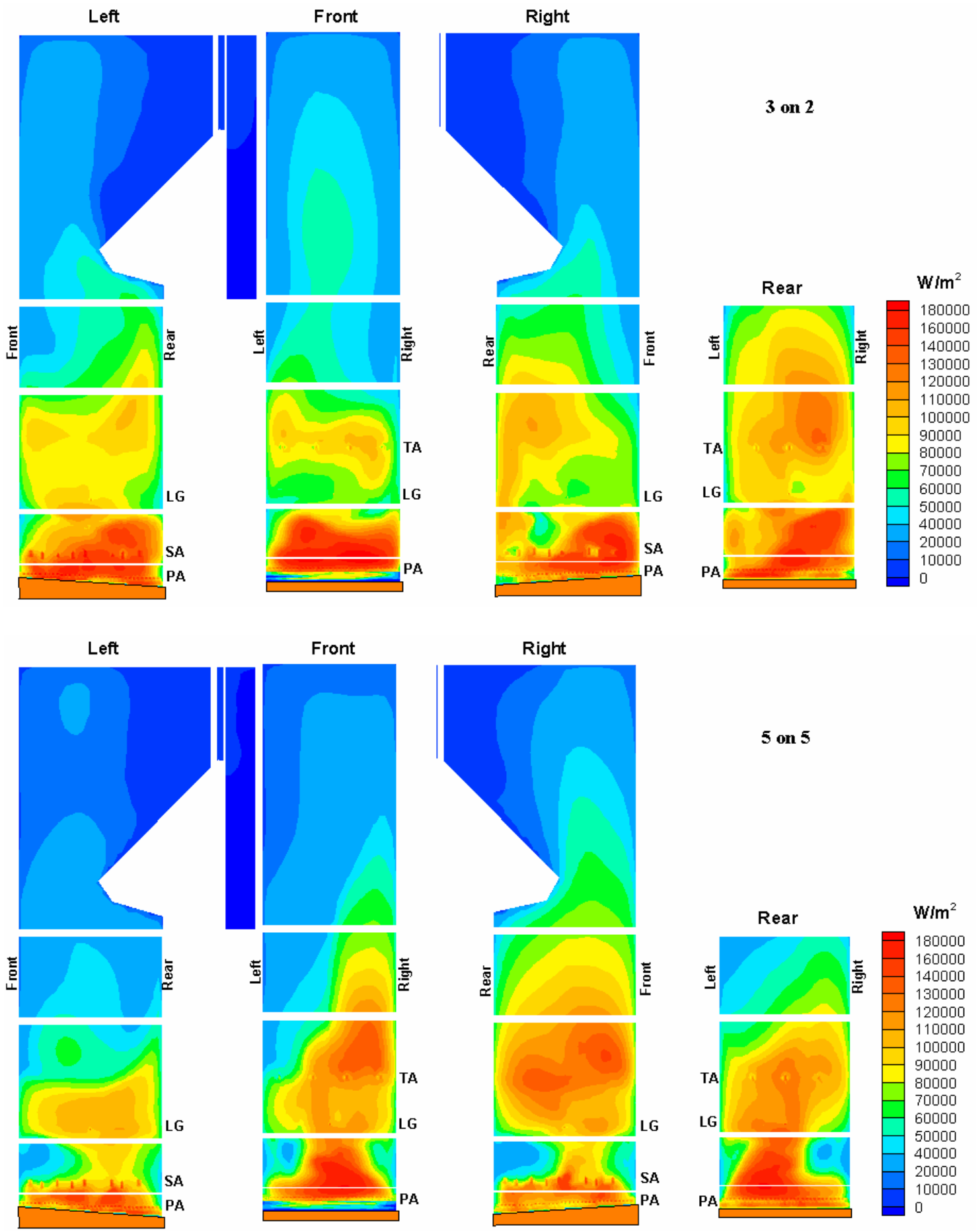

Fig. 51(b). Heat flux under different secondary air distribution modes in Boiler-Q. 


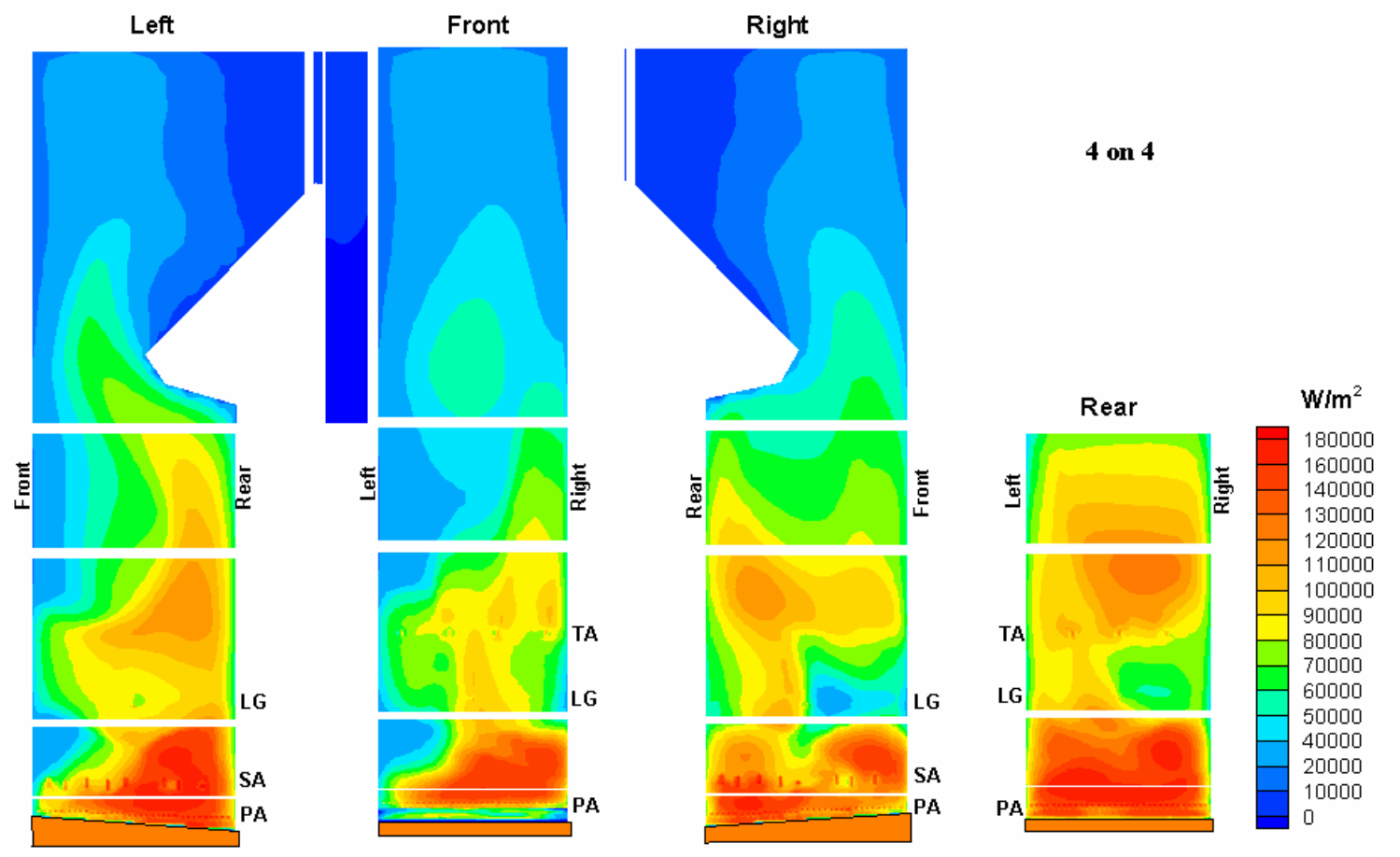

Fig. 51(c). Heat flux under different secondary air distribution modes in Boiler-Q. 


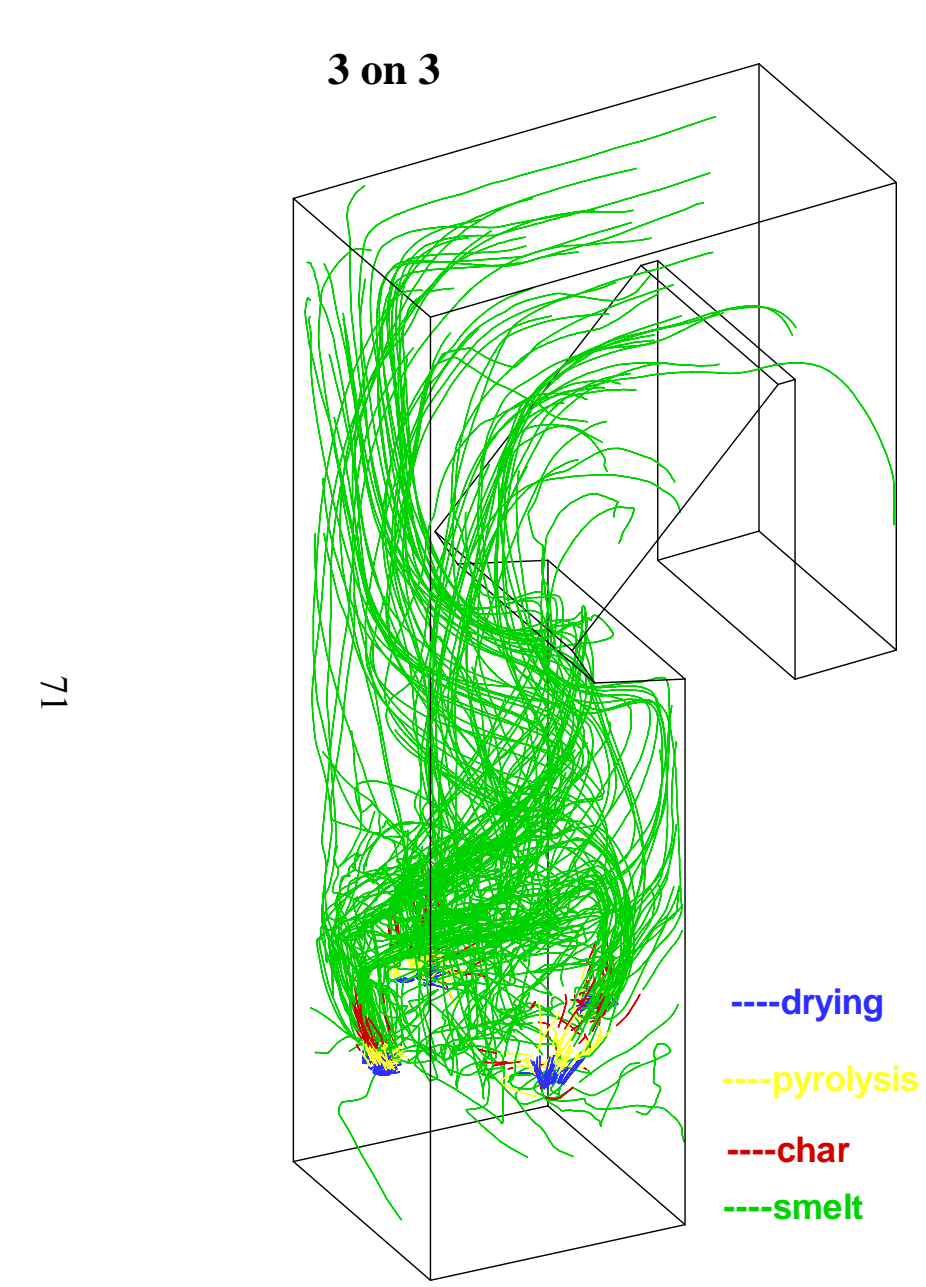

$0<\mathrm{d}<0.6 \mathrm{~mm}$

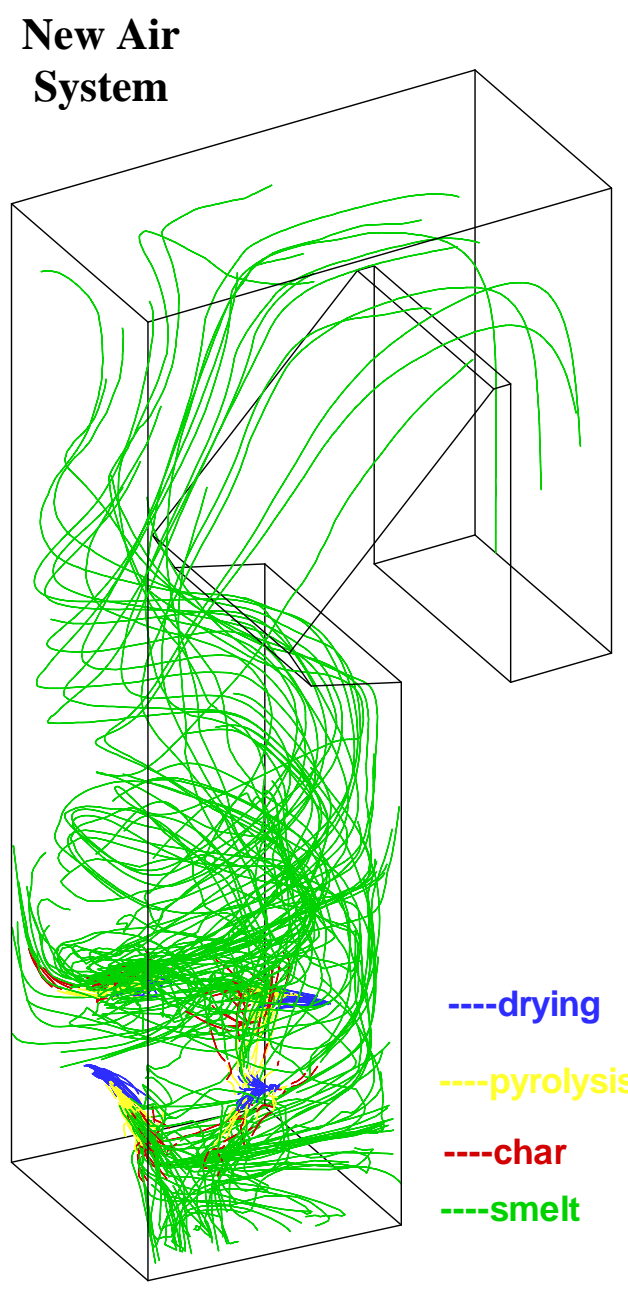

$0<\mathrm{d}<0.6 \mathrm{~mm}$

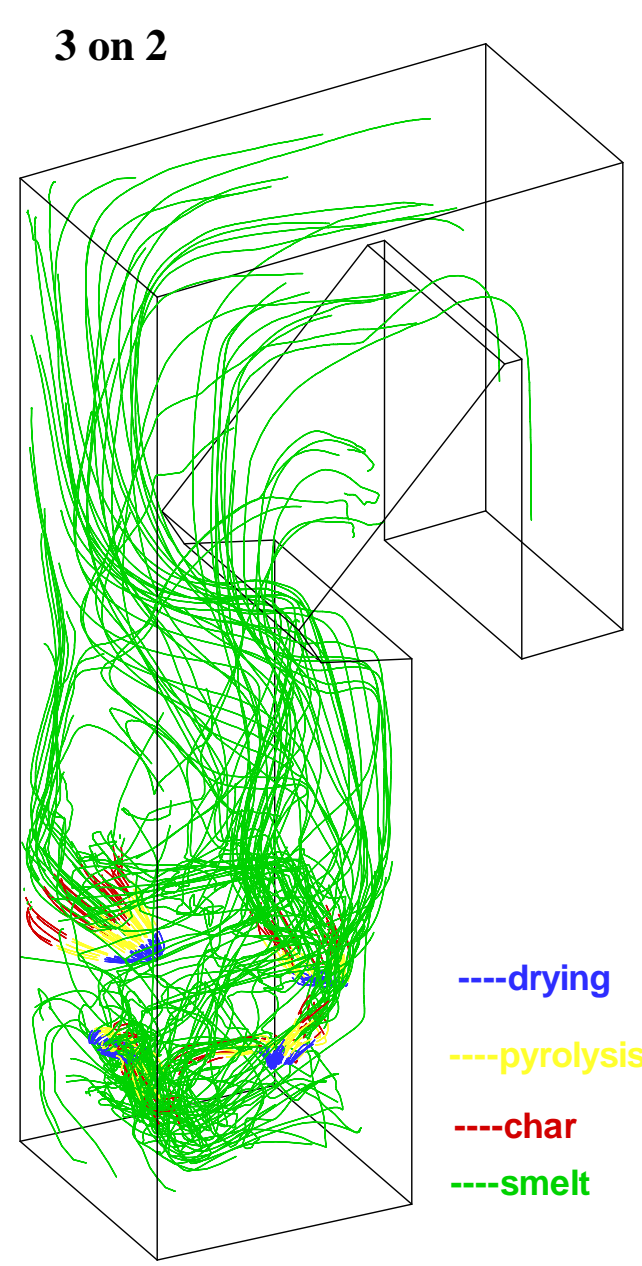

$0<\mathrm{d}<0.6 \mathrm{~mm}$

Fig. 52(a). Trajectories of small droplets under different secondary air distribution modes in Boiler-Q. 


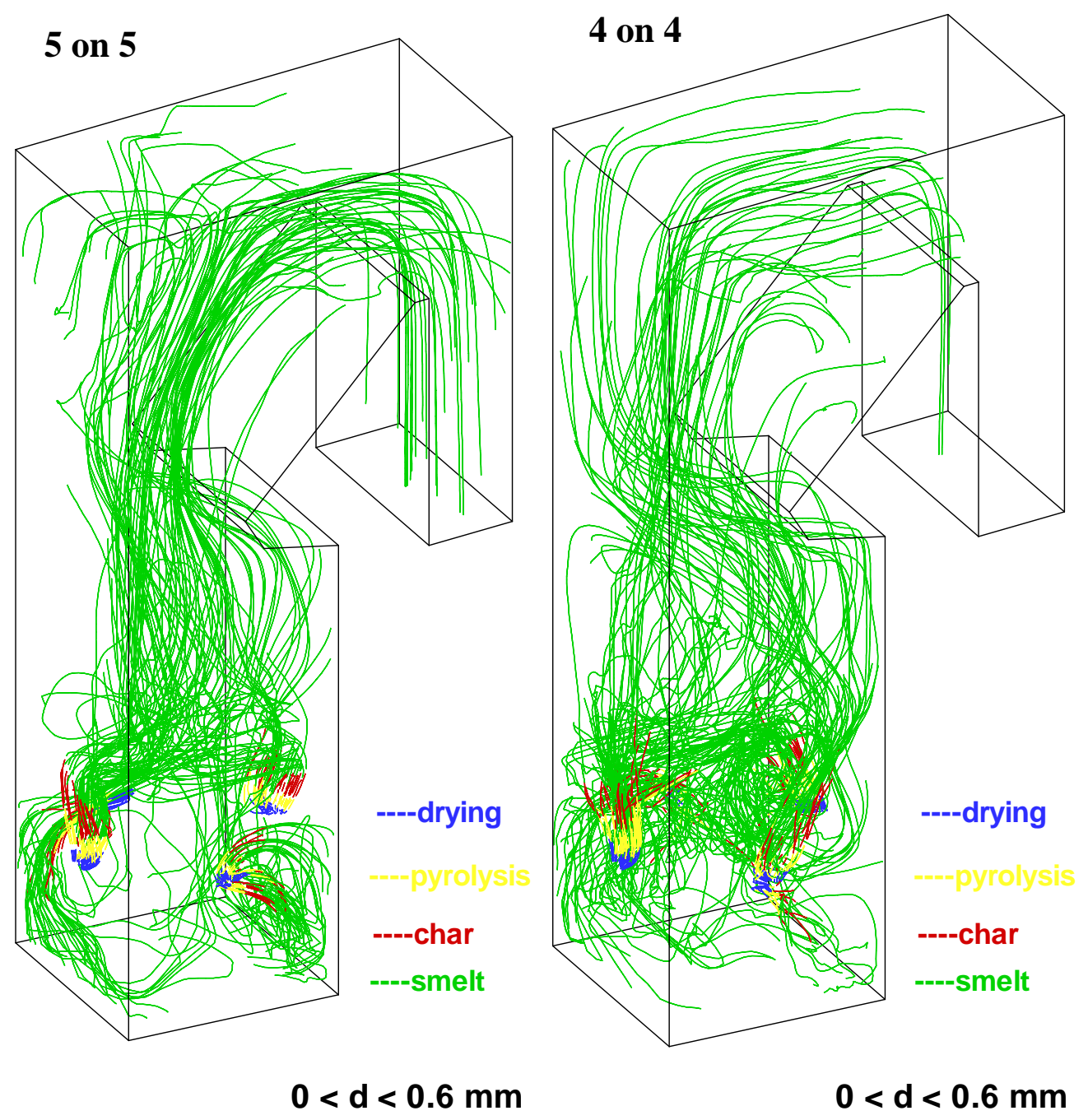

Fig. 52(b). Trajectories of small droplets under different secondary air distribution modes in Boiler-Q. 


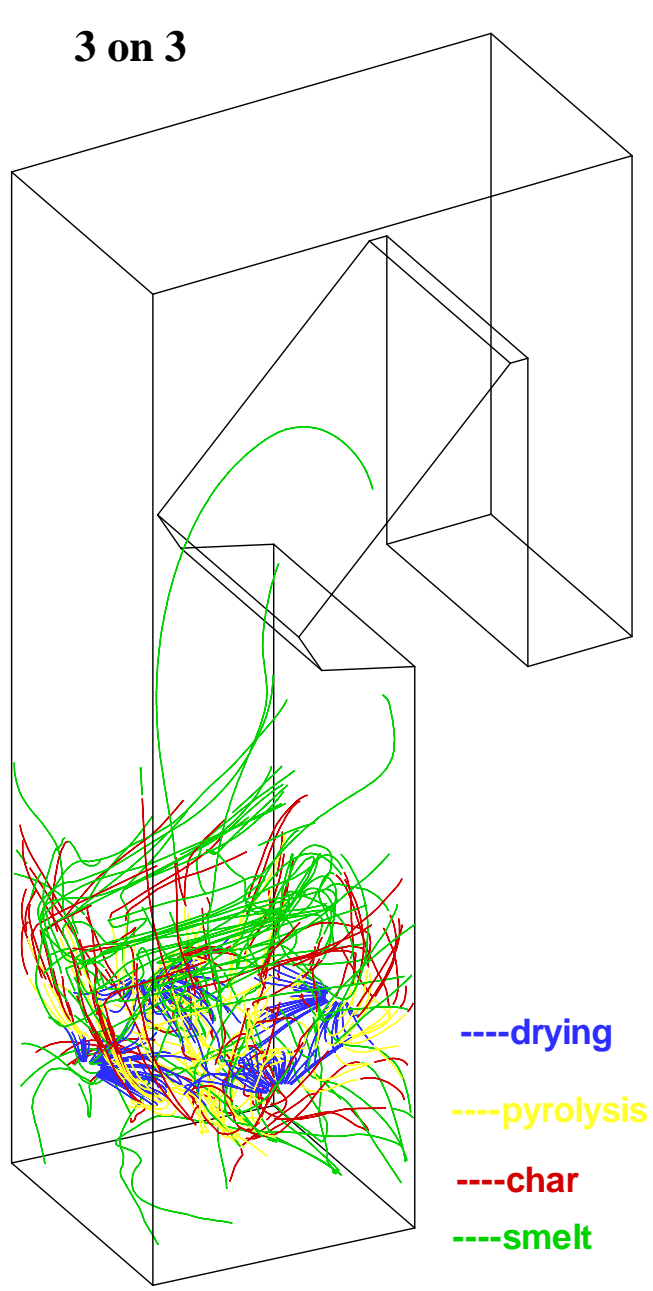

$0.6<\mathrm{d}<1.5 \mathrm{~mm}$

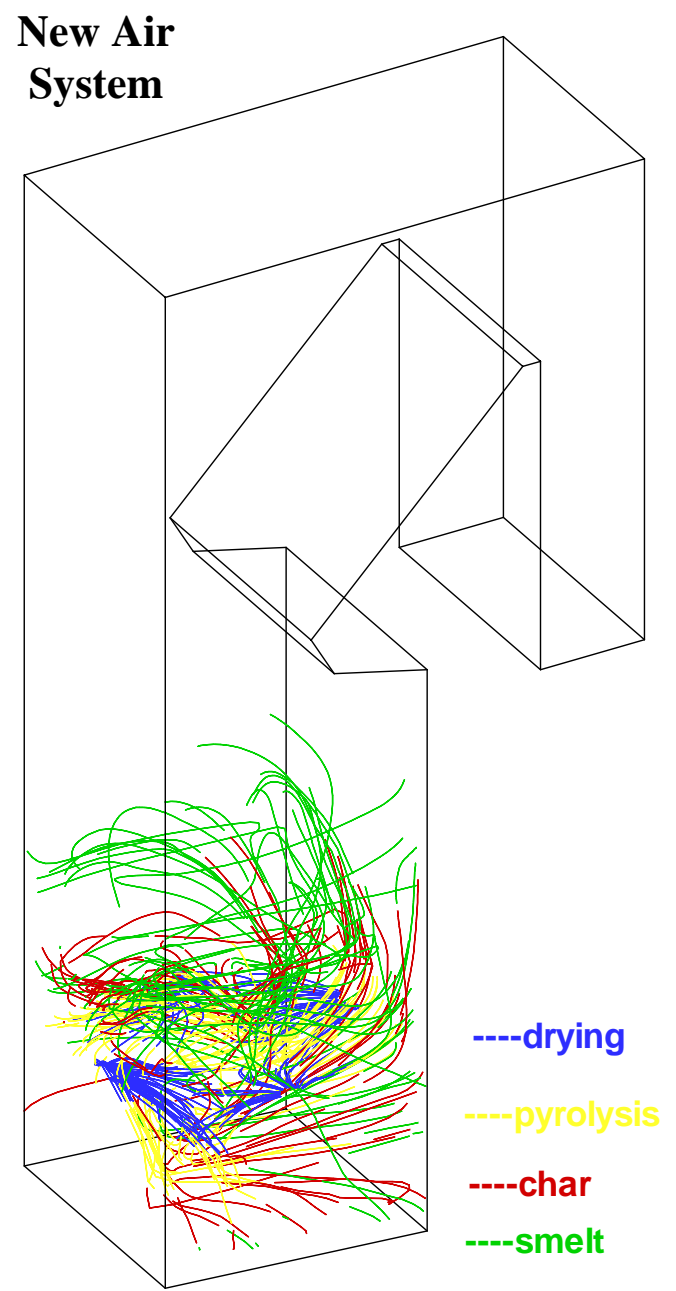

$0.6<\mathrm{d}<1.5 \mathrm{~mm}$

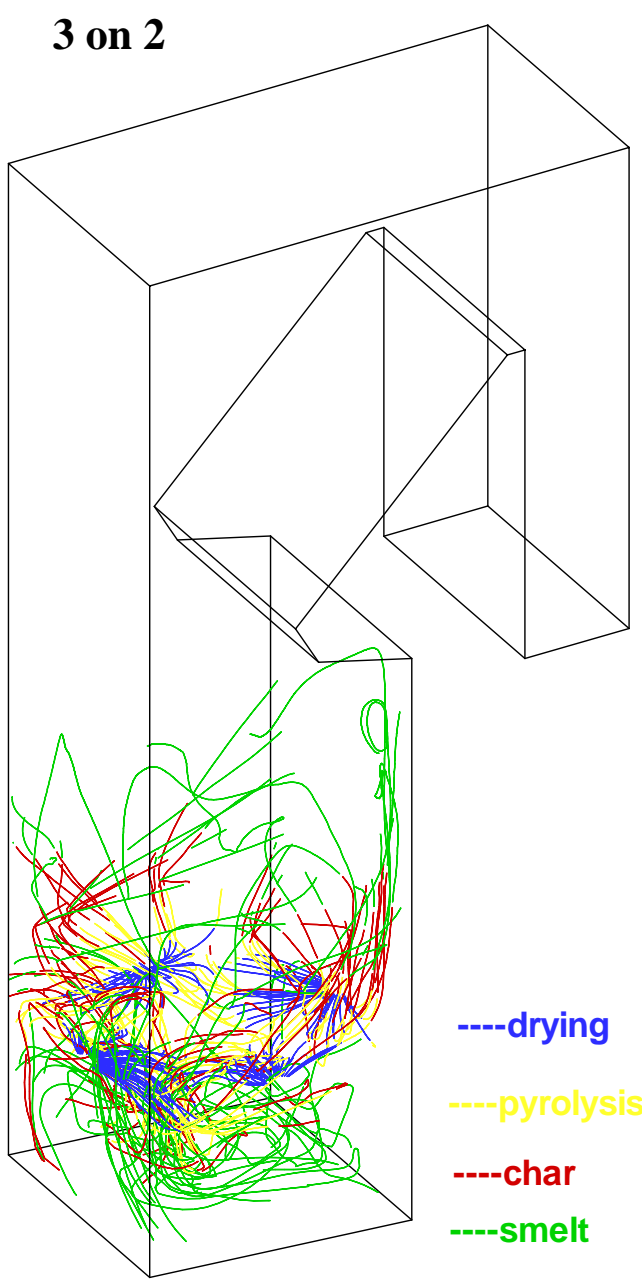

$0.6<\mathrm{d}<1.5 \mathrm{~mm}$

Fig. 53(a). Trajectories of medium droplets under different secondary air distribution modes in Boiler-Q. 


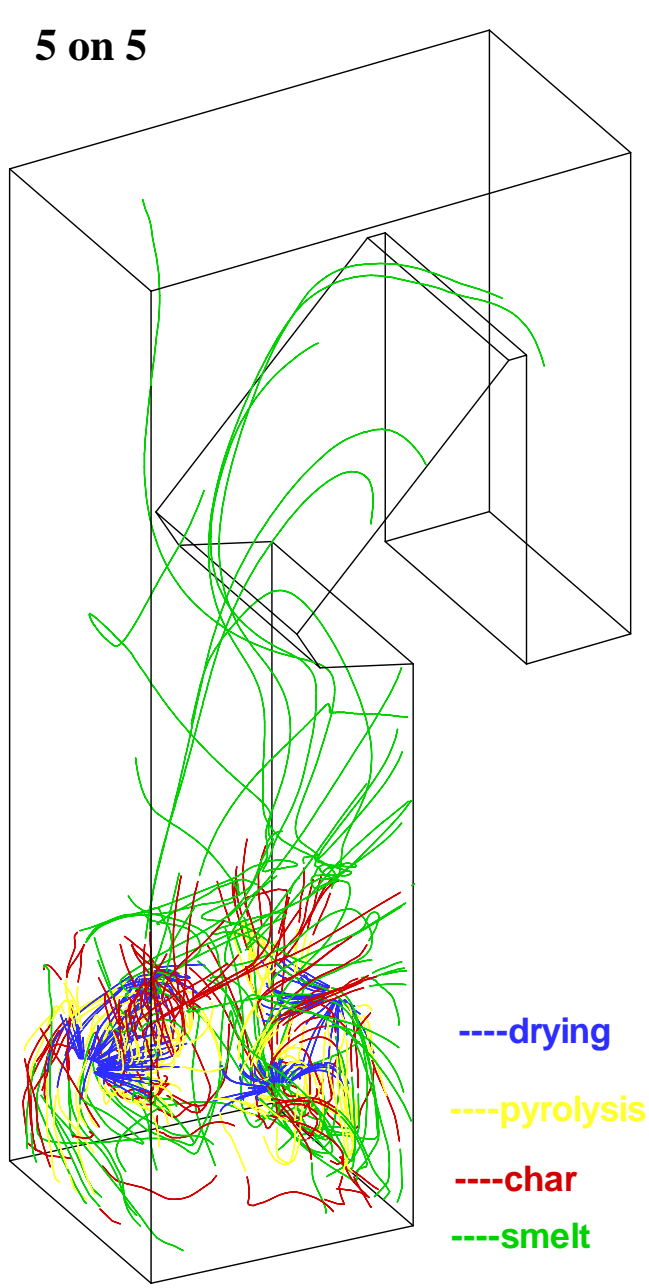

$0.6<\mathrm{d}<1.5 \mathrm{~mm}$

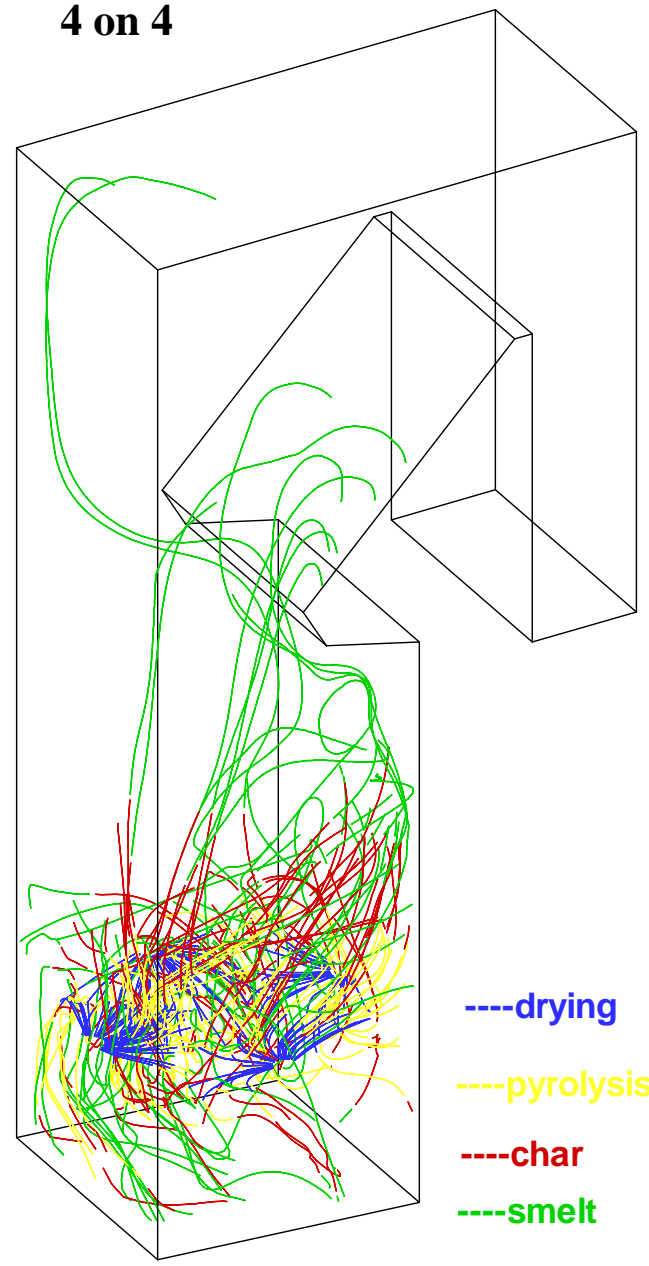

$0.6<\mathrm{d}<1.5 \mathrm{~mm}$

Fig. 53(b). Trajectories of medium droplets under different secondary air distribution modes in Boiler-Q. 

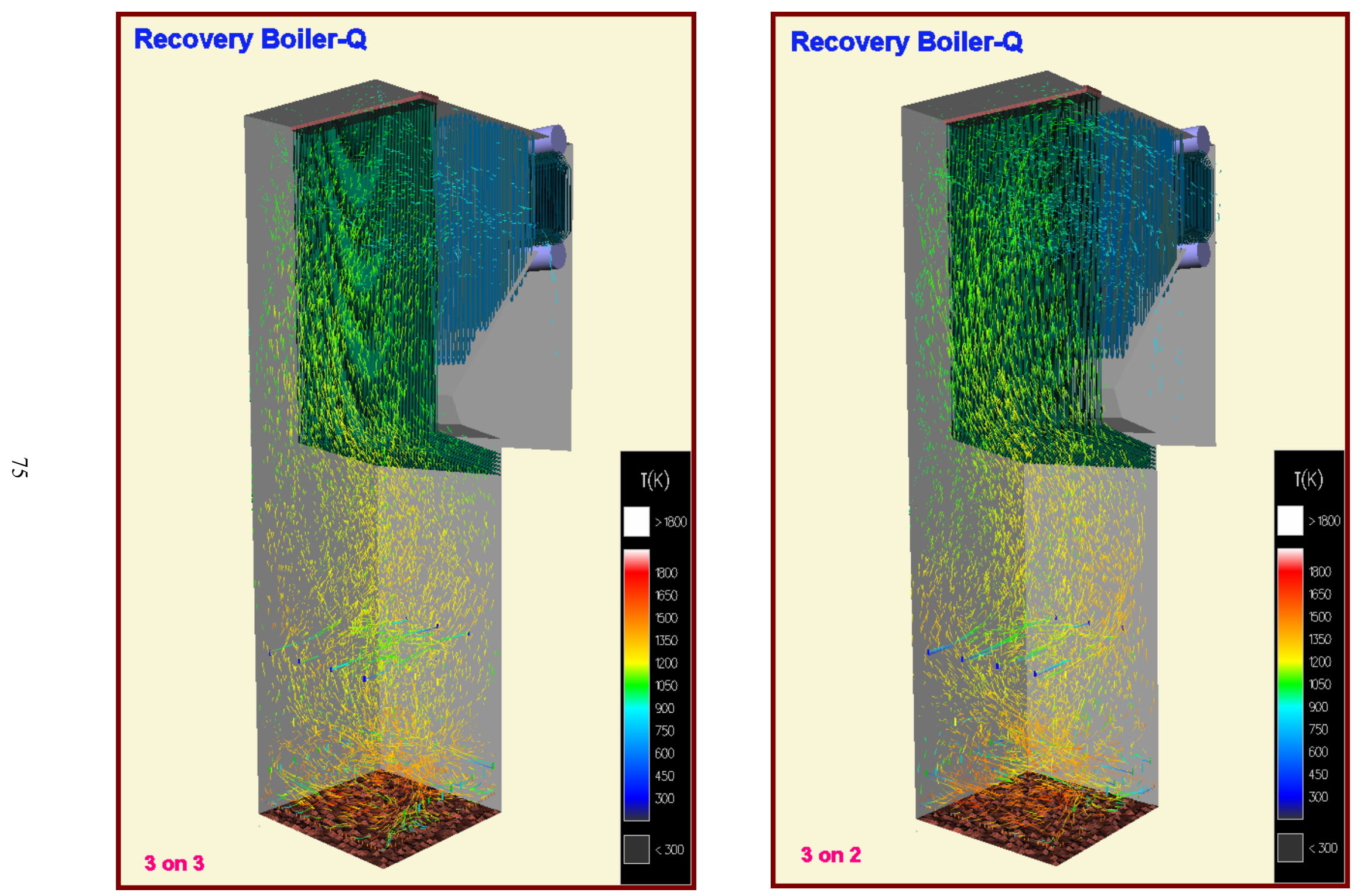

Fig. 54(a). Air flow under different secondary air distribution modes in Boiler-Q. 

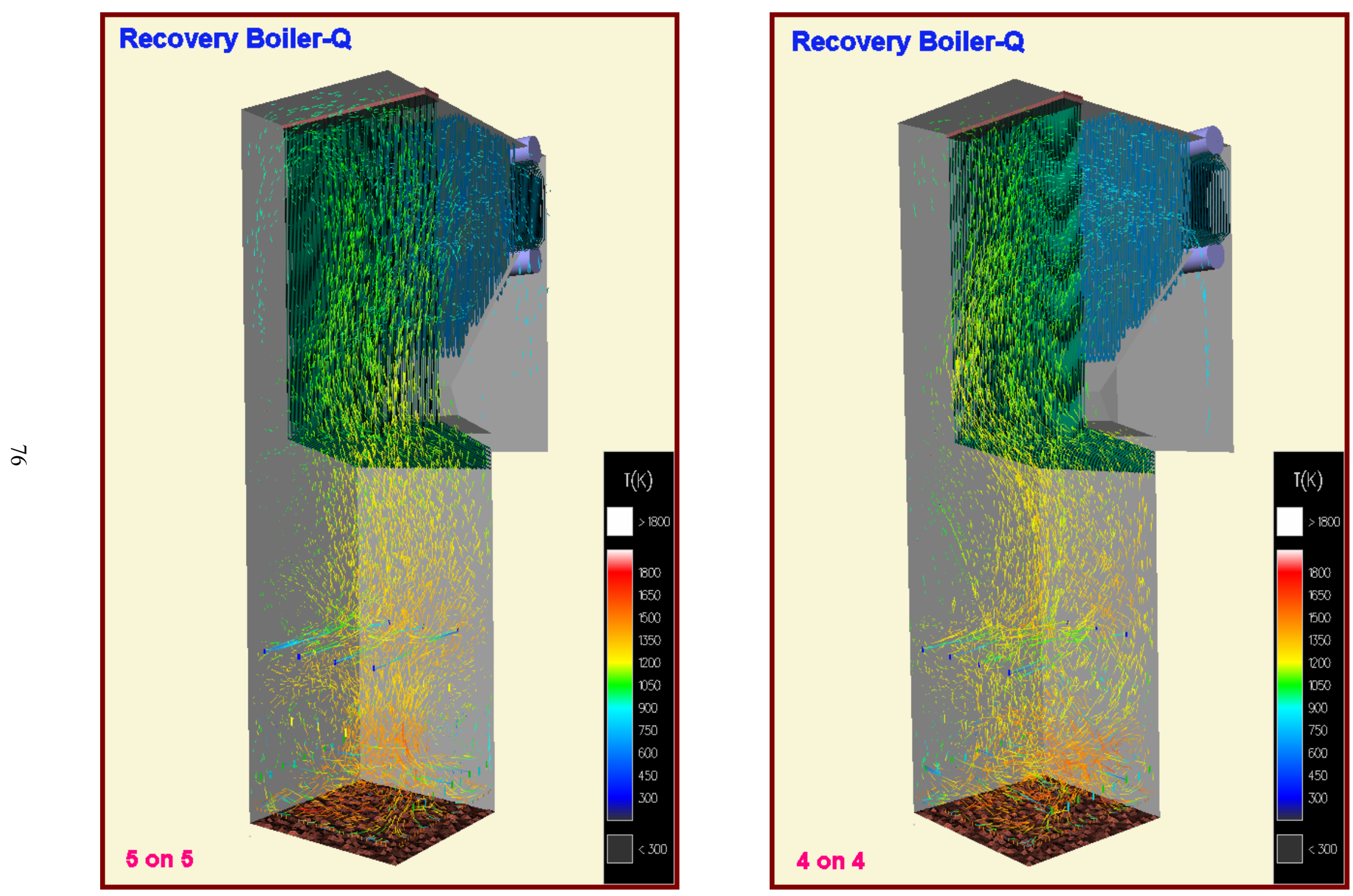

Fig. 54(b). Air flow under different secondary air distribution modes in Boiler-Q. 


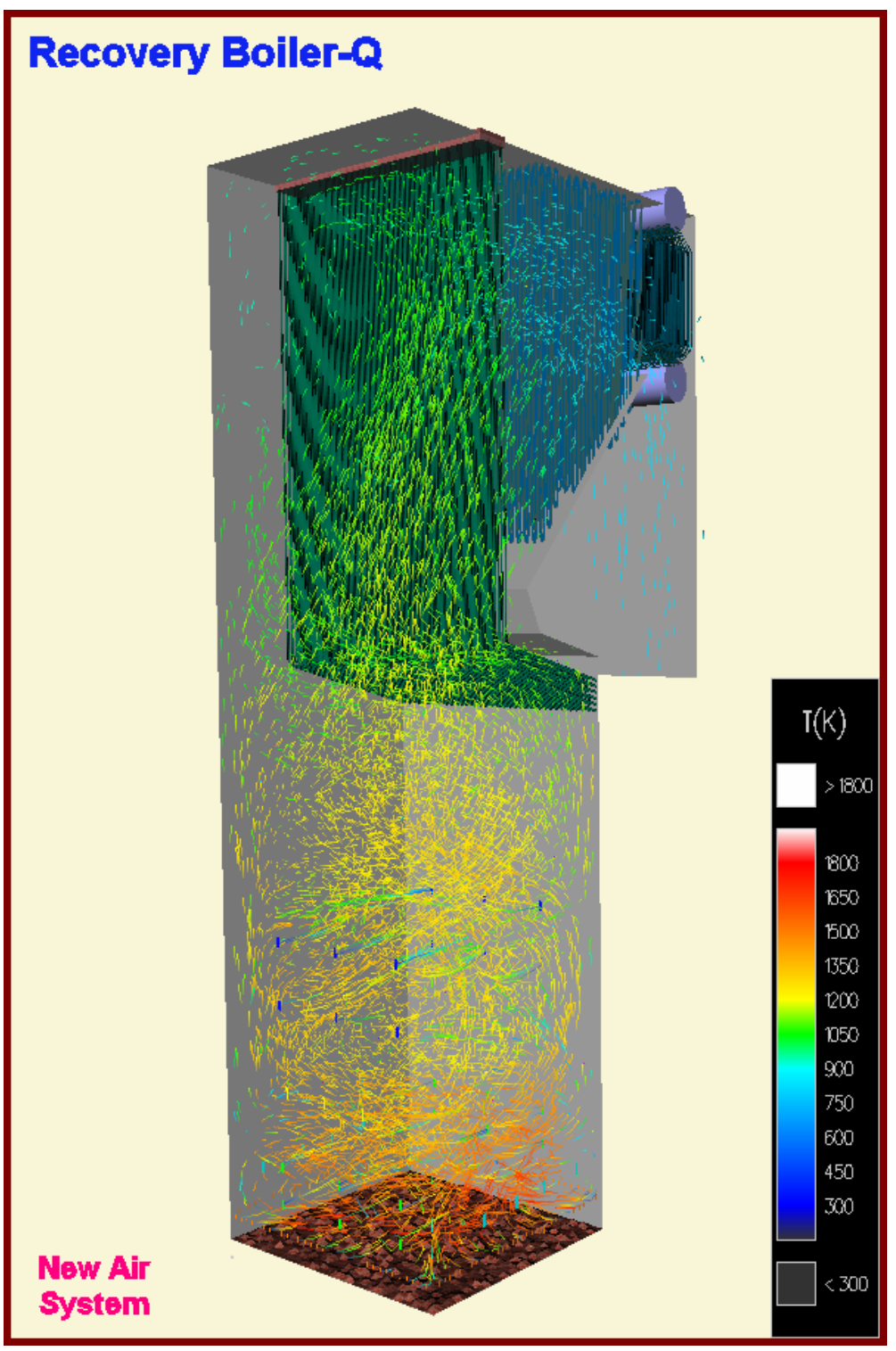

Fig. 54(c). Air flow under different secondary air distribution modes in Boiler-Q. 
Table 10. Summary of modeling predictions of five cases with different secondary air distribution in Boiler-Q

\begin{tabular}{|c|c|c|c|c|c|c|}
\hline Flue gas composition at furnace $e$ & & Case 1 & Case 2 & Case 3 & Case 4 & Case 5 \\
\hline $\mathrm{O}_{2}$ & wt, \% & 4.5 & 4 & 4.2 & 4.4 & 4.1 \\
\hline $\mathrm{CO}_{2}$ & wt, \% & 19 & 19.6 & 19.4 & 19.1 & 19.6 \\
\hline $\mathrm{H}_{2} \mathrm{O}$ & wt, \% & 11.5 & 11.7 & 11.7 & 11.4 & 11.5 \\
\hline co & wt, ppm & 11 & 2 & 4 & 4 & 10.5 \\
\hline $\mathrm{H}_{2}$ & wt, ppm & 6 & $\mathbf{0}$ & 3 & 0 & 7 \\
\hline Flue gas temperature at bull nose & $\mathbf{K}$ & 1143 & 1140 & 1137 & 1139 & 1158 \\
\hline Carry-over & kg/hr & 54 & 6 & 14.6 & 183 & 209 \\
\hline $\begin{array}{l}\text { Un-burned carbon on the bed } \\
\text { Energy released to (below bull nos }\end{array}$ & kg/hr & 208.8 & 118.8 & 56.16 & 198 & 228.96 \\
\hline Front wall & MW & 19.05 & 22.15 & 18.43 & 19.37 & 16.86 \\
\hline Rear wall & MW & 21.52 & 22.16 & 23.79 & 20.78 & 24.4 \\
\hline Left wall & MW & 20.95 & 19.72 & 21.05 & 16.49 & 21.1 \\
\hline $\begin{array}{l}\text { Right wall } \\
\text { Averaged heat flux to (below bull }\end{array}$ & MW & 20.46 & 20.14 & 21.19 & 23.81 & 21.54 \\
\hline Front wall & $\mathrm{MW} / \mathrm{m}^{2}$ & 0.078 & 0.090 & 0.075 & 0.079 & 0.069 \\
\hline Rear wall & $\mathrm{MW} / \mathrm{m}^{2}$ & 0.088 & 0.090 & 0.097 & 0.085 & 0.100 \\
\hline Left wall & $\mathrm{MW} / \mathrm{m}^{2}$ & 0.080 & 0.075 & 0.080 & 0.063 & 0.081 \\
\hline Right wall & $\mathrm{MW} / \mathrm{m}^{2}$ & 0.078 & 0.077 & 0.081 & 0.091 & 0.082 \\
\hline Liquor depostion & & & & & & \\
\hline Wall deposition rate & $\%$ & 57.234 & 59.150 & 56.617 & 56.123 & 57.425 \\
\hline Bed deposition & $\%$ & 8.386 & 4.337 & 7.277 & 5.263 & 7.164 \\
\hline In flight & $\%$ & 34.329 & 36.506 & 36.092 & 38.438 & 35.209 \\
\hline
\end{tabular}

None of the changes in air distribution or port geometry had a big effect on the distribution of liquor deposition on the walls. There were however, as shown in Fig. 53, some differences in the droplet trajectories. In mode 5 on 5 and 4 on 4, there are many small and medium droplets being entrained by downward flow along the front and the rear walls and reaching the areas around the primary air ports. In mode 3 on 3, very few small and medium droplets reach the primary air port.

There are some differences in the gas temperature and the heat flux between the four different modes of secondary air distribution. However, there is no clear correlation between the differences and the cracking issue. In comparison, the new air system creates more uniform distribution of gas temperature across the furnace and more uniform heat flux onto the walls than the existing air system.

The major difference between the five cases is the flow pattern and instability. Both the distribution of vertical velocity and the air flow animation show that the flow is not fully filling the cross section in the low and mid furnace and there is a big recirculation zone in the cases of 5 on 5 and 4 on 4 . For the case of 3 on 3 the flow is more uniform in the areas of the lower and mid furnace. By comparison, the new air system forms a much more stable and uniform flow in the furnace. Any small change in operational conditions should not create significant disturbance to the flow and therefore will not produce significant tube temperature excursions.

It is mentioned above that the secondary air ratio in these five cases is fairly low. As a result, to some extent the collision of the jets in the center of the boiler is reduced. If the secondary air ratio were as high as in "Case Before," it is expected that the different modes of secondary air distribution would make a more significant difference in how the boiler operates. 


\subsubsection{Modeling of Recovery Boiler-P and Recovery Boiler-A}

Boiler-P has the same type and the same load as Boiler-Q. The major differences between the two boilers are in the secondary air system, the tertiary air system, and the primary air port design. Figure 55 shows the secondary air system of Boiler $P$, which has four ports on each side wall interlaced. The tertiary air system of Boiler-P is shown in Fig. 56, which is a $3 \times 4$ front/rear system instead of a $4 \times 3$ front/rear system in Boiler-Q. The primary air port in Boiler-P has the same port width, taller port height, more sloped bottom $\left(30^{\circ}\right)$, and shorter casting as comparing with that in Boiler-Q. The model of Boiler-P is shown in Fig. 57. No serious cracking was reported in this boiler.

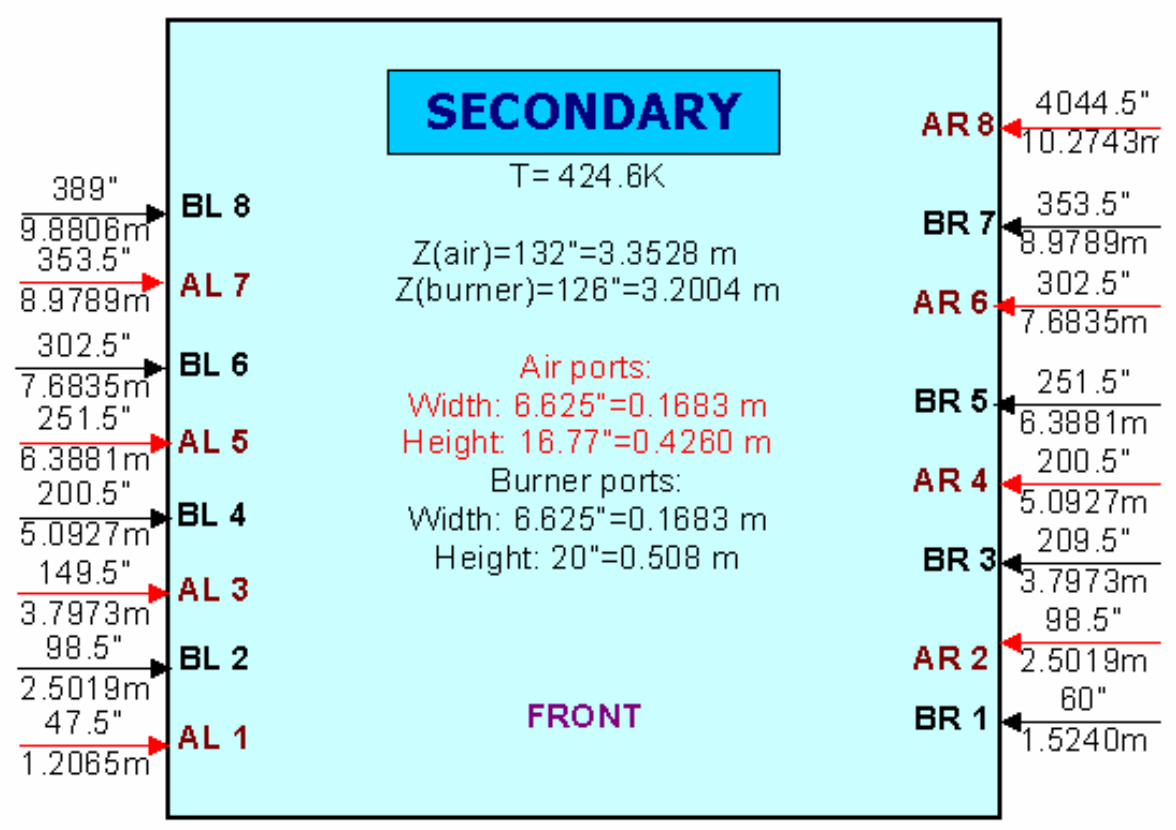

Fig. 55. Secondary air system of Boiler-P.

Boiler-A is from a different manufacture and has a different design. Figures 58 to 60 show the air systems of primary, secondary and tertiary, respectively. Primary air ports are on four walls, with 36 ports on each wall. The port is designed narrower and taller compared to those in Boiler-Q and Boiler-P. The secondary uses a four-wall system, consisting of 64 small ports. The tertiary air system is an $18 \times 18$ front/rear system. The model of Boiler-A is shown in Fig. 61. No serious cracking issues have been reported in this boiler.

Some of the modeling results of boilers $\mathrm{P}$ and $\mathrm{A}$ are presented in the following figures and are compared with those of Boiler-Q using cases that should permit meaningful comparisons. The vertical velocity distribution in Fig. 62 and the air animation pictures in Fig. 63 show significant differences of flow pattern in three boilers. The four-wall secondary air system in Boiler-A forms a strong upward flow in the boiler center, but the upward flow starts off center above the tertiary level. The flow in the lower furnace looks uniform and stable, but the strong upward flow creates a very high carryover. The interlaced $4 \times 4$ secondary air system in Boiler-P forms less jet collision in the lower furnace compared to non-interlaced secondary air system in Boiler-Q. As a result, the flow in the low furnace distributes more uniformly and looks more stable than that in Boiler-Q. 


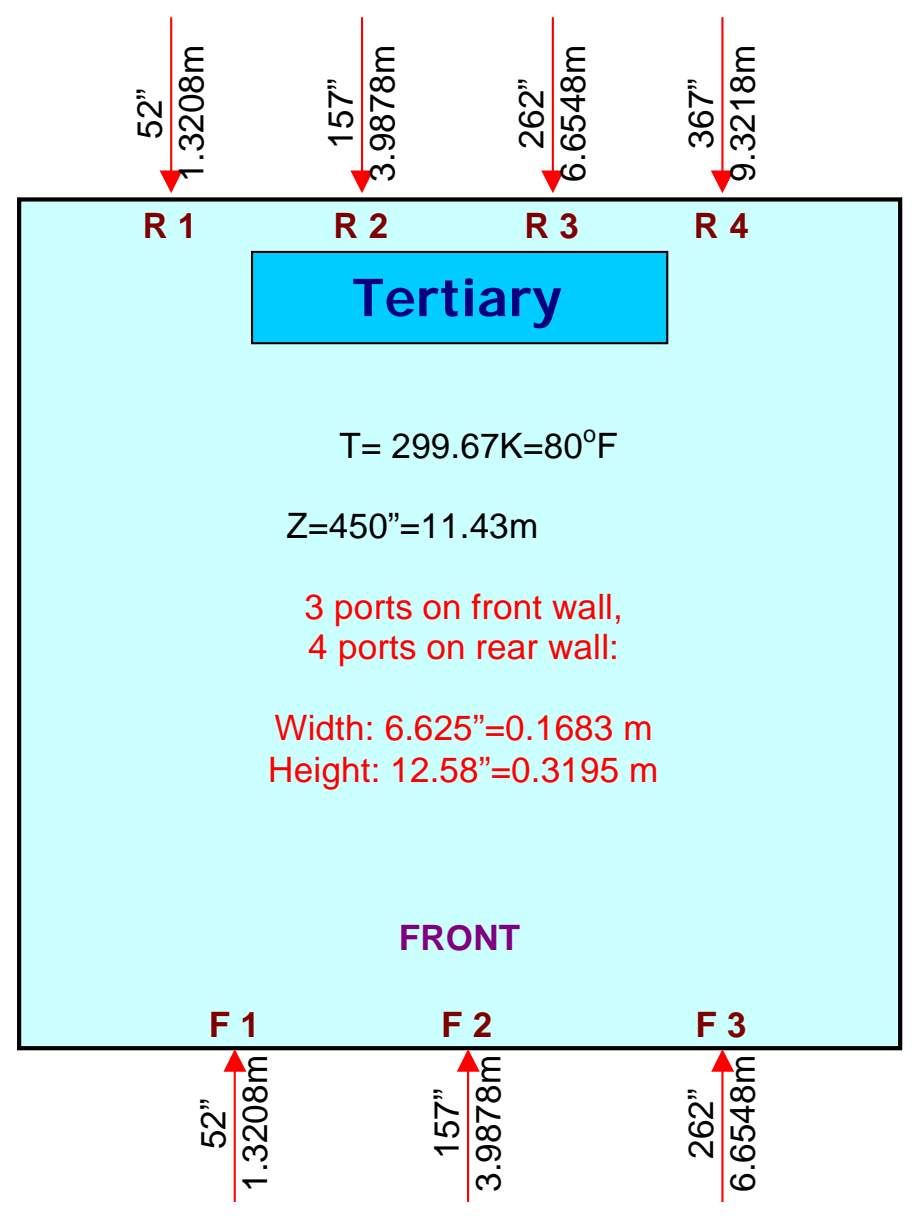

Fig. 56. Tertiary air system of Boiler-P. 


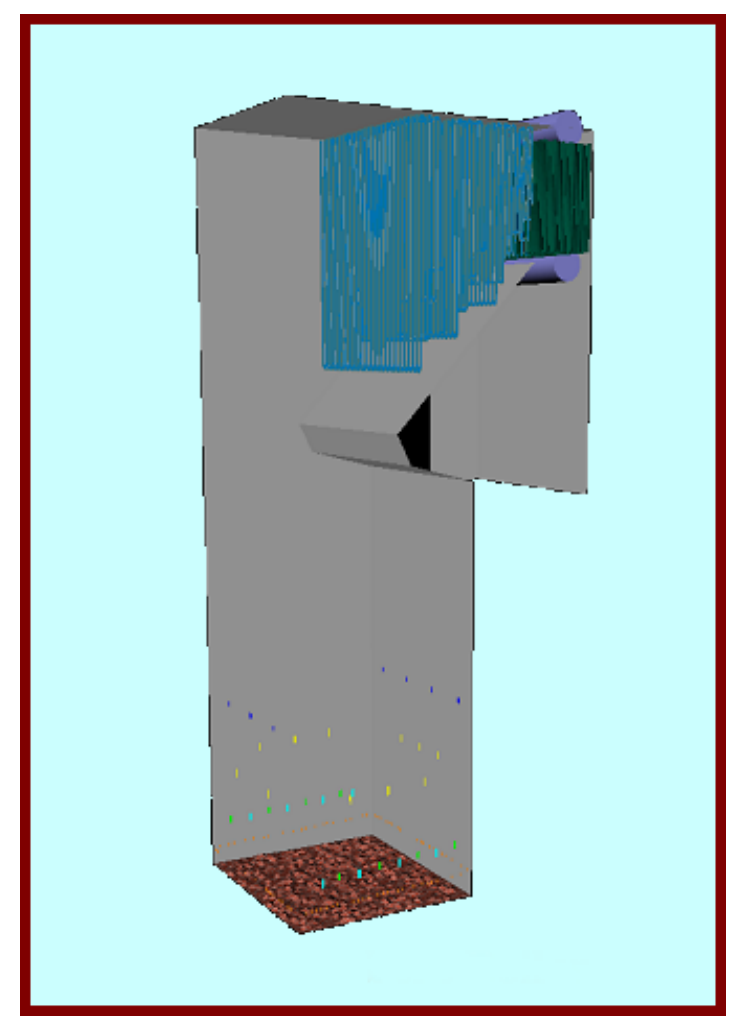

Fig. 57. Model of Boiler-P.

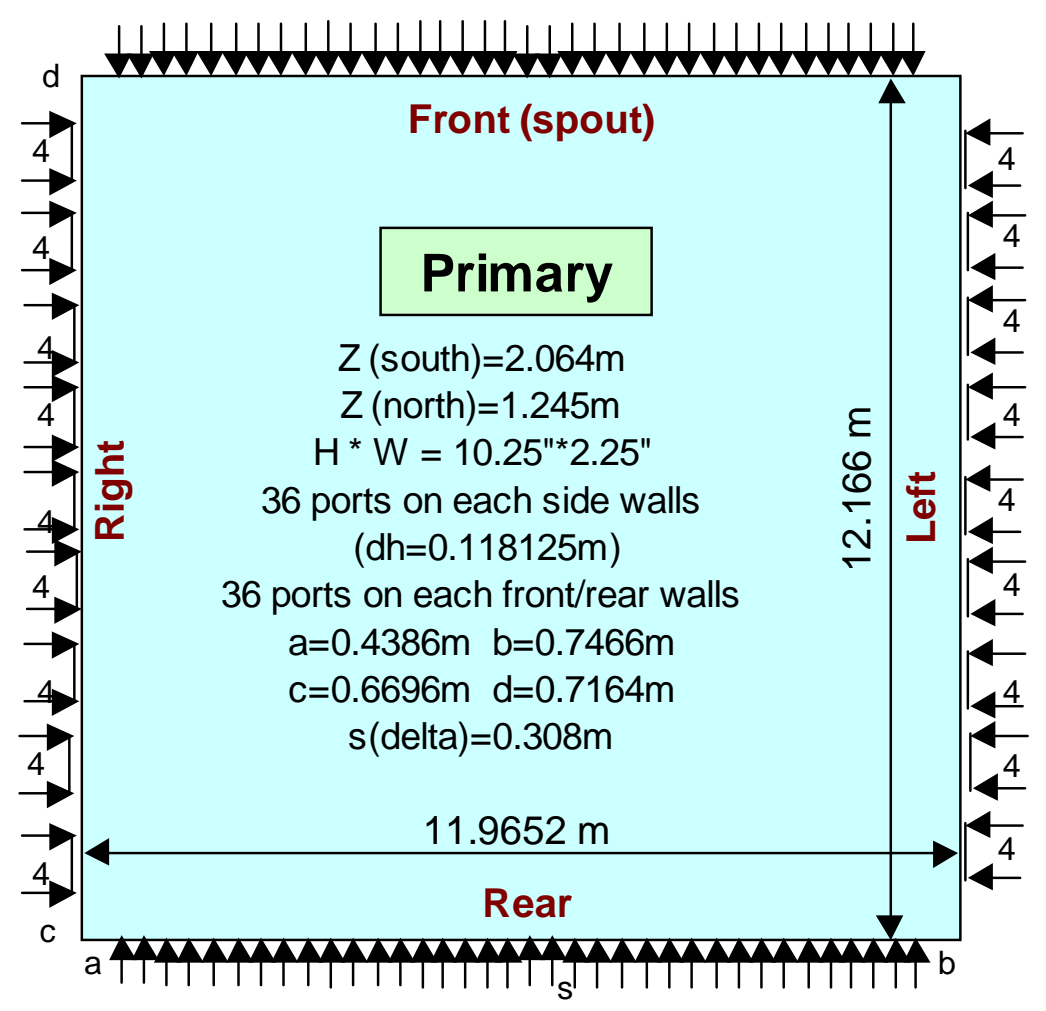

Fig. 58. Primary air system of Boiler-A. 


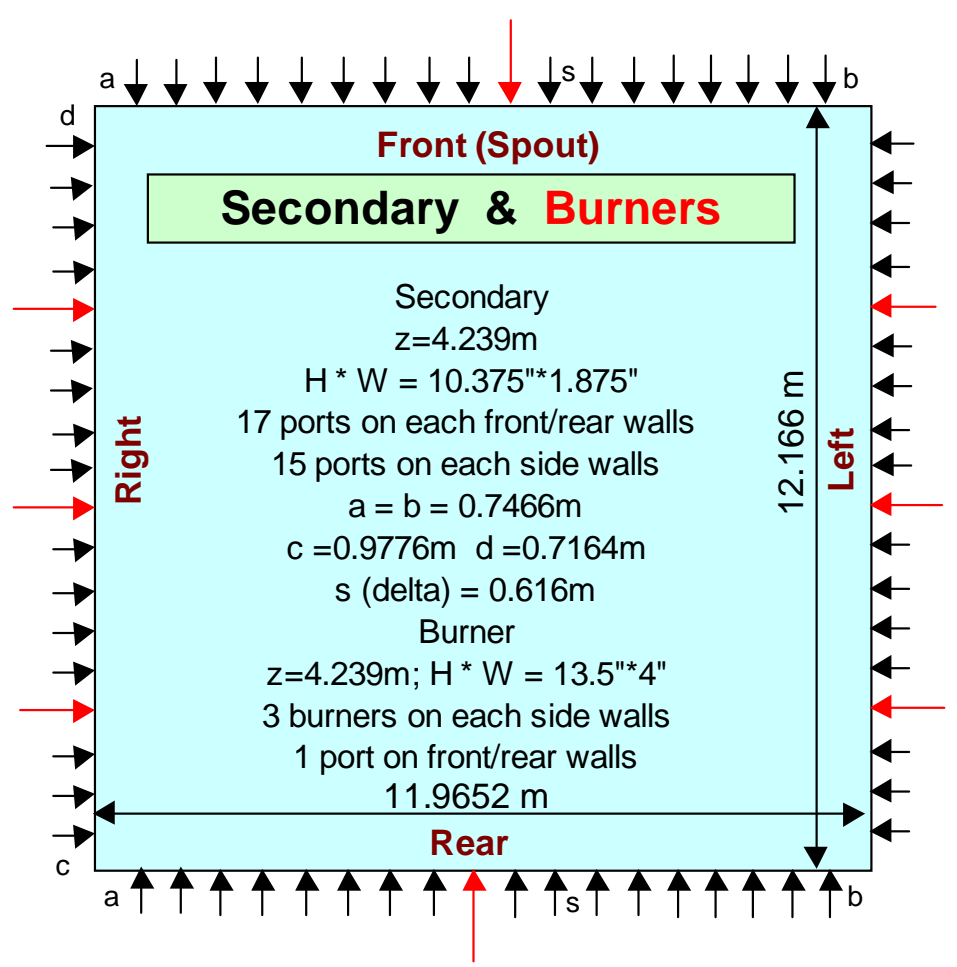

Fig. 59. Secondary air system of Boiler-A.

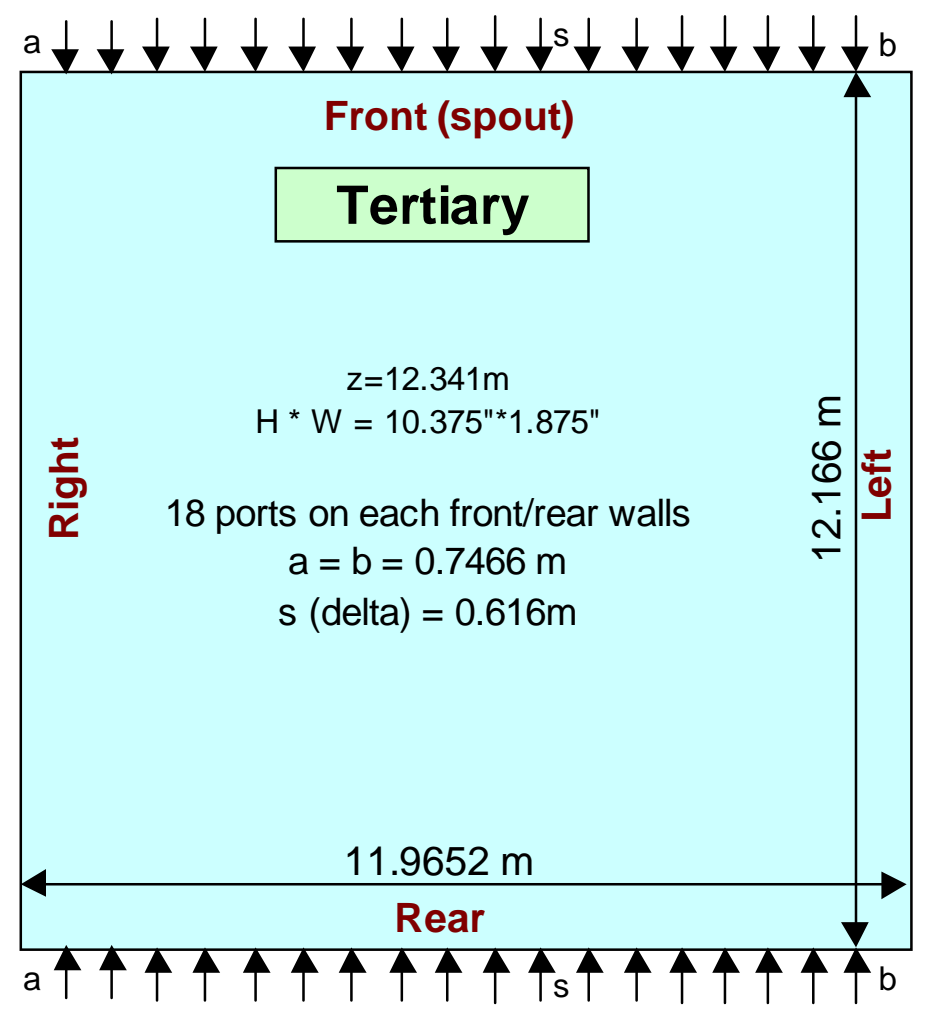

Fig. 60. Tertiary air system of Boiler-A. 


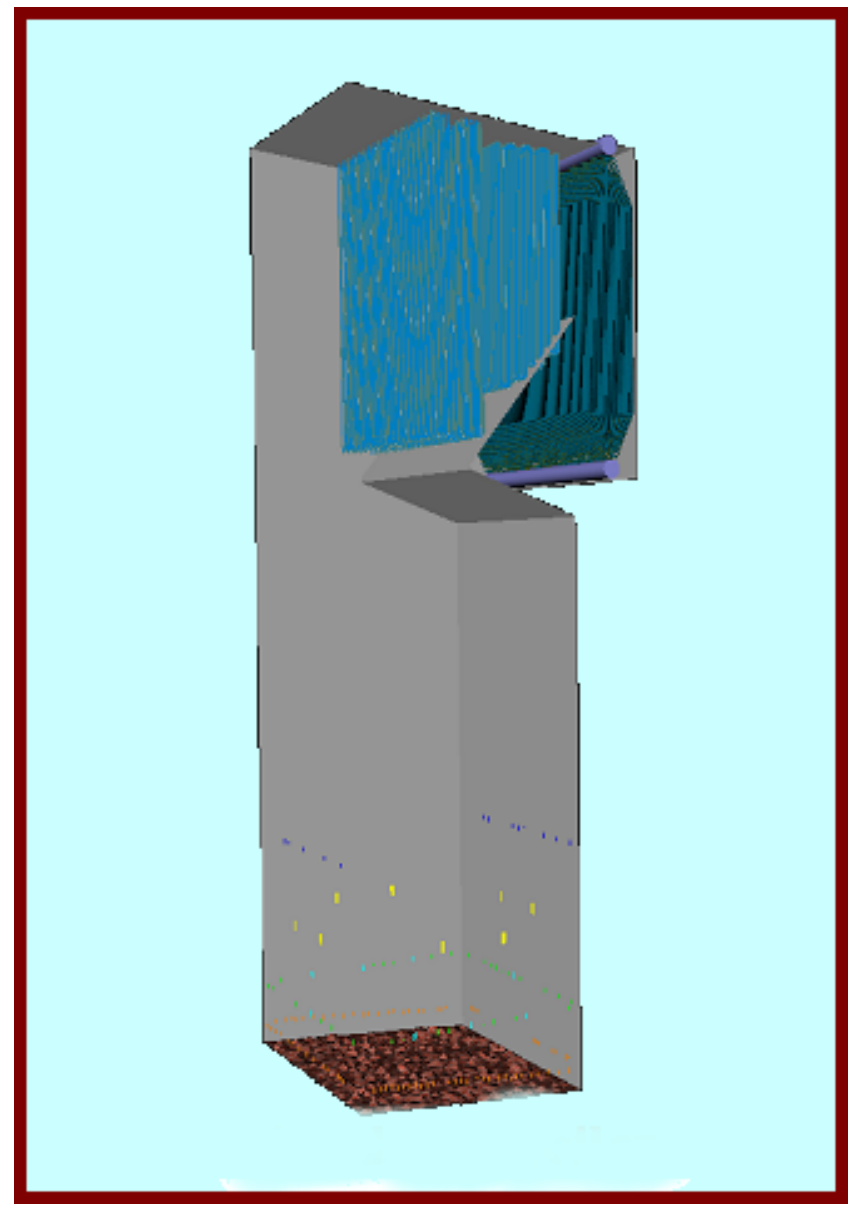

Fig. 61. Model of Boiler-A. 


\section{Case 15}

$\stackrel{\infty}{\perp}$

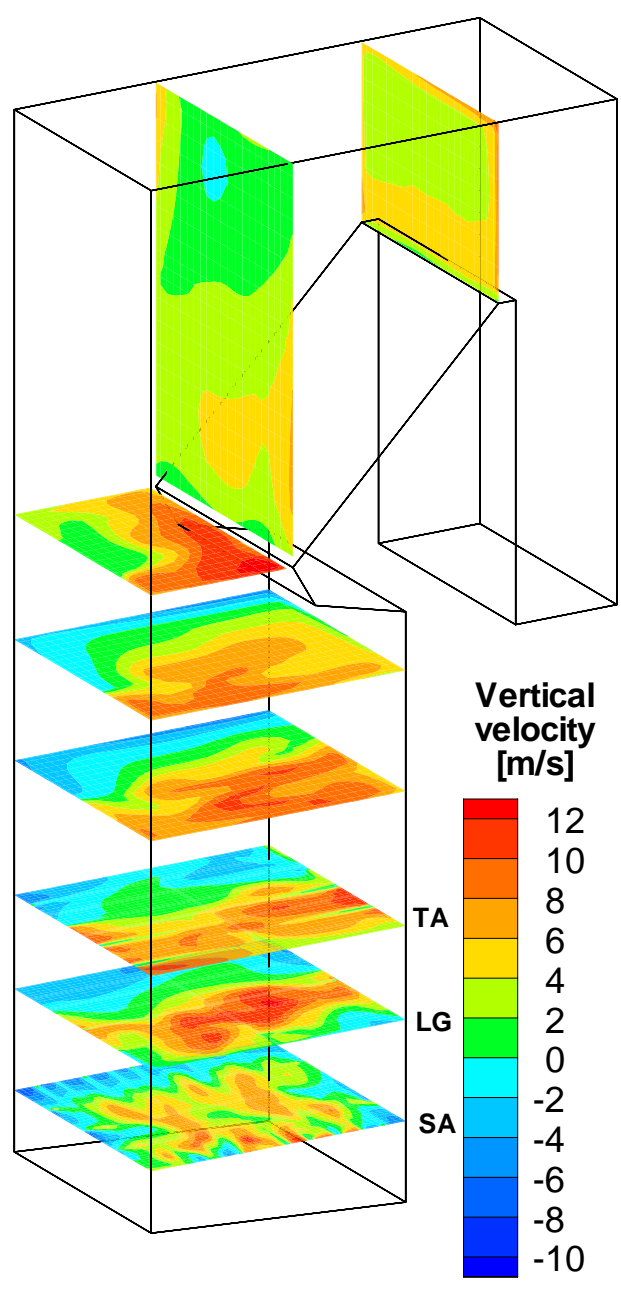

Boiler-Q

\section{Case 2}

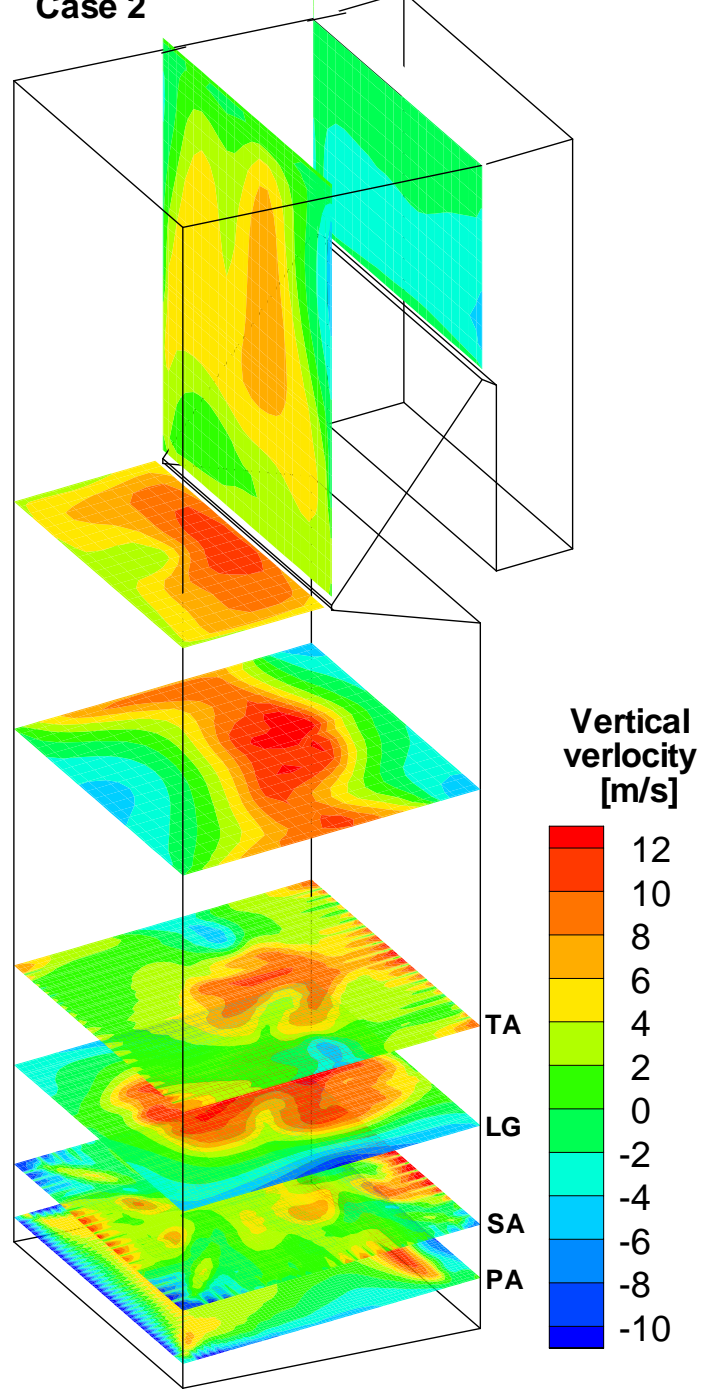

Boiler-A

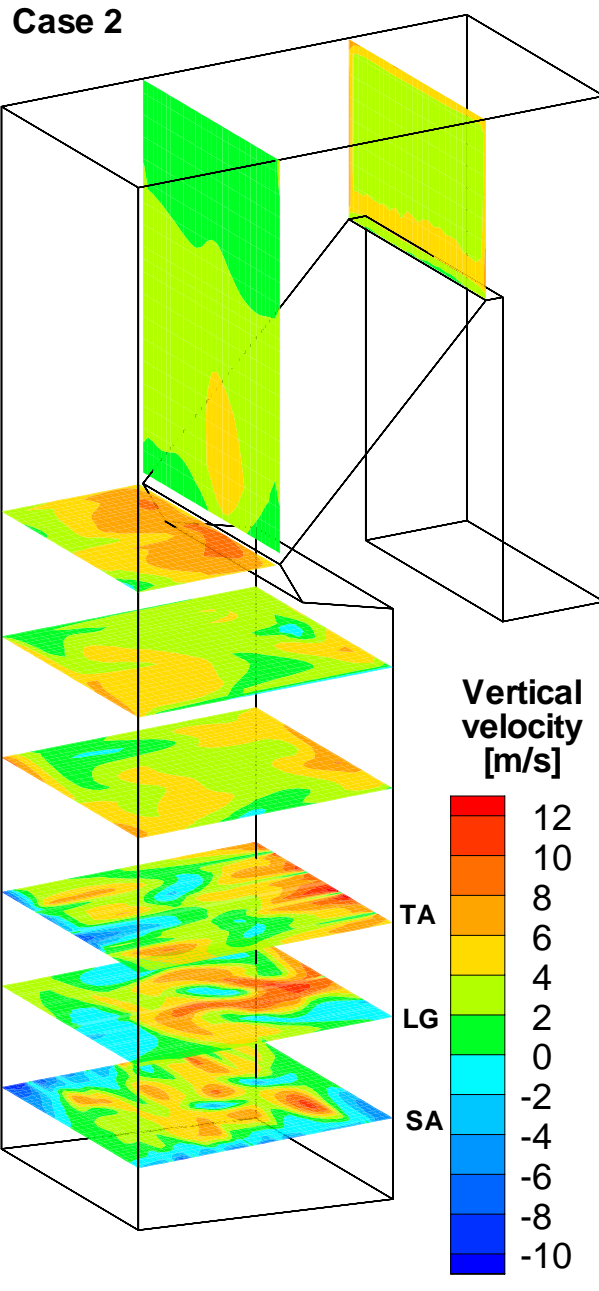

Boiler-P

Fig. 62. Vertical velocity distributions in three boilers. 


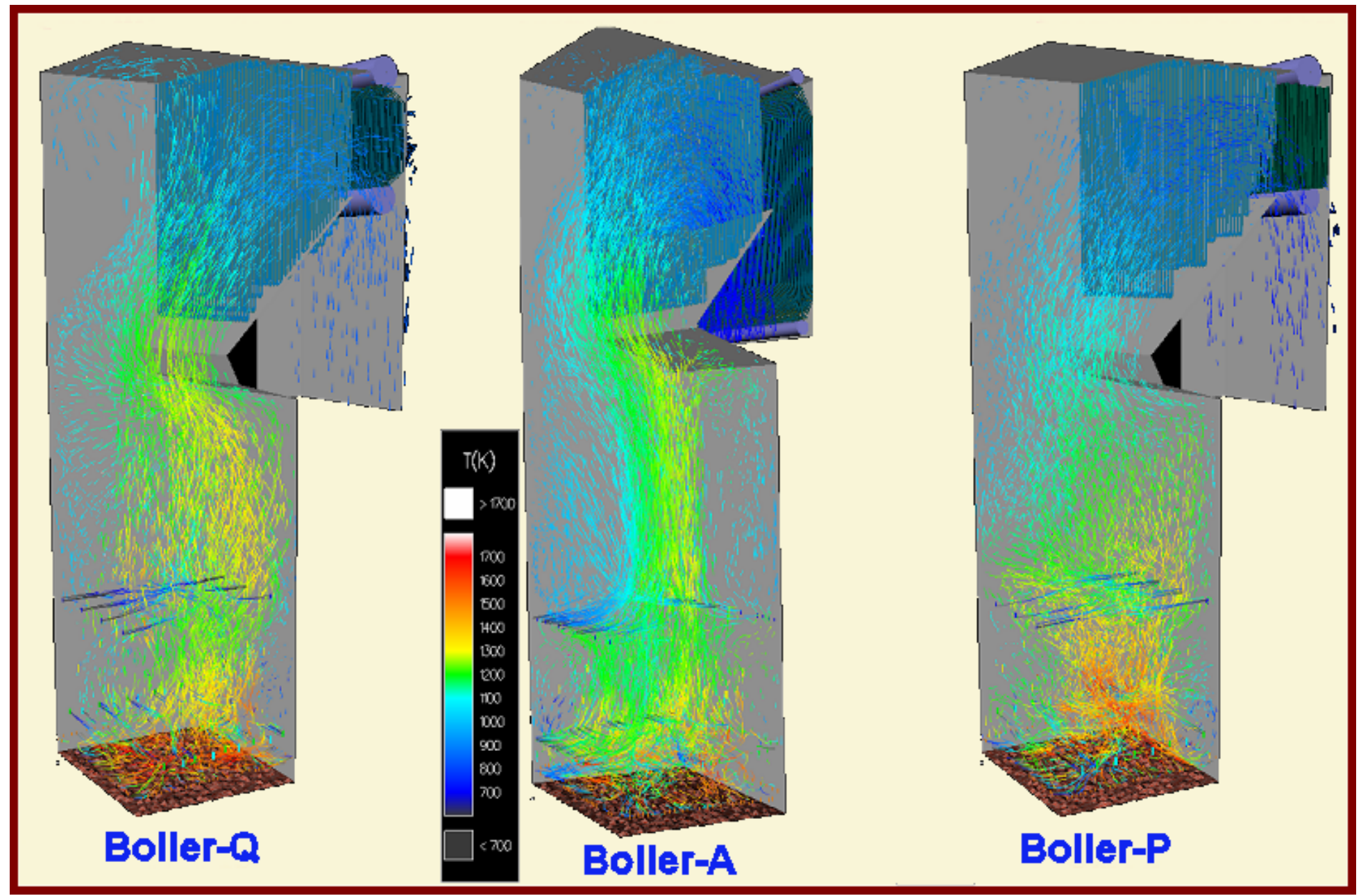

Fig. 63. Air flow animations in three boilers. 
The gas temperature distribution in Fig. 64 also shows a more uniform combustion in Boiler-P. The temperature distribution around primary air ports on the rear wall and one of the side walls for each boiler is shown in Figs. 65 and 66. It is seen here that Boiler-Q has the higher gas temperature around the primary air ports, especially below the ports. The next subsection describes how the design of the air port impacts gas temperatures.

The liquor deposition on the walls is shown in Fig. 67. Boiler-Q is significantly higher than that in the other two boilers. It is important to note that both Boiler-Q and Boiler-P use four liquor guns and splash plates and have the same size and location of liquor gun ports. Moreover, the liquor size distribution was the same in the modeled cases. Due to these geometric similarities, the significant difference in liquor deposition rate between Boiler-Q and Boiler-P should contribute to the aerodynamics in the low and mid furnace. Boiler-A has the lowest deposition rate among the three boilers. The four-wall secondary air jets push liquor droplets away from the walls. However, many droplets are entrained by the strong upward flow causing very high carryover.

\subsection{MODELING OF SELECTED PRIMARY AIR PORTS}

As discussed earlier, the primary air port design and fabrication could be a cause of the cracking. Different air port designs could make differences in the aerodynamics and local gas environment around the air port. In the global boiler modeling, each primary air port is simplified as an inlet patch to the boiler with a uniform velocity distribution across it. The simplification is acceptable for the whole boiler modeling, but it does not completely show the impact of air port design on the local environment around the air port. To investigate the impact of air port design, selected primary air ports were modeled in some detail and were coupled with the global boiler modeling.

Three different air port designs were selected for the numerical study since they were installed in Boiler-Q for comparison. Table 11 shows the simulation conditions, and Fig. 68 shows the sketch of three designs. Compared to Design A, Design B has the same port width, taller height, larger sloped angle, and shorter casting. Design $\mathrm{C}$ has a narrower and taller port compared to Design A and Design B. Moreover, Design A has a $15^{\circ}$ slope, Design B has a $30^{\circ}$ slope, while Design C has a $20^{\circ}$ slope. Fig. 69 shows two examples of the model of single air port and boiler.

\subsubsection{Comparison between Different Designs at Same Location}

The single air port model is coupled with the global boiler model at the same location on the front wall for Design A and Design B, respectively. The modeling results, illustrated in Fig. 70, indicate that Design A has a strong recirculation below the air jet, which brings high temperature gas back to the bottom of the port. The strong recirculation favors a build up of the char bed below the air port, which is linked with temperature fluctuation. The predicted oxygen distribution reveals possible combustion in the bottom area of the port.

Design A and Design C were modeled at the same location on the right wall. Fig. 71 shows the local flow field and environment around the air port. Comparing both designs, Design $\mathrm{C}$ has less recirculation and therefore less high-temperature gas going back toward the bottom of the port.

\subsubsection{Comparison of Same Design between Different Locations}

As seen in Figs. 70 and 71, Design A has a strong recirculation at the two locations on the front wall and the right wall. One more location on the right wall is also modeled, and the modeling shows a similar strong recirculation. The difference between different locations is the maximum temperature at the bottom to the port. The temperature inside the port reaches $1780^{\circ} \mathrm{K}$ at the location of front wall, and $1490^{\circ} \mathrm{K}$ and $1120^{\circ} \mathrm{K}$, respectively, at the two locations of right wall. 


\section{Case 15}

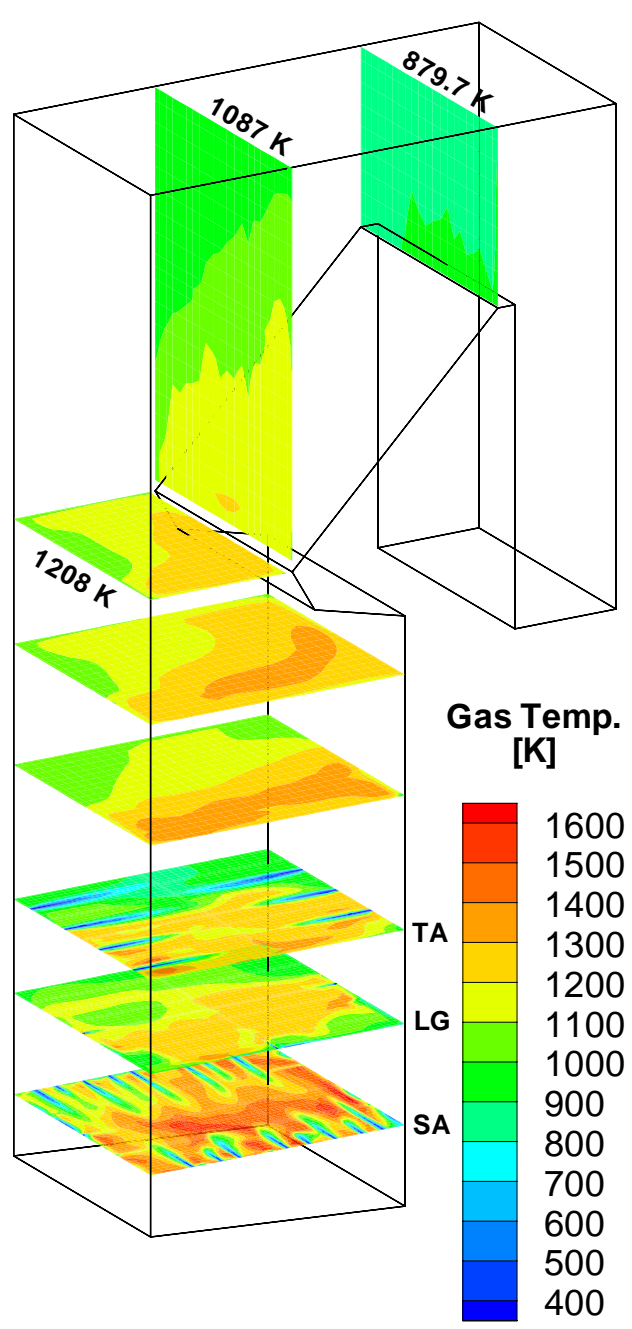

Boiler-Q

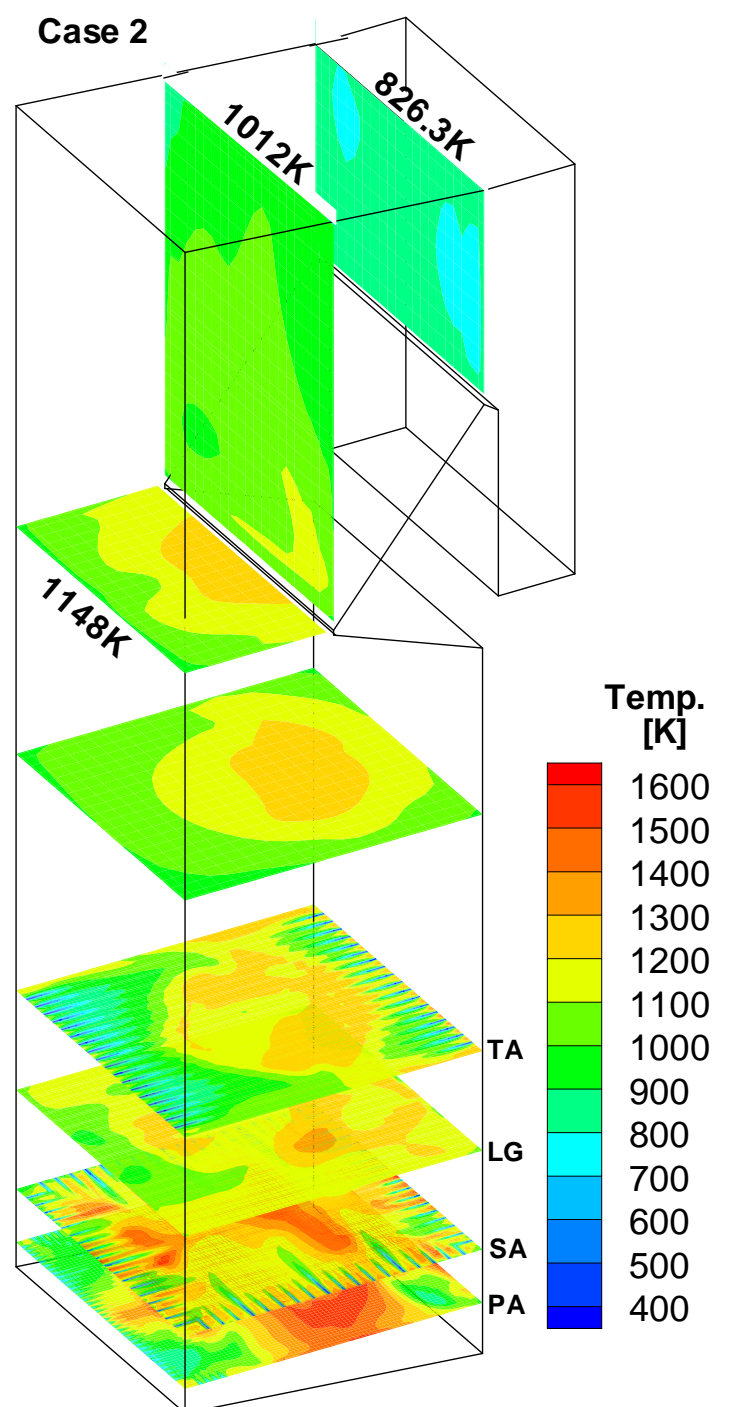

Boiler-A

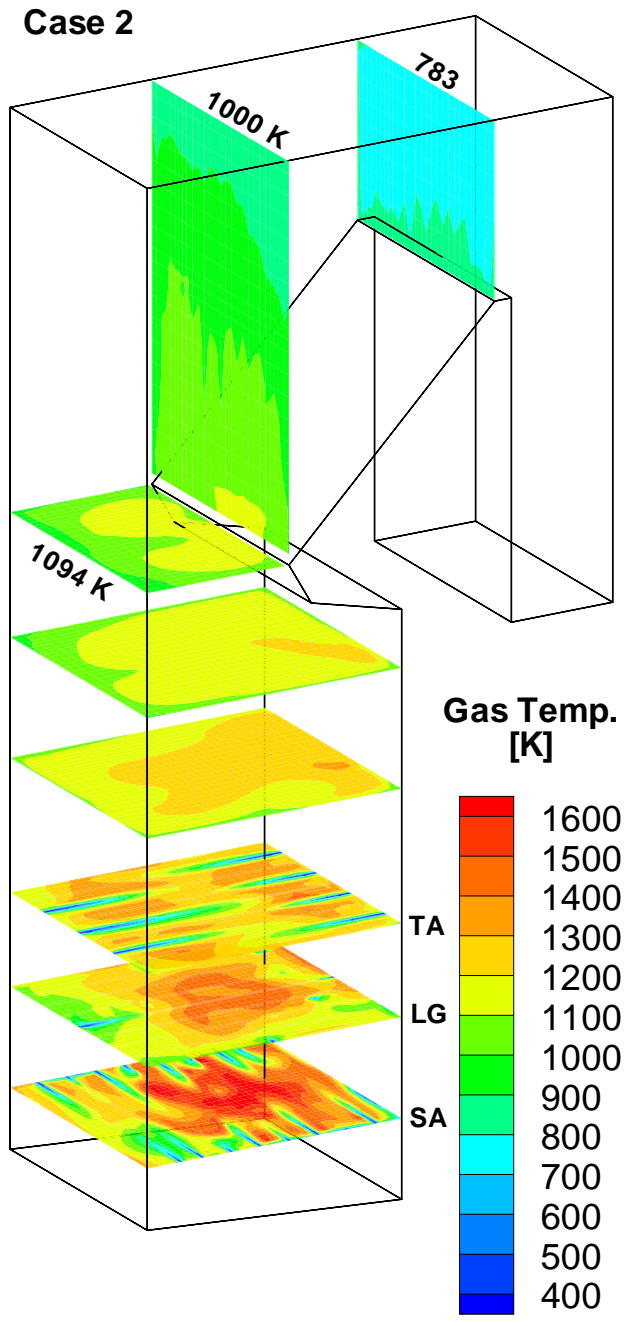

Boiler-P

Fig. 64. Gas temperature distributions in three boilers. 


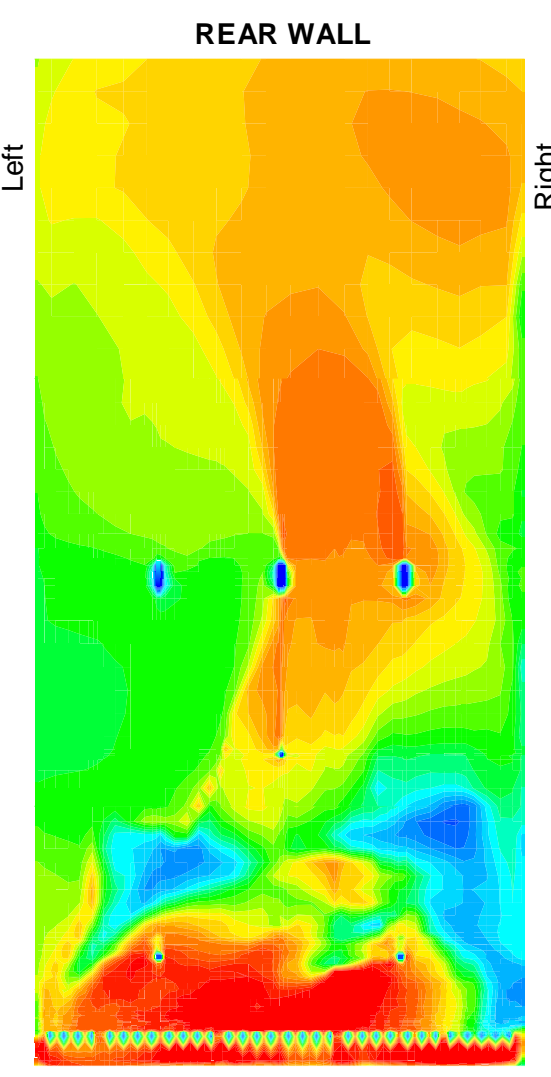

Near Wall Temperature (Case 15)

Boiler-Q

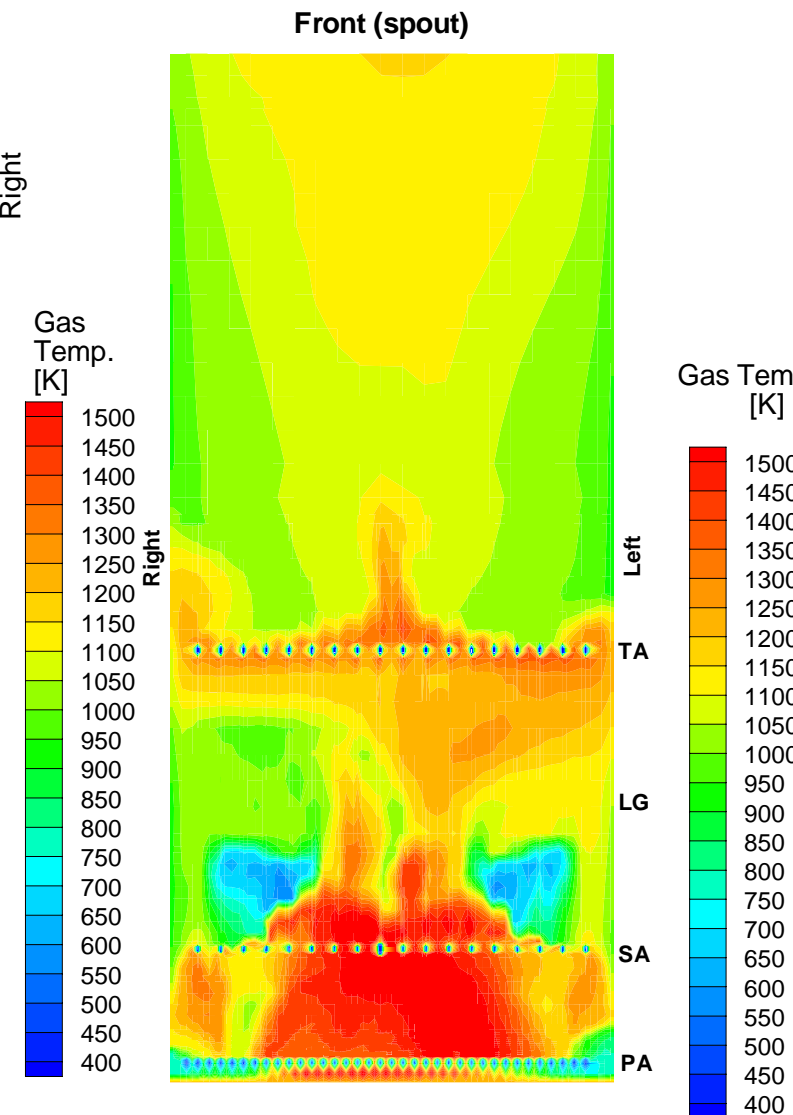

Near Wall Temperature

$$
\text { (Case 2) }
$$

Boiler-A

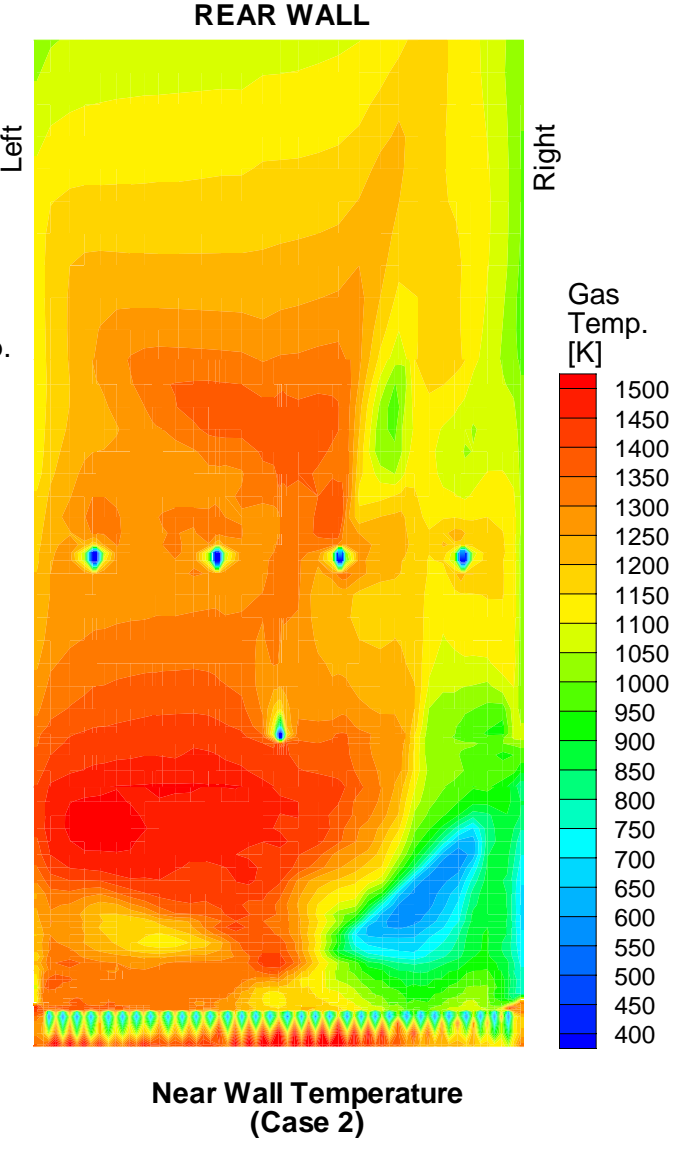

Boiler-P

Fig. 65. Gas temperature near the spout wall in three boilers. 

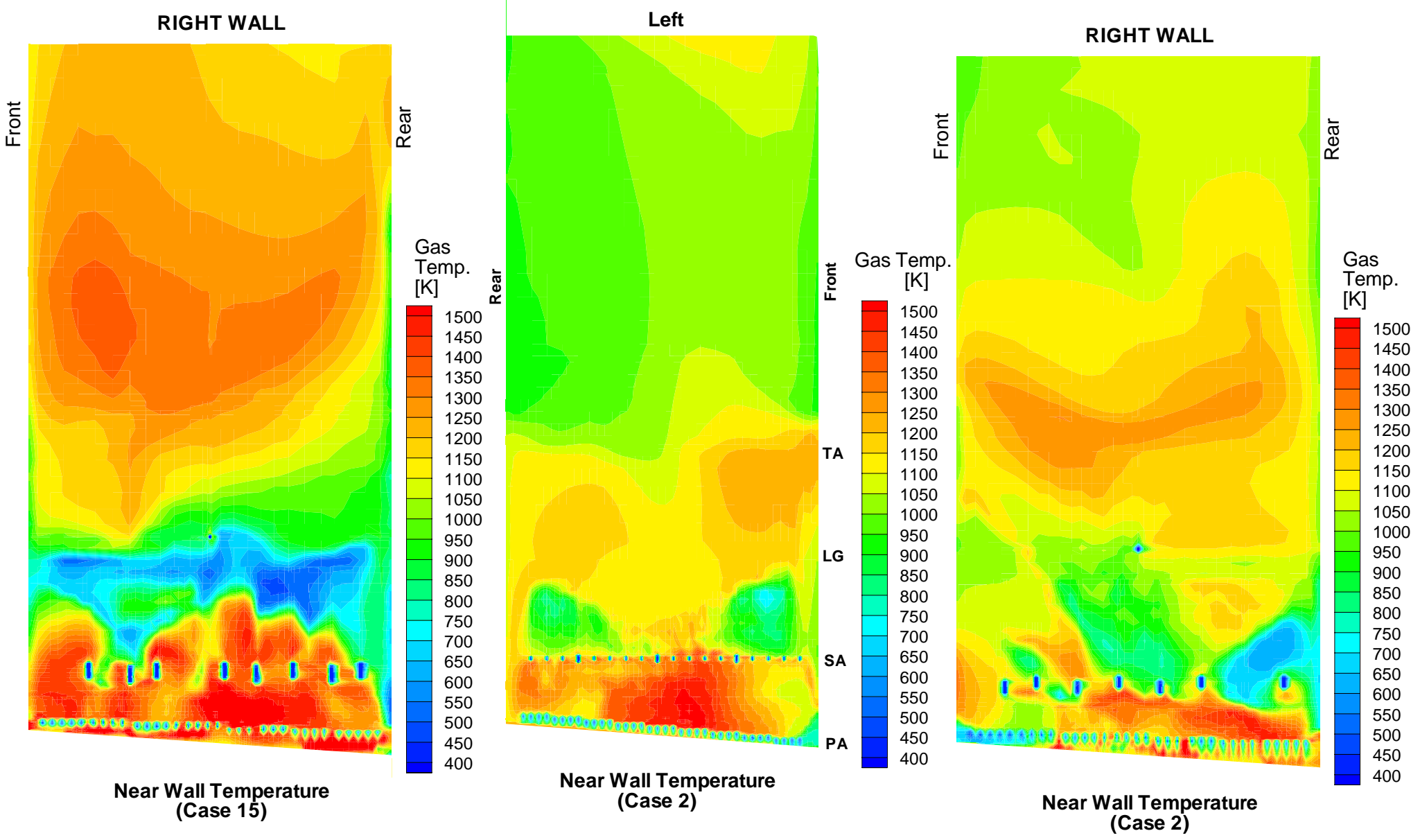

Boiler-Q

Boiler-A

\section{Boiler-P}

Fig. 66. Gas temperature near one side wall in three boilers. 

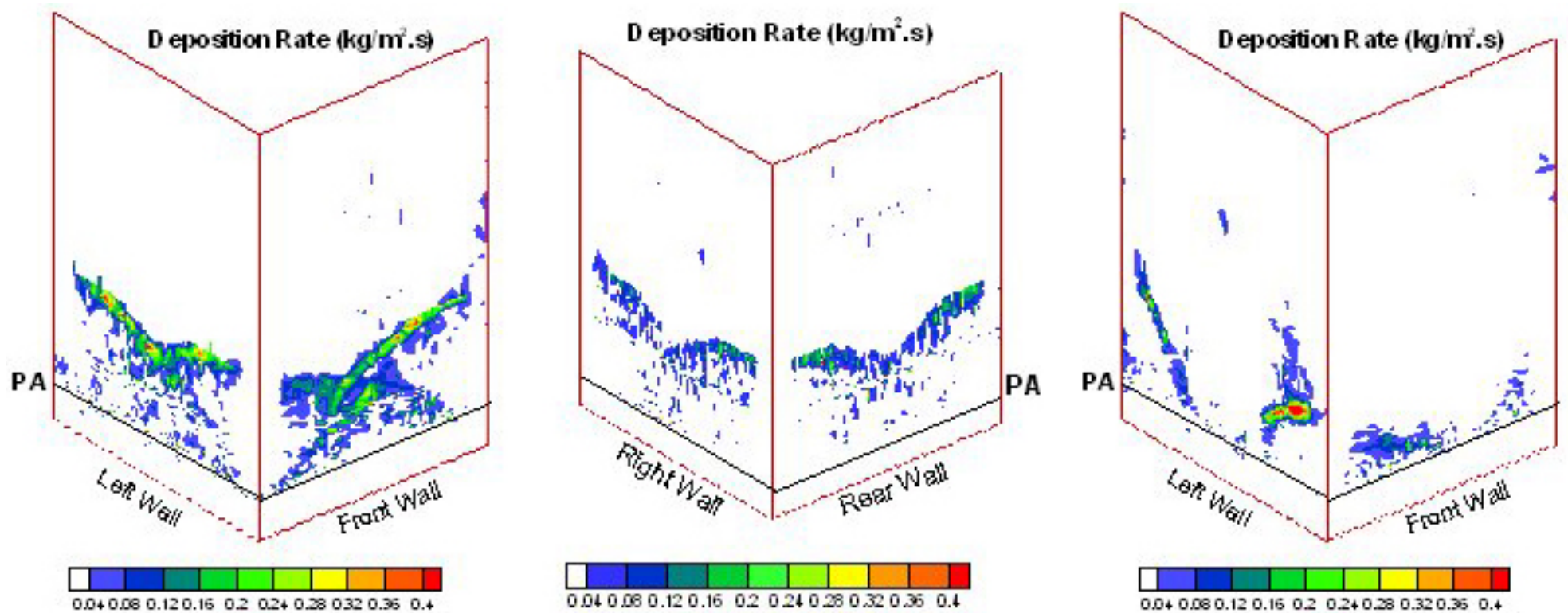

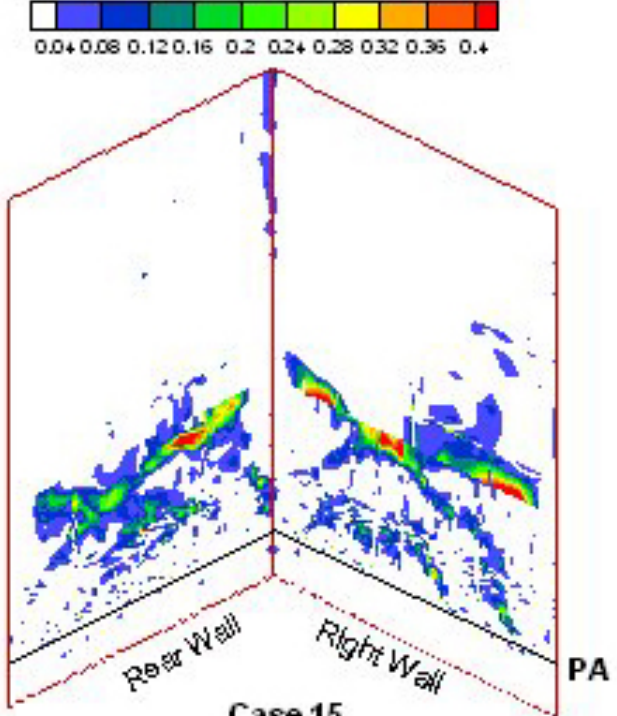

Boiler-Q

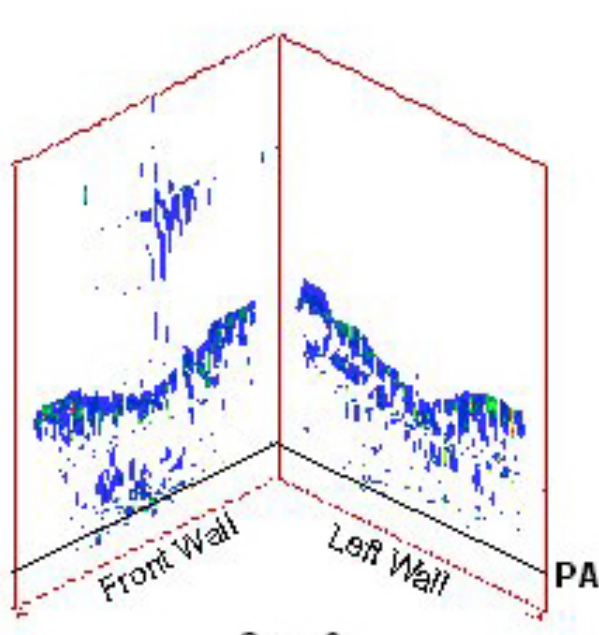

Boiler-A ${ }^{2}$

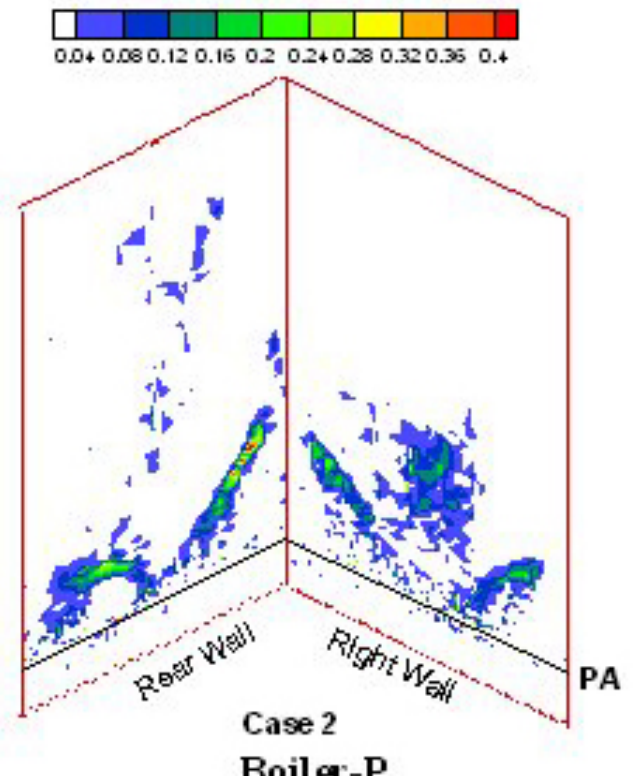

Boiler-P

Fig. 67. Liquor deposition on the walls in three boilers. 
Table 11. Simulation conditions of three recovery boilers

\begin{tabular}{|c|c|c|c|c|}
\hline & & Boiler-Q & Boiler-F & Boiler-A \\
\hline & & Case 15 & Case 2 & Case 2 \\
\hline Secondary air distribution & & 5 on 5 (L) & 4 on 4 & 4 walls \\
\hline Char bed & & flat & Flat & Flat \\
\hline Liquor gun number & & \#28 & \#34 & 8 \\
\hline Mean droplet size & $\mathbf{m m}$ & 2.5 & 2.5 & 2.5 \\
\hline Total forced air flow & $\mathrm{kg} / \mathrm{hr}$ & 383,599 & 376,869 & 446,342 \\
\hline Primary air flow & $\mathrm{kg} / \mathrm{hr}$ & 135,232 & 127,570 & 153,317 \\
\hline Primary air ratio of forced air & $\%$ & $35.3 \%$ & $33.9 \%$ & $34.3 \%$ \\
\hline Primary air temperature & ${ }^{\circ} \mathrm{C}$ & 150 & 156 & 138 \\
\hline Secondary air flow & $\mathrm{kg} / \mathrm{hr}$ & 143,705 & 139,355 & 179,626 \\
\hline Secondary air ratio of forced air & $\%$ & $37.5 \%$ & $37.0 \%$ & $40.2 \%$ \\
\hline Secondary air temperature & ${ }^{\circ} \mathrm{C}$ & 150 & 152 & 142 \\
\hline Tertiary air flow & $\mathrm{kg} / \mathrm{hr}$ & 104,662 & 109,944 & 113,400 \\
\hline Tertiary air ratio of forced flow & $\%$ & $27.3 \%$ & $29.2 \%$ & $25.4 \%$ \\
\hline Tertiary air temperature & ${ }^{\circ} \mathrm{C}$ & 30 & 34 & 23 \\
\hline Total air leakage & $\mathrm{kg} / \mathrm{hr}$ & 3,154 & 3,150 & 0 \\
\hline Liquor gun port air leakage & kg/hr & 3,152 & 3,150 & 0 \\
\hline Smelt spout air leakage & $\mathrm{kg} / \mathrm{hr}$ & 2 & 0 & 0 \\
\hline Air temperature & ${ }^{\circ} \mathrm{C}$ & 30 & 34 & 29 \\
\hline Total air flow rate & $\mathrm{kg} / \mathrm{hr}$ & 386,753 & 380,019 & 446,342 \\
\hline Excess air ratio & $\%$ & $17.0 \%$ & $29.0 \%$ & $34.3 \%$ \\
\hline Black liquor feed rate & kgDS/hr & 77,099 & 69,681 & 88,830 \\
\hline Black liquor nozzle type & & Splash & Splash & Splash \\
\hline Number of liquor guns & & 4 & 4 & 8 \\
\hline Steam generation & $\mathrm{kg} / \mathrm{hr}$ & 250,000 & 250,000 & 306,627 \\
\hline Operation pressure & $\mathrm{kPa}$ & 8,690 & 8,690 & 5840 \\
\hline Operation temperation & ${ }^{\circ} \mathrm{C}$ & 480 & 480 & 447 \\
\hline
\end{tabular}



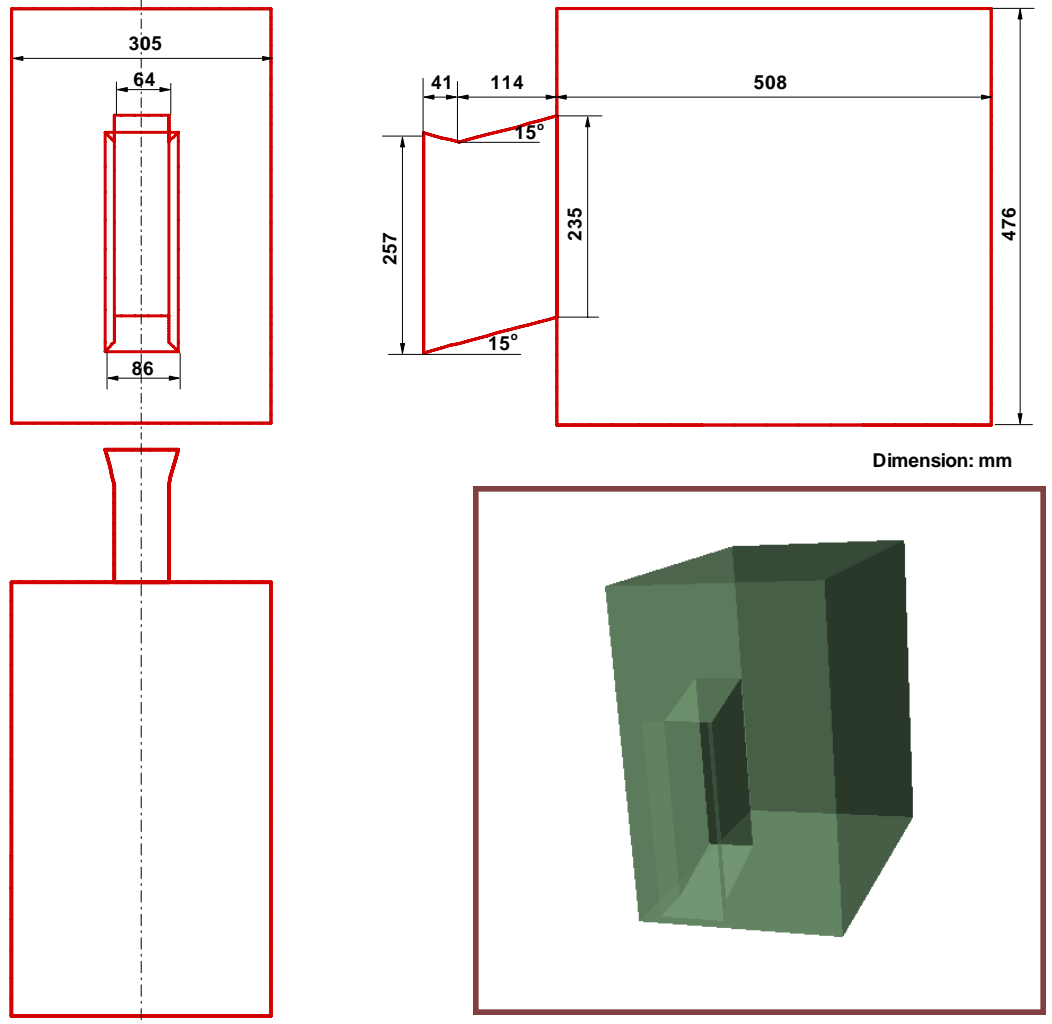

(a) Design A
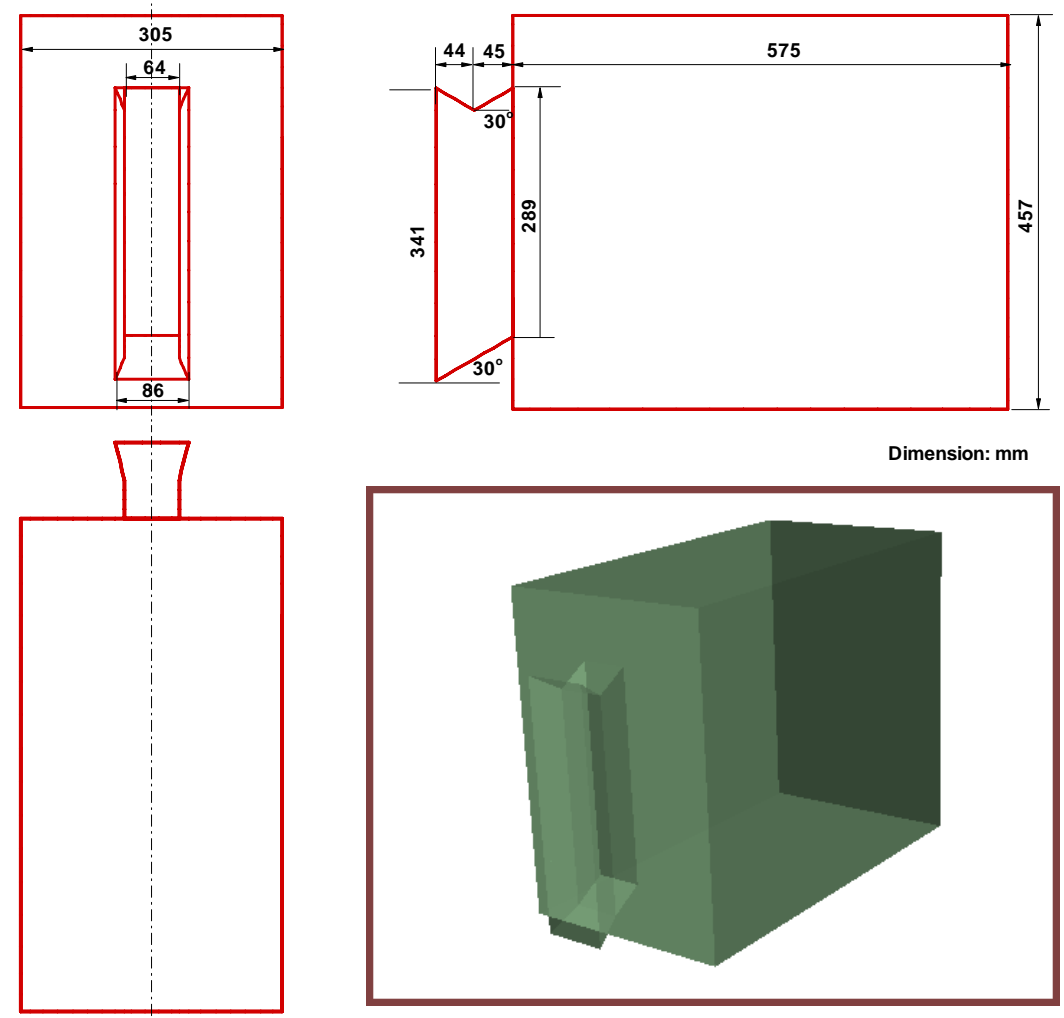

(b) Design B

Fig. 68. Three different air port designs. 

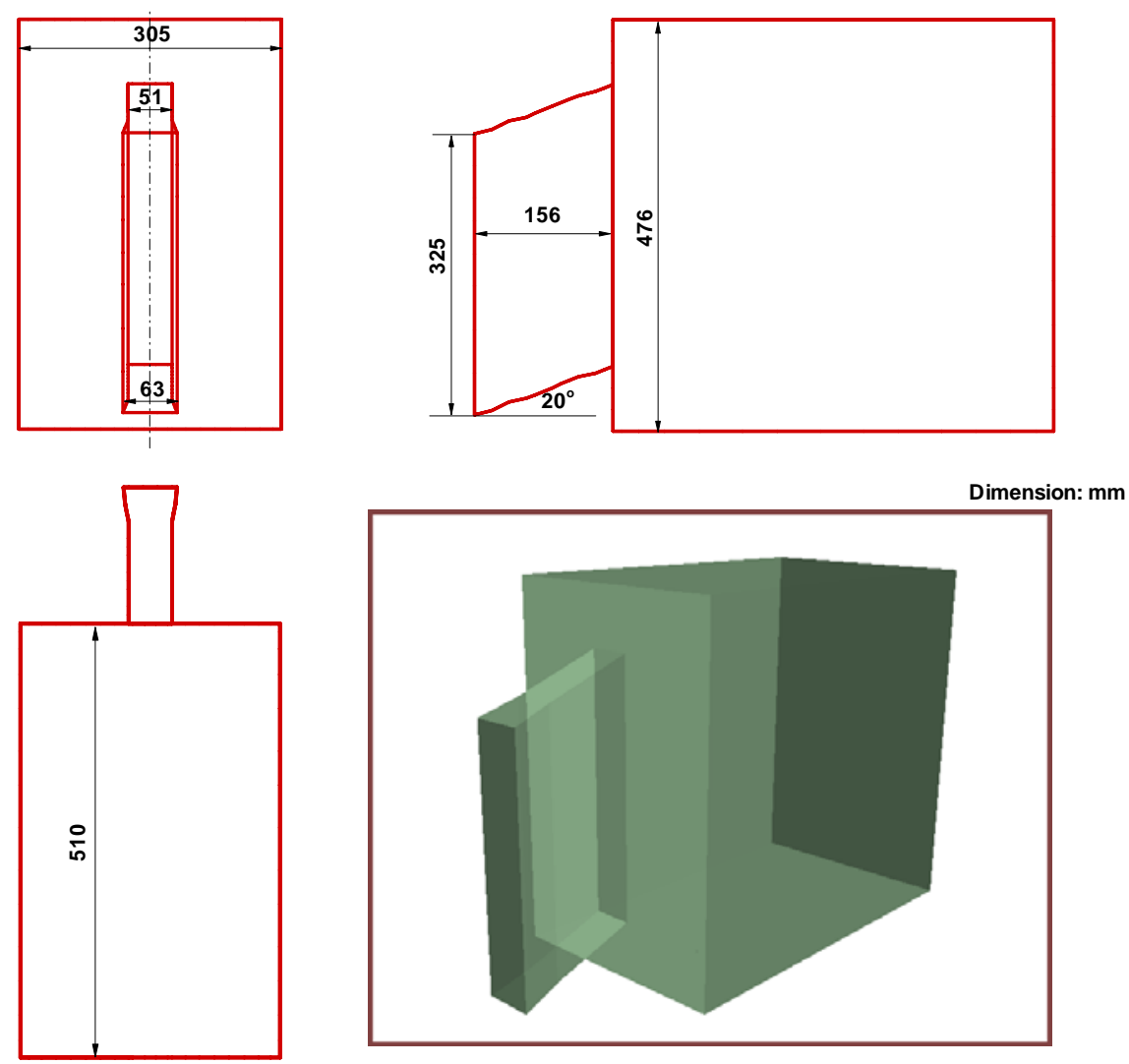

(c) Design C

Fig. 68. (continued). 

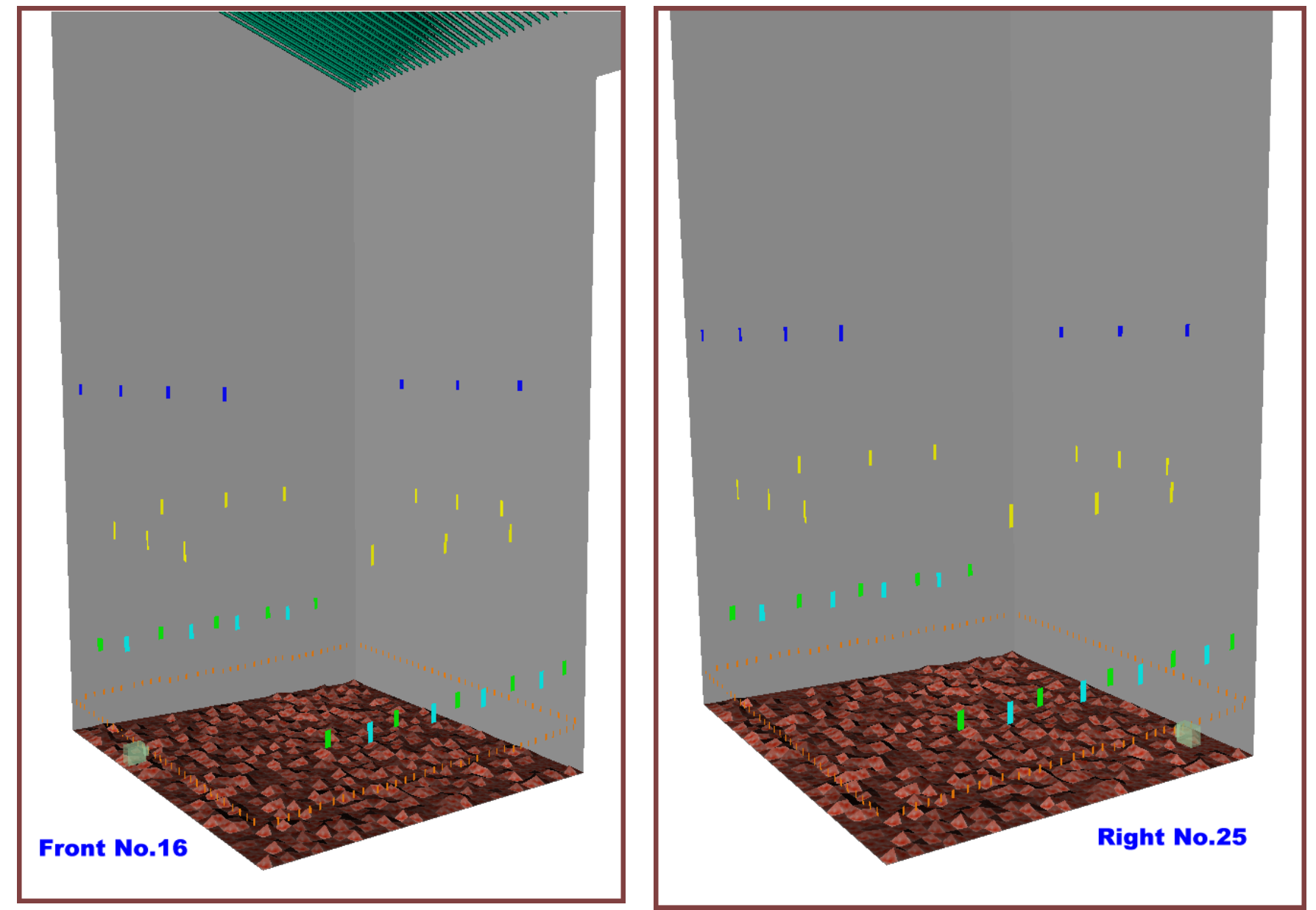

Fig. 69. Models of single air port and boiler. 

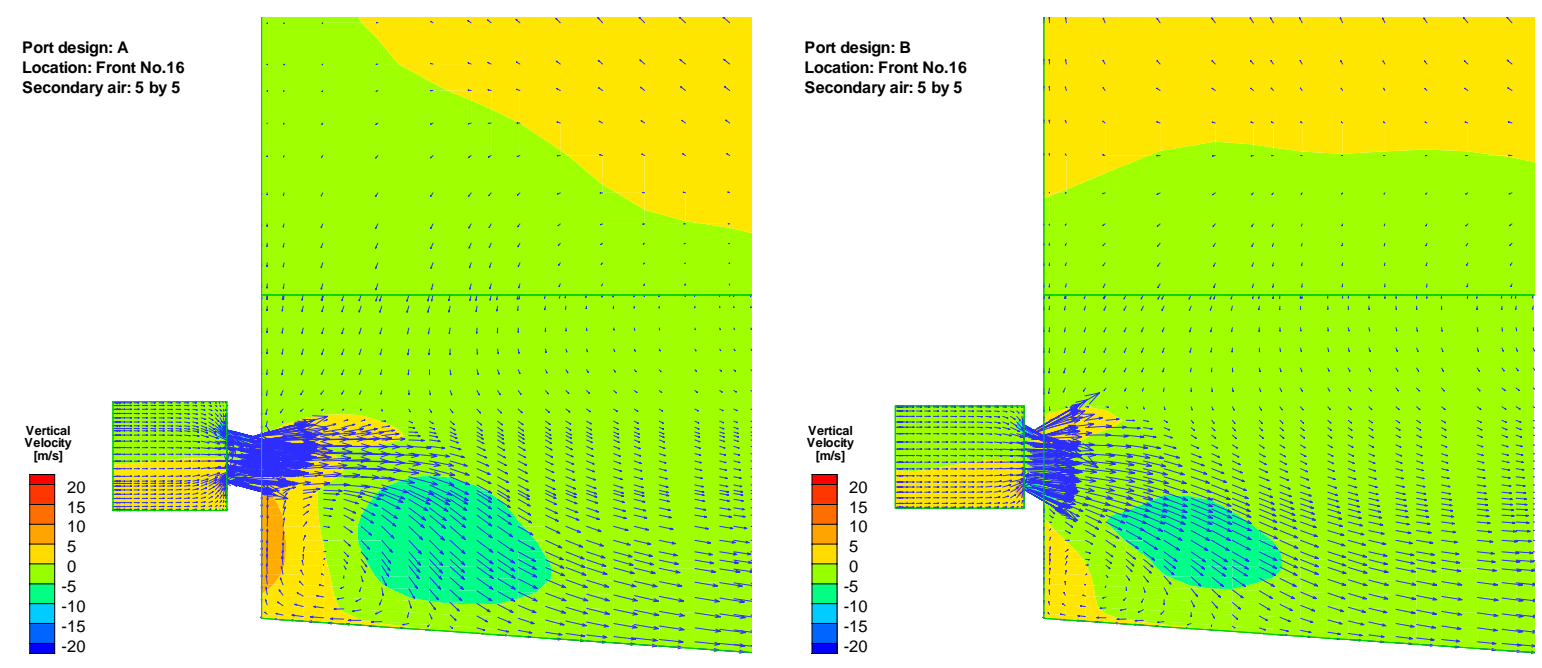

(a) Velocity

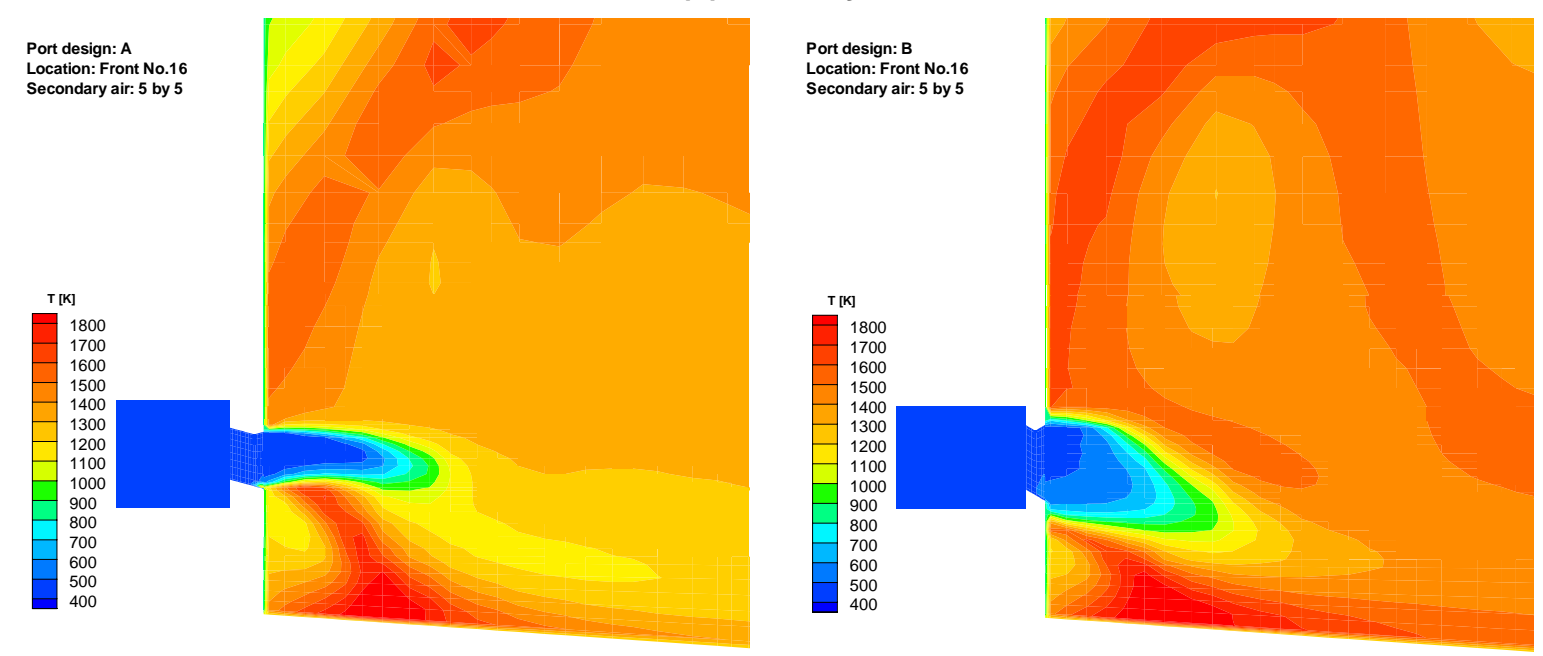

(b) Gas temperature

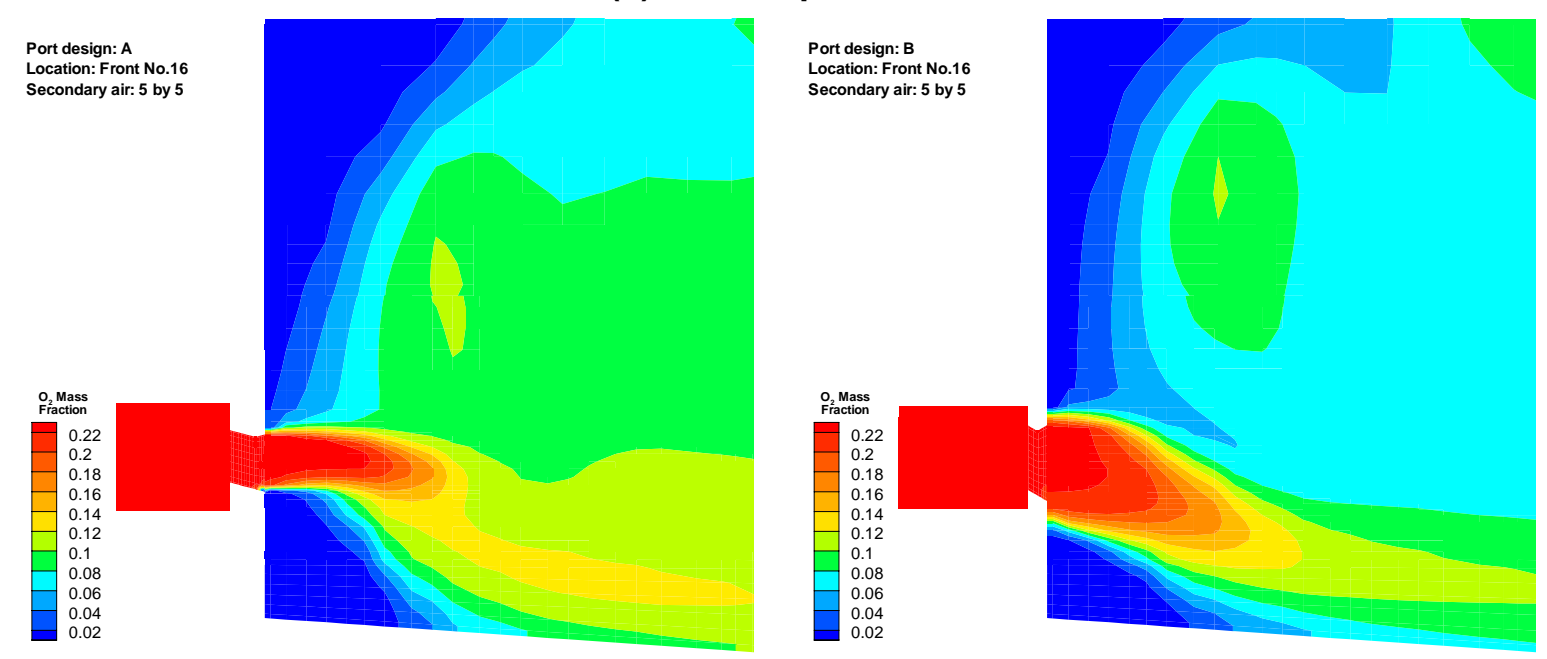

(c) Oxygen

Fig. 70. Comparison between Design A and Design B at same location. 

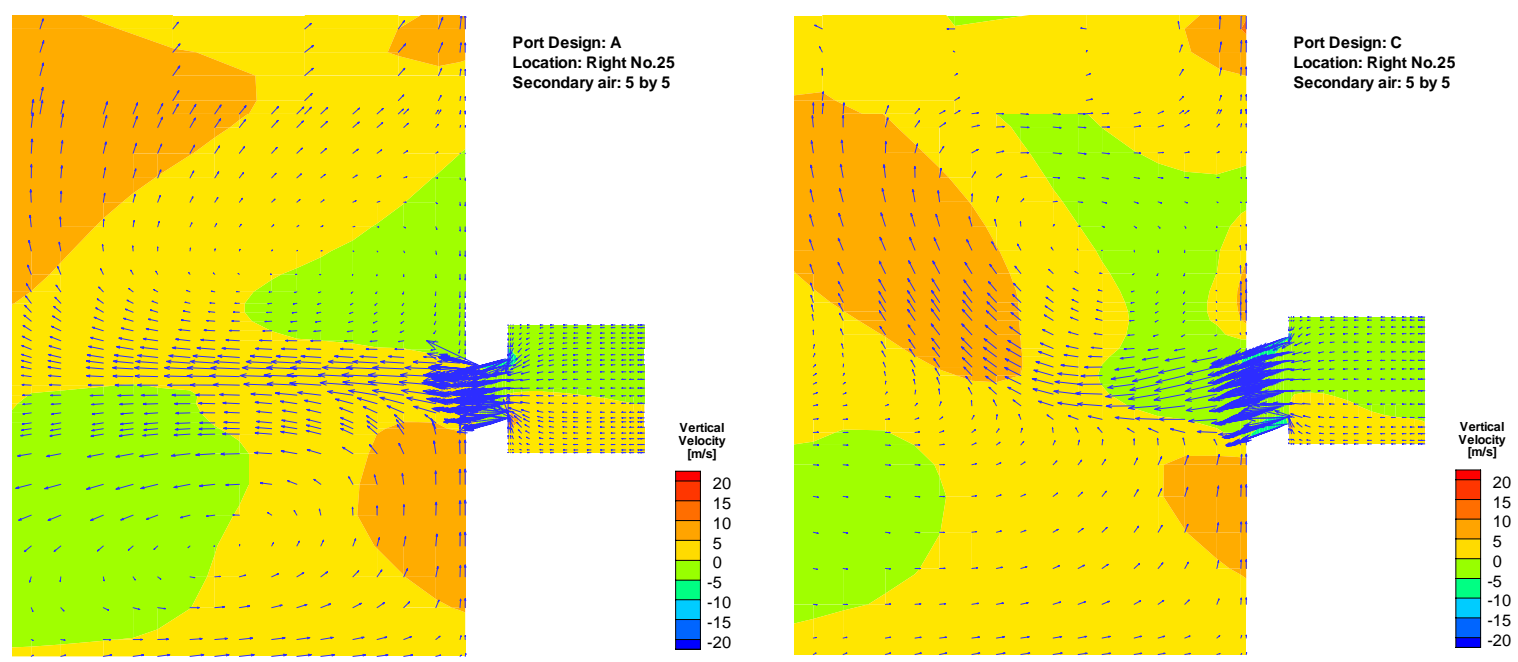

(a) Velocity

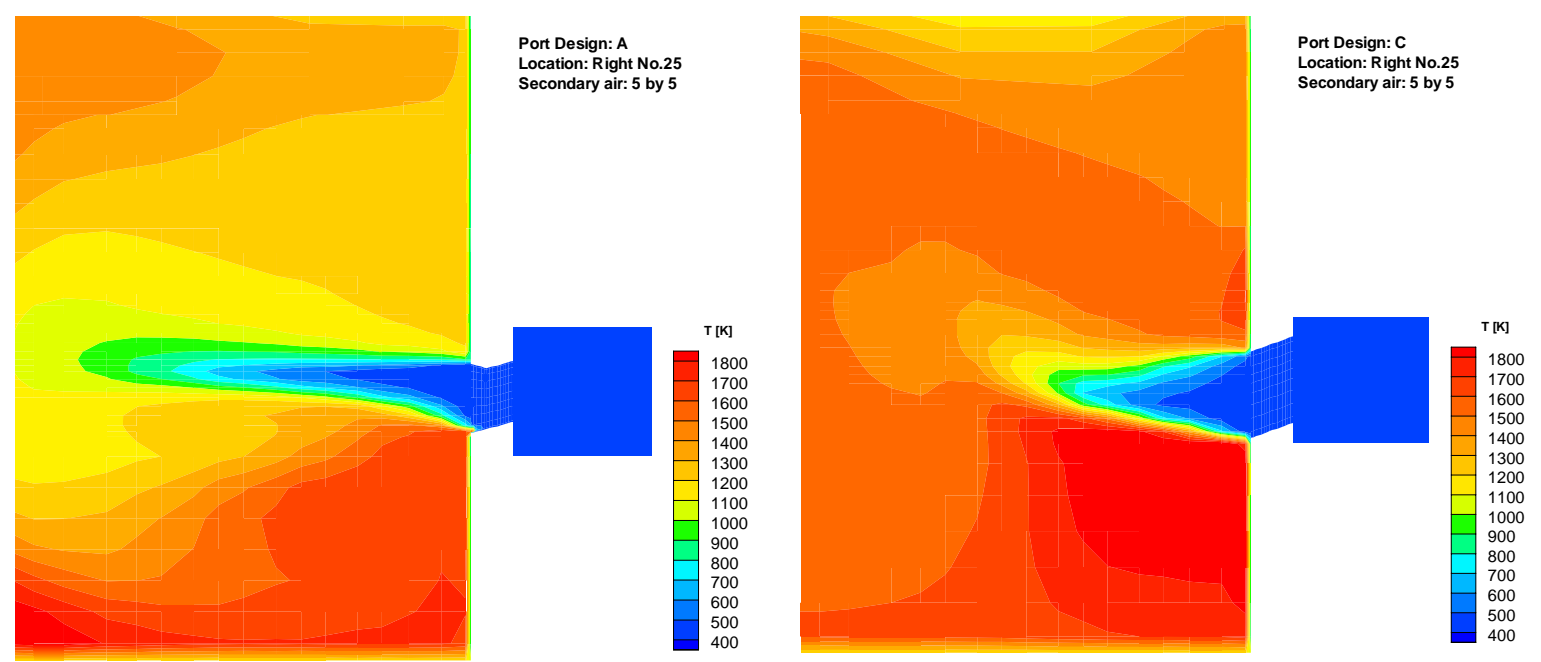

(b) Gas temperature
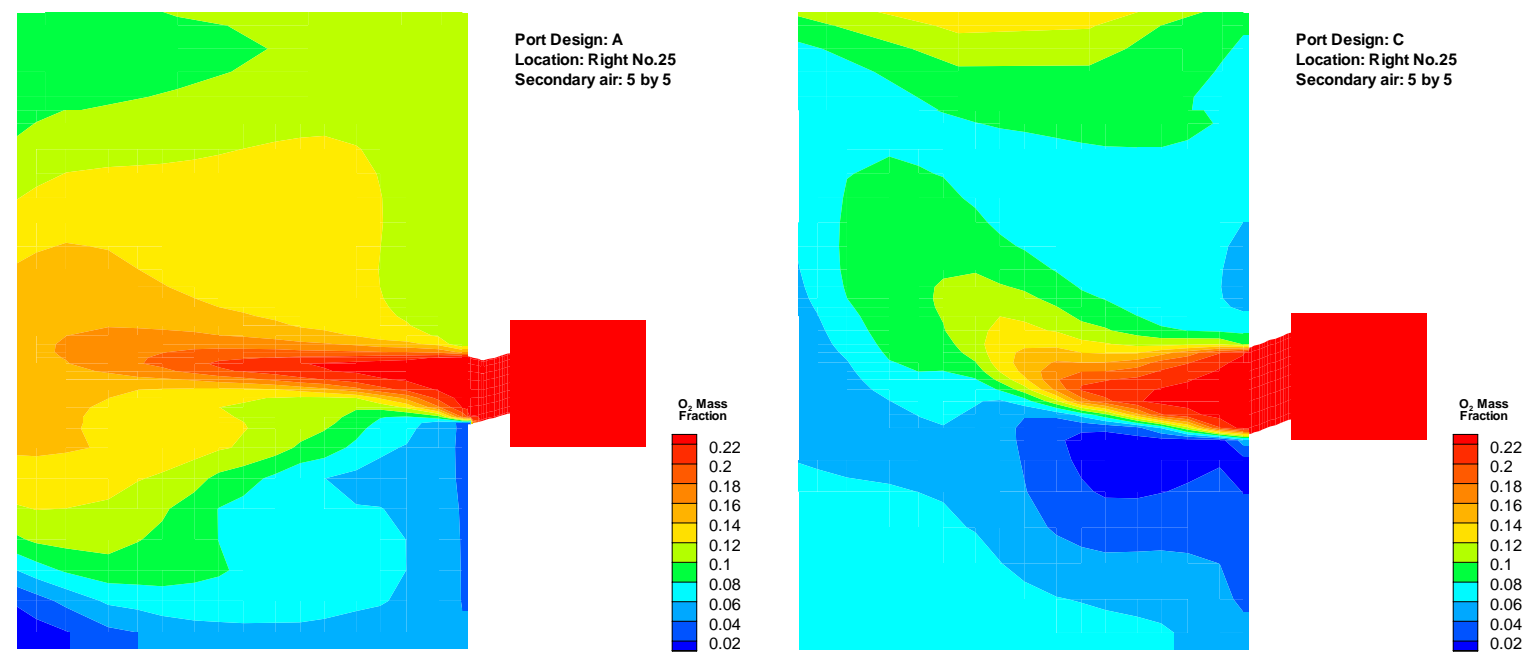

(c) Oxygen

Fig. 71. Comparison between Design A and Design $C$ at same location. 


\subsubsection{Comparison of Same Design under Different Operation Conditions}

As revealed by the global boiler modeling, secondary air distribution has a significant influence on the boiler performance. It can be speculated that the secondary air distribution should also have an influence on the local environment around primary air ports. A primary air port of Design A at location No.16 on the front wall was modeled in coupling with the whole boiler operated under different modes of secondary air distribution. Four modes were modeled: 5 on 5,3 on 3,2 on 3 , and 3 on 2 . The local flow field and gas temperature around the air port is shown in Fig. 72 for different operation conditions. The common feature in the flow patterns is that a recirculation zone is always formed under the primary jet, regardless of secondary air distribution. While always being present, the level of recirculation is stronger in some cases and weaker in others. As a result of the recirculation, the gas temperatures in the port bottom area are different. The maximum calculated gas temperature inside the port are, in decreasing temperature, $1658^{\circ} \mathrm{C}$ for Case 2 on $3,1507^{\circ} \mathrm{C}$ for Case 5 on $5,1321^{\circ} \mathrm{C}$ for Case 3 on 2 , and $915^{\circ} \mathrm{C}$ for Case 3 on 3. The data is also shown in Table 12. Figure 73 shows the gas velocity, gas temperature and oxygen content for two air port designs. The maps in the left hand column show the pattern for the conventional, wide, short primary air port while the maps on the right show the patterns for the longer, narrower primary air port.

The modeling of single air port designs within the whole recovery boiler shows that different air port designs behavior differently, interestingly, the same port design can behave differently at different locations under similar operating conditions. Among three air port designs modeled, Design A creates the strongest level of recirculation below the primary jet. The strong recirculation can bring hot gas, hot smelt, and/or burning droplets back to the bottom of the port, which could cause the temperature fluctuation on the tube surface. Also, the recirculation varies as a function of location and operating conditions.

\subsection{SUMMARY}

The CFD modeling study suggests the root causes of tube cracking are related to the overall air system design, primary air port design, and boiler operation. Under some conditions, the burning droplets, or sometimes the combustible materials in these droplets, are caught in the strong recirculating gas flow below primary air jets and are swept up to the bottom of the port. Heat generation from burning droplets on the tube, from oxidizing smelt, and/or from local gas combustion create temperature excursions on the tube surface.

To prevent cracking in primary air port tubes, the CFD modeling study indicates the flow and combustion in the furnace needs to be stabilized by either adjusting the air split and/or air distribution among ports or updating air system design. Computer modeling can help to optimize the operation and design and to evaluate the stability of the flow and combustion. Avoiding strong recirculating gas flows below primary air jets can be achieved with an air port that is designed to remove burning droplets and local gas combustion from tube surface. It is also important to minimize the number of liquor droplets hitting the walls, which could be achieved by

choosing different nozzle designs, or changing liquor properties such as temperature and solid content. Computer modeling can also help to evaluate the liquor combustion process in recovery boilers. 

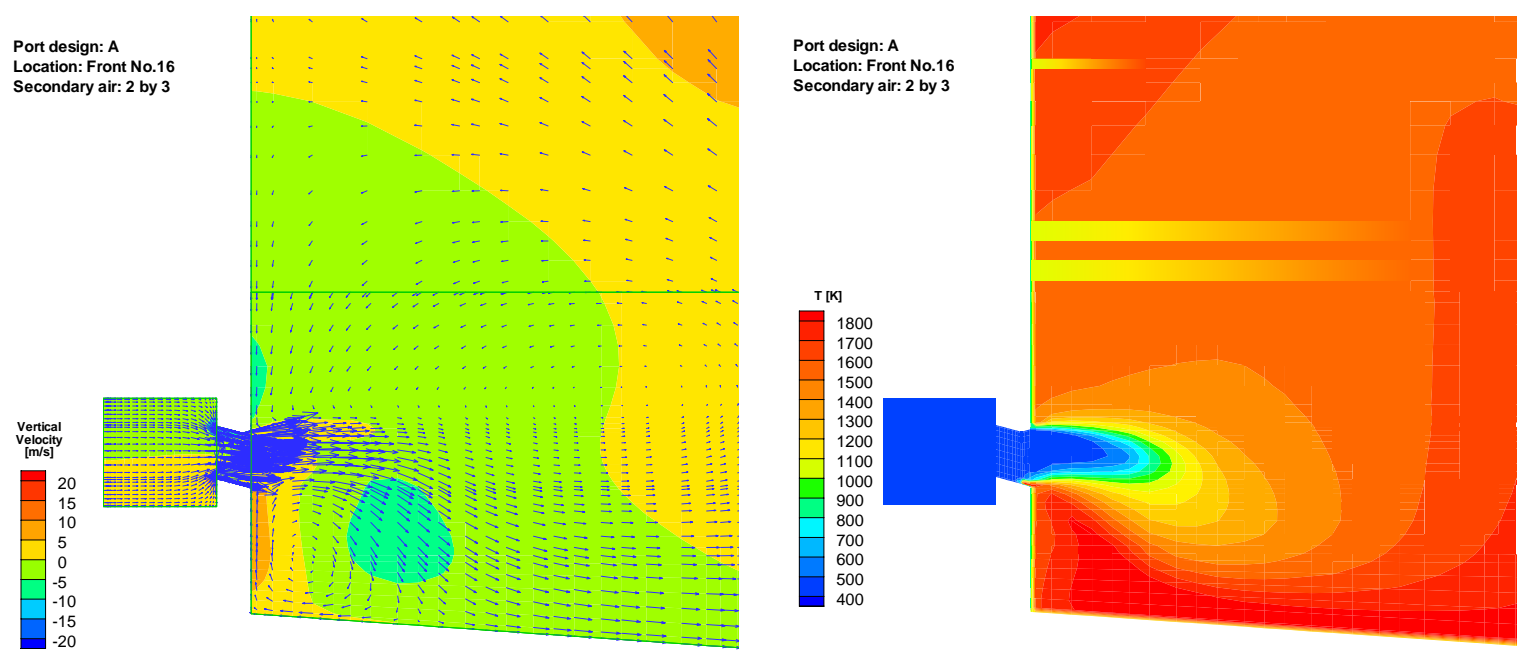

(a) 2 on 3

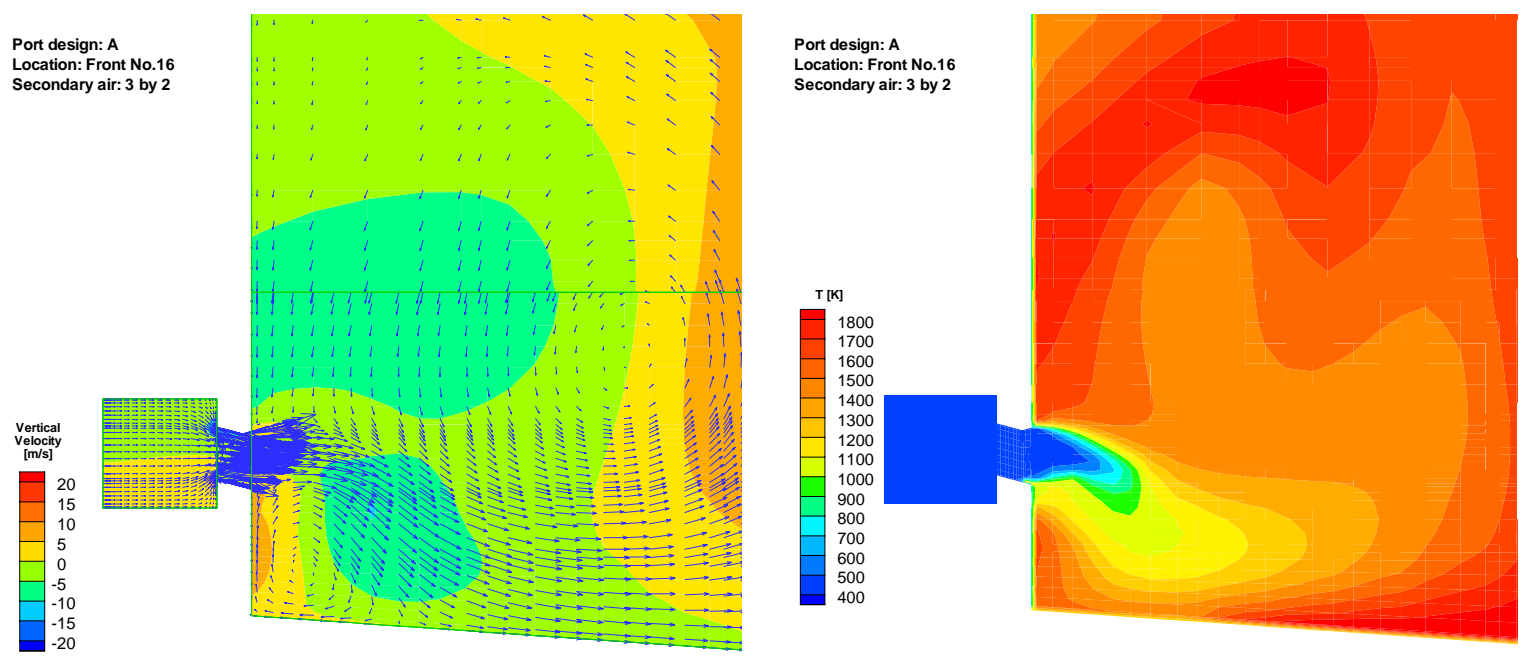

(b) 3 on 2

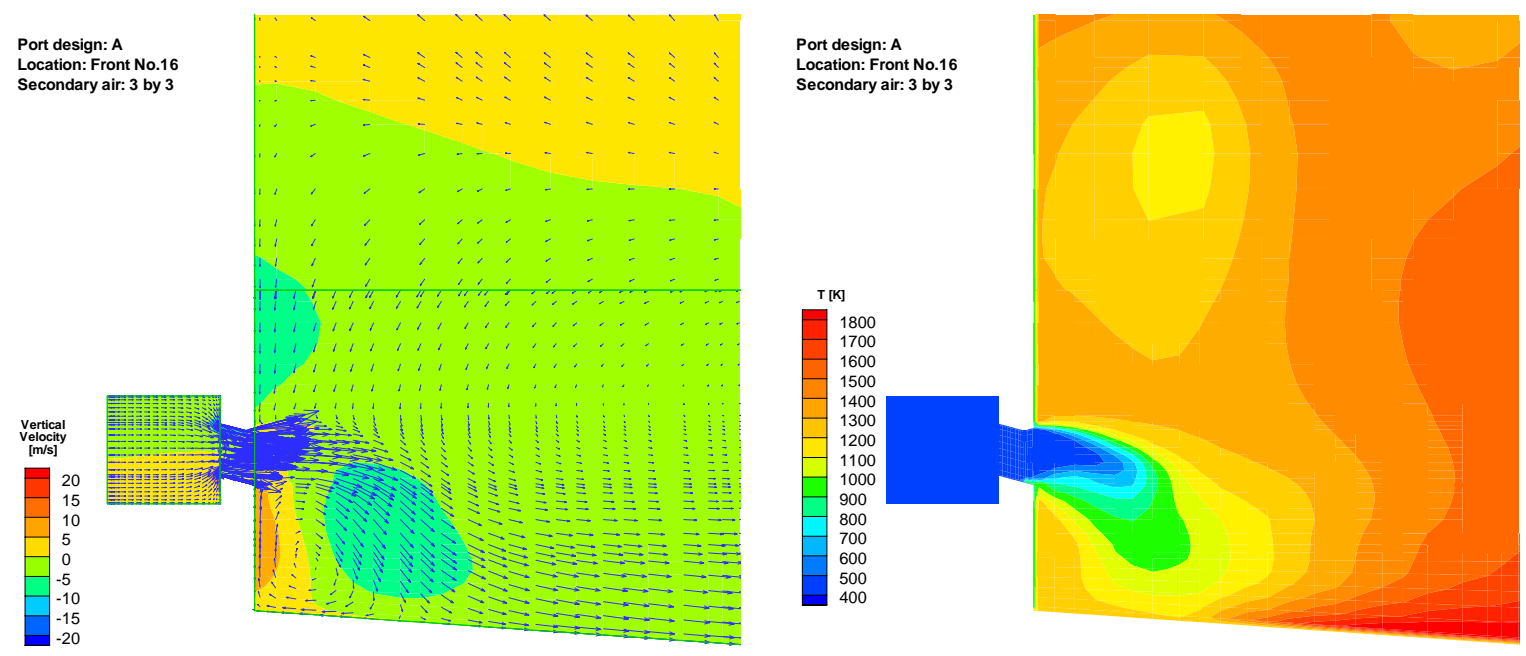

(c) 3 on 3

Fig. 72. Comparison of same design under different operation conditions. 
Table 12. Maximum gas temperature inside primary air port

\begin{tabular}{lllll}
\hline Design and location & A @ F16 & B @ F16 & A @ R25 & C @ R25 \\
\hline Gas temperature & $1780 \mathrm{~K}$ & $592 \mathrm{~K}$ & $1490 \mathrm{~K}$ & $437 \mathrm{~K}$ \\
Design and operation & A @ $5 \times 5$ & A @ $2 \times 3$ & A @ $3 \times 2$ & A @ $3 \times 3$ \\
Gas temperature & $1780 \mathrm{~K}$ & $1931 \mathrm{~K}$ & $1594 \mathrm{~K}$ & $1188 \mathrm{~K}$ \\
\hline
\end{tabular}



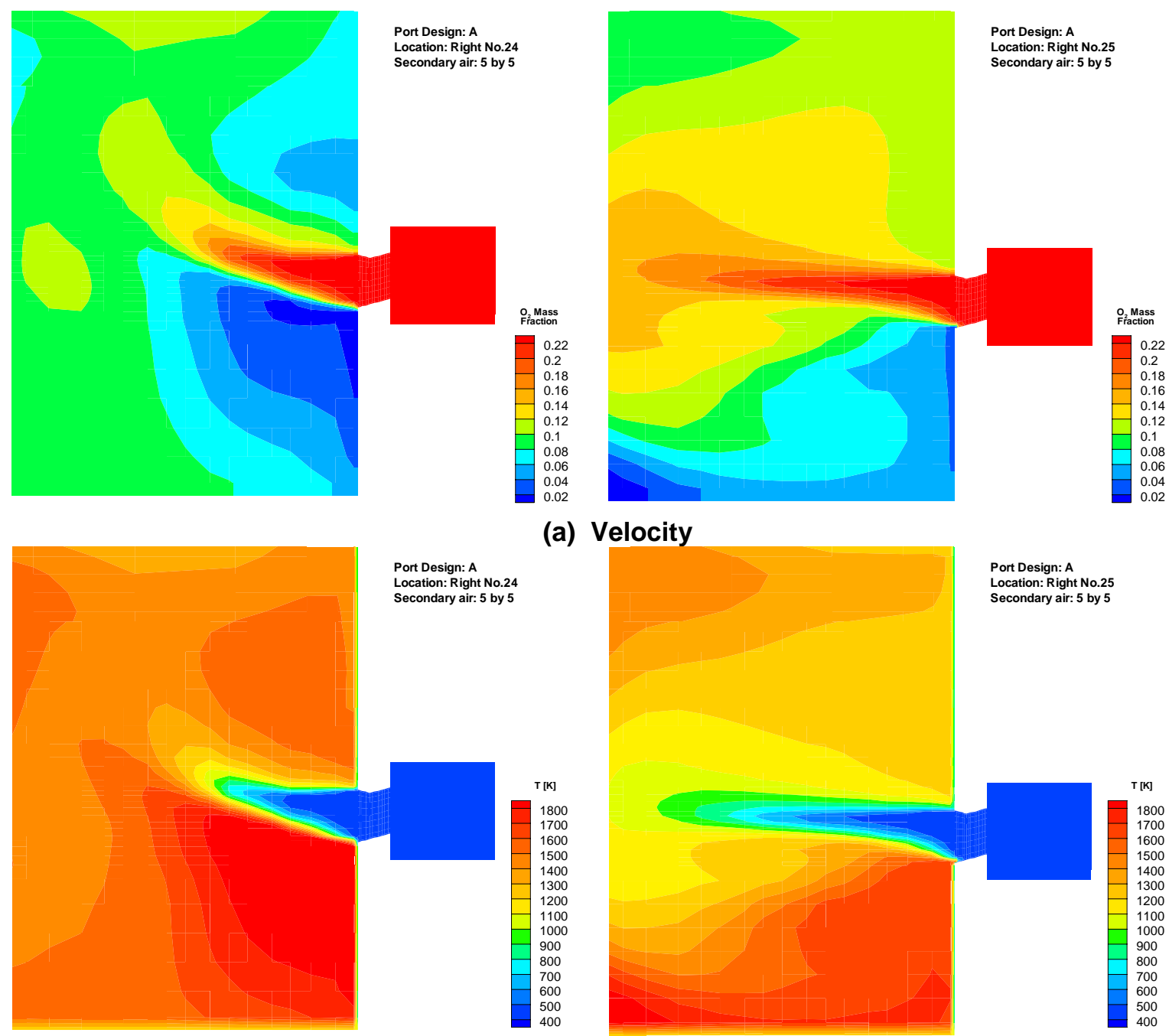

(a) Velocity

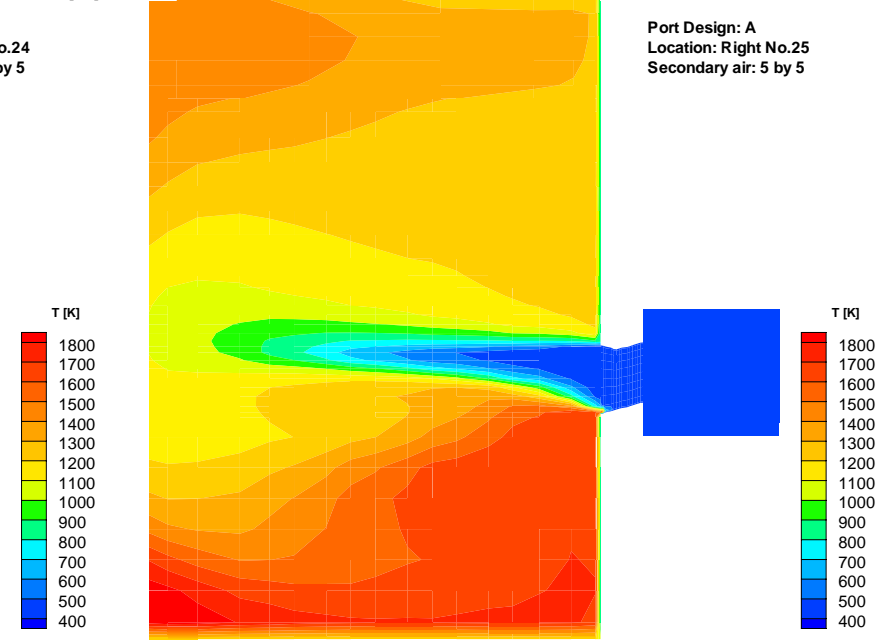

(b) Gas temperature
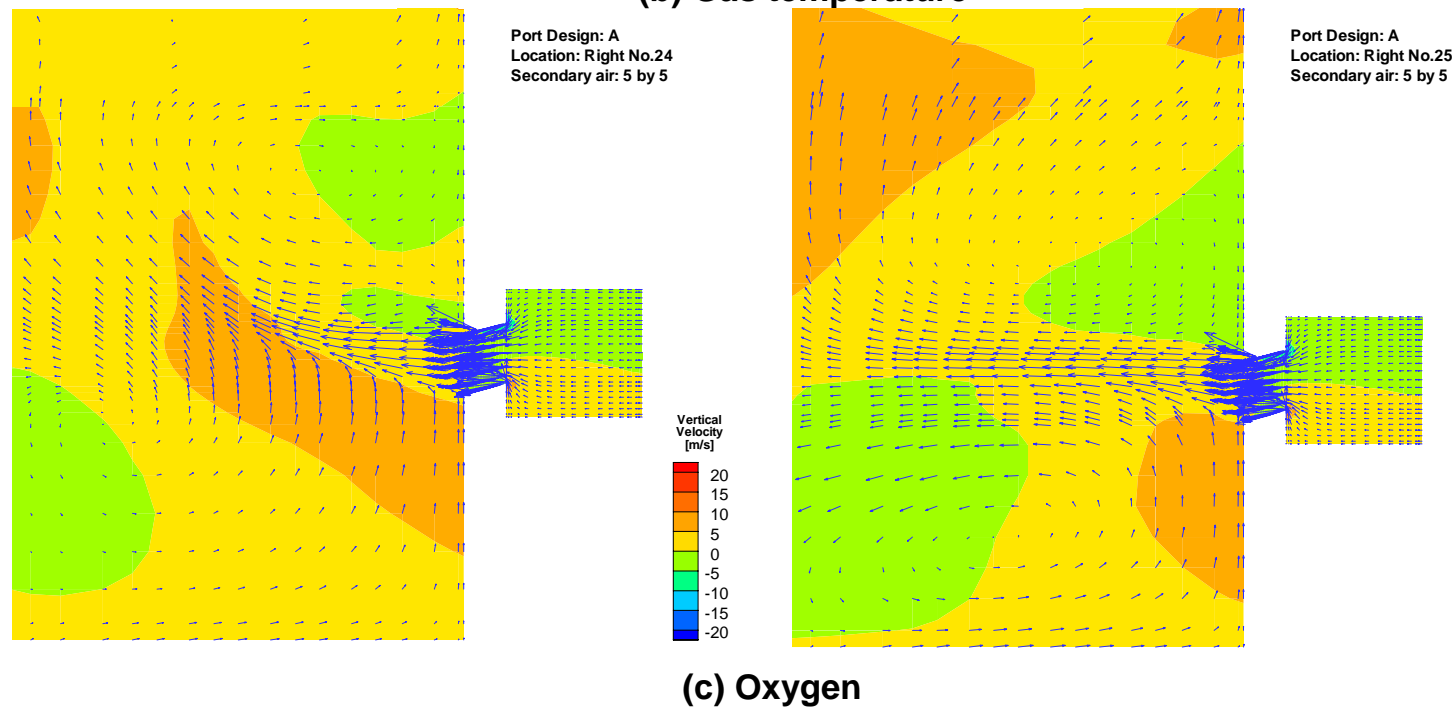

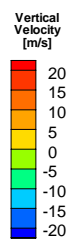

Fig. 73. Comparison of Design A at different locations. 


\section{REDUCING THERMAL EXCURSIONS THROUGH CHANGES IN BOILER OPERATION}

It is widely recognized that the extent of thermal fluctuations on the port tubes is an indicator of the likelihood of cracking. As described in section 5 of this report, surface mounted thermocouples on port tubes with a history of cracking tend to show large fluctuations in temperature, whereas those that do not have a history of cracking tend to show much smaller variations [8,49-51]. It follows that any means through which the large fluctuations can be reduced, if not eliminated, should decrease the likelihood of cracking. One possible means involves a change in boiler operation, either to the asfired black liquor properties, black liquor delivery system, combustion air system, or to any combination thereof. Boiler operation is implicated as a contributing factor for two reasons: (i) not all instrumented port tubes, within a given boiler, show large fluctuations at the same time, and (ii) thermal fluctuations on all instrumented port tubes, within a given boiler, do not occur in the absence of black liquor (as illustrated by switching from black liquor to oil burning (see Fig. 22)).

As described in section 5 of this report, a total of 48 thermocouples were installed on the fireside surface of composite tubes (primary air port opening tubes and adjacent straight tubes) of a North American kraft recovery boiler with a rather serious composite tube cracking problem. Making use of these thermocouples, a set of extended process trials designed to explore the possible influences of boiler operation on the frequency and magnitude of the measured thermal fluctuations were conducted. The major findings from those trials are documented below.

\subsection{TRIAL DETAILS}

\subsubsection{Recovery Boiler}

The affected recovery boiler is a 1997 vintage single-drum co-generation unit constructed using $63.5 \mathrm{~mm}\left(2^{1 / 2 "}\right)$ diameter tubes on $76.2 \mathrm{~mm}\left(3^{\prime \prime}\right)$ centers in a membrane-type design with a sloped floor. The unit typically burns 3.6 million $\mathrm{lbs}(1.63$ million $\mathrm{kg}$ ) of black liquor dry solids per day to produce steam at $8.62 \mathrm{MPa}(1250 \mathrm{psig})$ and $254^{\circ} \mathrm{C}\left(490^{\circ} \mathrm{F}\right)$. The unit is $10.6 \mathrm{~m}$ (34' 9") wide by $11.4 \mathrm{~m}$ ( $\left.37^{\prime} 6^{\prime \prime}\right)$ deep, at the black liquor gun level, and is $26.1 \mathrm{~m}\left(85^{\prime} 7^{\prime \prime}\right)$ high to the top of the bullnose, which gives an aspect ratio (height divided by the square root of the cross-sectional area) of 2.4. There are four smelt spouts located on the rear wall.

Only softwood black liquor at $73-75 \%$ solids has been fired in the unit since the original startup. During the first few years of operation, soap was burned in batches. Since then, soap has been burned in combination with black liquor on a regular basis at a target soap flow rate of $4 \%$ of the black liquor volumetric flow rate. Black liquor is delivered using four stationary guns, with one gun located in the center port of each wall. Combustion air is delivered using a three level system, two of which (primary and secondary) are below the black liquor guns. At the primary and secondary levels, air can be delivered through each of the four walls. At the tertiary level (above the black liquor guns), the air is delivered in an interlaced pattern through the front (four ports) and rear walls (three ports) only.

\subsubsection{Operating Parameters}

The primary objective of the process trials was to reduce the thermal fluctuations without adversely affecting boiler performance. As it was anticipated that this may be achieved by modifying the as-fired black liquor properties, black liquor delivery system, or combustion air system, several parameters from each were systematically varied. Table 13 summarizes the six major process trials conducted in terms of the major operating parameters studied. The list of as-fired black liquor variables under study include temperature, solids content, flow, and burning soap in combination with black liquor. The latter two were not intended variables, but were adjusted during the process trials 
Table 13. Summary of process trials

\begin{tabular}{|c|c|c|c|c|c|}
\hline \multirow[b]{2}{*}{ Trial } & \multicolumn{2}{|c|}{ Date (mm/dd/yy) } & \multicolumn{3}{|c|}{ Operating parameters } \\
\hline & Start & Finish & $\begin{array}{c}\text { Black liquor } \\
\text { property }\end{array}$ & $\begin{array}{l}\text { Black liquor } \\
\text { delivery }\end{array}$ & Combustion air \\
\hline I & $02 / 14 / 00$ & $02 / 17 / 00$ & None & None & $\begin{array}{l}\text { PA/SA/TA split } \\
\text { PA arrangement } \\
\text { SA arrangement }\end{array}$ \\
\hline II & $04 / 11 / 00$ & $04 / 19 / 00$ & $\begin{array}{l}\text { Soap } \\
\text { Flow rate }\end{array}$ & $\begin{array}{l}\text { Nozzle type } \\
\text { Tilt angle }\end{array}$ & $\begin{array}{l}\text { PA/SA/TA split } \\
\text { PA arrangement }\end{array}$ \\
\hline III & $03 / 20 / 01$ & $04 / 11 / 01$ & $\begin{array}{l}\text { Temperature } \\
\text { Soap } \\
\text { \% Solids }\end{array}$ & $\begin{array}{l}\text { Nozzle diameter } \\
\text { Tilt angle }\end{array}$ & $\begin{array}{l}\text { PA arrangement } \\
\text { SA arrangement }\end{array}$ \\
\hline IV & $02 / 11 / 02$ & $02 / 22 / 02$ & $\begin{array}{l}\text { Temperature } \\
\text { Flow rate }\end{array}$ & $\begin{array}{l}\text { Nozzle diameter } \\
\text { Nozzle number } \\
\text { Tilt angle } \\
\text { Splashplate angle }\end{array}$ & $\begin{array}{l}\text { PA arrangement } \\
\text { SA arrangement }\end{array}$ \\
\hline V & $09 / 16 / 02$ & $09 / 28 / 02$ & Flow rate & $\begin{array}{l}\text { Nozzle diameter } \\
\text { Tilt angle } \\
\text { Splashplate angle }\end{array}$ & $\begin{array}{l}\text { PA/SA/TA split } \\
\text { PA arrangement } \\
\text { SA arrangement }\end{array}$ \\
\hline VI & $06 / 08 / 03$ & $06 / 15 / 03$ & $\begin{array}{l}\text { Soap } \\
\text { Flow rate }\end{array}$ & $\begin{array}{l}\text { Nozzle type } \\
\text { Nozzle diameter } \\
\text { Splashplate angle }\end{array}$ & SA arrangement \\
\hline
\end{tabular}

nevertheless to maintain throughput and stable operation. As for the black liquor delivery system, nozzle type (wedge versus conventional splash plate), nozzle diameter, splash plate angle, and tilt angle were systematically varied to some extent. Combustion air system parameters varied include total air split between the three levels (primary/ secondary/tertiary), and the primary and secondary air arrangements (wall split and pattern).

Of the combustion air parameters, only the secondary air arrangement was an intended variable. Both the total air split and the primary air arrangement were meant to be held constant once optimized for performance (thermal efficiency, atmospheric emissions, reduction efficiency, and carryover). Optimizing the total air split involved diverting a portion of air flow from the secondary level to the primary level and to the tertiary level. Optimizing the primary air arrangement involved adjusting the dampers (to at least $75 \%$ open) to promote an equal or balanced flow through each wall (front: $25 \%$; right: $25 \%$, rear: $25 \%$, left: $25 \%$ ) and through each port in each wall. All subsequent changes to the total air split and primary air arrangement recorded during the trials were essentially made to reestablish the optimized settings.

\subsubsection{Data Collection}

Figure 74 schematically identifies the location of the primary air ports instrumented with surface mounted thermocouples and the locations of the thermocouples. Each wall contains several instrumented air ports, which were selected to provide insight into spatial variation. Each instrumented air port had thermocouples mounted in the \#1 \& \#2 positions, which represent the location where the majority of cracks were found. The remaining thermocouple positions were selected to provide insight into the elevation and air flow variations. Thermocouples were held in place by a shield made of the same material as the tube cladding and welded to the tube.

Measurements were taken every 10 seconds by a computer dedicated to this task. Personnel at ORNL downloaded and analyzed the data. Most of the relevant process data was automatically recorded by the mill's data collection system (DCS). Air flow distributions were determined from static air pressure measurements made in every primary and secondary windbox (including the burner ports). Black liquor gun tilt angles were measured manually. 


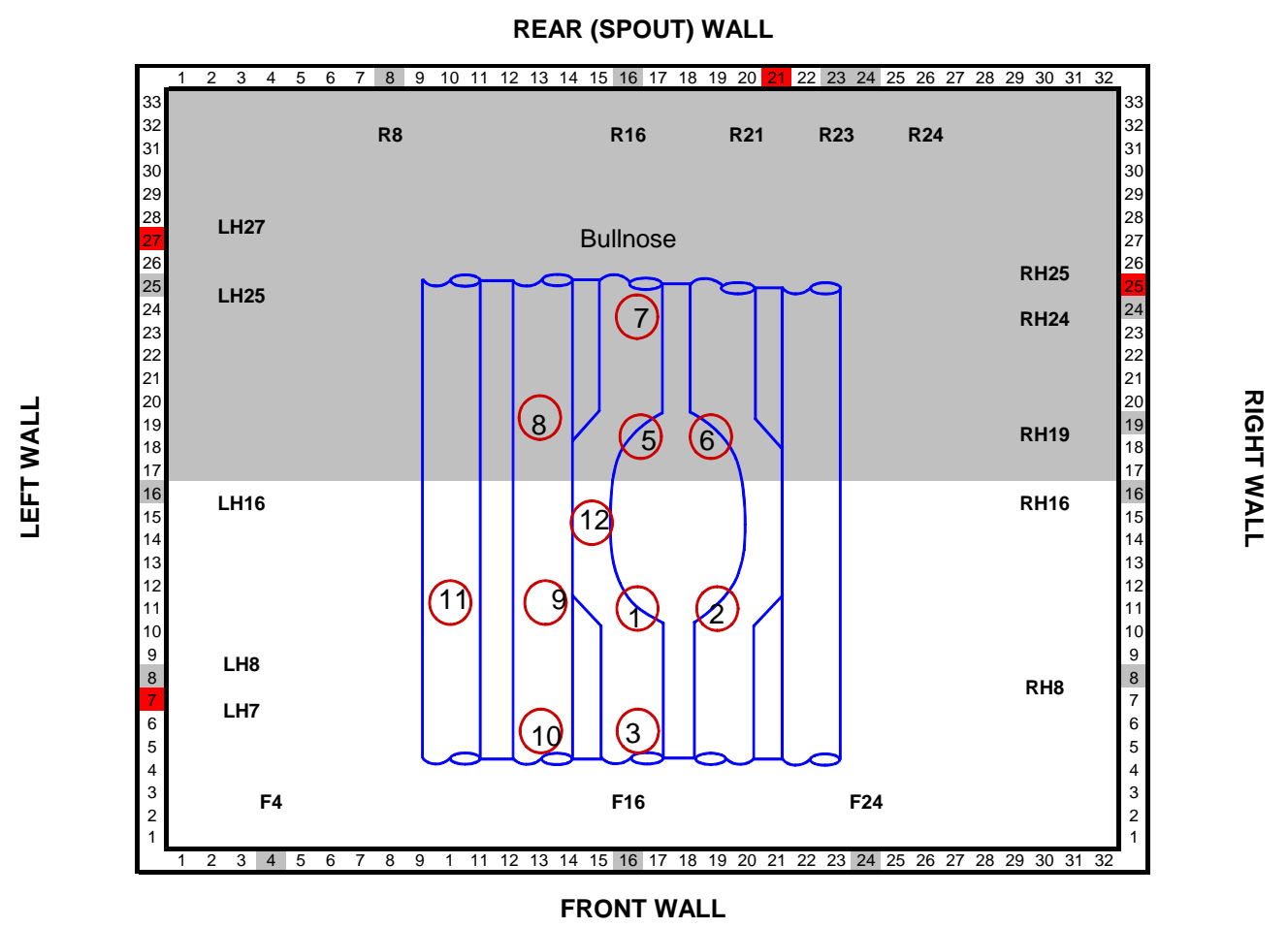

Fig. 74. Schematic illustration showing primary air ports instrumented with thermocouples and their locations on tubes in and around primary air ports. All ports were instrumented with thermocouples in the \#1 and \#2 locations. Ports highlighted in red identify those used to construct the thermal activity summary plot presented in Fig. 2. Circled numbers on port opening represent locations where surfacemounted thermocouples were installed.

\subsubsection{Data Analysis}

As described previously, temperature fluctuations measured at the primary air ports are described by "excursions" and "cycles," and a method for calculating each has been published elsewhere [52]. Using these parameters, the large thermal fluctuations associated with cracking are represented by a high excursion AND cycle count. In contrast, the small thermal fluctuations not associated with cracking are represented by a low excursion count, regardless of the cycle count.

\subsection{RESULTS AND DISCUSSION}

\subsubsection{Operating Parameters and Thermal Fluctuations}

Upon completion of each trial, the boiler was set to operate in a mode that was based on the observations made during that particular trial, as well as those made during the previous ones. In other words, the set of trials were interdependent in providing information to select the optimized boiler operating mode in terms of reduced cracking likelihood (thermal fluctuations) and performance. Consequently, it is worthwhile to examine the collective influence of these process trials on the occurrence of both cracking and thermal fluctuations observed as a function of time. Figure 75 compares the trend in cracking statistics as a function of time with the trend in thermal fluctuations as a function of time. Trials are superimposed onto the thermal activity plot in Fig. 75 as vertical lines located by the month in which the trial was conducted. There is a dramatic 
$\square$ Tubes with Linear Cracks $\square$ Tubes with Cracks

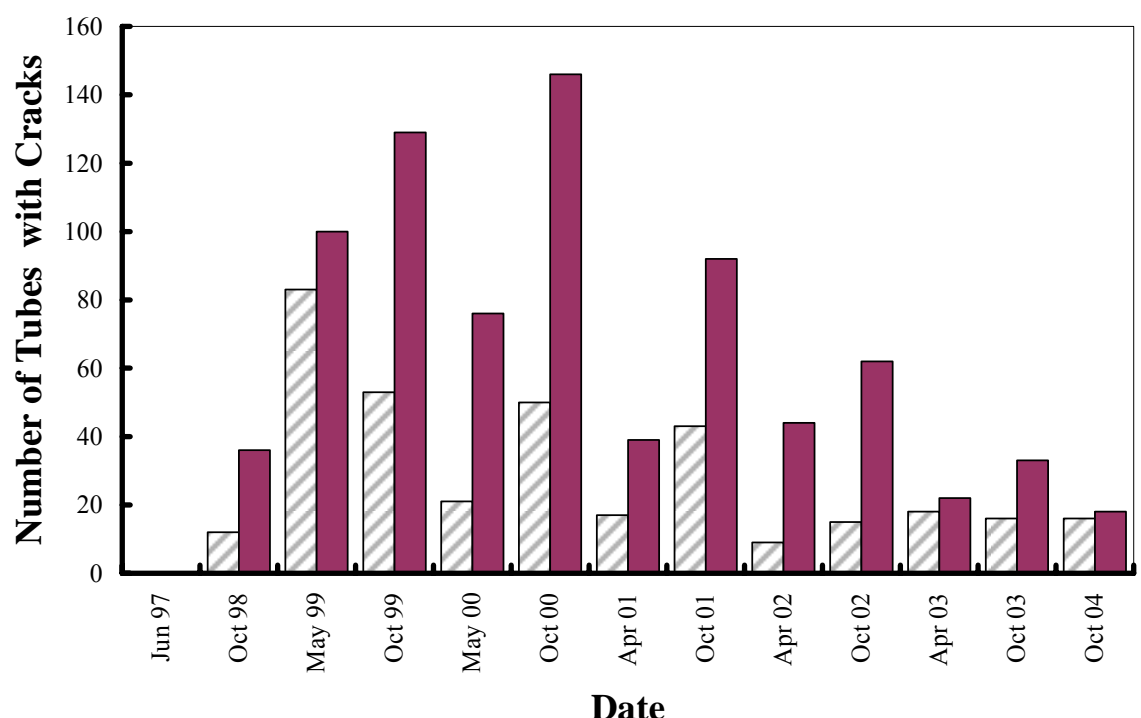

(a)

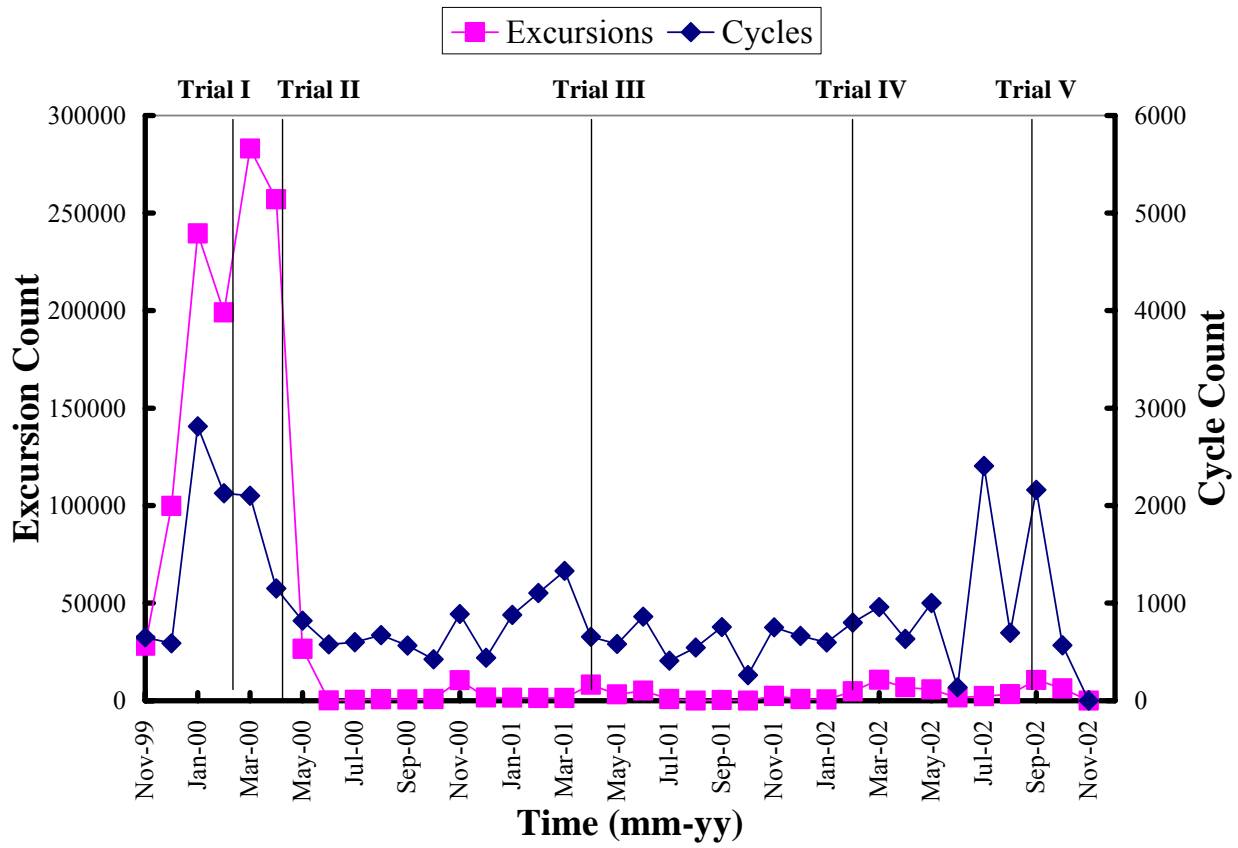

(b)

Fig. 75. Plots comparing trend in cracking statistics with trend in thermal activity. (a) number of tubes with cracks as a function of time (inspection period) and (b) cumulative thermal activity as a function of time. 
long-term reduction in temperature fluctuations (excursions and cycles) and a less remarkable, but significant, long-term reduction in the number of port opening tubes with cracks. The dramatic reduction in thermal fluctuations occurred immediately after the April 2000 shutdown, which followed the February 2000 (Trial I) and April 2000 (Trial II) process trials. This implies that the combined set of changes made during Trials I and II are likely responsible in a large part for the dramatic reduction.

Table 14 compares key parameters characterizing the operating mode at the start (initial) and finish (final) of Trials I and II. During Trial I, changes in operating parameters were restricted to the combustion air system (Table 13) while optimizing performance. Major changes were made to the total air split, and to the primary and secondary air arrangements in order to balance/optimize the air system. The end result of these changes on the primary and secondary air arrangements are illustrated in Figs. 76 and 77 respectively. As Fig. 76 shows, a significant increase in the jet momentum through every primary air windbox was achieved. As Fig. 77 shows, the major change to the secondary air arrangement involved a switch from a 4-wall mismatch (non-interlaced) pattern to a 2-wall mismatch pattern. From Fig. 75, the initial set of changes to the combustion air system in Trial I did not coincide with any significant reduction in the thermal fluctuations. This implies that the additive changes made during Trial II were necessary for the dramatic reduction.

There are two major additional changes that were made during Trial II, namely the switch from a wedge type splash plate (wedge) nozzle to a conventional type splash plate nozzle, and the burning of soap in combination with the black liquor. As illustrated in Figs. 76 and 77, the primary air and secondary air arrangements, respectively, were not significantly altered during Trial II. The key question here is which one of those two additive changes (nozzle type or soap burning) was responsible for the significant reduction in thermal fluctuations? To help answer this question, thermal fluctuations, determined for each case in Table 14, are compared for the required simultaneous marked reduction in both excursions and cycles. It proved worthwhile to consider a fifth case (Trial IIc), which was similar to Trial IIb except that soap was not burned in combination with the black liquor (Trial IIc was based on 7 hours of stable operation).

Table 14. Summary of selected operating parameters from Trials I and II

\begin{tabular}{|c|c|c|c|c|}
\hline Operating parameter & $\begin{array}{c}\text { Trial Ia initial } \\
\text { mode }\end{array}$ & $\begin{array}{c}\text { Trial Ib final } \\
\text { mode }\end{array}$ & $\begin{array}{c}\text { Trial IIa initial } \\
\text { mode }\end{array}$ & $\begin{array}{l}\text { Trial IIb final } \\
\text { mode }\end{array}$ \\
\hline Time, $\mathrm{h}$ & 24 & 24 & 12 & 13 \\
\hline \multicolumn{5}{|c|}{ Black liquor properties } \\
\hline Temperature, ${ }^{\circ} \mathrm{C}$ (as-fired) & 120 & 120 & 121 & 120 \\
\hline Pressure, kPa (as-fired) & 296 & 305 & 251 & 208 \\
\hline Flow rate (DS), $\mathrm{kg} / \mathrm{h}$ & 71,009 & 71,277 & 78,152 & 67,378 \\
\hline Soap in combination & No & No & Yes & Yes \\
\hline \multicolumn{5}{|c|}{ Black liquor delivery system } \\
\hline Nozzle type & Wedge & Wedge & Wedge & Splashplate \\
\hline Nozzle diameter ${ }^{a}$ & $2-\# 30,2-\# 32$ & $2-\# 30,2-\# 32$ & $4-\# 30$ & $4-\# 28$ \\
\hline Splashplate angle & 49 & 49 & 49 & 49 \\
\hline Tilt angle, degrees ${ }^{b}$ & $\mathrm{~N} / \mathrm{a}$ & $\mathrm{N} / \mathrm{a}$ & $-5 /-5 /-5 /-5$ & $-9 /-5 /-5 /-5$ \\
\hline \multicolumn{5}{|c|}{ Combustion air system } \\
\hline Total air split, PA/SA/TA & $30 / 51 / 19$ & $35 / 35 / 30$ & $37 / 35 / 28$ & $38 / 38 / 24$ \\
\hline PA split, $\%^{b}$ & $18 / 30 / 26 / 26$ & $25 / 26 / 23 / 27$ & $20 / 24 / 31 / 25$ & $21 / 25 / 24 / 30$ \\
\hline SA split, $\%^{b}$ & $17 / 35 / 15 / 33$ & $11 / 38 / 5 / 46$ & $6 / 41 / 2 / 51$ & $8 / 46 / 11 / 35$ \\
\hline SA interlaced pattern & 4-Wall mismatch & 2-Wall mismatch & 2-Wall mismatch & 2-Wall mismatch \\
\hline
\end{tabular}

${ }^{a}$ Nozzle diameter expressed as \#/32" (\#32 = 1" diameter nozzle).

${ }^{b}$ Expressed as front wall/right wall/rear wall/left wall. 

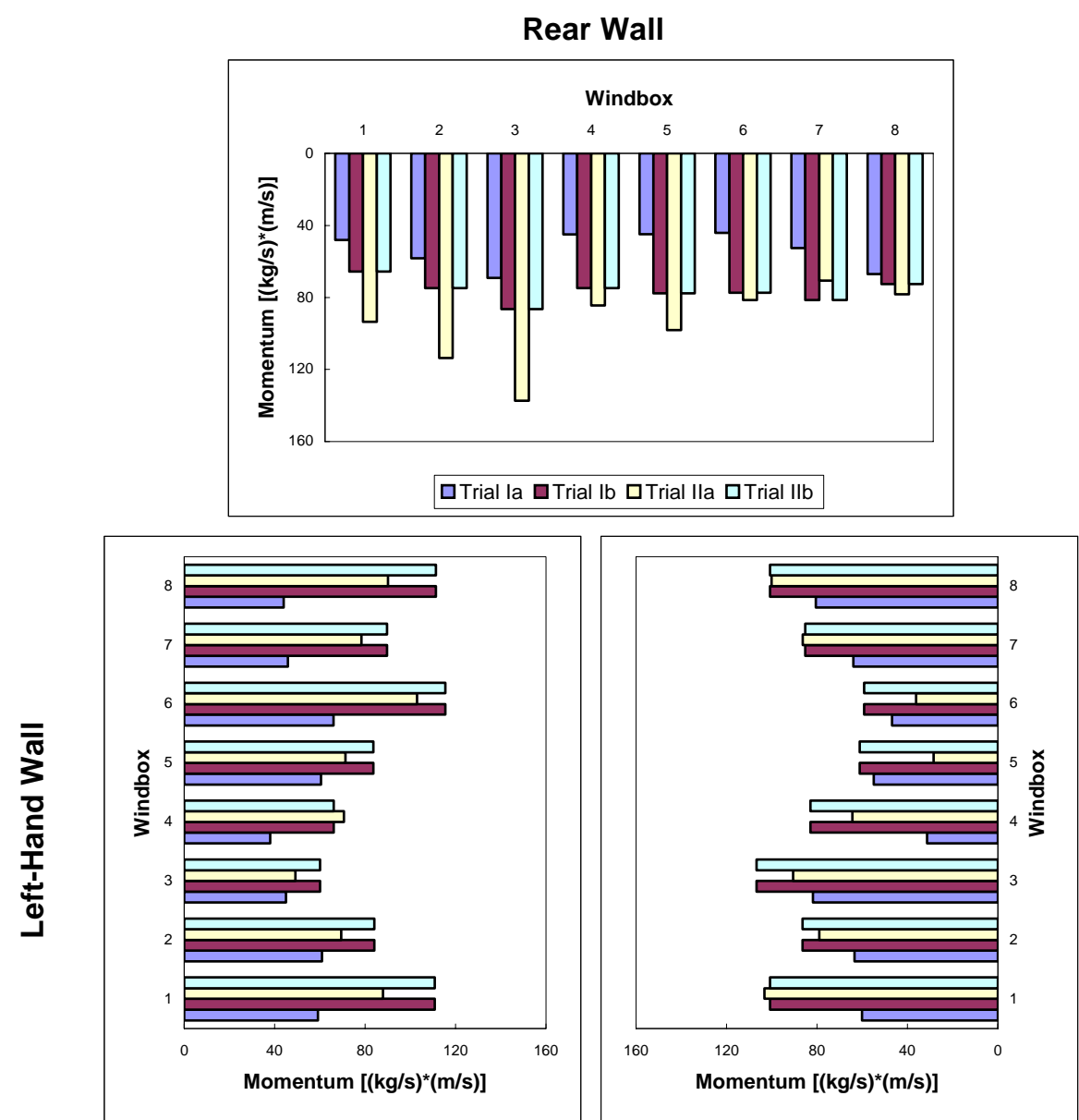

$\overline{\bar{\pi}}$
3
$\frac{0}{0}$
$\frac{0}{1}$
$\frac{1}{\overline{0}}$
$\frac{0}{\alpha}$

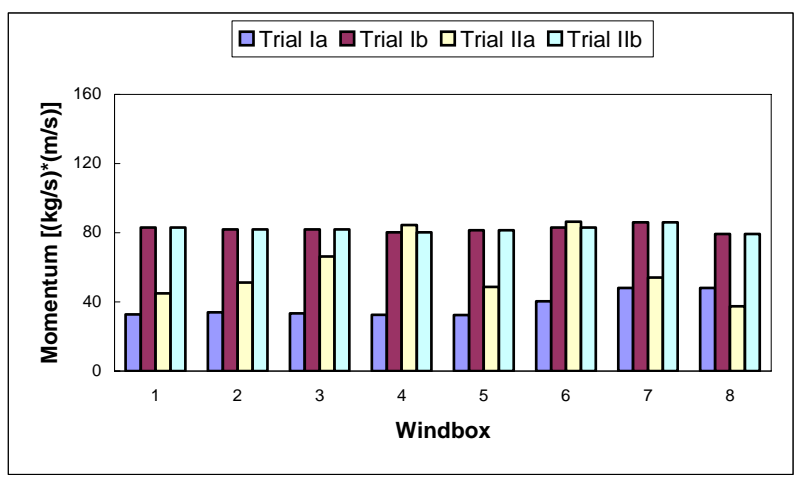

Front Wall

Fig. 76. Plot of primary air jet momentum as a function of the windbox showing influence of combustion air changes made to optimize the system during Trials I and II. [ $\mathrm{a}=$ initial operating mode of trial, and $b=$ final operating mode of trial.] See Table 14 for parameters. 


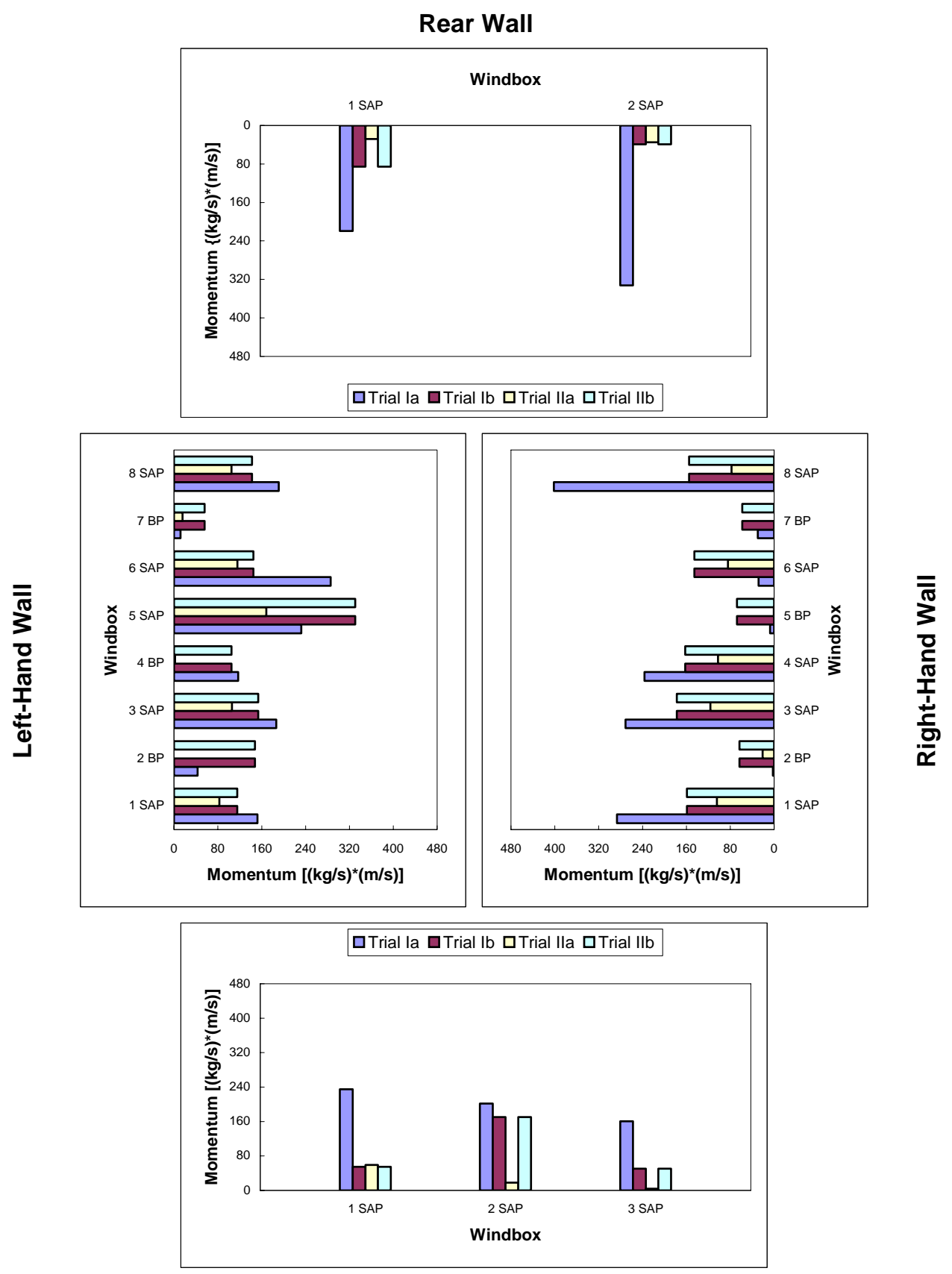

Front Wall

Fig. 77. Plot of secondary air jet momentum as a function of the windbox showing influence of combustion air changes made to optimize system during Trials I and II. [ $a=$ initial operating mode of trial, and $b=$ final operating mode of trial.] See Table 14 for parameters. 
Figure 78 graphically illustrates the influence that burning soap in combination with black liquor had on the thermal fluctuations during Trial II for operation using wedge nozzles, and for operation using splash plate nozzles. For operation using wedge nozzles, a significant reduction in excursions occurred when burning soap in combination with liquor. However, that marked reduction is coupled with a small increase in cycles. For operation with splash plate nozzles, the comparison shows the required simultaneous reduction in excursions and cycles. However, those relative changes are considered too small to be significant. Consequently, burning soap in combination alone was likely not responsible for the marked reduction in thermal fluctuations achieved after Trial II.

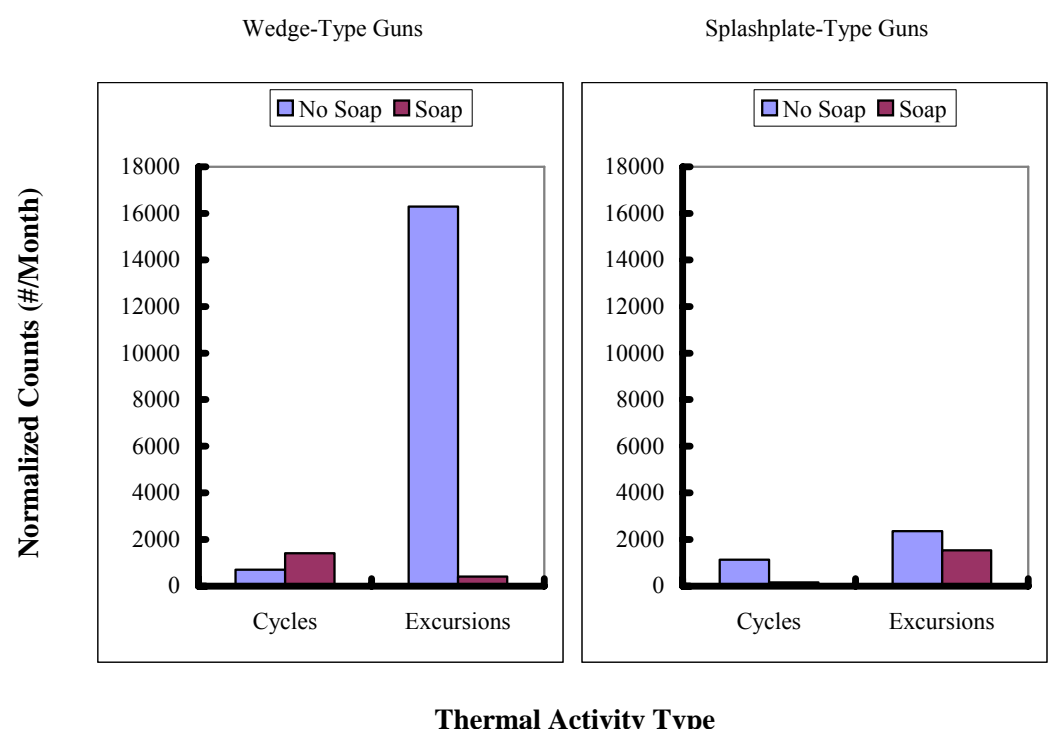

Fig. 78. Plot comparing thermal activity for trial pairs showing the influence of burning soap in combination with black liquor for each nozzle type under study. The thermal activity measured during Trial Ib (No Soap) and IIa (Soap) are compared in the "Wedge Nozzle" plot, whereas the thermal activity measured during Trial IIc (No Soap) and Trial IIb (Soap) are compared in the "Splashplate Nozzle" plot.

The influence that nozzle type had on thermal fluctuations during Trial II is graphically illustrated in Fig. 79 for operation with and without burning soap in combination with the black liquor. Neither of the two comparisons shows the required simultaneous reduction in both excursions and cycles. Consequently, a change in nozzle type alone was likely not responsible for the marked reduction in thermal fluctuations achieved after Trial II. A similar conclusion was drawn during Trial VI, in which a change between 4-\#28 conventional splash plate nozzles and 4-\#28 wedge nozzles produced no significant change in thermal activity.

A third possibility is that both additive changes were required for the simultaneous marked reductions. Figure 80 shows the influence that the combined changes had on thermal fluctuations during Trial II. As the comparison shows, a simultaneous marked reduction in both excursions and cycles did indeed occur when both additive changes are considered together.

Table 15 compares key parameters characterizing the initial and final operating modes of the four remaining trials (Trials III to VI). Parameters intentionally varied during those remaining trials include nozzle diameter, nozzle number, tilt angle, splash plate angle, black liquor temperature, soap burning, and the secondary air arrangement. It is noted that the final mode of Trial IV involved the use of four \#30 splash plate nozzles ( $49^{\circ}$ splash plate angle). The eight \#24 splash plate nozzle trial is listed as the final mode to document this important change. As Fig. 75 shows, none of those further 


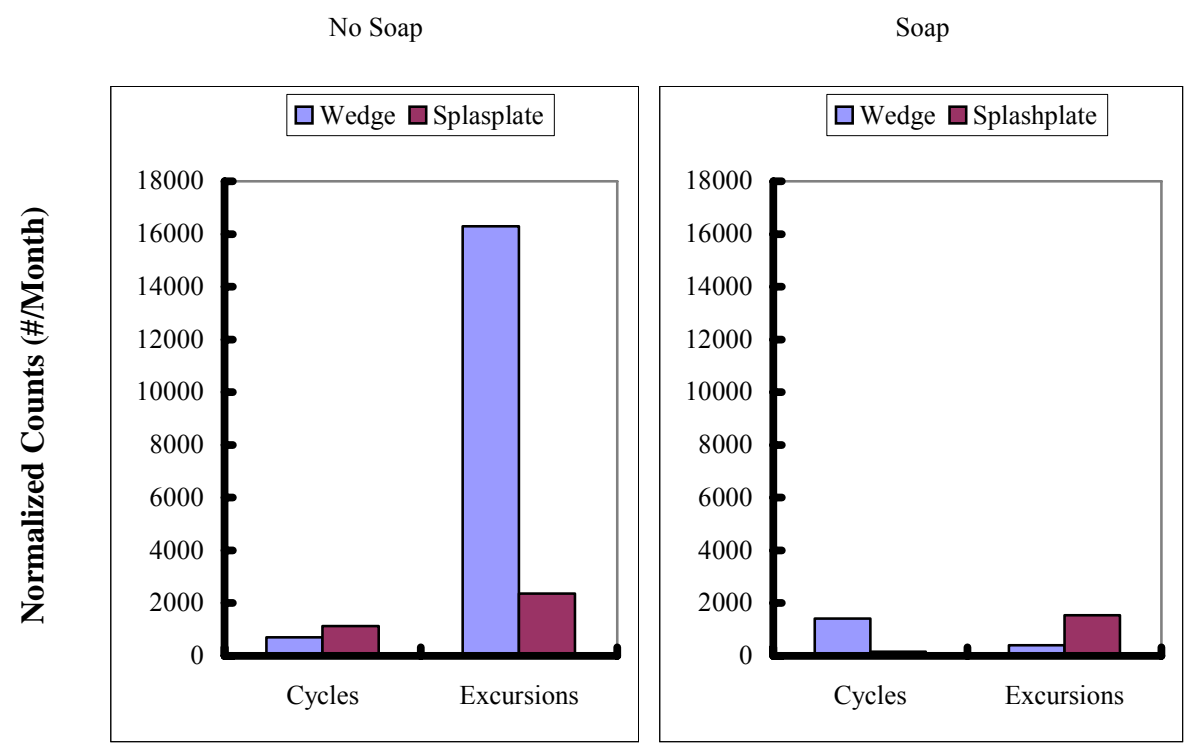

Thermal Activity Type

Fig. 79. Plot comparing thermal activity for trial pairs showing the influence of nozzle type under study with and without the burning of soap in combination with black liquor. The thermal activity measured during Trial Ib (Wedge) and IIc (Splashplate) are compared in the "No Soap" plot, whereas the thermal activity measured during Trial IIa (Wedge) and Trial IIb (Splashplate) are compared in the "Soap" plot.

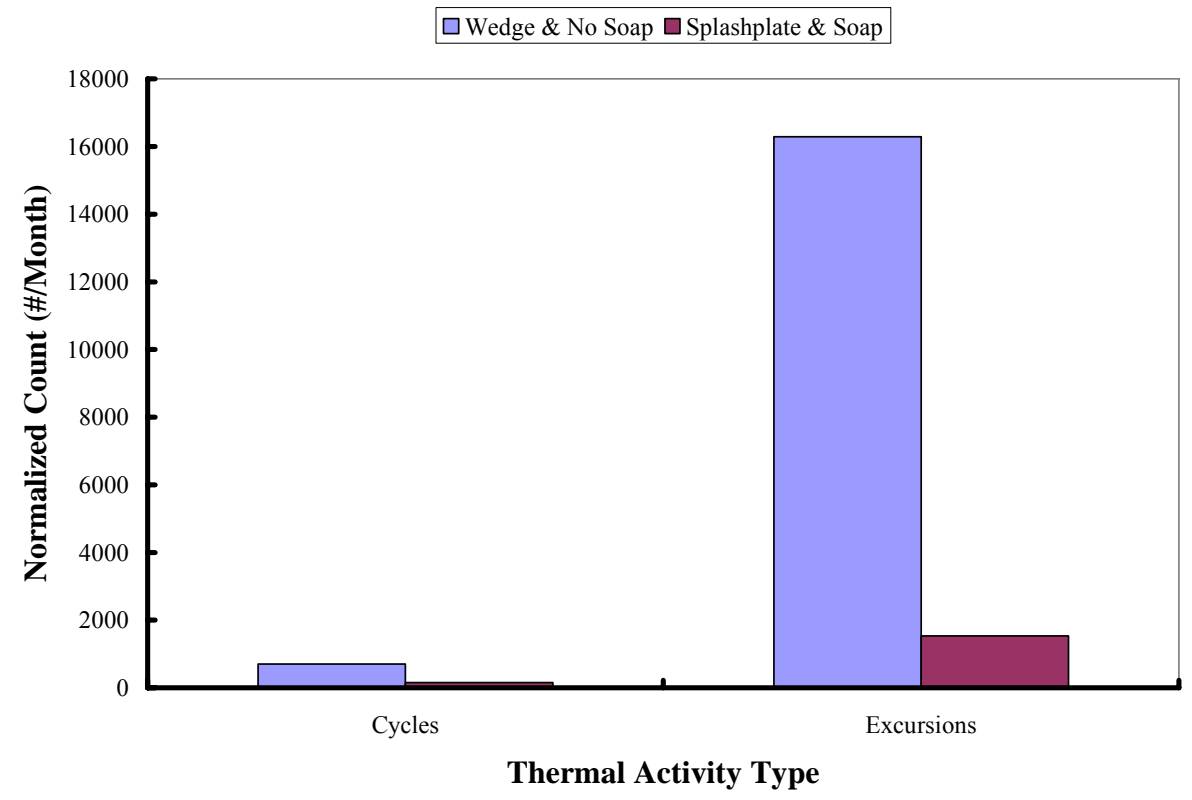

Fig. 80. Plot comparing thermal activity for trial pairs showing the combined additive influence of nozzle type and burning of soap in combination with black liquor. The thermal activity measured during Trial Ib (Wedge \& No Soap) is compared with that measured during Trial IIb (Splashplate \& Soap). 
Table 15. Summary of selected operating parameters from Trials III through VI

\begin{tabular}{|c|c|c|c|c|c|c|c|c|}
\hline Operating parameter & $\begin{array}{c}\text { Trial IIIa } \\
\text { initial mode }\end{array}$ & $\begin{array}{l}\text { Trial IIIb } \\
\text { final mode }\end{array}$ & $\begin{array}{c}\text { Trial IVa } \\
\text { initial mode }\end{array}$ & $\begin{array}{c}\text { Trial IVb final } \\
\text { mode }\end{array}$ & $\begin{array}{c}\text { Trial Va } \\
\text { initial mode }\end{array}$ & $\begin{array}{c}\text { Trial Vb } \\
\text { final mode }\end{array}$ & $\begin{array}{l}\text { Trial Via } \\
\text { initial mode }\end{array}$ & $\begin{array}{l}\text { Trial VIb } \\
\text { final mode }\end{array}$ \\
\hline Time, $\mathrm{h}$ & 12.5 & 12 & 16 & 23 & 26.5 & 24.5 & 25.5 & 10.5 \\
\hline \multicolumn{9}{|c|}{ Black liquor properties } \\
\hline Temperature, ${ }^{\circ} \mathrm{C}$ (as-fired) & 124 & 134 & 128 & 132 & 129 & 128 & 128 & 129 \\
\hline Pressure, $\mathrm{kPa}$ (as-fired) & 259 & 247 & 265 & 160 & 238 & 261 & 254 & 229 \\
\hline Flow Rate (DS), $\mathrm{kg} / \mathrm{h}$ & 76,958 & 73,676 & 67,270 & 71,314 & 67,792 & 71,426 & 72,118 & 68,679 \\
\hline Soap In Combination & Yes & No & Yes & No & Yes & Yes & Yes & Yes \\
\hline \multicolumn{9}{|c|}{ Black liquor delivery system } \\
\hline Nozzle Type & Splashplate & Splashplate & Splashplate & Splashplate & Splashplate & Splashplate & Splashplate & Splashplate \\
\hline Nozzle Diameter $^{a}$ & $4-\# 28$ & $4-\# 30$ & $2-\# 24,2-\# 30$ & $8-\# 24$ & $4-\# 28$ & $4-\# 28$ & $4-\# 30$ & $4-\# 30$ \\
\hline Splashplate Angle & 49 & 49 & 49 & 49 & 49 & 40 & 49 & 40 \\
\hline Tilt Angle, Degrees ${ }^{b}$ & $-4 /-10 /-6 /-10$ & $-4 /-10 /-6 /-10$ & $-10 /-15 /-10 /-10$ & $-15 /-10 /-15 /-15$ & $-9 /-9 /-11 /-8$ & $-15 /-9 /-11 /-10$ & $-16 /-14 /-11 /-14$ & $-18 /-15 /-16 /-13$ \\
\hline \multicolumn{9}{|c|}{ Combustion air system } \\
\hline Total Air Split, PA/SA/TA & $36 / 36 / 28$ & $35 / 35 / 30$ & $36 / 36 / 28$ & $36 / 36 / 28$ & $35 / 36 / 29$ & $35 / 35 / 30$ & $36 / 35 / 29$ & $35 / 36 / 29$ \\
\hline PA Wall Split, $\%^{b}$ & $26 / 22 / 24 / 28$ & $24 / 26 / 24 / 26$ & $21 / 25 / 29 / 25$ & $27 / 23 / 31 / 19$ & $16 / 22 / 38 / 23$ & $24 / 26 / 24 / 25$ & $26 / 25 / 26 / 23$ & $27 / 24 / 25 / 24$ \\
\hline SA Wall Split, $\%^{b}$ & $16 / 37 / 14 / 33$ & $8 / 43 / 5 / 44$ & $6 / 41 / 10 / 43$ & $8 / 43 / 3 / 46$ & $5 / 53 / 1 / 41$ & $4 / 46 / 4 / 46$ & $8 / 50 / 1 / 41$ & $13 / 41 / 7 / 39$ \\
\hline SA Interlaced Pattern & $\begin{array}{l}\text { 4-Wall } \\
\text { mismatch }\end{array}$ & $\begin{array}{l}\text { 2-Wall } \\
\text { mismatch }\end{array}$ & $\begin{array}{l}\text { 3-Wall } \\
\text { mismatch }\end{array}$ & $\begin{array}{l}\text { 2-Wall } \\
\text { mismatch }\end{array}$ & $\begin{array}{l}\text { 2-Wall } \\
\text { mismatch }\end{array}$ & $\begin{array}{l}2-\text { Wall } 5 \times 4 \\
\text { interlaced }\end{array}$ & $\begin{array}{l}2-\text { Wall } 4 \times 4 \\
\text { interlaced }\end{array}$ & $\begin{array}{l}2-\text { Wall } 5 \times 4 \\
\text { interlaced }\end{array}$ \\
\hline
\end{tabular}

${ }^{a}$ Nozzle diameter expressed as \#/32" (\#32 = 1" diameter nozzle).

${ }^{b}$ Expressed as front wall/right wall/rear wall/left wall. 
additive changes coincided with a significant, sustained simultaneous increase in excursions and cycles. The same is true for the short-term eight \#24 splash plate trial.

It is recognized that a significant change was also made to the secondary air arrangement during Trial I. Furthermore, there were also differences in boiler load, nozzle diameter, and possibly tilt angle between Trials I and II. However, those changes are not considered significant since many subsequent changes were made to those parameters during Trials III to V (see Table 15) without any significant sustained increase in thermal fluctuations (see Fig. 75).

\subsubsection{Critical Conditions for Thermal Fluctuations}

Observations during these trials, which include observations from in situ video imaging described in section 6 and reported separately [53], suggest there may be three critical conditions that must be present simultaneously to produce large thermal fluctuations: char bed contacting the port tube, high flux of black liquor droplets contacting the port tube while pyrolysis and possibly dehydration is incomplete, and low primary air jet momentum (Fig. 81). Two of those critical conditions (char bed contacting the port tube and low primary air jet momentum) are derived mainly from observations and measurements reported here. The third critical condition (high flux of black liquor droplets contacting port tubes while pyrolysis and possibly dehydration is incomplete) is derived mainly from observations made from in situ video imaging covered in section 6 [53].

Arguments in support of those critical conditions are made by answering the question: how do these global changes in operation, namely burning of soap in combination with black liquor, nozzle type, and high primary air jet momentum change the local conditions in and around primary air ports?

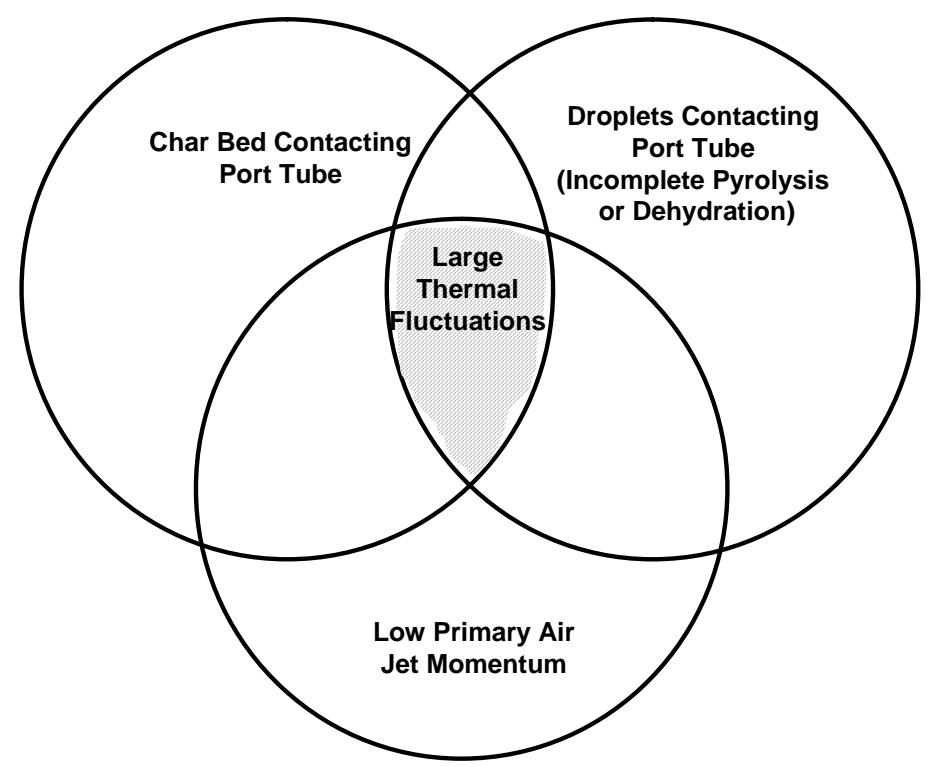

Fig. 81. The three critical conditions required for the large thermal fluctuations associated with primary air port cracking: simultaneous char bed contacting the port tubes, a high flux of droplets contacting the port tube while pyrolysis and possibly dehydration is incomplete, and low primary air jet momentum.

Burning the wood-derived soap in combination with black liquor, as modeled in section 7 , affects black liquor properties in two important ways. First, it increases the viscosity of black liquor and reduces the swelling of black liquor droplets during pyrolysis [54]. Higher viscosity would produce larger liquor droplets, while lower swelling would increase droplet density. The combined effect would be a higher probability that liquor droplets reach the char bed before the char burning is complete. Secondly, adding the higher heating value soap to black liquor increases the heating value 
of the black liquor [54]. Burning the higher heating value mixture would produce higher temperatures in the lower-furnace, which in turn would limit the growth of the char bed. Based on qualitative observation that the char bed height and volume were significantly reduced each and every time soap was burned in combination with black liquor during the trials, it seems as though the increase in heating value has the more significant influence.

The major design difference between the two splashplate nozzles is the presence of a triangular shaped deflector placed on the centerline of the nozzle where the black liquor spray leaves the plate [55]. The goal of the deflector is to direct the black liquor spray to the furnace perimeter. The conventional splashplate nozzle sprays black liquor over a spreading angle of about $180^{\circ}$ off the end of the plate [55]. In contrast, the wedge nozzle eliminates the spray of black liquor over a symmetrical $50^{\circ}$ arc off the end of the plate [55]. Recently, spray visualization [56] and CFD modeling [57] of black liquor sprays off plates of conventional splashplate nozzles demonstrate a variation in droplet size as a function of position and the distance from the centerline of the spreading angle. Droplets tend to be smaller at the edge of the spray and larger at the centerline. Considering the difference in spray pattern between the two nozzles, it is reasonable to assume that a higher fraction of large droplets would be directed towards the furnace perimeter (primary air ports) when using wedge nozzles. If true, then a higher fraction of droplets should contact the area in and around primary air ports while char burning is incomplete. Consequences would include a higher char bed adjacent to the primary air ports, as well as a higher probably of droplets contacting the port bottoms while dehydration and/or devolatilization is incomplete.

A high primary air jet momentum is considered a critical condition since it may affect possible furnace gas eddies below the air ports. Such eddies are believed to be a critical factor in the liquidphase corrosion (balding) mechanism affecting port opening tubes [56]. The formation of a liquid phase is an important consideration since the cracking mode of composite port opening tubes is believed to be environmentally-assisted in nature [49]. It is recognized that higher primary air jet momentum may also have additional benefits, such as physically pushing the bed away from the walls.

Figure 82 schematically illustrates a contour map of the char bed height made during Trial IV. As the map shows, the critical condition of a high char bed located adjacent to the primary air port is met for ports on the right wall, but it is not met for ports on the left wall. This situation provided an opportunity to test the hypothesis that three critical conditions must be present simultaneously for large thermal fluctuations. The test involved producing the two remaining critical conditions simultaneously at an instrumented air port located on each of the side walls (RH19 and LH16) and then observing the temperature response. Closing the damper of the windbox containing the instrumented port attained the critical condition of low primary air jet momentum. The remaining critical condition of droplets contacting the port bottom while pyrolysis and possibly dehydration is incomplete was attempted by closing the damper of the secondary air port located nearest to the instrumented port. In situ video imaging conducted during the experiment, the results of which are reported elsewhere [6], provide strong evidence that this was indeed achieved.

Figure 83 shows the temperature-time transients observed during the verification experiments conducted using ports RH19 and LH16. Superimposed onto the plots as vertical lines are the times at which dampers were closed and subsequently opened. Large thermal fluctuations were recorded in the port (RH19) where all three critical conditions were met upon closing the primary air windbox damper (reducing the primary air jet momentum). Large fluctuations were no longer observed at this port once the primary air windbox dampers were opened (increasing primary air jet momentum). In contrast, no large thermal fluctuations were observed on the port (LH16) where only two of the three (black liquor droplets contacting port tube while pyrolysis and dehydration is incomplete and low primary air jet momentum) critical conditions were met. 


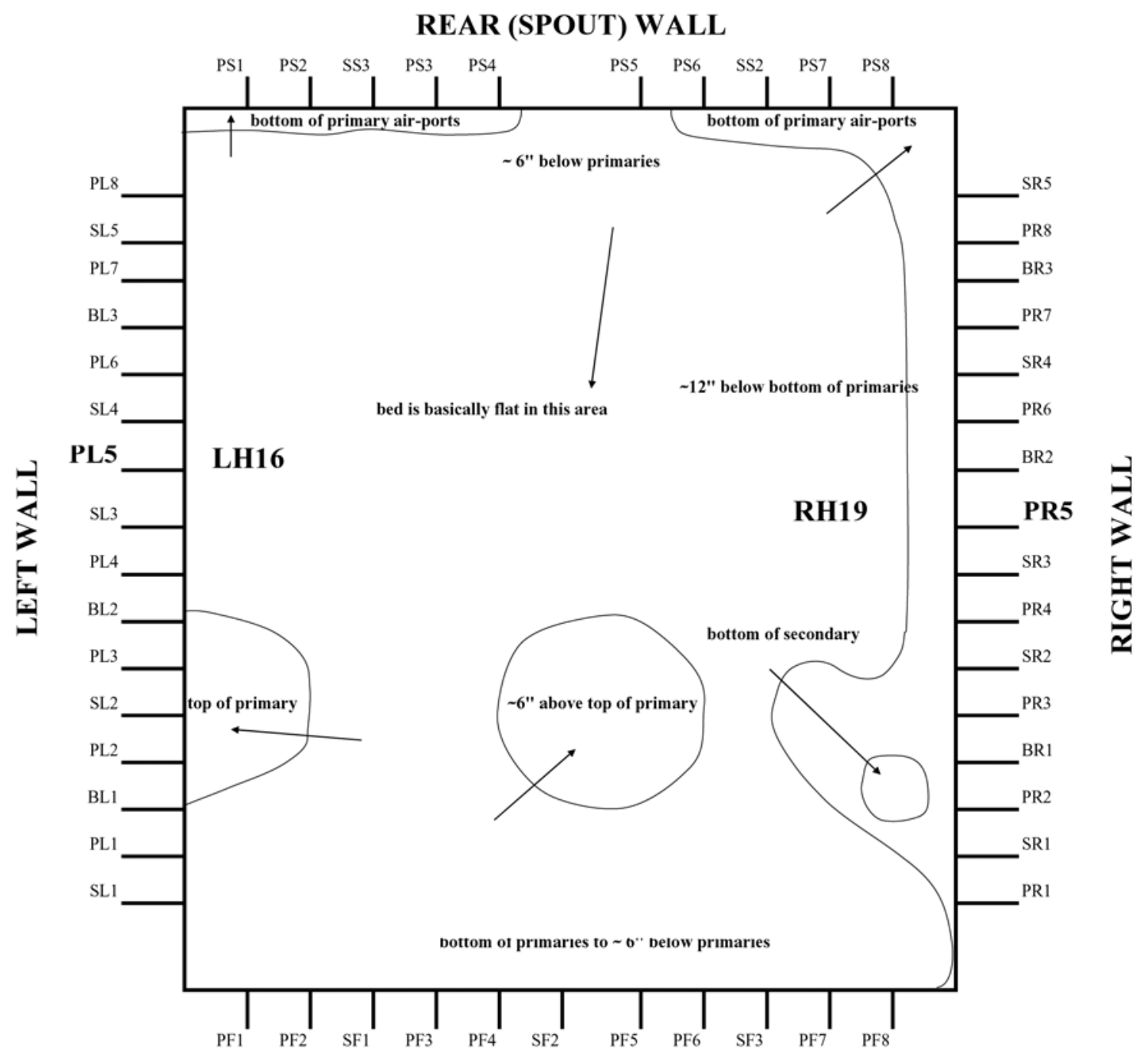

FRONT WALL

Fig. 82. Schematic contour map of char bed shape and height around the time of the verification experiments. Note that the height of the char bed is at the bottom of the primary air ports on the right wall and is about 6 inches below the primary air ports on the left wall along the majority of the wall. Arrows indicate direction of increasing char bed height. 

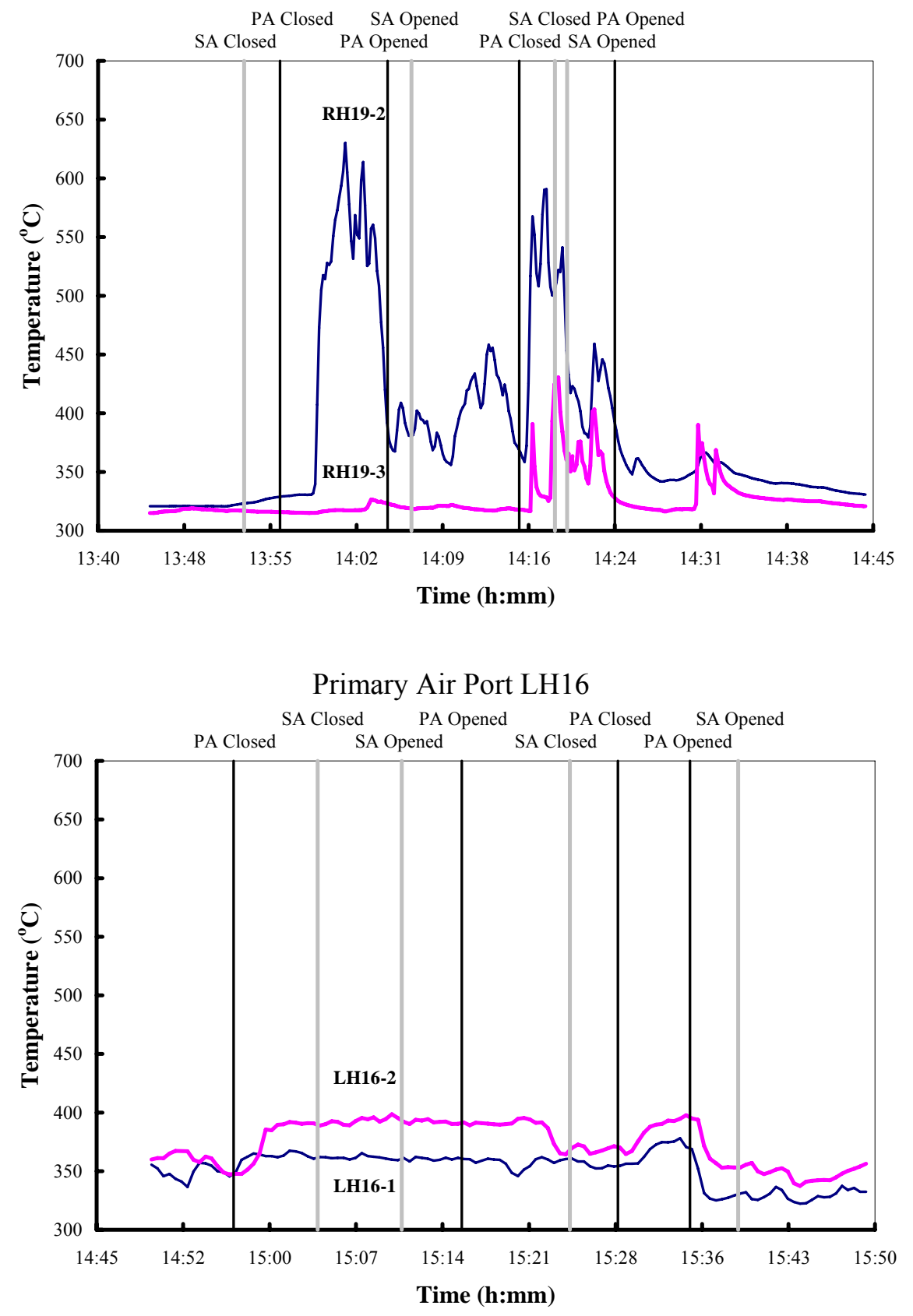

Fig. 83. Plot of temperature transients recorded during the verification experiment. Note the large temperature fluctuations observed for primary air port RH19 when all three critical conditions were met simultaneously. Also note the absence of large thermal temperature fluctuations for port LH16 when only two of the three critical conditions were met simultaneously (the condition of a high char bed contacting the primary air port was missing). 


\subsubsection{Mill Implications}

A strong case has been made that links the likelihood of primary air port cracking to the occurrence of large thermal fluctuations, which, in turn, is linked to a set of three critical operating conditions that must be present simultaneously. The series of links suggests boiler operators may be able to reduce the cracking likelihood by operating the boiler in a manner that simultaneously keeps the char bed away from the ports, prevents black liquor droplets from contacting the port bottoms while pyrolysis and possibly dehydration is incomplete, and provides a relatively high air jet momentum through the primary air ports. For the boiler under study, this involved increasing the primary air jet momentum through each primary air port, burning soap in combination with black liquor, and changing the nozzle type from a wedge to a conventional splashplate.

\subsection{SUMMARY}

- Large thermal fluctuations associated with primary air port cracking are influenced by boiler operation. A set of three additive changes were successful in eliminating large thermal fluctuations observed in the boiler under study, namely increasing the primary air jet momentum to each primary air port, burning soap in combination with black liquor, and changing the nozzle type from a wedge to a conventional splashplate.

- There may be three critical conditions that must be present simultaneously to produce the large thermal fluctuations associated with primary air port cracking: a high char bed contacting the primary air port tube, a high flux of black liquor droplets contacting the port tube while pyrolysis and possibly dehydration is incomplete, and low primary air jet momentum. Boiler operators should operate recovery boilers to avoid all three of those critical conditions as a possible means to reduce the likelihood of cracking. 



\section{MODELING OF STRESSES IN PRIMARY AIR PORT COMPOSITE TUBES}

As part of the overall effort to understand the cracking of composite tubes in primary air ports, modeling of the temperature and stress distributions in the composite tubes has been conducted using the commercial finite element program ABAQUS. The finite element mesh for the air port opening was generated using detailed measurements on primary air port sections provided by the mills. Based on the measurements, the geometry of the bent tube was approximated using a cubic spline.

Assuming symmetry, only one side of the air port opening was discretized using shell elements for the tubes and membranes, and solid elements for the welds, as shown in Fig. 84. The temperature values on the fireside surface were assigned based on the data from the various thermocouples installed at different mills. Representative values were assumed so that the fireside temperature increased from $310^{\circ} \mathrm{C}$ at the bottom of the air port to $360^{\circ} \mathrm{C}$ at the top. Under normal operation, the inside surface of the tube was assumed to be in contact with pressurized water at $295^{\circ} \mathrm{C}$. The cold side of the panel was assumed to be exposed to air at $100^{\circ} \mathrm{C}$. Thermal analysis was used to determine the temperature distribution in the air port for these conditions. Figure 85 shows temperature contours on the outside and inside surface of the tube under normal operating conditions.
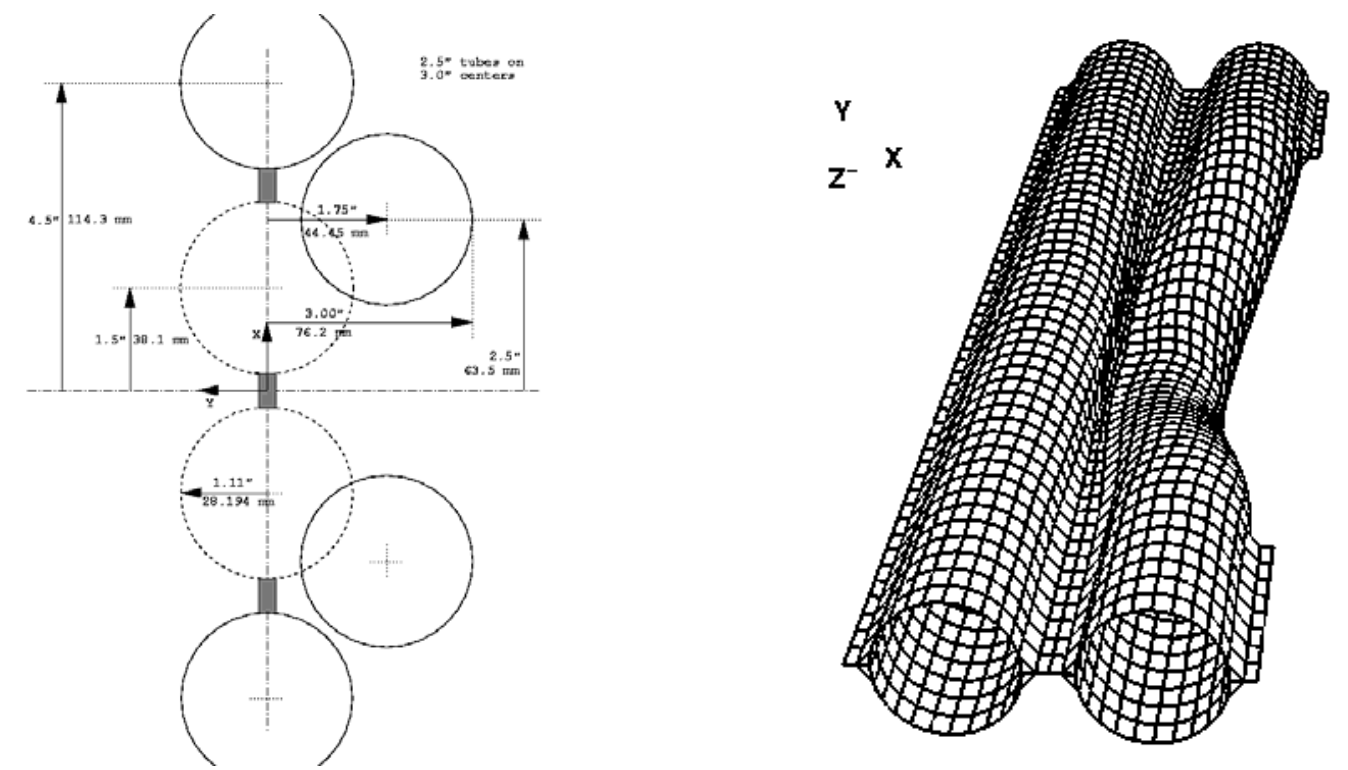

Fig. 84. Schematic representation based on measurements (left) was used to generate a finite element mesh for one side of the primary air port (right).
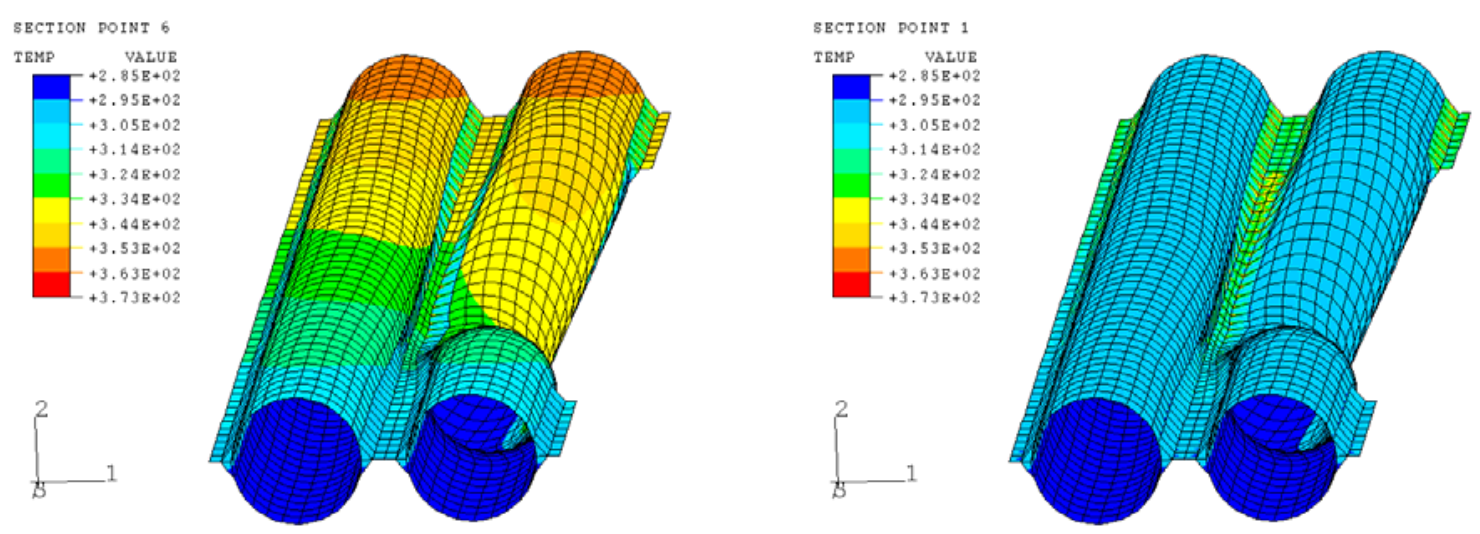

Fig. 85. Temperature $\left[{ }^{\circ} \mathrm{C}\right]$ contours on the outside (left) and inside (right) surface of the primary air port composite tubes under normal operating conditions. 
The computed temperature distribution was used in subsequent mechanical analyses to determine the resulting changes in the stress distribution in the air port panel. Due to lack of sufficient data, the panel was assumed to have no initial residual stresses. Analysis of a normal operating cycle, i.e., starting from room temperature and heating to normal operating condition followed by cooling back to room temperature, showed that the thermal expansion mismatch between $304 \mathrm{~L}$ stainless steel and SA210 carbon steel resulted in both the hoop and axial stress components at the surface of the 304L layer becoming tensile during cooling, as seen in Fig. 86. This result is similar to what was found earlier during analysis of the floor tubes [7]. The stress at the inside surface of the tube became slightly compressive at the end of the operating cycle.
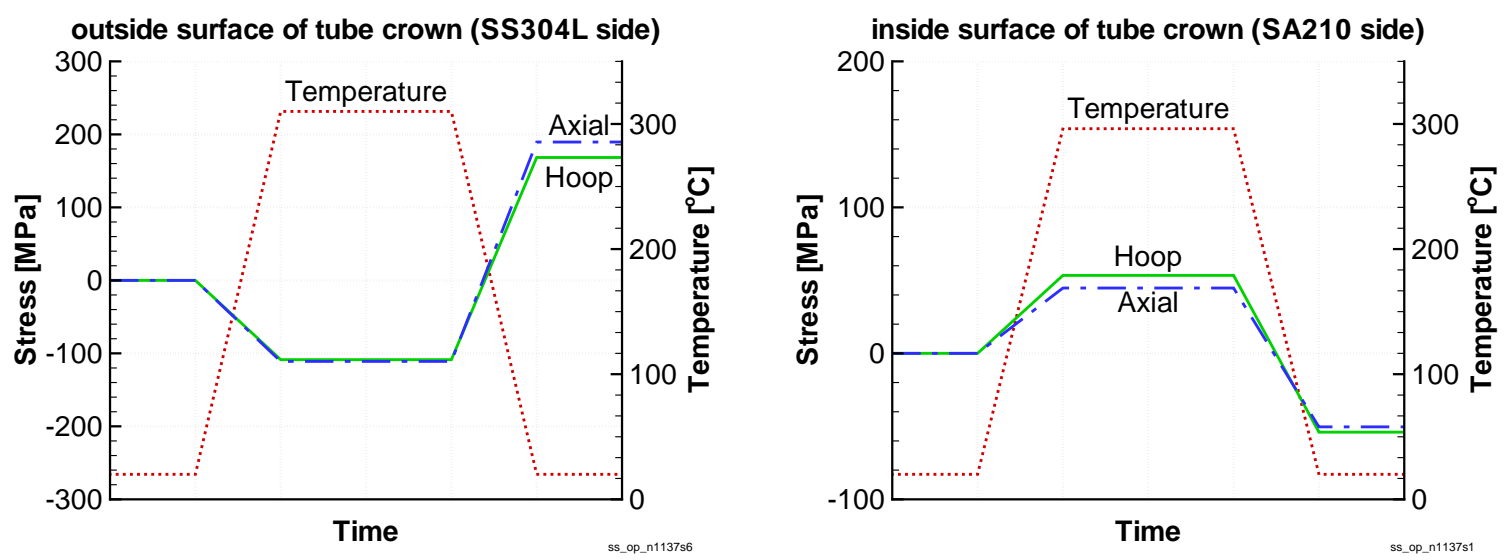

Fig. 86. Variation of hoop and axial stresses during a normal operating cycle at the fireside surface (left) and at the inside surface (right), of a primary air port composite tube.

One significant observation is a difference in the nature of cracking seen on recovery boiler floor tubes and on the bent tubes that form primary air ports. Cracks initiate at the surface in both cases, but they rarely proceed past the interface into the carbon steel in the floor tubes. However, cracks have been observed to propagate into the carbon steel in the lower portion of the bent tubes of primary air ports. Earlier work on modeling of floor tubes showed the presence of compressive axial stresses in the carbon steel, thus limiting circumferential cracks to the clad layer [7]. The model for the primary air port described above was used to examine the operating conditions under which the stresses in the carbon steel could become tensile, thus aiding crack propagation past the interface into the carbon steel layer.

The thermocouple data being collected from several mills indicate that essentially all primary air ports experience fluctuations in temperature, and, in some cases, the fluctuations reach fairly high magnitudes. These severe fluctuations are often limited to the lower portions of the air port opening. The effects of these localized temperature excursions were investigated through finite element modeling. The temperature rise was limited to a small region on the lower portion of the primary air port, while the balance of the tube remained under normal operating conditions. Figure 87 shows the temperature contours assumed for this model during the localized heating. The results of the modeling effort are presented at the surface of the clad layer and at two locations in the carbon steel layer-at the interface on the SA210 side and the inside surface of the tube at the crown of the tube on the fireside, since the interest is mainly in checking for development of tensile stresses in the carbon steel. 


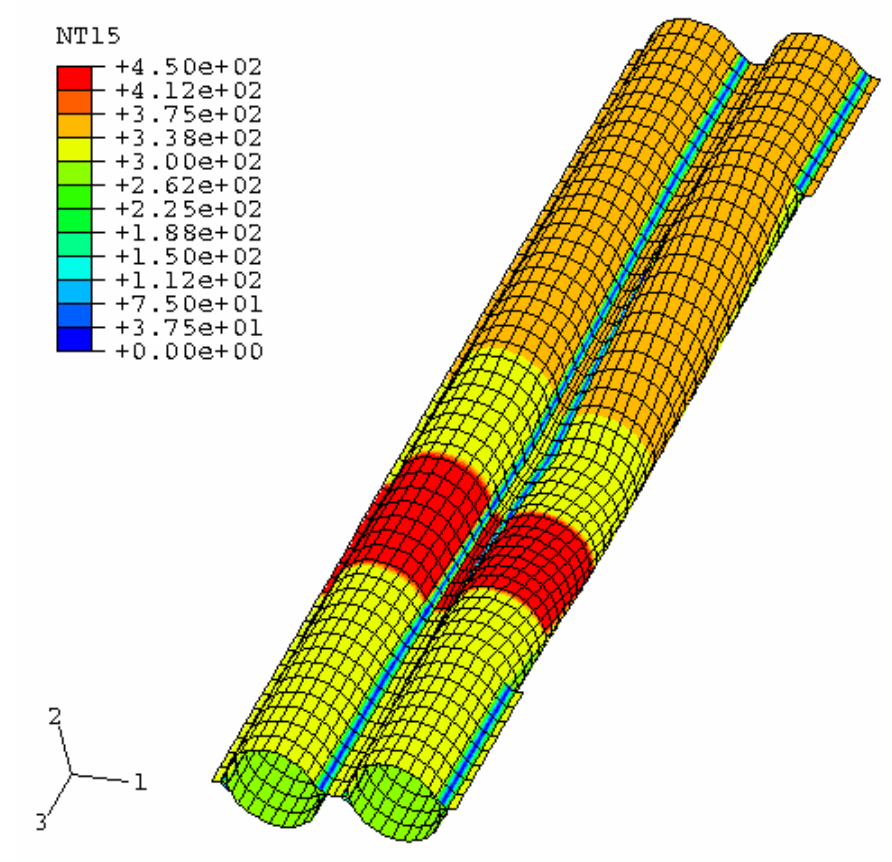

Fig. 87. Temperature $\left[{ }^{\circ} \mathrm{C}\right]$ contours at the fireside surface of primary air port during localized heating.

Figure 88 shows the changes in temperature and stress values at the fireside surface for 304L stainless steel clad tube. The operating cycles analyzed consisted of heating to normal operating temperature as well as localized heating to two different temperatures, $450^{\circ} \mathrm{C}$ and to $600^{\circ} \mathrm{C}$. Due to the large thermal expansion mismatch between stainless steel and carbon steel, the stresses in the clad layer become compressive during heating to operating temperature. Upon cooling back to room temperature, the stresses become highly tensile at the surface. Upon reheating to operating temperature the stresses again are compressive. When the temperature increases further during localized heating, the stresses continue to remain at compressive yield. This is because of the large increase in the temperature gradient through the tube wall, since the inside surface of the tube is assumed to be in contact with water at $295^{\circ} \mathrm{C}$. Removal of localized heating causes stresses to
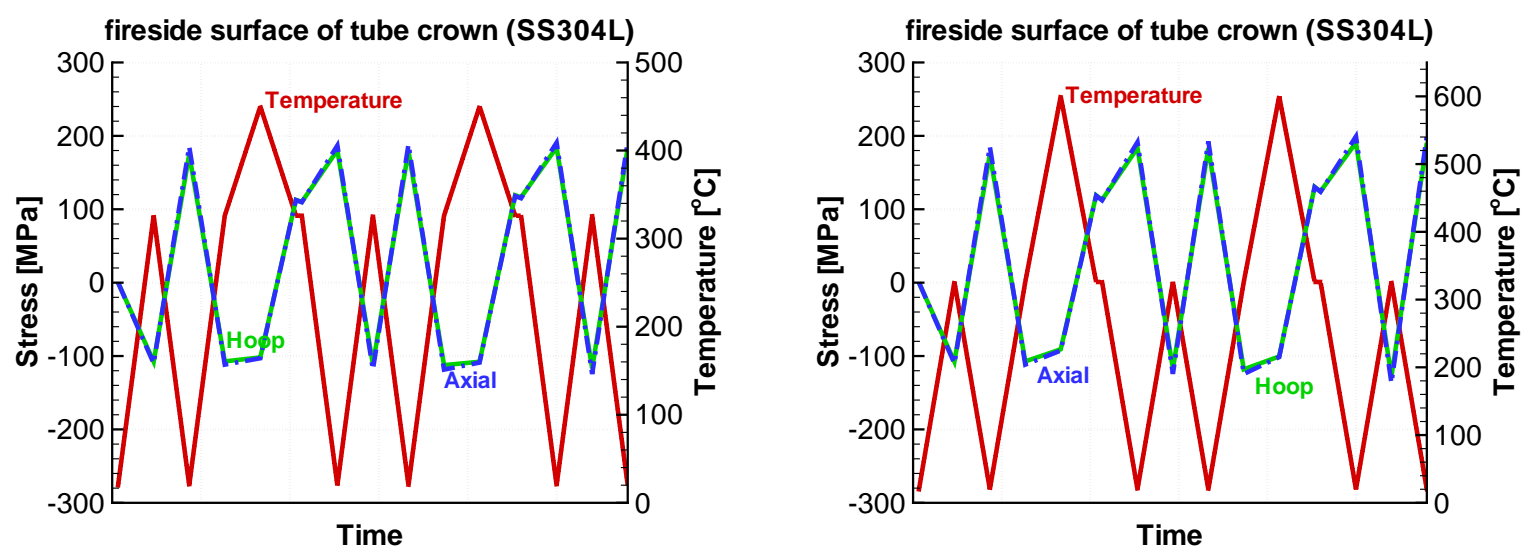

Fig. 88. Stress variation at the fireside surface of the 304L clad composite tube during normal operating cycle and during localized heating to $450^{\circ} \mathrm{C}$ (left) and $600^{\circ} \mathrm{C}$ (right). 
become highly tensile upon returning to operating temperature, and cooling to room temperature further increases their magnitude. A second cycle of localized heating and normal operation shows stress values similar to the first cycle. The results for temperature excursions to $450^{\circ} \mathrm{C}$ and $600^{\circ} \mathrm{C}$ are very similar at the tube surface, since both temperatures exceed the value required to cause yielding in the stainless steel layer. These results are significant, since they show that while stresses are expected to be compressive under normal operating conditions at the fireside surface of the 304L clad layer in primary air port composite tubes, localized temperature excursions can lead to tensile stresses even at normal operating temperature.

Figure 89 shows the temperature and stress variation on the carbon steel side at the interface with the clad layer during normal operation and for the $450^{\circ} \mathrm{C}$ and $600^{\circ} \mathrm{C}$ temperature fluctuations. Heating to operating temperature and cooling to room temperature during a normal operating cycle causes stresses to become slightly compressive. During localized heating to $450^{\circ} \mathrm{C}$, the interface on the SA210 side develops compressive stresses due to the constraint from the region closer to the inside surface which is at lower temperature. When the localized heating is removed, the stresses are less compressive at operating temperature and after cooling to room temperature. The stresses become slightly tensile upon subsequent heating back to operating temperature. When the localized fluctuation temperature is increased to $600^{\circ} \mathrm{C}$, the stresses during localized heating are even more compressive, and the stresses upon returning to operating temperature are now slightly tensile. What is of significance is that due to the plastic deformation resulting from the localized heating, the stresses at operating temperature and at room temperature are now slightly tensile instead of being compressive. Subsequent heating to normal operating temperature now causes tensile stresses of even higher magnitude in the SA210 at the interface, potentially aiding the propagation into the carbon steel layer of cracks that originate in the clad layer. A second cycle of localized heating and normal operation shows variation of stresses which is similar to the first cycle.
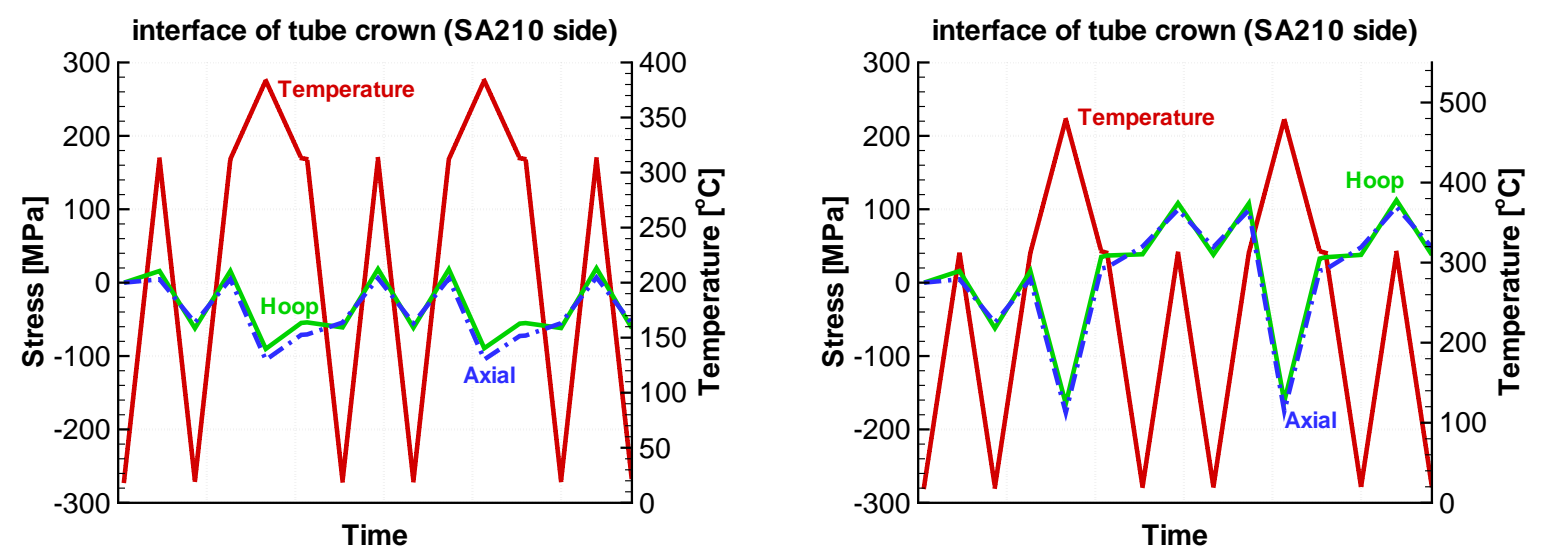

Fig. 89. Stress variation at the interface on the carbon steel side of the $304 \mathrm{~L}$ clad composite tube during normal operating cycle and during localized heating to $450^{\circ} \mathrm{C}$ (left) and $600^{\circ} \mathrm{C}$ (right).

The temperature and stress variations at the inside surface of the tube are shown in Fig. 90. The stresses become tensile during heating to normal operation and compressive upon cooling to room temperature. The tensile stresses increase in magnitude during localized heating due to the increased temperature gradient through the wall. Cooling to operating temperature causes stresses to become compressive, and cooling to room temperature causes further increase in their magnitude. The stress variation at the inside surface is qualitatively similar for localized fluctuations to $450^{\circ} \mathrm{C}$ and $600^{\circ} \mathrm{C}$, with some differences in the magnitudes. The higher temperature leads to a higher magnitude for the 

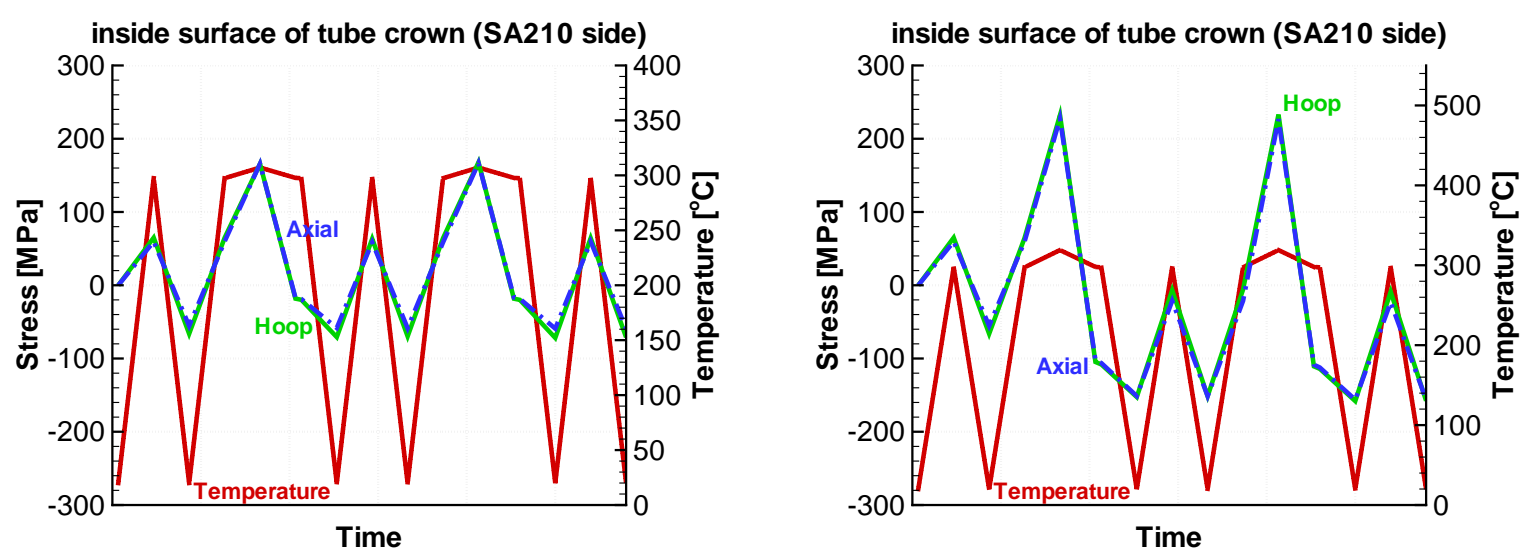

Fig. 90. Stress variation at the inside surface of the $304 \mathrm{~L}$ clad composite tube during normal operating cycle and during localized heating to $450^{\circ} \mathrm{C}$ (left) and $600^{\circ} \mathrm{C}$ (right).

compressive stresses at the end of the localized heating cycle, which would be beneficial in preventing cracks from progressing through the carbon steel layer all the way to the inside surface of the tube. A second cycle of localized heating and normal operation shows results very similar to the first cycle.

Since 304L stainless steel has low yield properties and high thermal expansion mismatch with carbon steel, alternate nickel-based alloys such as alloy 825 are being considered as potential replacements to form the clad layer of composite tubes in primary air ports. The modeling work to determine the stresses in the tubes, both under normal operation and during localized heating, was extended to alloy 825 clad composite tubes. Figure 91 shows the changes in temperature and stress values at the fireside surface for an alloy 825 clad tube. Due to the thermal expansion mismatch between alloy 825 and carbon steel, the stresses in the clad layer become compressive during heating to operating temperature. Upon cooling back to room temperature, the stresses return to their initial values. Upon reheating to operating temperature, the stresses again are compressive. When the temperature increases further during localized heating, the stresses become even more compressive at the surface of the clad layer, because of the large increase in the temperature gradient through the tube wall. Due to plastic deformation, removal of localized heating causes stresses to become much less compressive (almost zero) for the $450^{\circ} \mathrm{C}$ case, while they become highly tensile for the $600^{\circ} \mathrm{C}$ case. Subsequent cooling to room temperature further increases the magnitude of tensile stresses.
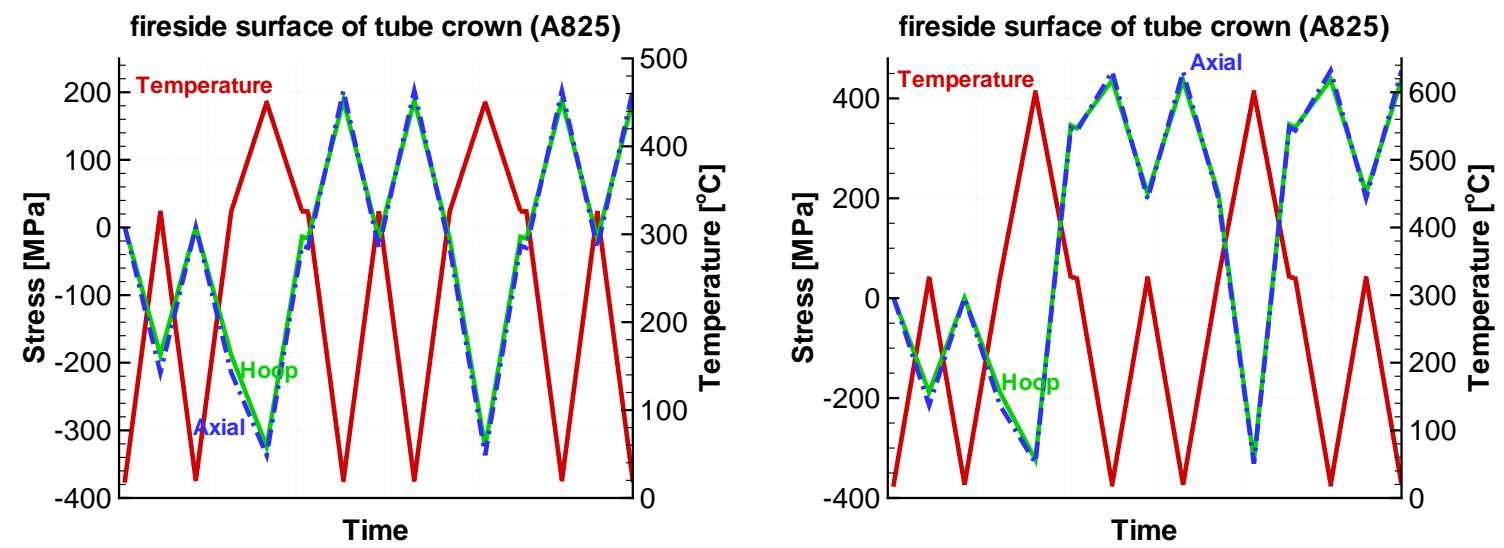

Fig. 91. Stress variation at the fireside surface of the alloy 825 clad composite tube during normal operating cycle and during localized heating to $450^{\circ} \mathrm{C}$ (left) and $600^{\circ} \mathrm{C}$ (right). 
A second cycle of localized heating and normal operation shows stress values remain in the tensile regime during normal operation, indicating that sufficiently large localized temperature excursions can lead to tensile stresses at the fireside surface of the alloy 825 cladding in primary air port composite tubes.

Figure 92 shows the temperature and stress variation on the carbon steel side of the interface with the clad layer during normal operation and for the $450^{\circ} \mathrm{C}$ and $600^{\circ} \mathrm{C}$ thermal excursions. During localized heating, the interface on the SA210 side develops compressive stresses due to the constraint from the region closer to the inside surface which is at lower temperature. When the localized heating is removed, the hoop stress is slightly tensile and axial stress is close to zero at operating temperature for the $450^{\circ} \mathrm{C}$ case. The stresses become compressive upon cooling to room temperature. During subsequent heating and cooling, the hoop stress changes between slightly tensile and slightly compressive values while the axial stress remains compressive. For the $600^{\circ} \mathrm{C}$ temperature fluctuation, both hoop and axial stresses become compressive during localized heating and remain compressive upon returning to operating temperature. The stresses remain compressive during subsequent normal operating cycle and localized heating and cooling. Unlike the stresses at the surface, the changes in stress values are not that large at the interface on the carbon steel side, and therefore effects of initial stress values would be significant in this case.

The temperature and stress variations at the inside surface of alloy 825/SA210 air port tubes are shown in Fig. 93. The stresses become tensile during heating to normal operation, and
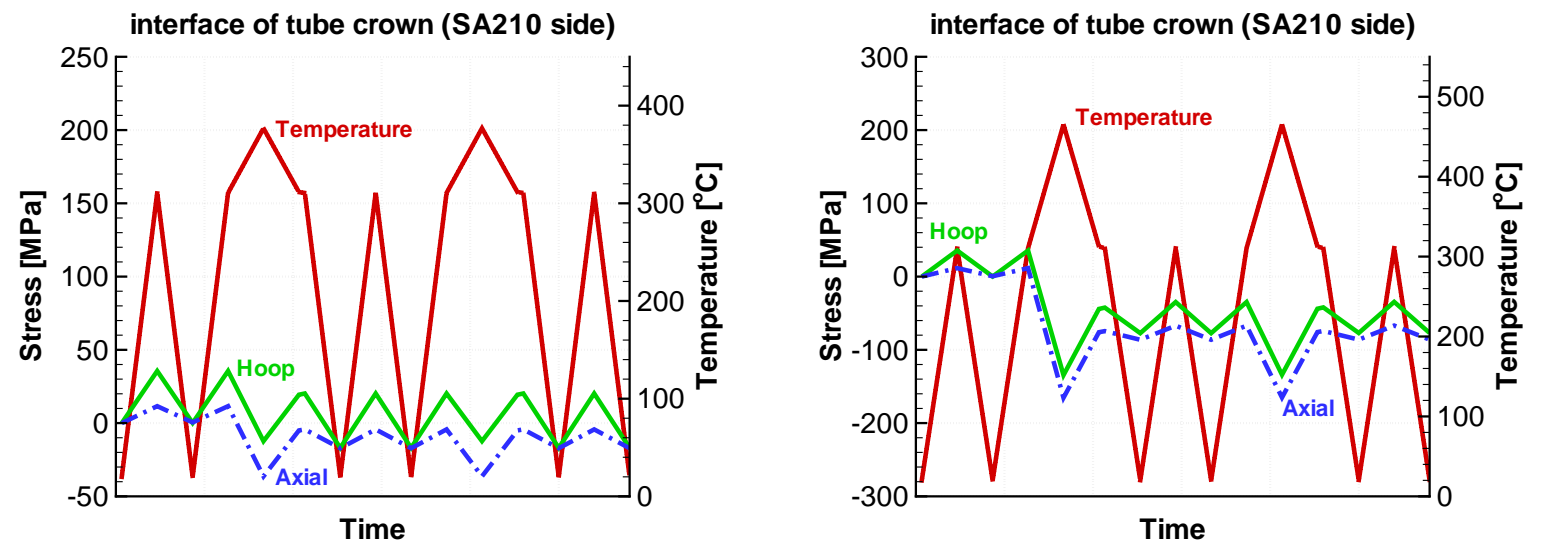

Fig. 92. Stress variation at the interface on the carbon steel side of the alloy 825 clad composite tube during normal operating cycle and during localized heating to $450^{\circ} \mathrm{C}$ (left) and $600^{\circ} \mathrm{C}$ (right).
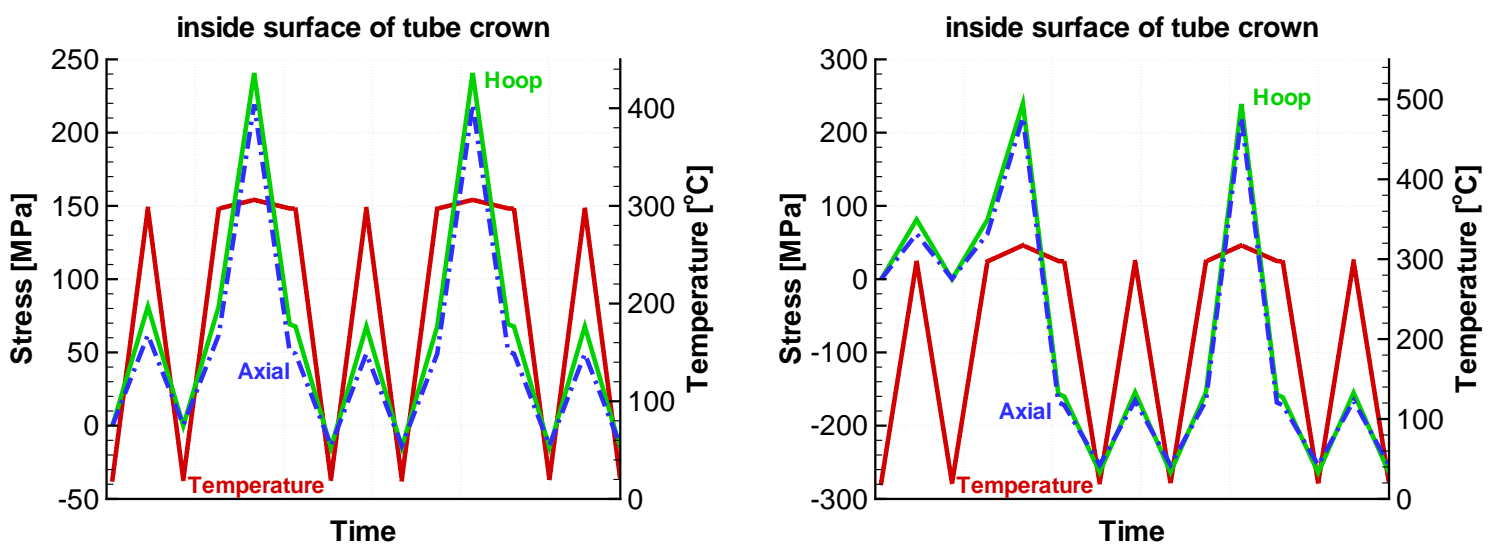

Fig. 93. Stress variation at the inside surface of the alloy 825 clad composite tube during normal operating cycle and during localized heating to $450^{\circ} \mathrm{C}$ (left) and $600^{\circ} \mathrm{C}$ (right). 
increase in magnitude during localized heating due to the increased temperature gradient through the tube wall. For the $450^{\circ} \mathrm{C}$ temperature excursion, cooling to operating temperature causes stresses to return close to values before the localized heating, and subsequent cycles show similar behavior. For the $600^{\circ} \mathrm{C}$ temperature excursion, cooling to operating temperature causes stresses to become compressive, and cooling to room temperature causes further increase in their magnitude. The stresses remain compressive during subsequent normal operation.

It must be emphasized that the results presented here were obtained assuming no initial stresses in the primary air port, and the magnitude of stresses would clearly change if the initial stresses were considered in the analyses. However, the modeling does highlight certain trends in the stress variation, and shows the possibility for developing tensile stresses in the presence of sufficiently large localized temperature excursions. There is also an indication from the modeling results that the initial stresses may not play a major role in determining the stresses at the fireside surface after the first cycle with localized heating, due to plastic deformation which permanently alters the stresses in this portion of the tube. This is especially true at the fireside surface of the tube with 304L stainless steel clad material. The alloy 825 clad material requires a larger temperature fluctuation to develop tensile stresses, but does not appear to be immune from this effect.

The large temperature gradient through the tube wall thickness appears to play the most significant role in development of the tensile stresses at the interface in the carbon steel layer for the 304L clad tubes. The fact that tensile stresses develop at the interface would suggest that cracks that initiate in the clad layer could proceed into the carbon steel. However, the presence of compressive stresses at the inside surface would indicate that the cracks will most likely stop before reaching the inside surface. The change in stress from approximately neutral or slightly tensile near the interface to highly compressive at the inside surface is supported by experimental data using neutron diffraction measurements at the lower portion of the bent tube on an air port panel taken from service [29]. Measurements on the same bent tube at the top portion of the air port showed compressive axial stresses throughout the carbon steel layer, which is consistent with the results when the temperature excursions are absent or when the peak temperatures are not very high. The data from the primary air port thermocouples also show the occurrence of temperature excursions with greater frequency and magnitude at the lower portion of the bent tube. Stresses in the carbon steel layer of tubes with alloy 825 as clad material remain at the initial values or become more compressive, depending on the temperature fluctuation. This would indicate that cracks developing in the clad layer will not progress into the carbon steel layer, unlike the stainless 304L clad composite tube, suggesting that materials with a lower thermal expansion mismatch with SA210 carbon steel and higher strength are more suitable choices for recovery boiler composite tubing at the primary air port level.

In addition to an association with crack initiation in the vicinity of the bottom of the air port, the temperature fluctuations, if severe enough, can make the tube vulnerable to penetration of the crack into the carbon steel. Experience from years of monitoring temperatures on primary air port tubes on the various instrumented boilers has shown that air port tubes that suffer from the cracking problem have occasional fluctuations that exceed $600^{\circ} \mathrm{C}$; in fact, temperatures over $750^{\circ} \mathrm{C}$ have been recorded. In view of this analysis, it is important to understand the cause of the temperature fluctuations and how this can be controlled without otherwise adversely affecting boiler operation. While it may not be possible to eliminate the temperature excursions entirely, limiting their magnitude would be an important step in reducing the potential for cracking of the composite tubes in primary air ports.

\subsection{MODELING OF HEAT FLUX REQUIRED TO CAUSE LOCALIZED TEMPERATURE EXCURSIONS}

As described in the previous section on modeling the stresses in the primary air port composite tubes, a sufficiently large localized rise and fall in temperature at the fireside surface of the tube can cause the stresses to become tensile. The presence of such large thermal excursions has been observed from the thermocouple data, and an attempt was made to investigate what could cause such 
fluctuations. In particular, modeling was carried out to determine the source and amount of heat flux required to cause the temperature increase. The three-dimensional finite element model described earlier was used to predict the temperature variations that might occur on a primary air port composite tube subjected to localized changes in the heat flux. Based on the observations from the camera work, two potential sources of heat release at the fireside surface of the tube were considered-combustion of black liquor droplets and oxidation of $\mathrm{Na}_{2} \mathrm{~S}$ from the smelt layer.

For both cases, the model used the assumption that the inside surface of the tube was in contact with water at $295^{\circ} \mathrm{C}$, and the increase in heat flux was assumed to occur over a $2 \times 2$ element region of approximately $375 \mathrm{~mm}^{2}\left(0.6 \mathrm{in}^{2}\right)$ area on the lower portion of the bent tube, as shown in Fig. 94 . Furthermore, it was assumed that all of the heat generated by the combustion or oxidation is directly felt by the tube surface, whereas, in practice, the tube fireside surface is often covered by a thin layer of frozen smelt-as has been documented by the video camera. The duration of the heat pulse modeled was assumed to be the result of a single event, even though the video camera work and personal observations indicated that both the liquor droplet deposition and the flow of molten smelt usually continued for a longer time.

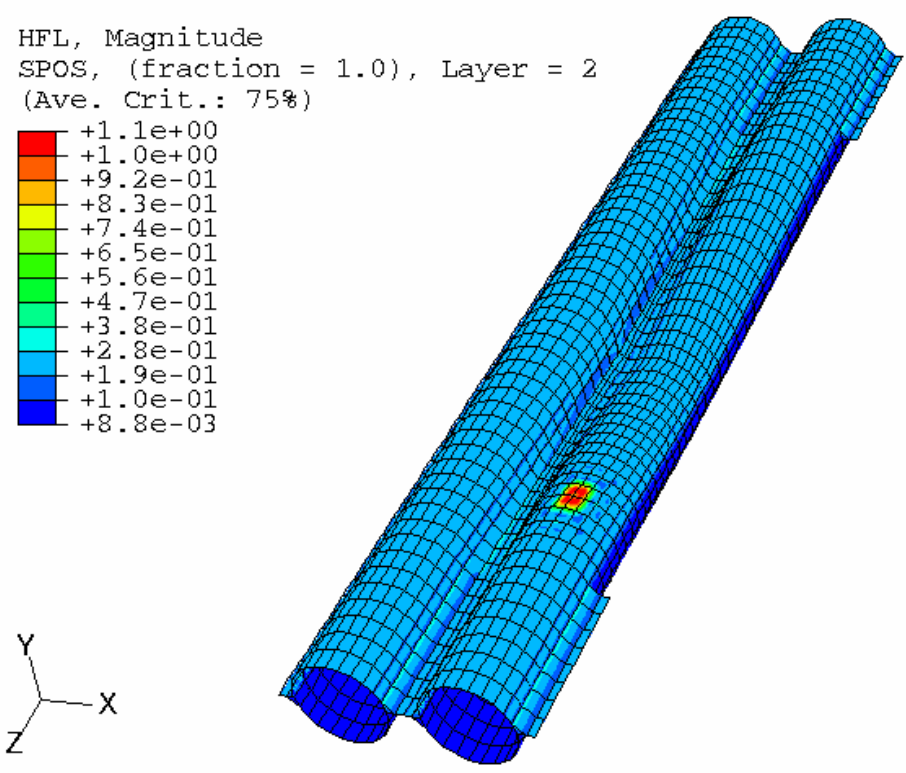

Fig. 94. Heat flux $\left[\mathrm{W} / \mathrm{mm}^{2}\right]$ contours on the outside surface of primary air port showing region of increased heat flux on the lower portion of the bent tube.

For the case of heat release from the combustion of black liquor droplets on the tube surface, the contributions from the volatile combustion (pyrolysis) and the char burning stages were considered. It was assumed that the total heat generated can be approximated by a heat flux profile which increases linearly over a fairly short period of time $(1.5-2.5 \mathrm{~s})$, before decreasing more gradually to the initial value. It was also assumed that the entire $2 \times 2$ element region of the tube surface was simultaneously under the influence of liquor droplets undergoing combustion. The variation in heat flux and the resulting temperature at the tube surface due to the combustion of liquor droplets is shown in Fig. 95 for three different droplet sizes. The smaller the droplet size, the higher is the peak heat flux and the temperature increase, and also the faster is the drop in temperature to its initial value. Since the heat flux is computed using an area measure based on the initial diameter of the droplet, the smaller droplet leads to a greater heat flux. It should be noted that the smaller droplet size causes a larger increase in temperature, but for a smaller duration. 

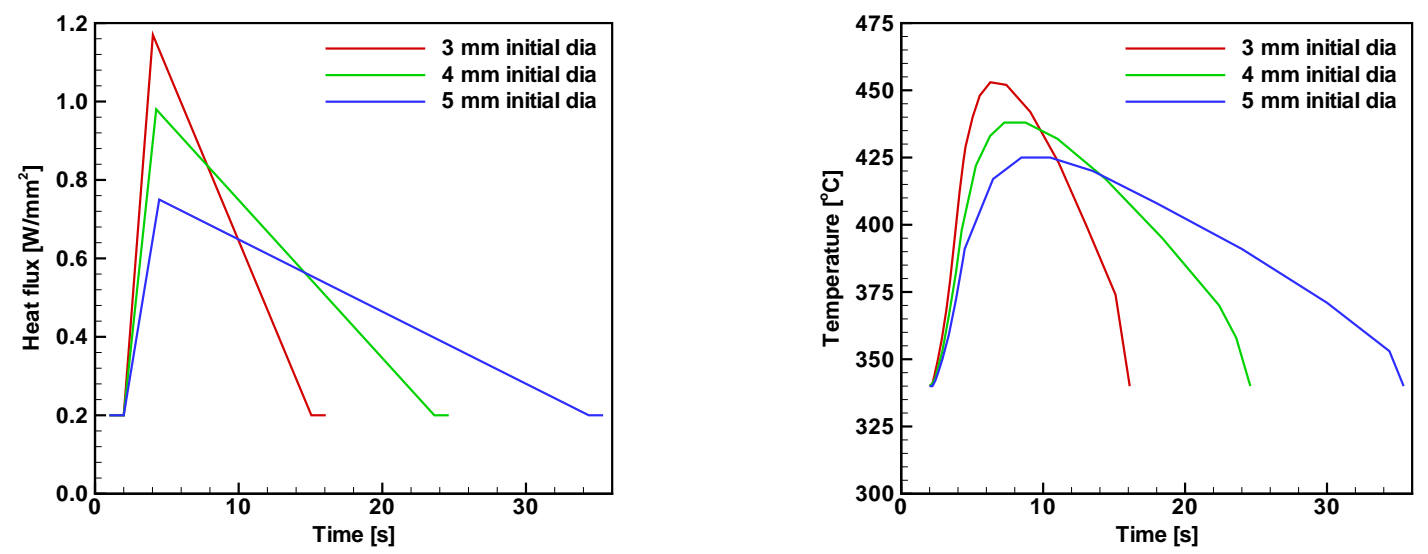

Fig. 95. Variation of heat flux (left) and corresponding temperature (right) during localized heating due to combustion of black liquor droplets on the primary air port tube surface.

The other source of heat for a localized increase in temperature considered in the analyses was the exothermic reaction of smelt oxidation, which converts $\mathrm{Na}_{2} \mathrm{~S}$ to $\mathrm{Na}_{2} \mathrm{SO}_{4}$. The maximum heat generated by the oxidation of a smelt layer on the tube surface was estimated, based on the assumption that sufficient oxygen was available to oxidize all the $\mathrm{Na}_{2} \mathrm{~S}$ in the smelt. In this case, the heat release was assumed to occur over a fixed period of 10 seconds, with a linear increase in heat flux over 3 seconds, followed by a linear decrease over the next 7 seconds. The heat flux increases with the thickness of the smelt layer, as does the maximum temperature at the center of the heated region (Fig. 96). Similar to the previous case, all of the heat from the smelt oxidation is assumed to go into heating the tube surface.
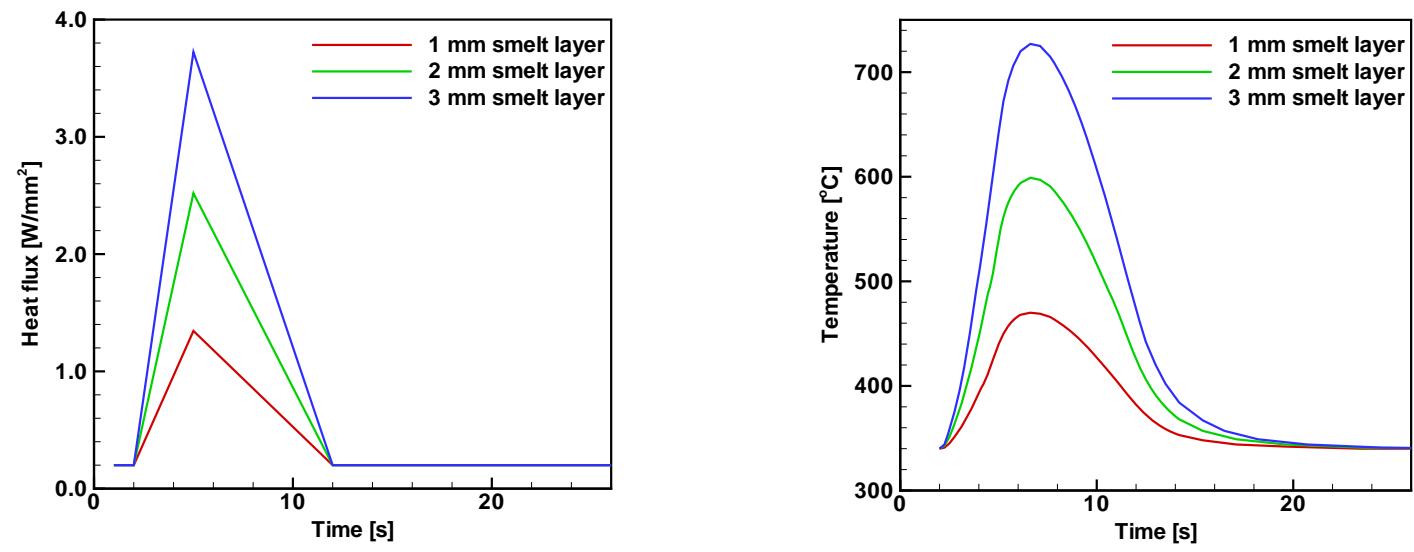

Fig. 96. Variation of heat flux (left) and corresponding temperature (right) during localized heating due to oxidation of $\mathrm{Na}_{2} \mathrm{~S}$ in the smelt on the primary air port tube surface.

The analyses described show that smelt oxidation is capable of causing a fairly large increase in temperature, although it should be mentioned that the magnitudes shown are based on calculations with several simplifying assumptions. The possible insulation offered by the frozen smelt layer has not been included in the analyses, and this could lower the maximum temperature during the localized heating. Nevertheless, the modeling results show smelt oxidation can lead to a fairly high heat flux and a significant increase in temperature, while the combustion of black liquor droplets leads to a comparatively smaller temperature rise. Thermocouple data recorded at 10 second intervals show, in 
some instances, the tube surface experiences elevated temperatures for significant periods of time, whereas the temperature variations shown here last for less than a minute. These analyses only considered "single event" cases, and it may be important to consider sustained heat release due to smelt running down the tube surface or delivery of black liquor droplets to the tube surface over much longer periods of time.

Calculations were also performed using a simple one-dimensional heat transfer model to estimate both the heat flux and the temperature of the boiler environment that could lead to an increase in the temperature of the fireside tube surface. Figure 97 shows the tube surface temperature as a function of the heat flux and the boiler temperature. A heat flux value of $0.25 \mathrm{MW} / \mathrm{m}^{2}$ leads to a tube fireside temperature of $351^{\circ} \mathrm{C}$, which corresponds to normal operating conditions. A heat flux of $1.6 \mathrm{MW} / \mathrm{m}^{2}$ is required to increase the tube fireside temperature to $644^{\circ} \mathrm{C}$. For the analyses of the temperature rise due to increase in the boiler temperature, two values of emissivity of the tube surface were considered-one corresponding to the value for 304L stainless steel and a higher value corresponding to a layer of frozen smelt on the tube surface. For the lower emissivity, a boiler temperature of $3000^{\circ} \mathrm{C}$ is required to cause the tube surface temperature to reach $650^{\circ} \mathrm{C}$. Even with the higher emissivity, the boiler temperature needs to be $2550^{\circ} \mathrm{C}$ to cause the thermal excursion to $650^{\circ} \mathrm{C}$, which is unlikely to occur with the frequency that is observed for the thermal fluctuations. Therefore, it is concluded the thermal fluctuations are caused by an increase in heat flux.
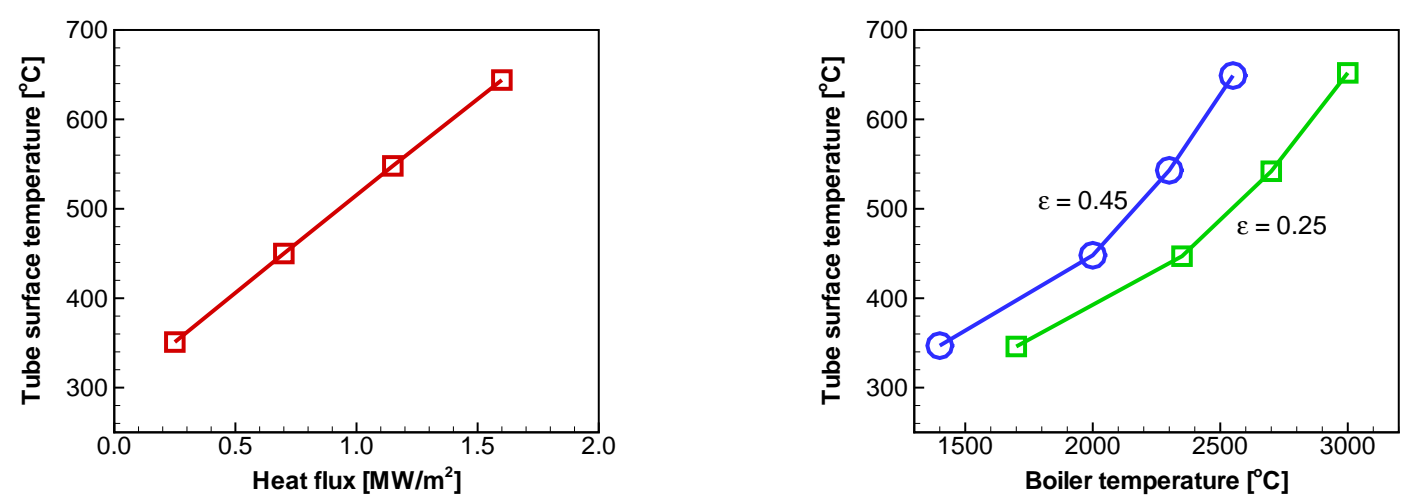

Fig. 97. Change in temperature at the fireside surface of primary air port tubes due to increase in heat flux (left) and due to increase in the boiler temperature (right).

While it is difficult to conclusively determine whether combustion of black liquor particles or smelt oxidation is the primary cause of the increased heat flux, it is considered likely that both mechanisms are operative at various times, and sometimes simultaneously, leading to the thermal fluctuations observed on the lower portion of the bent tubes in primary air ports. Therefore, avoiding these fluctuations requires operating the boiler in a manner which minimizes the potential for unburned black liquor droplets or smelt rich in $\mathrm{Na}_{2} \mathrm{~S}$ to come in contact with the tube surface close to the primary air port opening for extended periods of time. 


\section{NEUTRON AND X-RAY DIFFRACTION MEASUREMENT OF RESIDUAL STRESSES IN COMPOSITE TUBES}

Unlike floor tubes, some of the cracks occurring in the air port tubing continue into the carbon steel, making air port tube cracking a very serious issue. Measurement of stresses in floor tubes has shown that the carbon steel is in compression at the carbon steel/stainless steel interface. In contrast, previous measurements of stresses in the tubes forming primary air ports have shown that the stresses in the carbon steel were near neutral or tensile at the bottom of one air port. Determination of the exact nature of these stresses can offer a means to lessen the chances of cracks advancing into the carbon steel.

As has been previously described, both X-ray and neutron diffraction are used to measure the stresses, respectively, on the surfaces and within the wall of tubes [59,60]. Measurements on unexposed tubes provided the initial stresses for the finite element stress modeling studies of recovery boiler floors, and measurements on unexposed and exposed floor panels confirmed the predictions of the finite element models. Stress measurements have also been made on floor membranes, particularly the $25 \mathrm{~mm}$ ( 1 inch) wide membranes used in the 3-on-4 construction. These measurements have provided support for the modeling studies that predict tensile stresses in the carbon steel of the clad sheet used for membranes.

More recent studies have addressed the formidable task of measuring stresses on the curved surfaces of primary air port tubes. In order to avoid cutting the panel and relieving the stresses, every effort is made to keep the air port as a four-tube pack, but that makes positioning of the sample for measurements considerably more difficult. To provide appropriate samples for these studies, two boiler manufacturers, B\&W - Canada and Kvaerner Pulping, have provided four-tube panels containing a primary air port along with a single extra tube that is bent in the shape of the bent tube used in the air ports. This permitted measurement of the stresses in the single bent tube and in the bent and straight tubes after welding. Several paper companies have provided exposed (and usually cracked) air port panels for after-exposure testing.

$\mathrm{X}$-ray diffraction was used to measure the surface stresses in the single, unexposed, bent tube shown in Fig. 98. To avoid most effects of surface cold-work, the surface was electropolished to remove about $0.04 \mathrm{~mm}(0.0015 \mathrm{inch})$ in the areas where measurements were to be made. The bright circles on the side of the tube in Fig. 98 are the areas that were electropolished and used for surface stress measurements. Figure 99a shows the variation in axial residual stress measured along the length

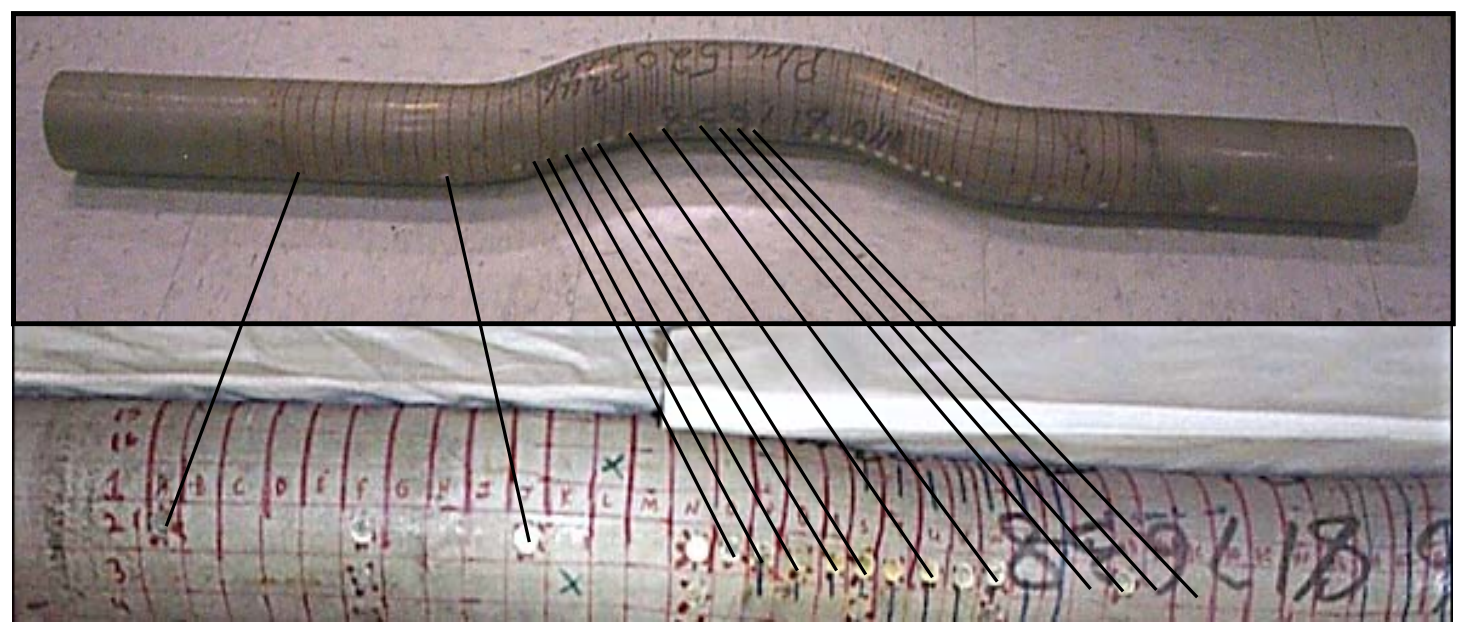

Fig. 98. Photo of a 304L stainless steel clad tube bent in the shape required for the most common air port design used in North American boilers. The shiny circles are the electropolished areas where X-ray diffraction residual stress measurements were made. 


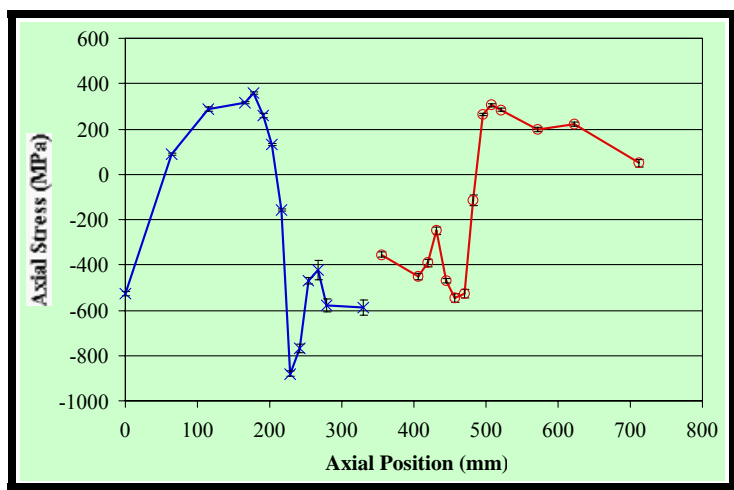

(a)

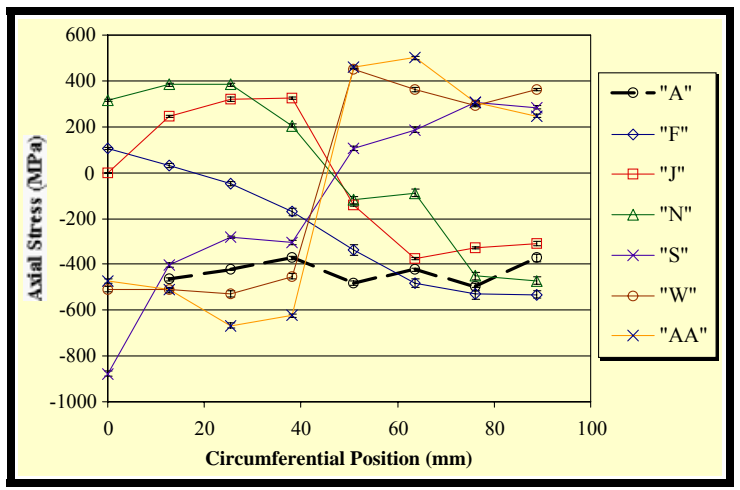

(b)

Fig. 99. Surface residual axial stresses measured (a) at selected locations along the tube and (b) at selected locations around the circumference of the tube.

of the tube in the locations indicated. In the unbent portion of the tube, the axial stress is compressive, but as the measuring location moves around the "stretched" portion of the tube, the stresses become tensile. As the measuring location moves on to the "compressed" area of the tube, the stresses become highly compressive then the sequence is reversed as the measuring location moves on to the second half of the tube.

Figure 99(b) shows the variation in axial stress at selected locations around the circumference of the tube. At section A in the unbent portion of the tubing, the axial stresses are compressive all the way around the tube. In the first portion of the bent tube, sections F, J and N, the stresses are generally tensile during the first half of the measurements, then they become compressive. In sections $\mathrm{S}, \mathrm{W}$ and AA, the stresses are compressive during the initial measurements, then become tensile during the latter measurements. Clearly, in the unexposed tube at room temperature, there are regions in the bent portion of the tube where the surface stresses are highly tensile.

Neutron diffraction measurements have also been made to determine the stresses within the stainless steel clad layer and within the ferritic carbon steel material. These measurements were made below the surface at approximately the same locations where the surface residual stress measurements were made. Fig. 100 shows the result of the neutron diffraction residual stress measurements. These indicate that the axial strains in the carbon steel are compressive in the straight portion of the tube, but they become tensile in some of the bent regions of the tube. It has to be noted that these measurements are made at room temperature in unwelded tubing and represent an average over the thickness of the carbon steel shell. Nevertheless, there is a clear indication that significant changes occur in the strains (and stresses) when the tubes are bent at this radius. Figure 101 shows the stresses measured at several points through the wall thickness of an exposed tube. These results show the stresses in the carbon steel near the interface in the bent portion of the tube are near neutral while stresses measured in comparable locations at the top of the air port were more compressive. 


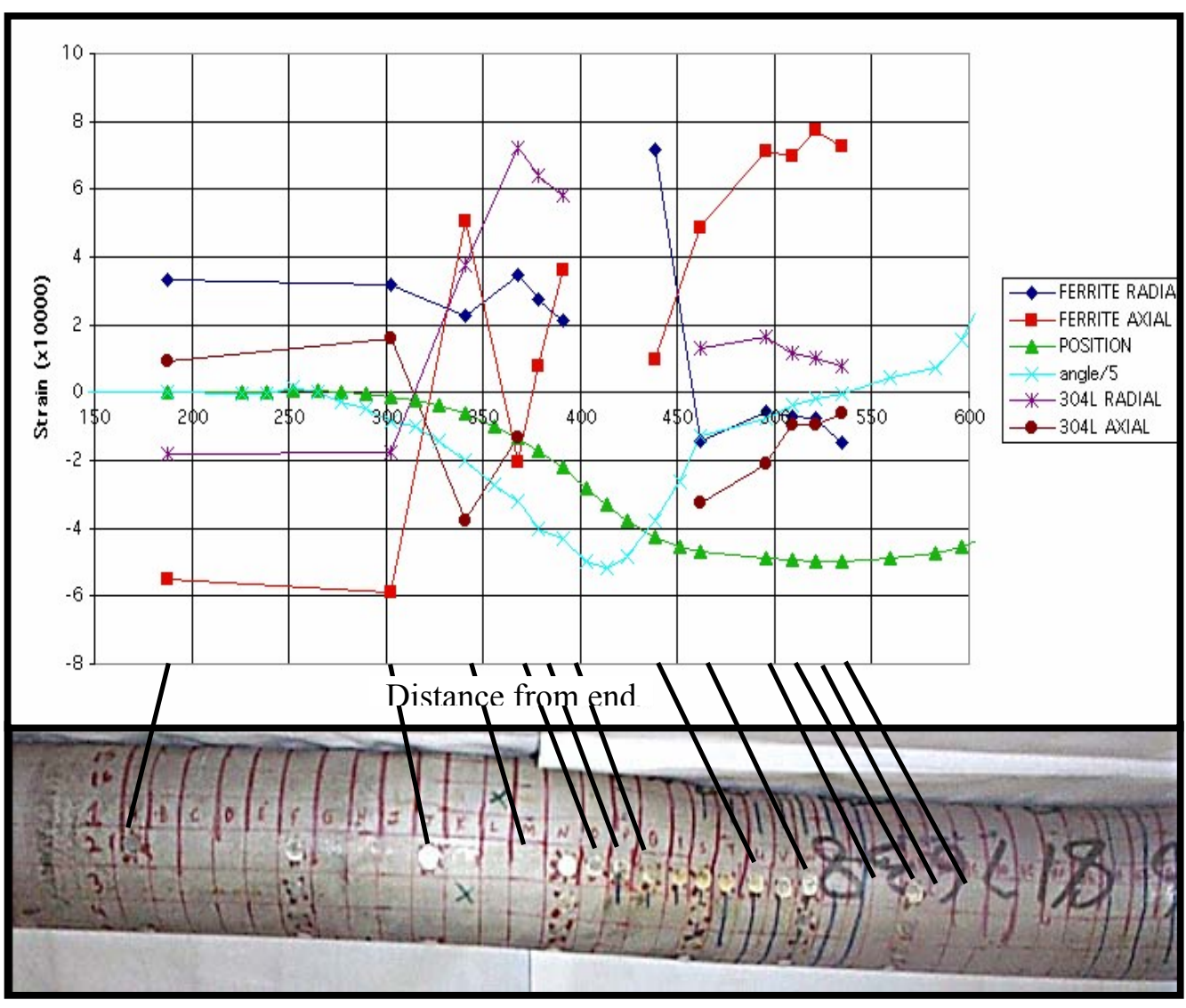

Fig. 100. Results of neutron diffraction residual stress measurements showing stresses in both the 304L stainless steel and the carbon steel (ferrite) as a function of position along the tube.

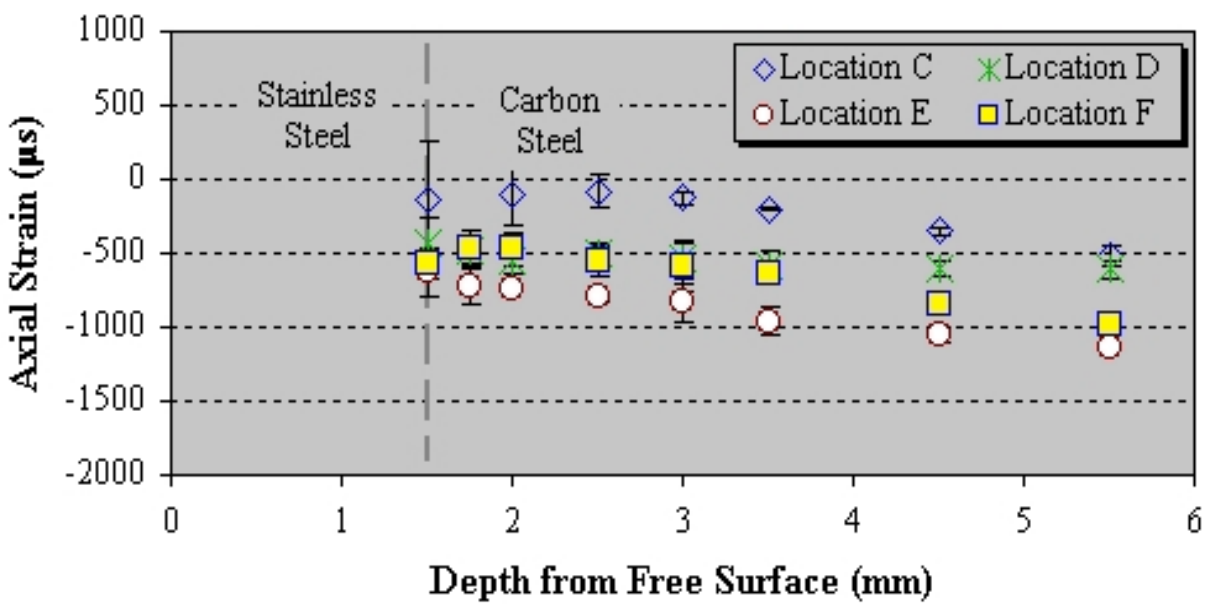

Fig. 101. Axial strain measured at several points through the wall thickness of a previously exposed 304L stainless steel/carbon steel tube. The locations shown are near the bottom of the air port and the strains are near neutral near the interface. The strains measured at the top of the air port were more compressive. 



\section{SCC RESISTANCE OF ALTERNATIVE COMPOSITE TUBE MATERIALS}

A laboratory-based investigation was undertaken to generate some relevant data that could be used to better assist with the selection of the composite tube system that will best mitigate the cracking problem. Data for 304L stainless steel, Alloy 825 and Alloy 625 were generated by conducting SCC tests in a simulated wash-water environment. Particular attention was given to documenting the influence of metallurgical condition on SCC susceptibility. A sensitized microstructure, in which chromium-rich carbides precipitate on grain boundaries, may be relevant, considering some of the peak temperatures attained during excursions are within the sensitizing (temperature-time) region of all three materials. A cold-worked condition may also be relevant considering primary air port openings are formed by cold bending adjacent tubes, and that there are about seven different designs of various bending radii and angles in service.

\subsection{EXPERIMENTAL DETAILS}

The adopted approach to produce SCC in the laboratory involved the use of U-bend test specimens as described in ASTM Standard G-30-90 [61]. Strips of 304L stainless steel and Alloy 625 were made from commercial sheet originally supplied in a mill-annealed condition. Strips of Alloy 825 were prepared from both commercial sheet and seamless tube originally supplied in a millannealed condition. Monolithic strips of Alloy 625 weld material were prepared from a two-pass weld-overlaid composite plate (carbon steel substrate) supplied in the as-welded condition by Welding Services Inc. The chemical composition of the various base alloy forms is provided in Table 16. It is noted that, compared to 304L stainless steel, both Alloy 825 and Alloy 625 have somewhat higher chromium content, and significantly higher nickel and molybdenum contents. For each wrought alloy, four metallurgical conditions were tested, which include mill-annealed (MA), sensitized (S), 50\% cold-worked (CW), and 50\% cold-worked then solution-annealed (SA). A 50\% cold-worked level was chosen based on actual microhardness measurements made on an Alloy 625based composite opening tube, which cracked after 12 months recovery boiler service [62]. In contrast, only two metallurgical conditions of the weld-overlaid Alloy 625 were tested, which include as-welded (AW) and sensitized (S). A description of the procedure used to produce each condition other than the mill-annealed condition is provided below.

To create a sensitized condition, strips approximately $94 \mathrm{~mm} \times 9 \mathrm{~mm}$ were prepared from the 3.2 mm-thick wrought (304L stainless steel, Alloy 825 and Alloy 625) sheet and the weld-overlaid Alloy 625 composite plate. Sensitizing involved soaking the alloy strips at $760^{\circ} \mathrm{C}\left(1400^{\circ} \mathrm{F}\right)$ in a muffle furnace (without an inert atmosphere) for 10 hours followed by cooling in air. Reported studies have shown that this heat treatment provides a high degree of sensitization in both Alloy 825 [63,64], and Alloy 625 [64-66]. Strips of 304L stainless steel were also given this particular heat treatment to maintain a comparative basis.

Table 16. Overview of base material used to construct U-bends

\begin{tabular}{lccccccc}
\hline \multirow{2}{*}{ Base material } & \multicolumn{9}{c}{ Composition } & \multirow{2}{*}{ U-bend } \\
\cline { 2 - 6 } & Fe & Ni & Cr & Mo & Nb/Ta & C & \\
\hline 304L, 3.2 mm-thick sheet & Bal. & 9.9 & 18.1 & 0.2 & - & 0.02 & 304L-MA, 304L-S \\
304L, 6.0 mm-thick sheet & Bal. & 10.2 & 18.4 & 0.2 & - & 0.02 & 304L-CW, 304L-SA \\
Alloy 825, 3.2 mm-thick sheet & Bal. & 43.9 & 22.3 & 3.2 & - & 0.01 & A825-MA, A825-S \\
Alloy 825, 4.9 mm thick tube & Bal. & 38.5 & 19.8 & 2.5 & - & 0.01 & A825-CW, A825-SA \\
Alloy 625, 3.2 mm-thick sheet & 3.9 & Bal. & 21.4 & 8.9 & 3.4 & 0.02 & A625-MA, A625-S \\
Alloy 625, 6.4 mm-thick sheet & 3.8 & Bal. & 22.0 & 9.0 & 3.4 & 0.04 & A625-CW, A625-SA \\
$\begin{array}{l}\text { Alloy 625, 2-pass weld- } \\
\text { overlay }\end{array}$ & 0.7 & Bal. & 21.7 & 9.6 & 3.5 & 0.01 & A625WO-AW, \\
& & & & & & & A625WO-S \\
\hline
\end{tabular}


To obtain the cold-worked condition, strips approximately $94 \mathrm{~mm} \times 9 \mathrm{~mm}$ of both 304L and Alloy 825 were prepared from the $6 \mathrm{~mm}$-thick sheet and the $4.9 \mathrm{~mm}$-thick (41.0 $\mathrm{mm}$ outer diameter) tube respectively. These strips were then cold-rolled to a 50\% reduction in thickness using a rolling press and re-machined to the original $94 \mathrm{~mm} \times 9 \mathrm{~mm}$ dimensions. In contrast, the $6.35 \mathrm{~mm}$ Alloy 625 sheet was first cold-rolled to a 50\% reduction in thickness and then sectioned to make strips approximately $94 \mathrm{~mm} \times 9 \mathrm{~mm}$. Solution annealing of $50 \%$ cold-worked Alloy 625 strips involved soaking at $1120^{\circ} \mathrm{C}\left(2048^{\circ} \mathrm{F}\right)$ for 60 minutes followed by quenching in water, whereas for $50 \%$ coldworked strips of Alloy 825 and 304L stainless steel strips, it involved soaking at $1040^{\circ} \mathrm{C}\left(1904^{\circ} \mathrm{F}\right)$ for 60 minutes followed by quenching in water. All solution annealing treatments were conducted in the aforementioned muffle furnace, again without an inert atmosphere.

Upon completion of all treatments, strips were wet-ground to a 240 -grit finish, ultrasonically cleaned, deformed into U-shapes, and clamped across the ends by use of a shoe. The procedure introduced both plastic and elastic strains, with the maximum tensile circumferential stress existing at the outer surface of the bend. No attempt was made to quantify the stress. A column listing all alloy U-bend specimens by their identification codes is included in Table 16.

Stressed U-bends were tested individually in a crucible containing a molten $75 \% / 25 \%$ $\mathrm{Na}_{2} \mathrm{~S} / \mathrm{NaOH}$ (dry weight \%) salt hydrate mixture at $180^{\circ} \mathrm{C}$ for a period of 48 hours. The environment, selected on the basis of results published previously for Type 304L stainless steel [67], was chosen to simulate an aggressive wash-water environment. Preparation involved melting the quantity of reagent grade $\mathrm{Na}_{2} \mathrm{~S} \bullet 9 \mathrm{H}_{2} \mathrm{O}$ required in the test crucible on a hot plate, and then dissolving the appropriate quantity of reagent grade $\mathrm{NaOH}$ into the molten hydrate. The test crucible was further heated using a temperature-controlled heating mantle, which maintained the set temperature to within $\pm 7^{\circ} \mathrm{C}$. A small atomizer spray system provided continuous water spray over the crucible just sufficient to prevent dehydration during the test. High purity nitrogen gas, which was required as a part of the water spray system, helped to minimize in situ oxidation of the molten salt hydrate mixture. A fresh mixture was used for each test. Figure 102 schematically shows the experimental apparatus employed for the stress corrosion cracking tests.

After exposure, U-bends were ultrasonically cleaned, unclamped, sectioned using a hack saw, hot mounted in black epoxy, wet-ground to a 600 grit finish and polished to a 1 micron finish. The cross-sections were then examined in the as-polished and as-etched condition using an optical microscope.

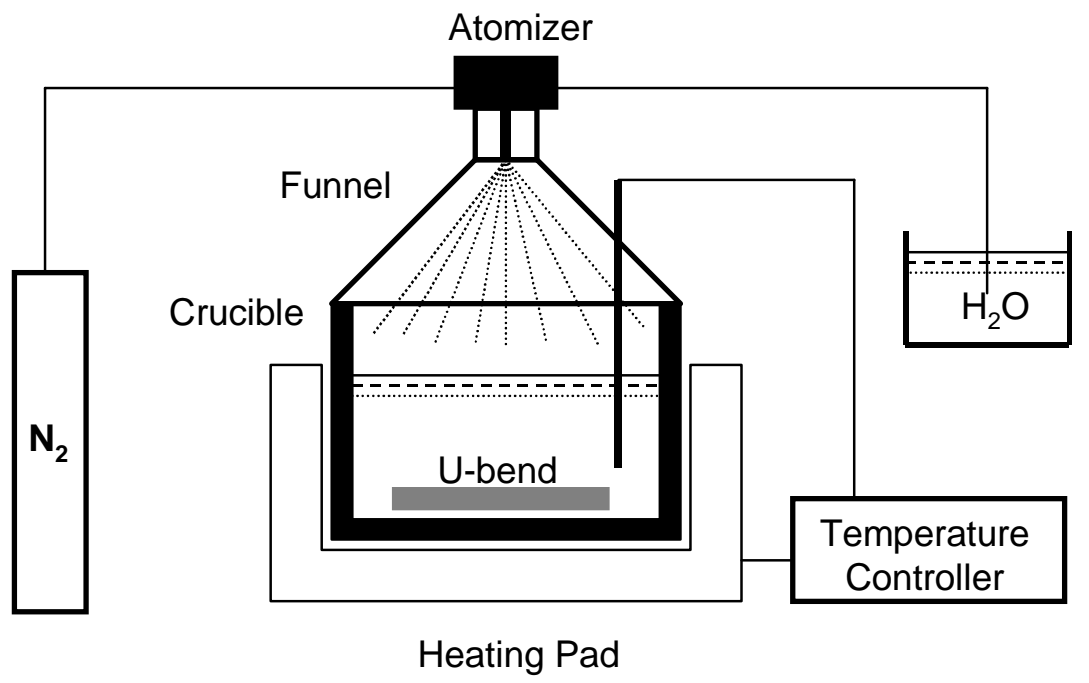

Fig. 102. Schematic drawing of U-bend SCC testing apparatus. 
An electrical conductivity measurement was also employed to confirm that the hydrate mixture remained in a molten state during the entire 48-hour exposure. For this measurement, two cylindrical graphite electrodes were submerged in the molten hydrate mixture in place of a U-bend specimen. A fixed electrical resistor was then placed between these two electrodes within the electrical circuit. The change in voltage across the fixed electrical resistor, resulting from a change in conductivity of the condensed mixture, was measured as a function of time using a computer-controlled data acquisition system.

\subsection{RESULTS AND DISCUSSION}

\subsubsection{Conductivity Measurement}

Figure 103 shows the change in conductivity (voltage) of the hydrate mixture as a function of time as the mixture is heated from room temperature to $180^{\circ} \mathrm{C}$, held at $180^{\circ} \mathrm{C}$ for 48 hours, then cooled back to room temperature. As Fig. 103 shows, prior to heating the conductivity (voltage) is low when the hydrate mixture is at room temperature. The low conductivity indicates the absence of a molten phase. However, the conductivity rises rapidly from almost zero to about $8 \mathrm{~V}$ as the temperature of the mixture approaches the set point of $180^{\circ} \mathrm{C}$, indicating the formation of a molten state. Once at the set temperature the conductivity remained stable at about $8 \mathrm{~V}$ for the entire 48 hour test period, indicating the mixture remained molten. The conductivity then decreased rapidly from the stable value of $8 \mathrm{~V}$ to almost zero as the mixture temperature cools from the set point back to room temperature, indicating the mixture solidified. It can be concluded with good confidence that the hydrate mixture under study remained molten for the entire 48 hour exposure of the various U-bends.

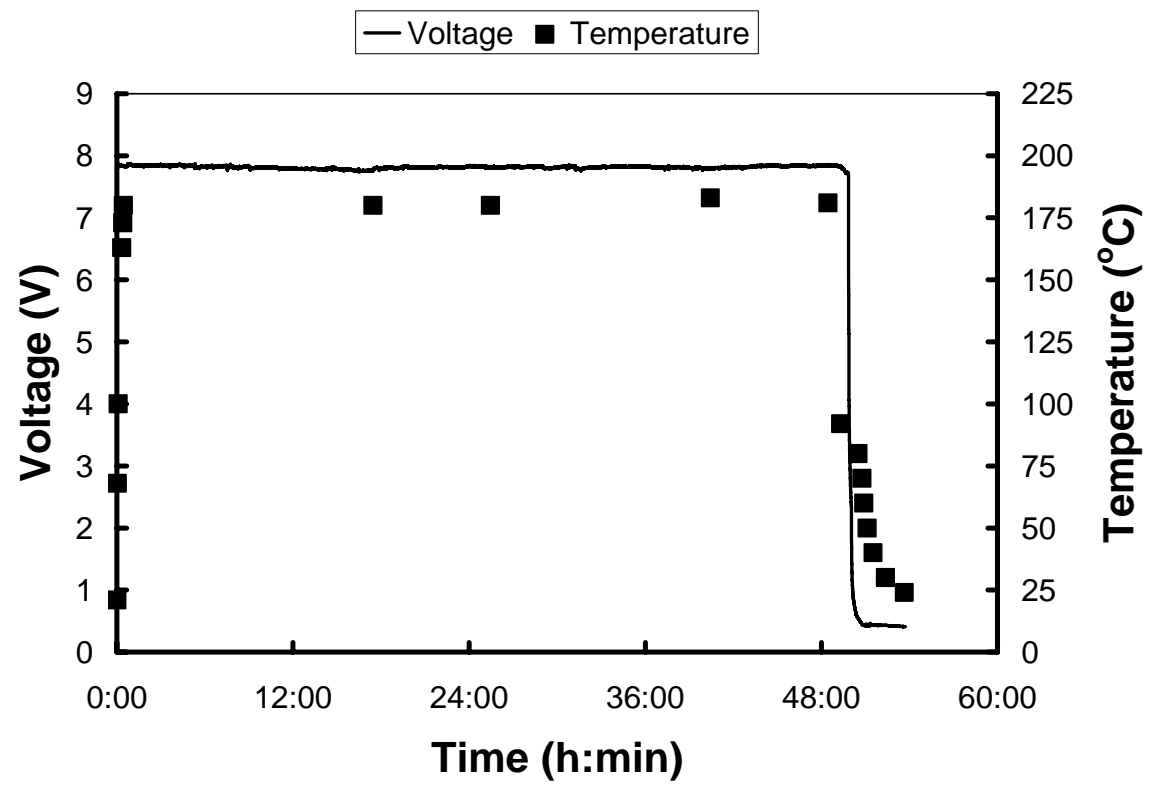

Fig. 103. Change in voltage across a fixed resistor in the apparatus circuit and temperature of $75 \% / 25 \% \mathrm{Na}_{2} \mathrm{~S} / \mathrm{NaOH}$ molten hydrate mixture.

\subsubsection{U-Bend SCC Tests}

Cracks initiated in every U-bend tested, regardless of the alloy and its metallurgical condition, after exposure to this particular environment. However, the extent of propagation was found to be strongly influenced by both the alloy type and its metallurgical condition. Propagation to the point of 
failure was not observed in any of the specimens. Photographs of metallographic cross-sections showing the nature of cracking exhibited by each U-bend tested are provided in Fig. 104. Cracks are well-developed and transgranular in nature in all 304L and Alloy 825 tests. Similar well-developed transdendritic cracks are also observed in both Alloy 625 weld overlay conditions tested. In contrast, for the wrought Alloy 625, well-developed cracks were only found in the 50\% cold-worked condition, and, unlike those found in the other alloys tested, cracks are intergranular in nature. It is also worth noting that a high number of cracks initiated in each U-bend, including the various Alloy 625 specimens.

Tests with U-bends are not well suited to the measurement of crack growth rates because the stress distribution within the specimen is not well characterized and is difficult to duplicate from specimen to specimen. For these reasons, extracting meaningful information regarding relative cracking resistance of crack-containing samples is not a trivial undertaking. In spite of this, an

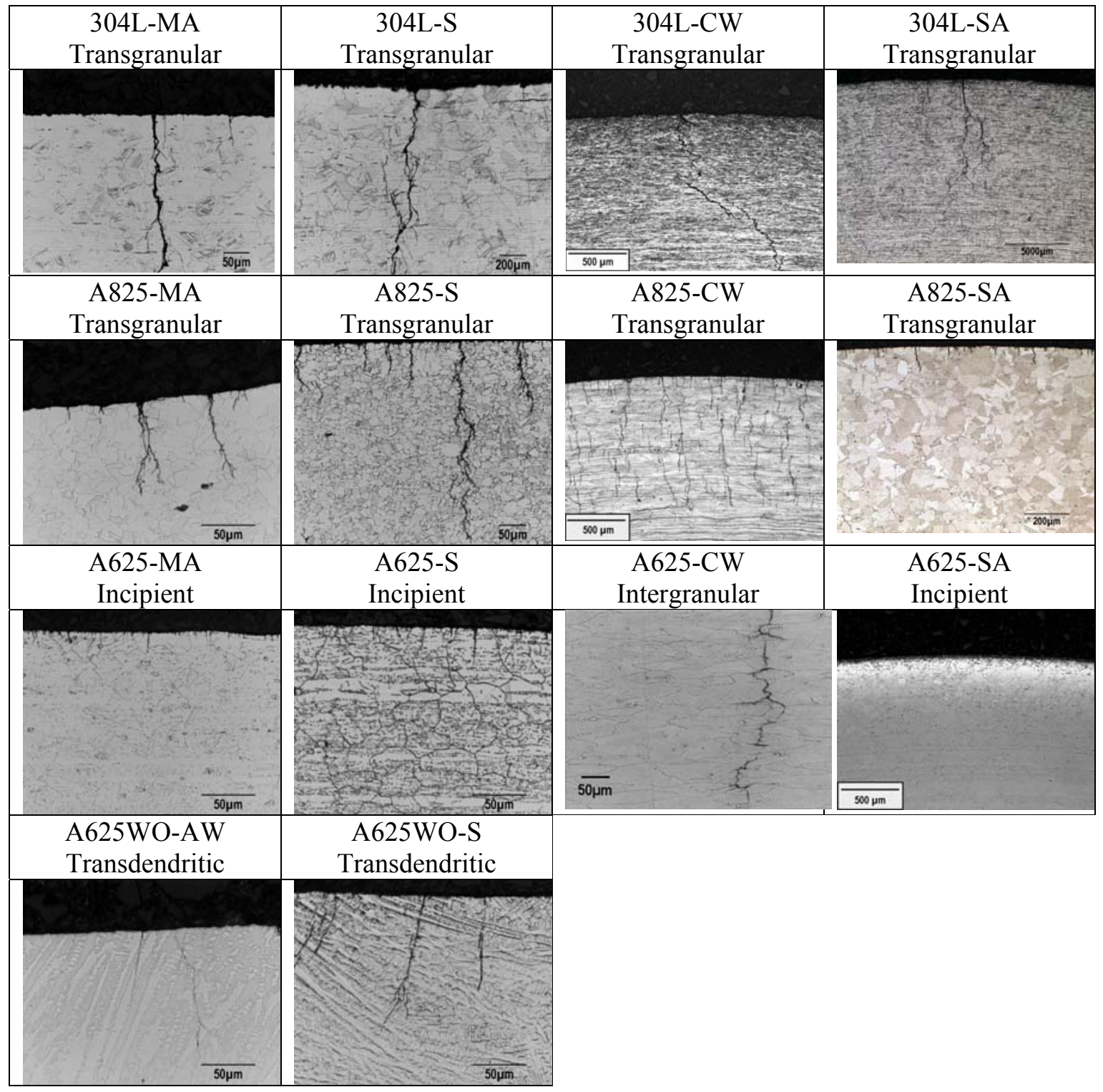

Fig. 104. Micrographs showing nature of cracking found in U-bends after exposure to $75 \%$ / $25 \% \mathrm{Na}_{2} \mathrm{~S} / \mathrm{NaOH}$ molten hydrate mixture at $180^{\circ} \mathrm{C}$ for 48 hours. 
attempt was made to compare the relative cracking resistance using the maximum crack depth observed in cross-section as a comparative basis, Fig. 105. Several interesting observations can be extracted from that comparison regarding the relative SCC resistance in molten $75 \% / 25 \%$

$\mathrm{Na}_{2} \mathrm{~S} / \mathrm{NaOH}$ hydrate mixture at $180^{\circ} \mathrm{C}$. It is clear that, of the set of alloys tested, $304 \mathrm{~L}$ stainless steel exhibited the lowest relative SCC resistance, regardless of its metallurgical condition. The alloy type with the highest relative SCC resistance depended on the metallurgical condition. In both the mill annealed and sensitized condition, Alloy 625 exhibited the highest relative resistance. However, this improved relative SCC resistance exhibited by Alloy 625 is clearly lost in the $50 \%$ cold worked condition. In that case, all three wrought alloys exhibited a low SCC resistance. Of the two metallurgical conditions that decreased the relative SCC resistance, the cold-worked condition (CW) has a significantly stronger influence on SCC resistance than did the sensitized condition (S). The solution annealing treatment (SA) was successful in restoring the level of SCC resistance found with the mill-annealed condition (MA). Regarding Alloy 625, the wrought specimen appears to exhibits a somewhat higher SCC resistance than the weld-overlaid specimen. However, the apparent lower SCC resistance exhibited by the weld-overlaid specimen may be related in part to residual weld stresses inherent to the as-welded condition.

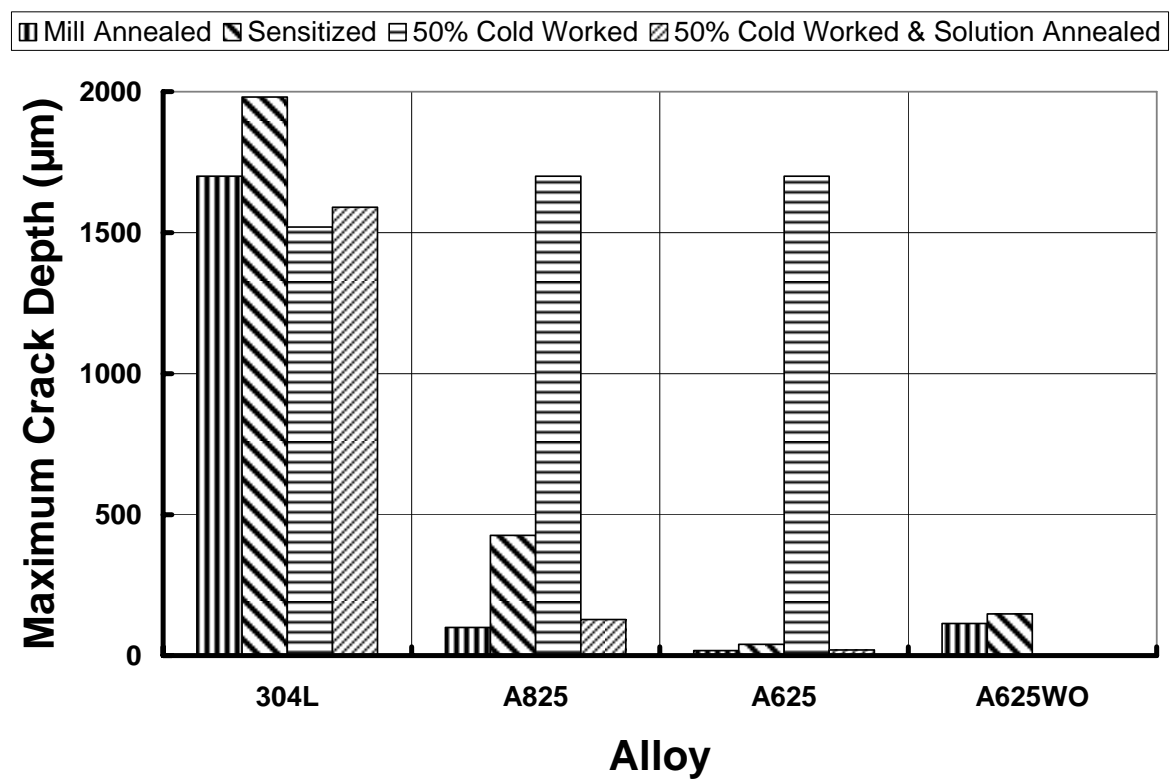

Fig. 105. Bar chart comparing influence of metallurgical condition on the maximum crack depth recorded in U-bends after exposure in to $75 \% / 25 \% \mathrm{Na}_{2} \mathrm{~S} / \mathrm{NaOH}$ molten hydrate mixture at $180^{\circ} \mathrm{C}$ for 48 hours.

\subsection{SUMMARY}

- Type 304L stainless steel was not resistant to SCC in the simulated wash-water environment under study $\left(75 \% / 25 \% \mathrm{Na}_{2} \mathrm{~S} / \mathrm{NaOH}\right.$ molten salt hydrate mixture at $\left.180^{\circ} \mathrm{C}\right)$, regardless of its metallurgical condition.

- In the annealed condition, both Alloy 825 and Alloy 625 exhibited significantly better resistance to SCC in the simulated wash-water environment under study. Unlike 304L stainless steel, the SCC resistance of these two alternative alloys was strongly influenced by their metallurgical condition. In the $50 \%$ cold-worked condition, the resistance to SCC of both alloys was similar to 304L stainless steel. 



\section{NORTH AMERICAN EXPERIENCE WITH ALTERNATIVE COMPOSITE TUBE SYSTEMS}

Replacing the conventional 304LSS/CS composite tube system with a more cracking- and corrosion-resistant composite tube system represents one possible resolution to both the cracking and corrosion problems. Correspondingly, boiler tube suppliers have made available alternative coextruded composite tubes [68,69], weld-overlaid composite tubes [70,71] and chromized composite tubes [72] as upgrade replacement tubes. Although not developed specifically for kraft recovery boilers, these composite tubes were installed in many North American recovery boilers as replacements tubes on the perception that the exterior layers should have improved resistance to cracking and corrosion. One task of the research program was to participate in field inspections during mill shutdowns in order to document the service performance of those alternative composite tubes installed in North American recovery boilers. Major observations recorded during the program are summarized below.

\subsection{ALTERNATIVE MATERIALS}

The composite tubes that have been used most widely as an alternative to the conventional coextruded 304L stainless steel/carbon steel composite tube in kraft recovery boilers are listed in Table 17. Included in that table are the nominal compositions for comparison. Unifuse ${ }^{\mathrm{TM}} 309$ is a weld overlaid version of type 309L stainless steel. Sanicro ${ }^{\mathrm{TM}} 38$ and 63 are modified versions of Alloy 825 and Alloy 625 respectively. Sanicro ${ }^{\text {TM }} 65$ is essentially a niobium-free version of Sanicro $^{\mathrm{TM}} 63$ and Unifuse ${ }^{\mathrm{TM}} 625$ is a weld overlaid version of Alloy 625. Compared with 304L stainless steel, these materials collectively have slightly higher chromium content and a significantly higher nickel and/or molybdenum content. The GBEST ${ }^{\mathrm{TM}}$-processed tubes were given a propriety thermal-mechanical surface treatment, prior to panel fabrication, designed to optimize the metallurgical structure in an attempt to improve the resistance to cracking (and corrosion) [73]. These alternative composite tubes have replaced the conventional 304L composite tubes at locations where frequent cracking occurred.

Table 18 summarizes some essential details of the various recovery boilers under study in which these alternative composite tubes have been installed. Included in the set of recovery boilers considered are several of the major manufacturers, as well as both construction designs and floor types, and a range of typical design loads and pressures.

Table 17. Summary of alternative composite tubes under study

\begin{tabular}{|c|c|c|c|c|c|c|c|}
\hline Exterior layer & Tube type & ID in report & Fe & $\mathrm{Cr}$ & $\mathbf{N i}$ & Mo & $\mathbf{N b}$ \\
\hline 304L SS & Co-extruded & 304L/CS & Balance & 18 & 8 & - & - \\
\hline Unifuse $^{\text {TM }} 309 \mathrm{SS}$ & Weld-overlaid & UNI309/CS & Balance & 20 & 12 & - & - \\
\hline Sanicro $^{\mathrm{TM}} 38$ & Co-extruded & SAN38/CS & Balance & 20 & 38 & 2.5 & - \\
\hline Sanicro $^{\mathrm{TM}} 63$ & Co-extruded & SAN63/CS & 3 & 21 & Balance & 8.5 & 3.4 \\
\hline Sanicro $^{\mathrm{TM}} 65$ & Co-extruded & SAN65/CS & 5 & 21 & Balance & 8.5 & - \\
\hline Alloy 625 & Co-extruded & $\mathrm{A} 625 / \mathrm{CS}$ & 5 & 21.5 & Balance & 9 & 3.7 \\
\hline Unifuse $^{\text {TM }} 625$ & Weld-overlaid & UNI625/CS & 5.2 & 20.9 & Balance & 8.6 & 3.5 \\
\hline $\begin{array}{l}\text { GBESTT }^{\text {TM }} \\
\text { Unifuse }^{\text {TM }} 625\end{array}$ & Weld-overlaid & GBEST/CS & 5.2 & 20.9 & Balance & 8.6 & 3.5 \\
\hline
\end{tabular}


Table 18. Summary of recovery boilers under study

\begin{tabular}{|c|c|c|c|c|c|}
\hline Boiler & Manufacturer & Construction & Floor type & $\begin{array}{c}\text { Design load } \\
\text { (MlbsDS/d) }^{a}\end{array}$ & $\begin{array}{c}\text { Design } \\
\text { pressure } \\
\text { (Psig) } \\
\end{array}$ \\
\hline 1 & Andritz & Membrane, $2^{1 / 2 "}$ on $3 "$ & Decanting & 3.5 & 900 \\
\hline 2 & Andritz /Ahlstrom & Membrane, $2^{1 / 2}$ " on $3 "$ & Decanting & 2.7 & 1150 \\
\hline 3 & $\mathrm{~B} \& \mathrm{~W}$ & Membrane, $2^{1 / 2 "}$ on $3 "$ & Sloped & 5.5 & 1500 \\
\hline 4 & $\mathrm{~B} \& W$ & Membrane, $2^{1 / 2 "}$ on $3 "$ & Sloped & 5.0 & 1800 \\
\hline 5 & $\mathrm{~B} \& \mathrm{~W}$ & Membrane, $2^{1 / 2}$ " on $3 "$ & Sloped & 2.4 & 750 \\
\hline 6 & $\mathrm{~B} \& \mathrm{~W}$ & Membrane, $2^{1 / 2}$ " on $3 "$ & Sloped & 5.7 & 1315 \\
\hline 7 & $\mathrm{~B} \& \mathrm{~W}$ & Membrane, $2^{1 / 2 "}$ on 3" & Sloped & 5.4 & 1625 \\
\hline 8 & $\mathrm{~B} \& \mathrm{~W}$ & Membrane, $2^{1 / 2} 2^{\prime \prime}$ on $3 "$ & Sloped & 4.0 & 1125 \\
\hline 9 & $\mathrm{~B} \& \mathrm{~W}$ & Membrane, $2^{1 / 2}$ " on $3 "$ & Sloped & 3.8 & 1525 \\
\hline 10 & $\mathrm{~B} \& \mathrm{~W}$ & Membrane, $2^{1 / 2} 2^{\prime \prime}$ on $3 "$ & Sloped & 3.8 & 1525 \\
\hline 11 & $\mathrm{~B} \& \mathrm{~W}$ & Membrane, $3 "$ on 4" & Sloped & 2.4 & 1625 \\
\hline 12 & $\mathrm{~B} \& W$ & Membrane, $3 "$ on $4 "$ & Sloped & 3.0 & 1475 \\
\hline 13 & $\mathrm{~B} \& \mathrm{~W}$ & Membrane, $3 "$ on 4" & Sloped & 4.1 & 1450 \\
\hline 14 & $\mathrm{~B} \& \mathrm{~W}$ & Membrane, $3 "$ " on 4" & Sloped & 5.6 & 900 \\
\hline 15 & $\mathrm{~B} \& \mathrm{~W}$ & Membrane, $3 "$ on 4" & Sloped & 4.0 & 1700 \\
\hline 16 & B\&W Rebuilt CE & Membrane, $2^{1 / 2} 2^{\prime \prime}$ on $3 "$ & Decanting & 3.5 & 1075 \\
\hline 17 & B\&W Rebuilt CE & Membrane, $3 "$ on $4 "$ & Decanting & 0.9 & 850 \\
\hline 18 & Kvaerner/Götaverken & Tangent, 3" & Decanting & 4.5 & 1150 \\
\hline 19 & Kvaerner/Götaverken & Tangent, 3" & Decanting & 4.4 & 1250 \\
\hline
\end{tabular}

${ }^{a}$ Million pounds dry solids per day

\subsection{PERFORMANCE EXPERIENCE}

Service performance was summarized simply in terms of whether or not cracking and corrosion were observed on the alternative composite tube systems. Two categories, "Tube" and "Membrane" were used to summarize cracking. "Tube" refers to cracks found in the composite tube itself, and includes both horizontal and craze cracks, whereas, "Membrane" refers to cracks found in the weld and/or membrane anywhere on the floor, or below the lower membrane termination between adjacent port opening tubes. For this summary, cases where cracking and/or corrosion was observed, the time period of observation was noted; otherwise the time period of the most recent inspection was noted. The cases reported were primarily from first hand accounts where at least one of the authors was present to make the observation. By no means do the cases reported account for all cases that exist in North America.

\subsection{FLOOR TUBES}

A summary of the cases under study in which alternative composite tubes were installed as floor tubes is provided in Table 19. Of the various alternative floor tubes installed, only SAN38/CS composite tubes have yet to exhibit either tube and/or membrane cracks. For the only installation of UNI309/CS composite tubes, tube and membrane cracks were found after 24 months of exposure. No other tube cracks in the other alternative composite tubes were observed. However, membrane cracks were reported for two Alloy 625 versions (SAN65/CS and UNI625/CS) installed within the same boiler (Boiler 11). It is noted that there are two recovery boilers in which several alternative composite tubes have been installed (Boiler 11 and 18) giving a direct comparison of the cracking behavior of different exterior layers and fabrication techniques. The specific performance history of each case is described in more detail below. 
Table 19. Performance history of alternative composite floor tubes

\begin{tabular}{|c|c|c|c|c|c|c|}
\hline \multirow{2}{*}{ Boiler } & \multirow{2}{*}{$\begin{array}{l}\text { Composite } \\
\text { tube }\end{array}$} & \multirow{2}{*}{ Installed } & \multicolumn{4}{|c|}{ Fireside cracking } \\
\hline & & & Tube & Observed & Membrane & Observed \\
\hline 18 & UNI309/CS & Spring 1995 & Yes & Spring 1997 & Yes & Spring 1997 \\
\hline 18 & SAN38/CS & Spring 1995 & No & Spring 2003 & No & Spring 2003 \\
\hline 15 & SAN38/CS & Fall 1996 & No & Spring 2003 & No & Spring 2003 \\
\hline 2 & SAN38/CS & Spring 1997 & No & Spring 2001 & No & Spring 2001 \\
\hline 4 & SAN38/CS & Spring 1997 & No & Spring 2001 & No & Spring 2001 \\
\hline 9 & SAN38/CS & Fall 1999 & No & Spring 2003 & No & Spring 2003 \\
\hline 1 & SAN38/CS & Spring 2001 & No & Spring 2002 & No & Spring 2002 \\
\hline 18 & A625/CS & Spring 1995 & No & Spring 2003 & No & Spring 2003 \\
\hline 11 & SAN65/CS & Fall 1998 & No & Fall 1999 & Yes & Fall 1999 \\
\hline 18 & UNI625/CS & Spring 1995 & No & Spring 2003 & No & Spring 2003 \\
\hline 13 & UNI625/CS & Spring 1996 & No & Spring 2000 & No & Spring 2000 \\
\hline 2 & UNI625/CS & Spring 1997 & No & Spring 2000 & No & Spring 2000 \\
\hline 16 & UNI625/CS & Fall 1997 & No & Fall 2000 & No & Fall 2000 \\
\hline 11 & $\mathrm{UNI} 625 / \mathrm{CS}^{a}$ & Fall 1997 & \multicolumn{2}{|c|}{ Not Applicable } & Yes & Fall 1998 \\
\hline
\end{tabular}

In Boiler 18, five floor panels were installed consisting of conventional 304L/CS, UNI309/CS, SAN38/CS, SAN65/CS and UNI625/CS composite tubes. No cracking was found in any of the five panels after 12 months of exposure. However, extensive cracking was found in the panels containing the conventional 304L/CS and UNI309/CS composite tubes after 24 months of exposure. An example of the cracking in the UNI309/CS composite tube is shown in Fig. 106. Cracks propagated through the weld overlay and either terminated at the (carbon steel) interface or continued to propagate along the interface. The weld-overlaid UNI309/CS composite tubes were no improvement over the conventional co-extruded 304LSS/CS composite tubes. No cracking was found in the remaining panels (SAN38/CS, SAN65/CS and UNI625/CS) after 8 years of service.

(a)

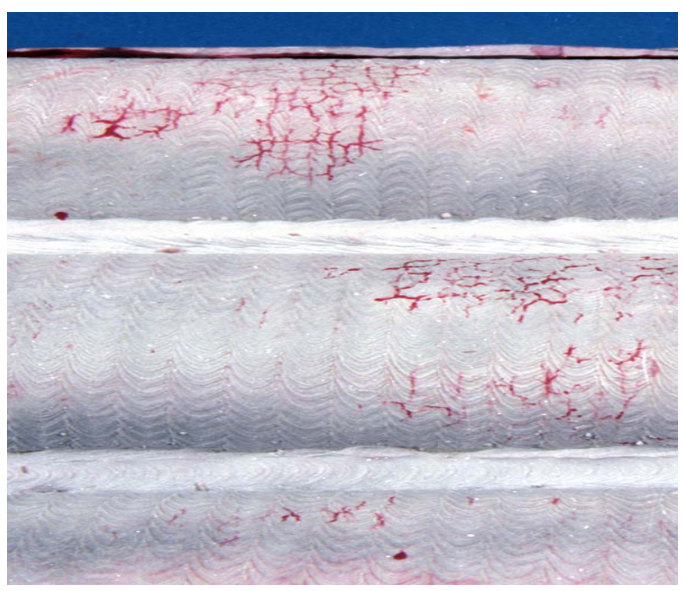

(b)

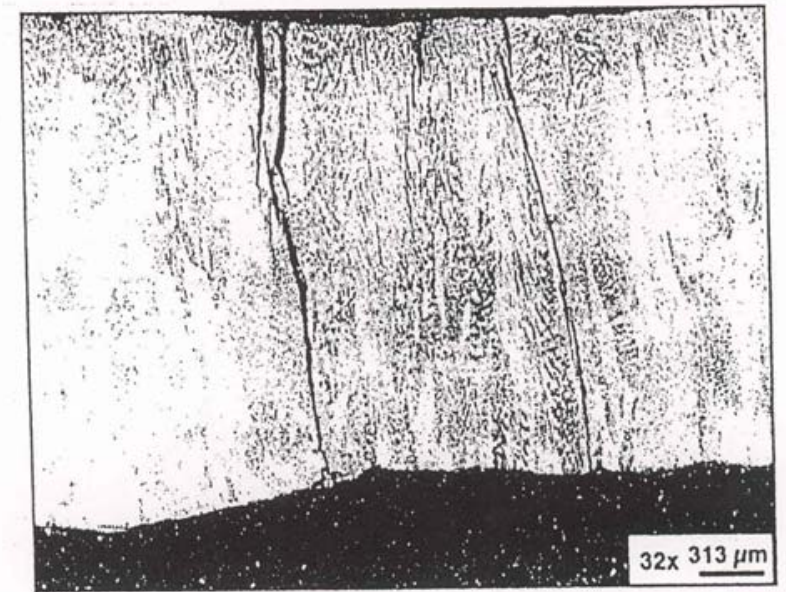

Fig. 106. Cracks formed in weld-overlaid UNI309/CS composite floor tubes installed in Boiler 18 after 24 months of exposure. (a) Crack indications as revealed by liquid dye penetrant inspection of the tube surface. (b) Micrograph of polished cross-section showing cracks, which have propagated through the weld overly and terminated at the carbon steel interface. 
In Boiler 11, SAN65/CS composite tubes were installed using two versions of Alloy 625 composite membranes, which include SAN65/CS and UNI625/CS. Cracks were found in both membranes after about 12 months of service. A subsequent metallographic examination revealed that these cracks tended to propagate through the Alloy 625, regardless of the version, and either terminated at the (carbon steel interface) or continued as a corrosion pit in the carbon steel, Figs. 107 and 108. Convincing evidence of overheating was found upon examining the microstructure of the carbon steel substrate for both versions of Alloy 625 composite membrane. It is tempting to correlate the overheating and cracking to the wider one inch $(25.4 \mathrm{~mm})$ membrane used in the 3 " tubes on 4 "centre membrane construction. However, UNI625/CS composite floor tubes were also installed in Boiler 9, which has a similar construction, and no membrane cracking was observed after about 36 months of exposure.

(a)

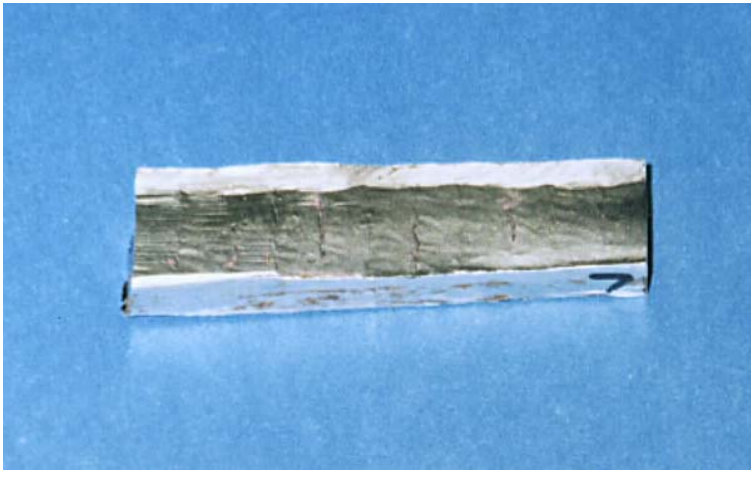

(b)

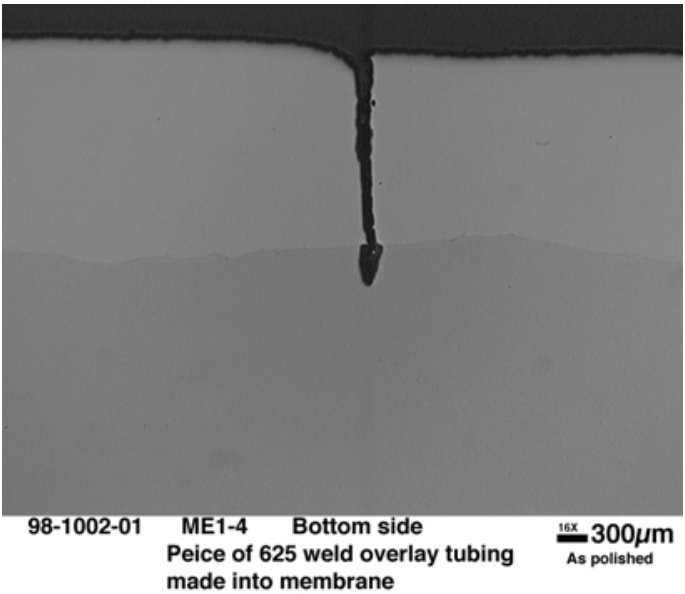

Fig. 107. Cracks in weld-overlaid UNI625/CS composite floor membrane installed in Boiler 11 after 12 months exposure. (a) Crack indications as revealed by liquid dye penetrant inspection of the membrane surface. (b) Micrograph of polished cross-sections showing a crack, which has propagated through the weld overlay and formed a corrosion "pit" at the crack tip in the carbon steel substrate.

(a)

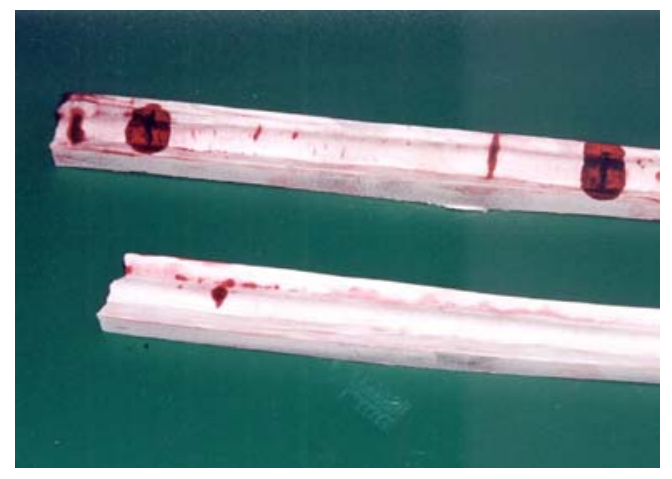

(b)

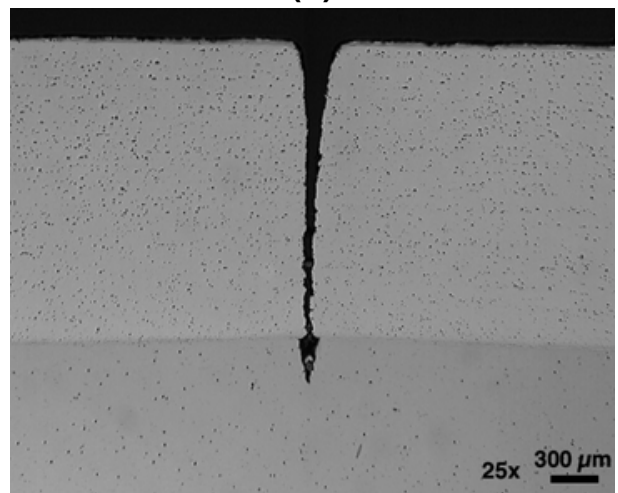

Fig. 108. Cracks in co-extruded SAN65/CS composite floor membrane installed in Boiler 11 after 12 months exposure. (a) Crack indications as revealed by liquid dye penetrant inspection of the membrane surface. (b) Micrograph of polished cross-sections showing a crack, which has propagated through the cladding and formed a corrosion "pit" at the crack tip in the carbon steel substrate. 


\subsection{SPOUT OPENING TUBES}

Table 20 summarizes the service performance of several smelt spout openings fabricated from alternative composite tubes. All alternatives had either cracked or corroded. However, each alternative composite tube had an improved service performance compared to the conventional 304L/CS composite tubes since their use has generally prolonged service life by a significant margin [40].

Both versions of installed Alloy 625-based composite tube systems, A625/CS and UNI625/CS, were one of the earliest installations of co-extruded and weld-overlaid Alloy 625 composite tubes, respectively, in a recovery boiler. The exact inspection period at which corrosion of the UNI625/CS spout opening was found was not confirmed. The spout opening was removed during the spring of 2002 where a subsequent metallographic examination revealed areas of corrosion. The A625/CS spout opening was removed after 48 months of service because of cracks that were discovered. A subsequent metallographic examination shows that the cracks were limited to the Alloy 625 cladding, but propagated in an intergranular mode, Fig. 109, contrary to the transgranular cracking found in

Table 20. Performance history of alternative composite spout opening tubes

\begin{tabular}{rllllll}
\hline Boiler & $\begin{array}{c}\text { Exterior } \\
\text { layer }\end{array}$ & \multicolumn{1}{c}{ Installed } & \multicolumn{2}{c}{ Fireside cracking } & \multicolumn{2}{c}{ Fireside corrosion } \\
\hline & & & Tube & Observed & Tube & Observed \\
6 & SAN38/CS & 1990 & Yes & Spring 1997 & No & Spring 1998 \\
12 & SAN38/CS & Spring 1995 & No & Spring 2001 & No & Spring 2001 \\
10 & SAN38/CS & Spring 1997 & Yes & Spring 2000 & Yes & Spring 2000 \\
4 & SAN38/CS & 1997 & Yes & Spring 2001 & No & Spring 2001 \\
9 & SAN38/CS & Fall 1999 & No & Spring 2003 & No & Spring 2003 \\
1 & SAN38/CS & Spring 2001 & No & Spring 2002 & No & Spring 2002 \\
5 & UNI625/CS & 1987 & \multicolumn{2}{c}{ Not verified } & Yes & Spring 2001 \\
18 & SAN65/CS & Spring 1995 & Yes & Spring 2001 & Yes & Spring 2001 \\
3 & A625/CS & Spring 1994 & Yes & Spring 1998 & & Not verified \\
\hline
\end{tabular}

(a)

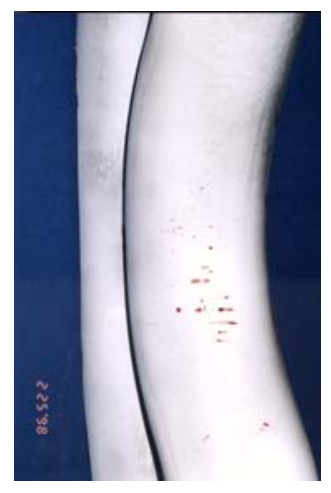

(b)

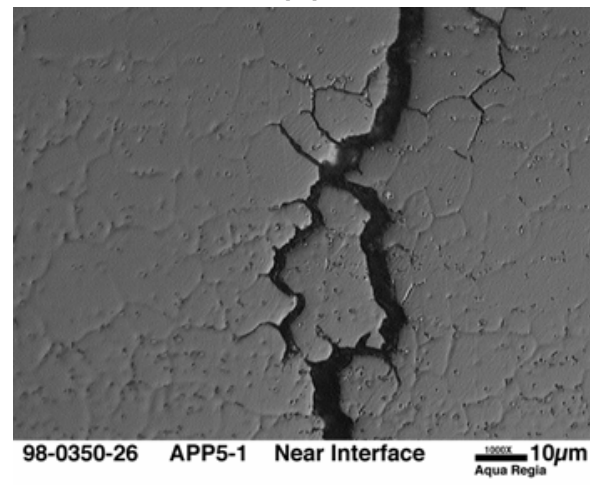

Fig. 109. Cracks in co-extruded A625/CS composite tube installed in a spout opening after 48 months of exposure in Boiler 3. (a) Crack indications as revealed by liquid dye penetrant inspection of the tube surface. (b) Micrograph of polished cross section showing a crack and its intergranular propagation mode. Examination of carbon steel microstructure reveals evidence of overheating. 
304L stainless steel cladding [40]. Examination of the stainless steel/carbon steel interface showed considerable precipitation and a thicker decarburization zone that what is normally present. These features indicate overheating had occurred. Some concern has been expressed about the accuracy of the fabrication and heat treatment history of these particular tubes since a torch was used to heat the opening tubes in order to unplug the opening and re-establish flow.

\subsection{PRIMARY AIR PORTS}

Alternative composite tubes were installed with eight different primary air port designs, Fig. 110. Major differences include the bend angle and radius as wells as the casting design and its seal with the opening tubes. Each port design is given a letter designation, which is included in the service performance history summary table (Table 21).

A summary of several cases in which alternative composite tubes were installed as primary air port openings is provided in Table 21. All of the various alternative composite tube systems were susceptible to tube cracking, membrane cracking and corrosion. It is noted that that the tube cracks found in the weld-overlaid Alloy 625 system were restricted to the GBEST ${ }^{\mathrm{TM}} / \mathrm{CS}$ version, where the proprietary thermal-mechanical surface treatment results in a fine, closely aligned grain structure at the near (fireside) surface [73].

Of the various alternative composite opening tubes considered, SAN38 (modified alloy 825)/CS had been in service for the longest period. Tube cracks were found only in one installation during the time periods noted (Boiler 1). A subsequent metallographic examination revealed some evidence of overheating (sensitization) in the SAN38 exterior layer, indicating boiler operation likely had a significant influence on the cracking observed, Fig. 111. Membrane cracking was found in SAN38/CS ports, of different design, in two installations (Boilers 1 and 8). Unlike the case for cracking, corrosion of SAN38/CS opening tubes occurred in two recovery boilers, which happen to different port designs (Port B in Boiler 1, and Port F in Boiler 8). It is noted that no membrane cracks were found on SAN38/CS port tubes fabricated with Port E in Boiler 10, despite the longer service life. Minor corrosion of SAN38/CS port tubes was found in three recovery boilers, all of which had different primary air port designs. One of these cases (Port B in Boiler 10) is illustrated in Fig. 112, which shows a small, yet real cladding thickness loss in the lower crotch area of the port, adjacent to the casting insert.

The service performance of the three versions of Alloy 625 composite tubes varied widely depending on version and port design. The weld-overlaid version of Alloy 625, UNI625/CS, had the longest exposure history. Such port openings were installed in four recovery boiler, three of which have a similar port design (Port B). Tube cracks were not found in any of theses opening tubes within the time periods noted. However, membrane cracks and corrosion were found in several installations. Figure 113 illustrates the nature of the membrane cracks found in Boiler 8, which has Port B openings. Membrane cracks were found in the lower crotch of the port, near the membrane termination. Cracks similar in nature and in location were found in UNI625/CS openings (Port D) installed in Boiler 13. Corrosion of UNI625/CS opening tubes was found just above the lower membrane termination, adjacent to the casting insert, in one installation (Boiler 10) after just 6 months of service, Fig. 114. Corrosion is evident by the large overlay thickness loss in the lower crotch area of the port, adjacent to the casting insert.

Primary air ports comprised of the surface-modified, weld-overlaid version of Alloy 625, GBEST/CS, were installed in two recovery boilers, which happen to have a similar port design (Port B). Corrosion of these opening tubes occurred within the first 12 months of service in both boilers. Corrosion was more severe in Boiler 8 where more than a 50\% loss in overlay thickness occurred in six months. The location (elevation) of the corroded area was similar to that found for the UNI625/CS opening tubes installed in Boiler 10. Tube and membrane cracks were also observed in the ports installed in Boiler 10. Figure 115 shows the nature of those cracks, which formed in the upper crotch area of the port after 36 months of service. 


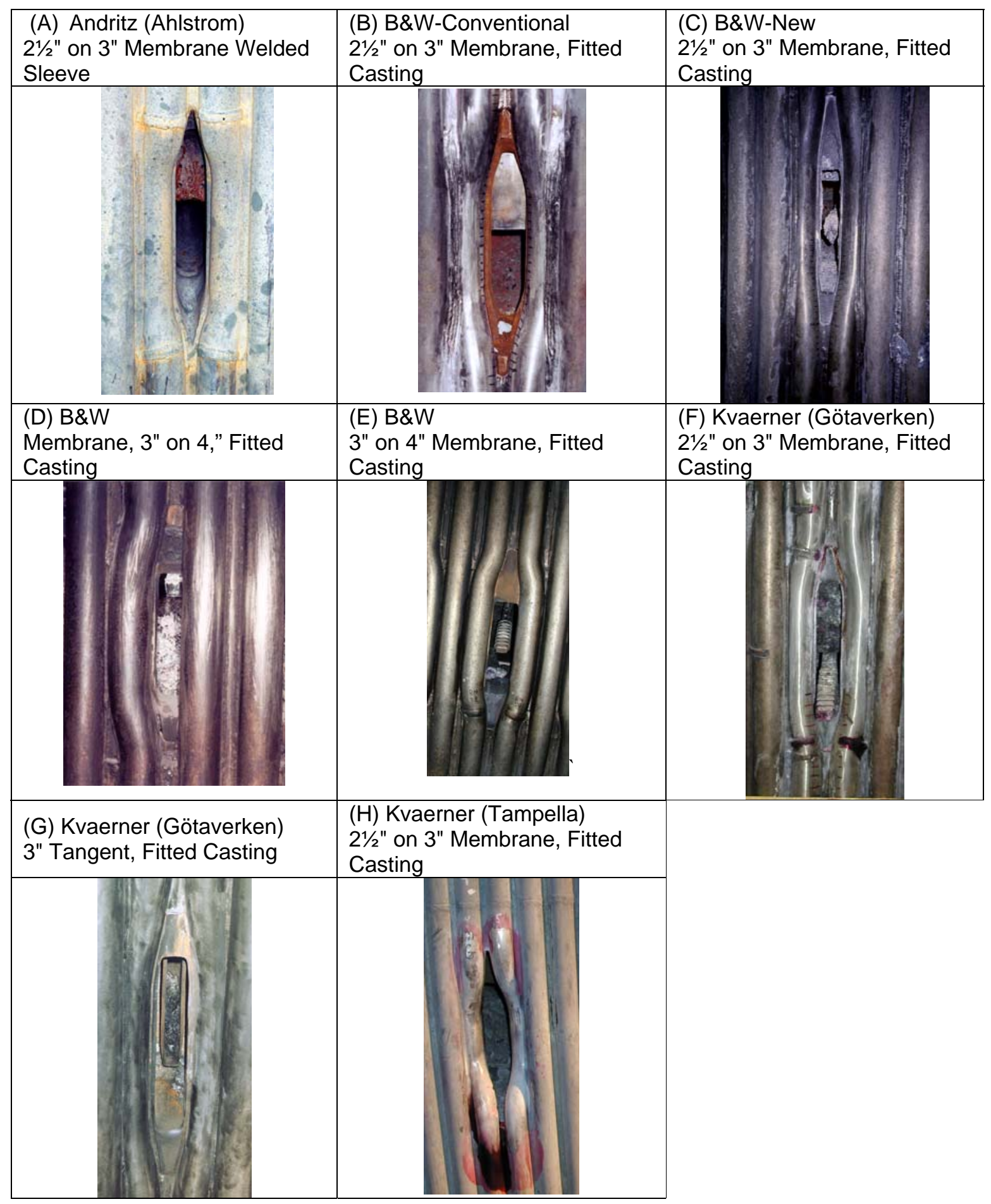

Fig. 110. Pictures of the various primary air port designs under consideration in this study. Note the differences in bend angle and radius, as well as the casting design and its seal with the opening tubes. 
Table 21. Performance history of alternative composite primary air port opening tubes

\begin{tabular}{|c|c|c|c|c|c|c|c|c|c|}
\hline \multirow{2}{*}{ Boiler } & \multirow{2}{*}{ Port } & \multirow{2}{*}{$\begin{array}{c}\text { Compo-site } \\
\text { tube }\end{array}$} & \multirow{2}{*}{ Installed } & \multicolumn{4}{|c|}{ Fireside cracking } & \multicolumn{2}{|c|}{ Fireside corrosion } \\
\hline & & & & Tube & Observed & Membrane & Observed & Tube & Observed \\
\hline 19 & G & SAN38/CS & 1995 & No & Spring 2001 & No & Spring 2001 & No & Spring 2001 \\
\hline 12 & $\mathrm{E}$ & SAN38/CS & Spring 1995 & No & Spring 2001 & No & Spring 2001 & Yes & Spring 2001 \\
\hline 15 & $\mathrm{E}$ & SAN38/CS & Fall 1996 & No & Spring 2003 & No & Spring 2003 & No & Spring 2003 \\
\hline 10 & B & SAN38/CS & Fall 2000 & No & Fall 2004 & No & Fall 2004 & Yes & Fall 2001 \\
\hline 10 & $\mathrm{~F}$ & SAN38/CS & Fall 2000 & No & Fall 2004 & No & Fall 2004 & No & Fall 2004 \\
\hline 1 & A & SAN38/CS & Spring 2001 & Yes & Spring 2003 & Yes & Spring 2002 & No & Spring 2002 \\
\hline 17 & $\mathrm{D}$ & SAN38/CS & Fall 2000 & No & Spring 202 & No & Spring 2002 & Yes & Spring 2002 \\
\hline 8 & $\mathrm{~F}$ & SAN38/CS & Fall 2001 & No & Fall 2002 & Yes & Fall 2002 & & Jot verified \\
\hline 10 & $\mathrm{C}$ & SAN38/CS & Fall 2002 & No & Fall 2004 & No & Fall 2004 & No & Fall 2004 \\
\hline 20 & $\mathrm{H}$ & SAN63/CS & Spring 2001 & Yes & Spring 2002 & Yes & Spring 2002 & No & Spring 2002 \\
\hline 8 & $\mathrm{~F}$ & SAN63/CS & Fall 2001 & Yes & Fall 2002 & No & Fall 2002 & & Not verified \\
\hline 8 & B & UNI625/CS & Fall 1998 & No & Spring 2001 & Yes & Fall 1999 & No & Spring 2001 \\
\hline 10 & B & UNI625/CS & Fall 1999 & No & Fall 2004 & Yes & Fall 2000 & Yes & Spring 2000 \\
\hline 7 & B & UNI625/CS & Fall 1999 & No & Fall 2002 & Yes & Fall 2002 & No & Fall 2002 \\
\hline 13 & $\mathrm{E}$ & UNI625/CS & Spring 2000 & No & Spring 2001 & Yes & Spring 2001 & & Jot verified \\
\hline 8 & B & GBEST/CS & Fall 2000 & No & Spring 2001 & No & Spring 2001 & Yes & Spring 2001 \\
\hline 10 & $\mathrm{~B}$ & GBEST/CS & Fall 2000 & Yes & Spring 2003 & Yes & Spring 2003 & Yes & Fall 2001 \\
\hline
\end{tabular}

(a)

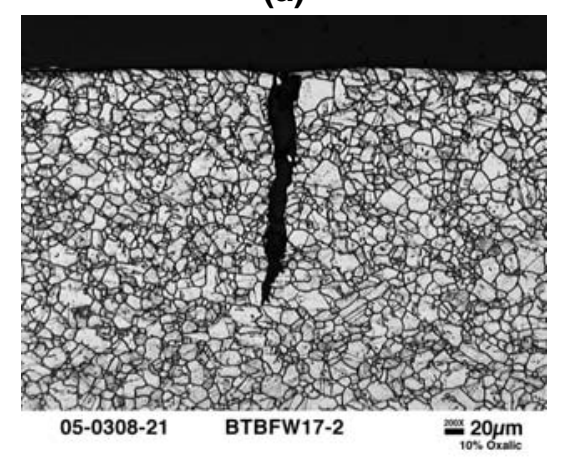

(b)

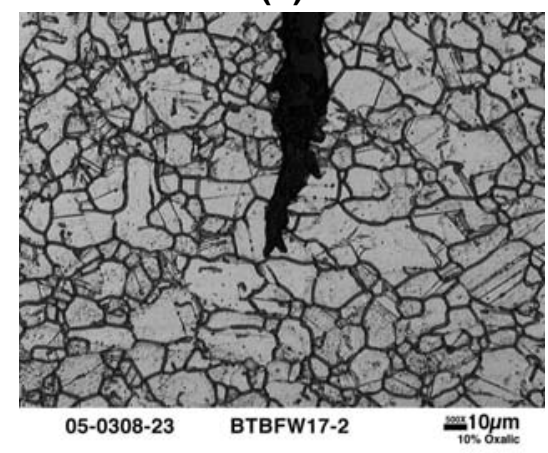

Fig. 111. Cracks in co-extruded SAN38/CS composite tube fabricated into primary air port installed in Boiler 1 after 42 months of service. (a) Micrograph of etched cross section showing crack indication found in SAN38 exterior layer. (b) Micrograph showing ditched structure, surrounding the crack tip, typically associated with sensitization. 

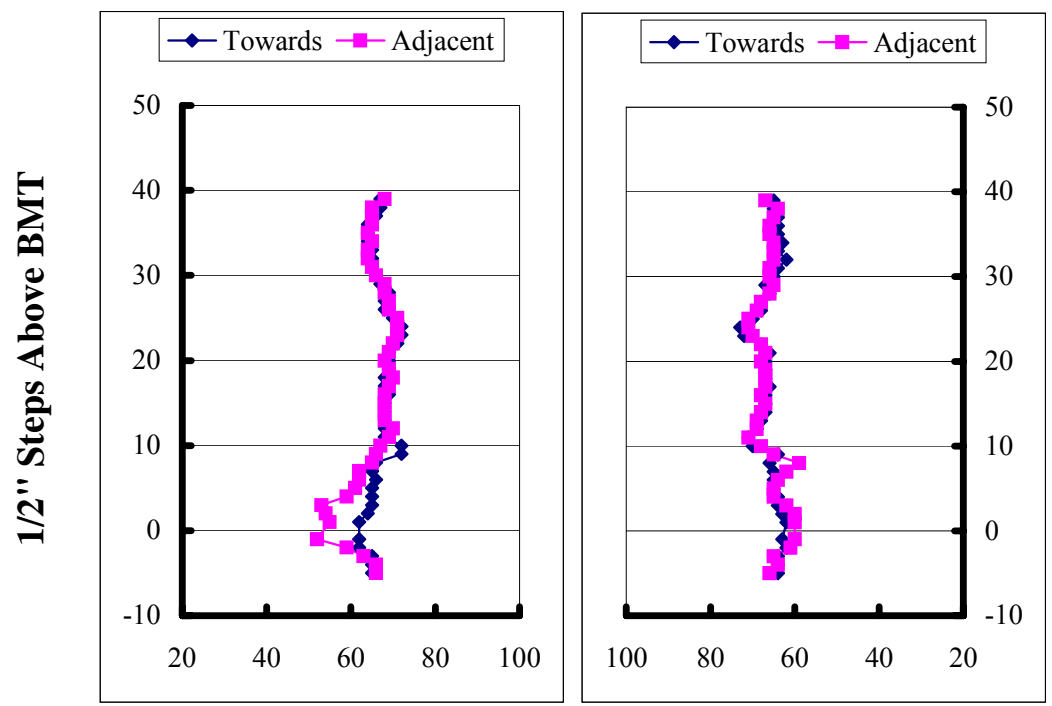

\section{Cladding Thickness (mils)}

Fig. 112. Cladding thickness of SAN38/CS composite tubes fabricated into Port B installed in Boiler 10 after 12 months of service. $(B M T=$ bottom membrane termination, adjacent and towards $=$ measurements made adjacent to membrane/casting, and towards fireside crown, respectively $)(1 \mathrm{mils}=0.001$ in $=$ $0.0254 \mathrm{~mm})$.

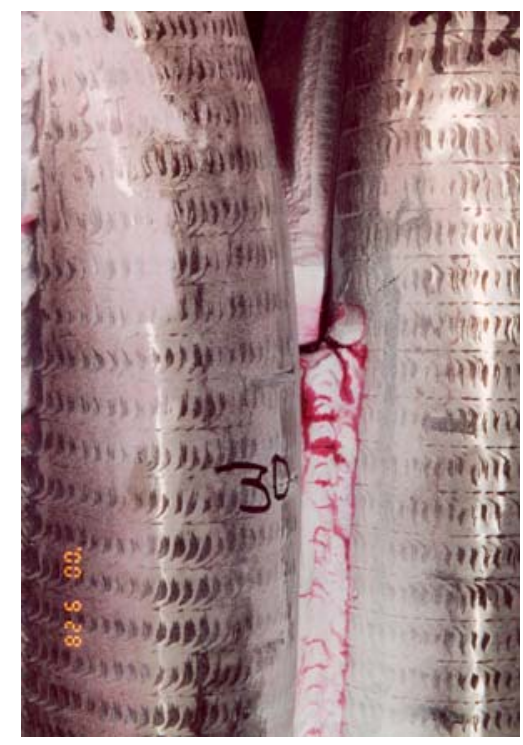

Fig. 113. Photograph showing membrane-type cracking in primary air port comprised of weld-overlaid UNI625/CS composite opening tubes installed in Boiler 8 after 12 months of service. 

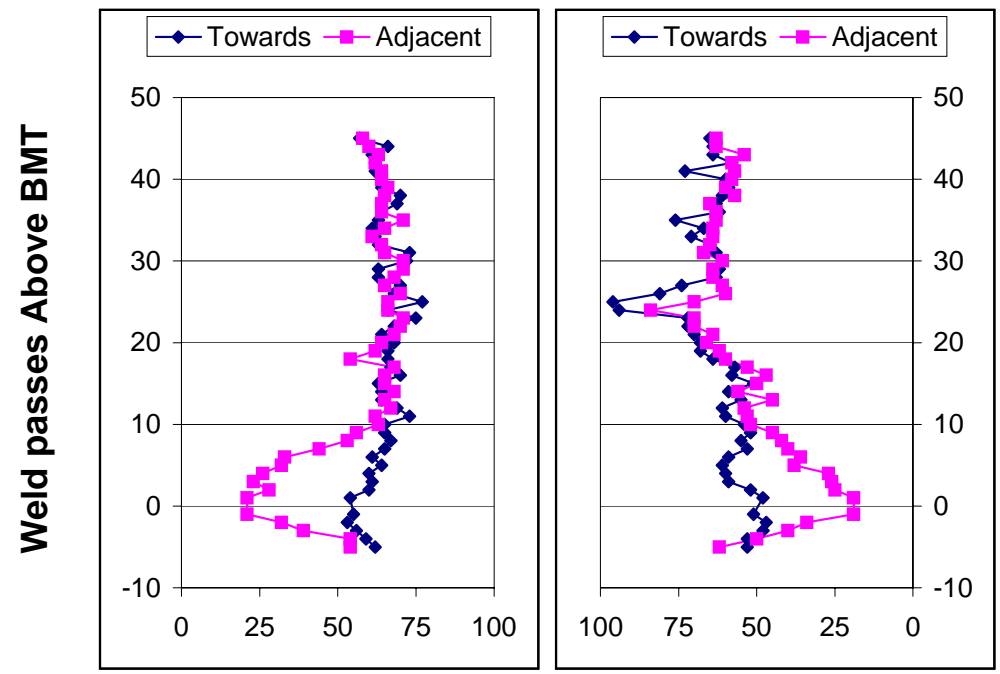

Overlay Thickness (mils)

Fig. 114. Overlay thickness of UNI625/CS composite tubes fabricated into Port $B$ installed in Boiler 10 after one year service. (BMT $=$ bottom membrane termination, adjacent and towards = measurements made adjacent to membrane/casting, and towards fireside crown, respectively) $(1 \mathrm{mils}=0.001 \mathrm{in}=0.0254 \mathrm{~mm})$.

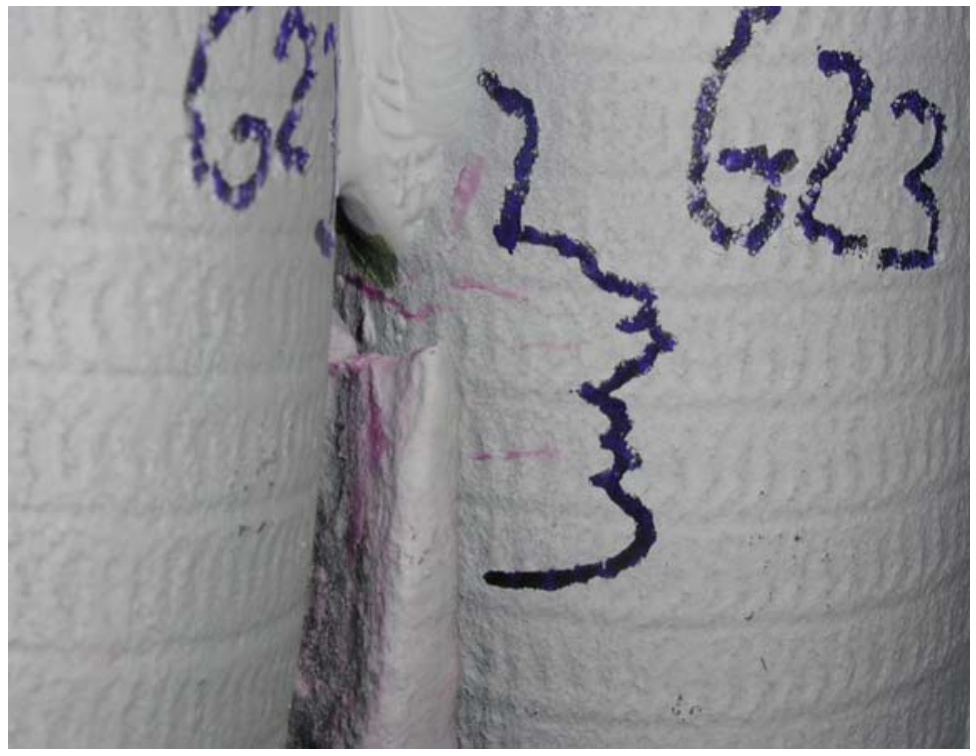

Fig. 115. Photograph showing tube and membrane cracks in upper crotch of a primary air port (Port B) comprised of GBEST/CS composite tubes installed in Boiler 10 after 36 months service. 
Primary air ports comprised of SAN63 (modified alloy 625)/CS opening tubes were installed in two recovery boilers, each with a different port design. In Boiler 8, with Port F, cracks were found in the SAN63/CS opening tubes after 12 months of service. Similarly, extensive tube cracking was found on those tubes opening installed in Boiler 20, with Port H. Several of the ports in this boiler were removed for a metallographic examination. Cracks propagated through the cladding, by an intergranular mode and either terminated at the (carbon steel) interface or continued to propagate along the interface, Fig. 116. Neither membrane cracks nor corrosion was found in this boiler.

(a)

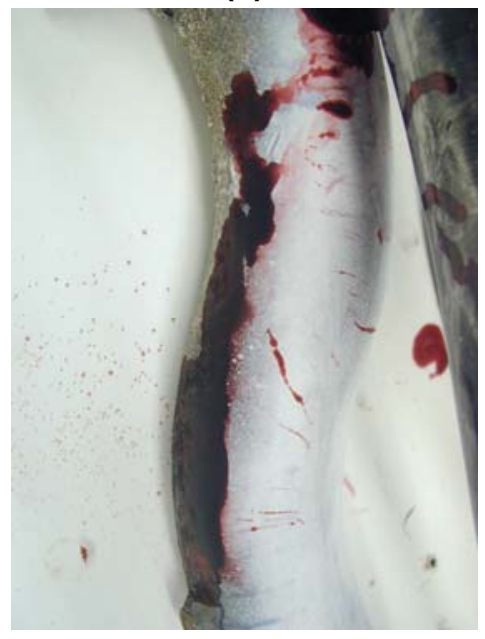

(b)

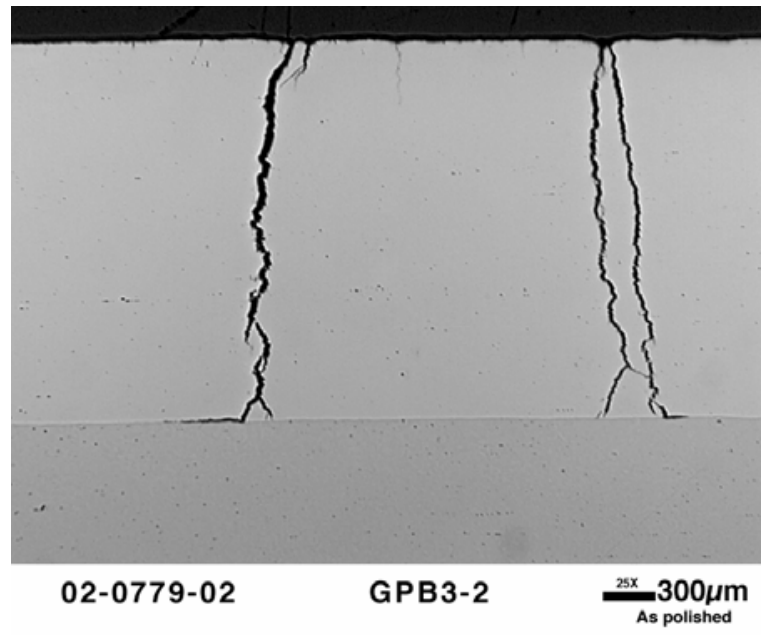

Fig. 116. Cracks found in SAN63/CS composite tubes fabricated into Port $\mathrm{H}$ installed in Boiler 20 after 12 months of service. (a) Crack indications as revealed by liquid dye penatrant inspection of the tube surface. (b) Micrograph of polished cross-section showing cracks, which have propagated through cladding, by an intergranular mode, and have either terminated at the carbon steel interface or continued to propagate along the interface.

\subsection{PRIMARY AIR PORTS-BOILER 10}

Several test panels containing various combinations of composite tube and port design were installed in Boiler 10. Panels were examined for cracking (dye penetrant testing), and corrosion (cladding/overlay thickness measurements) every six months since the time of their installation.

The results of the crack inspections are summarized in Table 22 as a function of time. No tube or membrane cracks were found in the SAN38/CS ports, regardless of port design, during any of their inspections. Tube cracks were found on more than one inspection in two of the four 304L/CS ports installed with the F design, whereas repetitive membrane cracks were found in only one these four ports. Membrane cracks were found in all six UNI625/CS ports after 12 months of service. Membrane cracks were found in all six ports at one period or another during subsequent inspections. No crack indications were found in the two GBEST/CS ports during their first four inspections. However, during the last two inspections reported, both tube and membrane cracks were found. The crack indications found in the GBEST/CS ports were located in the top membrane termination, as opposed to the bottom membrane termination, where all other crack indications reported were found. 
Table 22. Results of crack inspections

\begin{tabular}{|c|c|c|c|c|c|c|c|c|c|c|}
\hline Port & Tube & Design & S-00 & F-00 & S-01 & F-01 & S-02 & F-02 & S-03 & F-03 \\
\hline RHW25 & $304 \mathrm{~L} / \mathrm{CS}$ & $\mathrm{F}$ & None & $\mathrm{T}^{2}$ & $\mathrm{~T}^{3}$ & $\mathrm{~T}^{2}$ & $\mathrm{~T}$ & None & None & \\
\hline RHW26 & $304 \mathrm{~L} / \mathrm{CS}$ & $\mathrm{F}$ & $\mathrm{T}$ & M & None & $\mathrm{T}, \mathrm{M}$ & $\mathrm{T}, \mathrm{M}$ & $\mathrm{T}, \mathrm{M}$ & None & \\
\hline RHW27 & $304 \mathrm{~L} / \mathrm{CS}$ & $\mathrm{F}$ & None & None & None & None & None & None & None & None \\
\hline RHW28 & $304 \mathrm{~L} / \mathrm{CS}$ & $\mathrm{F}$ & None & None & None & None & None & None & None & None \\
\hline LHW 10 & SAN38/CS & $\mathrm{F}$ & $\mathrm{N} / \mathrm{I}$ & $\mathrm{N} / \mathrm{I}$ & None & None & None & None & None & None \\
\hline LHW11 & SAN38/CS & $\mathrm{F}$ & $\mathrm{N} / \mathrm{I}$ & $\mathrm{N} / \mathrm{I}$ & None & None & None & None & None & None \\
\hline LHW12 & $\mathrm{SAN} 38 / \mathrm{CS}$ & $\mathrm{F}$ & $\mathrm{N} / \mathrm{I}$ & N/I & None & None & None & None & None & None \\
\hline LHW20 & SAN38/CS & B & $\mathrm{N} / \mathrm{I}$ & $\mathrm{N} / \mathrm{I}$ & None & None & None & None & None & None \\
\hline LHW21 & SAN38/CS & B & $\mathrm{N} / \mathrm{I}$ & $\mathrm{N} / \mathrm{I}$ & None & None & None & None & None & None \\
\hline LHW22 & SAN38/CS & B & $\mathrm{N} / \mathrm{I}$ & N/I & None & None & None & None & None & None \\
\hline RHW10 & $\mathrm{SAN} 38 / \mathrm{CS}$ & $\mathrm{C}$ & $\mathrm{N} / \mathrm{I}$ & N/I & $\mathrm{N} / \mathrm{I}$ & N/I & $\mathrm{N} / \mathrm{I}$ & $\mathrm{N} / \mathrm{I}$ & None & None \\
\hline RHW11 & SAN38/CS & $\mathrm{C}$ & $\mathrm{N} / \mathrm{I}$ & $\mathrm{N} / \mathrm{I}$ & $\mathrm{N} / \mathrm{I}$ & $\mathrm{N} / \mathrm{I}$ & $\mathrm{N} / \mathrm{I}$ & $\mathrm{N} / \mathrm{I}$ & None & None \\
\hline RHW12 & SAN38/CS & $\mathrm{C}$ & $\mathrm{N} / \mathrm{I}$ & $\mathrm{N} / \mathrm{I}$ & $\mathrm{N} / \mathrm{I}$ & N/I & $\mathrm{N} / \mathrm{I}$ & $\mathrm{N} / \mathrm{I}$ & None & None \\
\hline RHW13 & SAN38/CS & $\mathrm{C}$ & $\mathrm{N} / \mathrm{I}$ & $\mathrm{N} / \mathrm{I}$ & $\mathrm{N} / \mathrm{I}$ & $\mathrm{N} / \mathrm{I}$ & $\mathrm{N} / \mathrm{I}$ & $\mathrm{N} / \mathrm{I}$ & None & None \\
\hline RHW14 & SAN38/CS & $\mathrm{C}$ & N/I & N/I & N/I & N/I & $\mathrm{N} / \mathrm{I}$ & $\mathrm{N} / \mathrm{I}$ & None & None \\
\hline LHW13 & UNI625/CS & B & None & M & None & None & $\mathrm{M}$ & M & None & \\
\hline LHW14 & UNI625/CS & B & None & M & None & None & $\mathrm{T}^{1}, \mathrm{M}$ & M & None & \\
\hline LHW15 & UNI625/CS & B & None & M & None & None & None & M & None & \\
\hline RHW10 & UNI625/CS & B & None & M & M & M & $\mathrm{M}$ & $\mathrm{N} / \mathrm{T}$ & $\mathrm{R} / \mathrm{B}$ & $\mathrm{R} / \mathrm{B}$ \\
\hline RHW11 & UNI625/CS & B & None & $\mathrm{M}$ & None & $\mathrm{T}^{1}, \mathrm{M}$ & $\mathrm{M}$ & $\mathrm{N} / \mathrm{T}$ & $\mathrm{R} / \mathrm{B}$ & $\mathrm{R} / \mathrm{B}$ \\
\hline RHW12 & UNI625/CS & B & None & $\mathrm{M}$ & None & $\mathrm{T}^{1}, \mathrm{M}$ & $\mathrm{M}$ & $\mathrm{N} / \mathrm{T}$ & $\mathrm{R} / \mathrm{B}$ & $\mathrm{R} / \mathrm{B}$ \\
\hline RHW13 & UNI625/CS & B & None & $\mathrm{M}$ & M & $\mathrm{T}^{1}, \mathrm{M}$ & $\mathrm{M}$ & $\mathrm{N} / \mathrm{T}$ & $\mathrm{R} / \mathrm{B}$ & $\mathrm{R} / \mathrm{B}$ \\
\hline RHW14 & UNI625/CS & B & None & M & None & None & $\mathrm{T}^{1}, \mathrm{M}$ & $\mathrm{N} / \mathrm{T}$ & $\mathrm{R} / \mathrm{B}$ & $\mathrm{R} / \mathrm{B}$ \\
\hline LHW23 & GBEST/CS & B & $\mathrm{N} / \mathrm{I}$ & $\mathrm{N} / \mathrm{I}$ & None & None & None & None & $\mathrm{T}$ & \\
\hline LHW24 & GBEST/CS & B & N/I & N/I & None & None & None & None & $\mathrm{T}, \mathrm{M}$ & \\
\hline
\end{tabular}

$\mathrm{T}=$ Tube Crack; $\mathrm{T}^{1}=$ Tube Crack Associated with Membrane; $\mathrm{T}^{2}=$ Tube Crack Associated with Thermocouple Weld; $\mathrm{T}^{3}=$ Tube Crack Associated with Crimp (Mechanical Damage); $\mathrm{M}=$ Membrane Crack; N/I = Not Installed; N/T = Not Tested; R/B = Removed from Boiler.

The thickness distribution, as measured adjacent to the casting/membrane, of the "worst case" port tube from each test panel is plotted, as function of elevation and time, in Fig.117.

Measurements at locations where surface grinding was conducted to remove a crack indication were omitted from the plots. Thickness losses were influenced by both metallurgy and the port design. The extent of thinning was lowest for the SAN38/CS opening tubes. Of the three test ports fabricated using SAN38/CS port tubes, a loss in cladding thickness was only observed on the tubes fabricated into Port B, and it occurred in a range from the BMT to an elevation corresponding to the bottom of the casting opening (BCO). In contrast, thinning of 304L/CS tubes did not depend on port design. A significant thickness loss occurred on the 304L/CS tubes fabricated into Port F over a range from, and to, an elevation corresponding to the top of the casting opening (TCO) to the top membrane termination (TMT). A similar rate of thinning was found on the original $304 \mathrm{~L} / \mathrm{CS}$ tubes fabricated into Port B. Unlike the case for SAN38/CS and UNI625/ CS port tubes, thinning of the 304L/CS tubes coincided with a degraded seal between the casting insert and the port tube, regardless of port design. A loss in overlay thickness was found on both weld-overlaid composite tubes, A625WO/CS and GBEST/CS, fabricated into Port B. The corroded area (elevation) is similar to that found on the SAN38/CS tubes fabricated into the same port design. The A625WO/CS tubes had the greater cladding/overlay thickness loss of all alternative composite tube-port design combinations. The majority of this loss occurred during the first 12 months of service. Significant changes were made to the liquor delivery system and the combustion air system during this time. Interestingly, similar losses in cladding thickness were not observed for any of the 304L/CS opening tubes fabricated into Port F during this time period. 

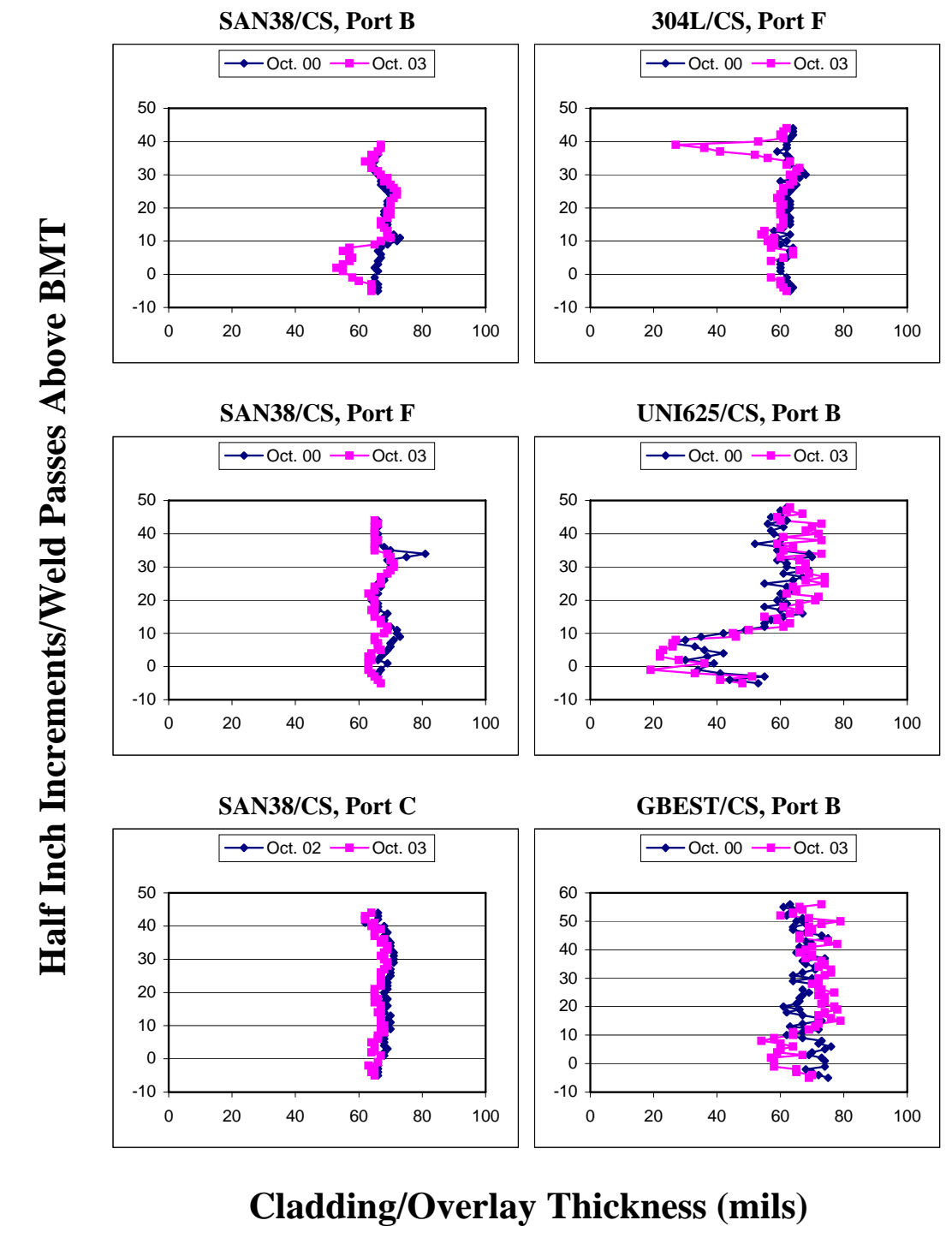

304L/CS, Port F

Fig. 117. Cladding/Overlay thickness of "worse case" port tube from test panels installed in Boiler A. (BMT = bottom membrane termination, adjacent and towards $=$ measurements made adjacent to membrane/casting, and towards fireside crown, respectively) $(1 \mathrm{mils}=0.001 \mathrm{in}=0.0254 \mathrm{~mm})$.

\subsection{DISCUSSION}

The near flawless performance history of the alternative composite floor tube systems is consistent with reported modeling [74] and laboratory studies (reported herein). In almost every case, floor tube cracks are formed by a stress corrosion mechanism, which requires a tensile stress and contact with a liquid. The thermal expansion difference between 304L stainless steel cladding and the carbon steel (SA210 Grade A-1), Table 23, is likely the major contributor of the required tensile stress. Finite element modeling to predict the stress state that would develop in straight composite tube systems based on Alloys 825 and 625 shows that, for those systems, more severe thermal cycles are required for the stress to become tensile, compared to what is required for a system based on 304L stainless steel [75]. Furthermore, only 304L stainless steel of the three candidate alloy composite tube systems is expected to plastically deform (cold work) during a typical operating cycle [8]. Washwater solutions, which typically contain sulfide, carbonate, hydroxide, sulfate, and other oxidized 
Table 23. Coefficient of thermal expansion comparison

\begin{tabular}{ll}
\hline Alloy & CTE, mean to $400^{\circ} \mathrm{C}, \times 10^{-6}{ }^{\circ} \mathrm{C}^{-1}$ \\
SA210 Grade A-1 carbon steel & 13.7 \\
304L Stainless steel & 17.4 \\
Alloy 825 & 14.9 \\
Alloy 625 & 13.5 \\
\hline
\end{tabular}

$\mathrm{CTE}=$ coefficient of thermal expansion.

sulfur compounds, are likely the stress corroding medium. Comparative laboratory studies show that annealed Alloy 825 and Alloy 625 are much more resistant than 304L stainless steel to stress corrosion cracking in such hydrated salt mixtures while in the metallurgical condition expected of each in composite floor tubes (cold-worked for 304L stainless steel, and either the mill-annealed or solution-annealed condition for Alloys 825 and 625).

Cracking in composite smelt opening and primary air port opening tubes systems is more consistent with a corrosion fatigue mechanism. Again, the thermal expansion difference between 304L stainless steel cladding and the carbon steel is likely the source of the required tensile stress. Random, yet frequent temperature excursions during operation are the likely contributor to the cyclic behavior required with this mechanism. Unlike the case for floor tubes, a strong correlation between temperature excursions and cracking has been found, particularly for composite primary air port opening tubes [75]. Such a correlation suggests that the required liquid phase is formed during operation.

Since port tubes are usually formed by an ambient temperature bending operation, usually without a post-bend, stress-relief heat treatment, and then installed with a non-uniform tube seal weld, they are expected to have an appreciable degree of cold work. From the relative SCC resistance reported herein, none of the three candidate alloys would be expected to have an improved SCC resistance. However, this prediction is not consistent with reported service performance. Although composite port tube systems based on Alloys 825 and 625 have cracked, in smelt spout openings and/or in primary air port openings, their comparative service performance suggests that Alloy 825based composite opening tubes exhibit a higher resistance to cracking in service. It is unlikely that the apparent discrepancy between the lab test results and field experience for port tubes is related to the corrosive environment under study. This is because the cracking mode exhibited by each cold-worked alloy in the lab tests $\left(75 \% / 25 \% \mathrm{Na}_{2} \mathrm{~S} / \mathrm{NaOH}\right.$ hydrate mixture at $\left.180^{\circ} \mathrm{C}\right)$ is the same as that found in examinations of cracked composite port tubes removed after service: transgranular for 304L- and Alloy 825-based composite tube systems, transdendritic for the weld-overlaid composite tube system, and intergranular for co-extruded Alloy 625-based composite opening tube systems. Considering the generally poor SCC resistance of 50\% cold-worked conditions, and the difference in CTE with carbon steel, the improved service performance of the Alloy 825-based composite port tube system may be strongly influenced by a stress (hardness) threshold.

The successful reproduction of the field-observed cracking mode in the lab tests suggests that sulfide and/or hydroxide may be key component(s) in the corrosive environment responsible for the cracking of composite opening tubes in service. As mentioned in the Introduction, strong circumstantial evidence suggests that a corrosive environment forms during operation, as opposed to during a water-wash. Rationalizing the presence of $\mathrm{Na}_{2} \mathrm{~S}$ is rather easy considering that it is expected to be a component of the frozen (smelt) layer that covers the fireside surface of composite opening tubes [30]. Regarding $\mathrm{NaOH}$, there are two possible delivery mechanisms. One possible mechanism involves the migration and subsequent condensation of $\mathrm{NaOH}$ vapor on the cold-side of opening tubes in poorly sealed port openings. Formation of molten hydroxide in this manner is believed to be responsible for the well-documented cold-side corrosion exhibited by the conventional 304L-based composite opening tube system [76]. A second possible mechanism involves the transport of incompletely dehydrated (wet) liquor droplets to the region prone to cracking. If $\mathrm{NaOH}$ is indeed present, molten $\mathrm{Na}_{2} \mathrm{~S} / \mathrm{NaOH}$ mixtures would be expected at operating conditions since the binary 
eutectic temperature (first melting temperature), $291^{\circ} \mathrm{C}$ [77], is sufficiently lower than the expected operating tube temperature of $325-375^{\circ} \mathrm{C}$.

Reported fireside corrosion of composite primary air port opening tubes is inconsistent with attack by molten $\mathrm{NaOH}$, which is the generally accepted cold-side corrosion mechanism [75,78-80]. The performance history suggests that Alloy 625 can corrode more rapidly than Alloy 825 and 304L stainless steel, which in turn corrode more rapidly than carbon steel. Reported corrosion studies in molten $\mathrm{NaOH}$ mixtures show that, of these materials, Alloy 625 exhibits the greatest corrosion resistance, even in its welded state [81]. Clearly some other corrosive environment, which forms during operation, is responsible for the observed corrosion.

\subsection{SUMMARY}

- All alternative composite tube systems installed in the lower-furnace section of kraft recovery boilers in North America have improved cracking resistance compared to the conventional composite tube system based on 304L stainless steel. One exception may be the co-extruded Alloy 625-based composite tube system fabricated into primary air ports, since it cracked just as quickly as the conventional $304 \mathrm{~L}$ composite port tube system.

- None of the alternative composite tube systems represents a universal solution to the cracking and corrosion problems associated with the conventional composite tube systems based on 304L stainless steel.

- For primary air ports tubes in particular, there is a strong material-design-operation dependence of cracking resistance.

- Of all the alternative composite tube systems, SAN38 (modified alloy 825)/CS has the more favorable service performance.

- The successful laboratory reproduction of the cracking mode found in composite opening tubes removed from service suggests that sulfide and/or hydroxide is/are key component(s) in the corrosive environment responsible for environmentally assisted corrosion of composite opening tubes. It is believed that these species are formed during boiler operation. 



\section{PROJECT CONCLUSIONS}

- Cracks that develop in the tubes that form primary air ports have been found, on some occasions, to continue into the carbon steel thus creating a significant concern.

- Studies using thermocouples installed on primary air port tubes have demonstrated that tubes in which cracks are likely to form experience significant temperature fluctuations.

- A combination of observations indicates that cracking in the primary air port tubes is not solely a result of thermal fatigue.

- Studies with a camera that permits observation of the fireside of the air port tubes have defined the conditions on the surface of the tubes that are necessary for temperature fluctuations to occur.

- CFD modeling studies have demonstrated differences in liquor distribution and other operating conditions between boilers in which air port tube cracking occurs and those without cracking.

- Extensive studies of the effects of operating parameters have shown that selection of operating parameters can avoid development of conditions conducive to the severe temperature fluctuations required for cracking of primary air port tubes.

- Modeling and measurement of residual stresses have shown that severe temperature fluctuations in the tube metal temperatures can change the residual stresses in the carbon steel so they become tensile near the stainless steel/carbon steel interface.

- Recommended steps to avoid severe temperature fluctuations include use of liquor nozzles that minimize spraying of liquor on the boiler walls, modification of the primary air flow to promote movement of the char bed away from the walls and adjustments of burning, possibly by continuously adding soap, to limit bed height.

- Conditions to be avoided include a char bed high enough that it contacts the air port tubes, a high flux of black liquor droplets on the walls and air port tubes, and low primary air jet momentum.

- Field and laboratory studies have established that co-extruded tubes made with modified alloy 825 are more resistant to cracking and corrosion than tubes fabricated using a 304L stainless steel cladding. 



\section{REFERENCES}

1. Sharp, W.B.A., "Composite Furnace Tubes for Recovery Boilers-a Problem Solved” TAPPI Journal, 64 (7), pp. 113-115 (1981).

2. Klarin, A., "Floor Tube Corrosion In Recovery Boilers," TAPPI Journal, 76 (12), pp. 183 (1993).

3. Pohjanne, P., Mäkipää, M., Ehrnstén, U., and Hänninen, H., "Cracking Of Compound Tubes In Black Liquor Recovery Boilers," proceedings from the $7^{\text {th }}$ International Symposium on Corrosion in the Pulp and Paper Industry, Atlanta, Georgia (1992).

4. Mäkipää, M., Nenonen, P., Salonen, J., and Hakkarainen, T., "Studies With TEM, SEM and Optical Microscope on the Cracking of BLRB Composite Floor Tubes," proceedings from the $8^{\text {th }}$ International Symposium on Corrosion in the Pulp and Paper Industry, Stockholm, Sweden (1995).

5. Hänninen, H., Pohjanne, P., and Nieminen, P., "Cracking And Corrosion Problems In Black Liquor Recovery Boilers," International Symposium On Plant Aging And Life Predictions Of Corrodible Structures, May 15-18, 1995, Sapporo, Japan (1995).

6. Singbeil, D.L., Prescott, R., Keiser, J.R., and Swindeman, R.W., "Composite Tube Cracking In Kraft Recovery Boilers-A State-of-the-Art Review," proceedings from the 1997 TAPPI Engineering Conference, Atlanta, Georgia.

7. Keiser, James; Singbeil, Douglas; Sarma, Gorti; Choudhury, Kimberly; Singh, Preet; Hubbard, Camden; Swindeman, Robert; Ely, Thomas; Kish, Joseph; Kenik, Edward; Maziasz, Philip; Bailey, Sarah, "Comparison Of Cracking In Recovery Boiler Composite Floor And Primary Air Port Tubes," proceedings from International Chemical Recovery Conference, Whistler, British Columbia (2001) also in Solutions!, Vol. 85: No. 2, pp. 1-7 (2002).

8. Keiser, J.R., Singbeil, D.L., Choudhury, K.A., Sarma, G.B., Hubbard, C.R., Ely, T.M., Kish, J.R., Singh, P.M., Kenik, E.A., Hall, L.M., "Characterization Of Primary Air Port Cracking In Black Liquor Recovery Boilers," Proceedings from $10^{\text {th }}$ International Symposium on Corrosion in the Pulp and Paper Industry,Hakkarainen, T., Editor, Helsinki, Finland (2001).

9. Swindeman, R.W., Keiser, J.R., Maziasz, P.J., "Fatigue Cracking Of Coextruded 304L/CS Tubes," proceedings from $9^{\text {th }}$ International Symposium on Corrosion in the Pulp and Paper Industry, Ottawa, Ontario (1998).

10. "Inspection For Cracking Of Composite Tubes In Black Liquor Recovery Boilers," Technical Information Paper 0402-30, TAPPI Press, Atlanta, Georgia (2001).

11. Wensley, A and Woit, B, "Inspection of Primary Air Port Opening Tubes in Recovery Boilers," proceedings from the 2001 TAPPI Engineering Conference, TAPPI, Atlanta, Georgia.

12. Bailey, S.E., Keiser, J.R., Swindeman, R.W., and Hall, L., "Comparison of Chordal and Surface Mounted Thermocouples", presented at Review Meeting for Development of Materials for Black Liquor Recovery Boilers project, October 18, 2000, Atlanta, GA.

13. Sarma, G.B., Choudhury, K.A., Keiser, J.R., Steinmoeller, F.E., Rivers, K.B., Mackenzie, C.M., Stone, B.B. and Kulig, J.A., "Recovery Boiler Wall Tube Temperature Measurements", MPLUS project report MC-01-005, Oak Ridge National Laboratory, Oak Ridge, TN (2002).

14. Keiser, J.R., Sarma, G.B., Wang, X.-L., Hubbard, C.R., Swindeman, R.W., Singbeil, D.L., Singh, P.M., "Why Do Kraft Recovery Boiler Composite Floor Tubes Crack?" proceedings from the 2000 TAPPI Engineering Conference, Atlanta, Georgia.

15. Keiser, J.R., Singbeil, D.L., Sarma, G.B., Choudhury, K.A., Kish, J.R., Frederick, L.A., Hubbard, C.R., Singh, P. M., "Relationship Of Recovery Boiler Parameters And Primary Air Port Cracking," proceedings from the TAPPI 2002 Fall Conference, San Diego, California.

16. Adams, T. N. Editor, "Kraft Recovery Boilers," Copyright 1997 AF\&PA, TAPPI Press, (Contributors: Frederick, Wm. J., Grace, T. M., Hupa, M., Iisa, K., Jones, A. k., Tran, H.), Atlanta, GA.

17. Green R.P., Hough, G., Editors, "Chemical Recovery in the Alkaline Pulping Processes" $3^{\text {rd }}$ Ed, 1992, TAPPI Press, Atlanta, GA. 
18. Forssen M., Hupa M., "Liquor to Liquor Differences in Combustion and Gasification Processes: AAU Black Liquor Database, Black Liquor Colloquium, May13-16, 2003, Park City, Utah.

19. Verrill L., Wessel R., "Detailed Black Liquor Drop Combustion Model for Predicting Fume in Kraft Recovery Boilers," TAPPI Journal Vol. 81: NO. 9, Pg.139, September 1998.

20. Baukal C.E., Schwartz R.E. Editors, “The John Zink Combustion Handbook,” CRC Press, 2000.

21. Ludwig C.B., Malkmus W., Reardon J.E., Thomson J.A.L., "Handbook of Infrared Radiation from Combustion Gases," National Aeronautics and Space Administration, 1973.

22. Tran H., Vafa S., Milbury C., Blaney B., Piroozmand F., Roherty A., Mott D., Anderson B., Rivers K., "Modifying Boiler Operation to Reduce Primary Air Port Cracking in a Recovery Boiler" Proceedings from the TAPPI 2002 Fall Technical Conference, San Diego, CA.

23. Green R.P., Hough G., "Chemical Recovery in the Alkaline Pulping Processes, 3rd Ed.," TAPPI Press 1992.

24. Wag, K.J., Frederick, W.J., Sricharoenchaikul, V., Grace, T.M., Kymalainen, M., "Sulfate Reduction and Carbon Removal During Kraft Char Burning," 1995 Int. Chemical Recovery Conference, B35-B50.

25. Sricharoenchaikul, V., Frederick, W.J., Grace, T.M., Kymalainen, M., "Sulfur Species Transformation and Sulfate Reduction During Pyrolysis of Kraft Black Liquor," 1995 International Chemical Recovery Conference.

26. Frederick L., Singbeil D., Kish J., "Using an In Situ video camera to diagnose the cause of temperature fluctuations of air port tubes in Kraft recovery boilers," 2003 TAPPI Engineering Conference Proceedings.

27. Kish J.R., Karidio I., Singbeil D.L., Frederick L.A., Keiser J.R., Choudhury K.A., Jette F., "Reducing Primary Air Port Composite Tube Cracking in a Kraft Recovery Boiler through Changes in Operation," TAPPI Fall Engineering Conference, 2003.

28. Keiser J.R., Singbeil D.L., Sarma G.B., Choudhury K.A., Kish J.R., Frederick L.A., Hubbard C.R., Singh P.M., "Relationship of Recovery Boiler Parameters and Primary Air Port Cracking" TAPPI Fall Engineering Conference, 2002.

29. Keiser, James R.; Singbeil, Douglas L.; Sarma, Gorti B.; Kish, Joseph R., Choudhury, Kimberly A.; Frederick, Laurie A.; Gorog, J. Peter; Jetté, François R.; Hubbard, Camden R.; Swindeman, Robert W.; Singh, Preet M.; Yuan, Jerry; Maziasz, Philip J., "Cracking And Corrosion Of Composite Tubes In Black Liquor Recovery boilers" 40 Years Recovery Boiler Co-operation in Finland, International Recovery Boiler Conference, Haikko Manor, Porvoo, Finland, May 12-14, 2004.

30. Adams, T.N., Editor, Kraft Recovery Boilers, (Atlanta, GA: TAPPI Press, 1997).

31. Singbeil D., Frederick L., Stead N., Colwell J., Fonder G., "Testing the effects of operating conditions on corrosion of water wall materials in kraft recovery boilers," 1996 TAPPI Engineering Conference Proceedings, Book 2, 647-680.

32. Keiser J.R., Singbeil D.L., Sarma G.B., Kish J.R., Choudhury K.A., Frederick L.A., Yuan J., Hubbard C.R., Swindeman R.W., Singh P.M., "Current Understanding of Cracking of Recovery Boiler Primary Air Port Composite Tubes," 2003 TAPPI Engineering Conference.

33. Tran H.N., "How does a kraft recovery boiler become plugged," Tappi Journal Vol. 69, No. 11, (1986).

34. K. Whitty, R. Backman, M. Forssen, M. Hupa, J. Rainio, V Sorvari, "Liquor-to-Liquor Differences in Combustion and Gasification Processes: Pyrolysis Behaviour and Char Reactivity," JPPS Vol. 23, No. 3, 1997.

35. Baxter L.L., Lind T., Kauppinen E., Robinson A., "Thermal Properties of Recovery Boiler Deposits," Int. Chemical Recovery Conf. Proceedings, 2001.

36. Wessel, R.A., Bailey, R.T., "Radiative Heat Transfer Properties for Black Liquor Combustion" Volume 4 (Appendix IV) of "Black liquor Combustion Validated Recovery Boiler 
Modeling Final Year Report," August 1998; Work Performed Under DOE Contract DE-FG0790CE40936 as subcontract No.1 between IPST and B\&W, August 1996.

37. "CRC Handbook of Chemistry and Physics," $71^{\text {st }}$ Ed, CRC Press, Boca Raton, Florida, USA, 1990.

38. Baukal C.E., "The John Zink Combustion Handbook," CRC Press 2001.

39. Miller J.L., Ed Friedman, "Photonics Rules of Thumb" SPIE Press, Bellingham, Wa, USA, 2003.

40. Singbeil, D., Prescott, B., Keiser, J., Swindeman, B., "Composite Tube Cracking in Kraft Recovery Boilers-A State-of-the-Art Review" in Proceedings of the TAPPI 1997 Engineering \& Papermakers Conference, TAPPI Press, Atlanta, GA: 1001-1023 (1997).

41. Sricharoenchaikul V., Frederick W.J., Grace T.M., "Thermal Conversion of Tar to Light Gases During Black Liquor Pyrolysis," 1995 International Chemical Recovery Conference, P. A209.

42. Verrill C.L., Wessel R.A., "Detailed black liquor drop combustion model for predicting fume in kraft recovery boilers," Tappi Journal Vol. 81: No.9, 1998.

43. Wessel, R.A., Verrill, C.L., Blue, J.D., Hiner, L.A.,"Black Liquor Combustion Model for Predicting Ash Chemistry in Kraft Recovery Boilers," Presented at the 1998 AIChE Annual Meeting, Session 291.

44. Verrill C.L., Wessel R.A., "Sodium loss during black liquor drying and devolatilizationApplication of modeling results to understanding laboratory data," 1995 International Chemical Recovery Conference.

45. Yuan J., Stropky D., Salcudean M., "Numerical Studies on Root Causes of Primary Airport Cracking in Recovery Boilers," International Chemical Recovery Conference 2004.

46. Keiser J.R., Singbeil D.L., Sarma G.B., Kish J.R., Choudhury K.A., Singh P.M., Hubbard C.R., Swindeman R.W., Ely T., Kish J., Kenik E., Maziasz P., Bailey S., "Comparison of Cracking in Recovery Boiler Composite Floor and Primary Air Port Tubes," Int. Chemical Recovery Conference, 2001.

47. Launder, B. E. and Sharma, B. I., "Application of the Energy Dissipation Model of Turbulence to the Calculation of Flow Near a Spinning Disc," Letters in Heat and Mass Transfer, Vol. 1, No.2, p.131-138, 1974.

48. Magnussen, B.F. and Hjertager, B.H., "On mathematical models of turbulent combustion with special emphasis on soot formation and combustion". In 16th Symp. (Int'l.) on Combustion. The Combustion Institute, 1976.

49. Keiser, J.R., Singbeil, D.L., Sarma, G.B., Kish, J.R., Choudhury, K.A., Hubbard, C.M., Frederick, L.A., Yuan, J., Singh, P.M., "Causes and Solutions for Recovery Boiler Primary Air Port Tube Cracking," Proceedings of the 11th International Symposium on Corrosion in the Pulp and Paper Industry, TAPPI Press, Atlanta, GA, CD-ROM version (2004).

50. Tran, H., Vafa, S., Milbury, C., Blaney, B., Piroozmand, F., Roherty, A., Mott, D., Anderson, B., Rivers, K., "Modifying Boiler Operation to Reduce Primary Air Port Cracking in a Recovery Boiler," Proceedings of the 2002 TAPPI Fall Technical Conference, TAPPI Press, Atlanta, GA, CD-ROM version (2002).

51. Vesak, R., Downing, B., Gauthier, M., Howard, S., Spirig, D., Neels, L., Tran, H., "Experience of Lower Furnace Tube Cracking in a Recovery Boiler," Proceedings of the 2003 TAPPI Fall Technical Conference: Engineering, Pulping \& PCE\&I, TAPPI Press, Atlanta, GA, CD-ROM version (2003).

52. Sarma, G.B., Choudhury, K.A., Keiser, J.R., Steinmoeller, F.E., Rivers, K.B., Mackenzie, C.M., Stone, B.B., Kulig, J.A., "Recovery Boiler Wall Tube Temperature Measurements," MPLUS Project Report MC-01-005, Oak Ridge National Laboratory, Oak Ridge, TN (2002).

53. Frederick, L.A., Singbeil, D.L., Kish, J.R., "Diagnosis of Conditions Contributing to High Fireside Temperatures and Cracking of Primary Air Port Tubes in Kraft Recovery Boilers," Proceedings of the 2005 TAPPI Fall Technical Conference, TAPPI Press, Atlanta, GA, CD-ROM version (2002). 
54. Thompson, R., "Black Liquor Characterization —-Initial Studies," Paprican Report PRR 1729, Paprican, Pointe Claire, QC, August 2004.

55. Kulig, J.A., Edgar, M.P., Orender, R., "Recovery Boiler Furnace Improvement by Black Liquor Spray to the Furnace Perimeter," Proceedings of the 1996 TAPPI Engineering Conference, p. 435, TAPPI Press, Atlanta, GA (1996).

56. Miikkulainen, P., Kankkunen, A., Jarvinen, M.P., "Predicting Droplet Size from Black Liquor Spray Characteristics," Proceedings of the 2004 International Chemical Recovery Conference, Volume 1, p. 71, TAPPI Press, Atlanta, GA (2004).

57. Levesque, D., Fard, M.P., Morrison, S., "BLSpray: Understanding the Effect of Black Liquor Properties and Splash Plate Nozzle Configuration on Spray Characteristics," Proceedings of the 2004 International Chemical Recovery Conference, Volume 1, p. 47, TAPPI Press, Atlanta, GA (2004).

58. Kuhn, D.C.S., Mao, T., Tran, H.N., "Boiler Air Port Corrosion: Part 2. Effect of Air Flow Pattern," Proceedings of the 1993 TAPPI Engineering Conference, p. 215, TAPPI Press, Atlanta, GA (1993).

59. Taljat, B., Zacharia, T., Wang, X.-L., Keiser, J.R., Swindeman, R.W., Hubbard, C.R., "Mechanical Design Of Steel Tubing For Use In Black Liquor Recover Boilers," proceedings from $9^{\text {th }}$ International Symposium on Corrosion in the Pulp and Paper Industry, Ottawa, Ontario (1998).

60. Wang, X-L., Hubbard, C.R., Spooner, S., Taljat, B., Keiser, J.R., "Residual Stresses Due to Processing of Composite Tubes," Proceedings from the Fifth International Conference on Residual Stress, Linkoping, University, Linkoping, Sweden.

61. ASTM Designation G30-90, "Standard Practice for Making and Using U-Bend StressCorrosion Test Specimens," Annual Book of ASTM Standards, Sect. 3, Vol. 03.02, ASTM, Philadelphia, PA (1990).

62. Keiser, J., Swindeman, B., Longmire, H., Hubbard, C., "Examination of Primary Air Port Panels from Georgia-Pacific's Brunswick Mill," presented at Spring 2003 Review Meeting for US Department of Energy Project DE-AC05-00OR22725, in Atlanta, GA, 2003.

63. Raymond E.L., Corrosion 24, 6 (1968): p. 180.

64. Brown M.H. and Kirchner R.W., Corrosion 29, 12 (1973): p.470.

65. Harris J.A. and Scarberry R.C., Journal of Metals September (1971): p. 45.

66. Kohler M. and Heubner U., "Time-Temperature-Sensitization and Time-TemperaturePrecipitation Behaviour," CORROSION 96, paper no. 427 (Houston, TX: NACE, 1996).

67. Prescott R., Eng P. and Singbeil D.L., Pulp and Paper Canada 100, 6 (1999): p. T202.

68. Wilson, A., Lundberg, M., Forsberg, U., “Alloy 825 Mod/SA210-A1 Composite Tubes for Black liquor Recovery Boilers" in Proceedings of the TAPPI 1997 Engineering \& Papermakers Conference, TAPPI Press, Atlanta, GA: 1043-1048 (1997).

69. Otsuka, N., Yamadera, Y., Kinomura, S., "A New Corrosion-Resistant Alloy for Composite Floor Tubes in Black Liquor Recovery Boilers" in Proceedings of the TAPPI 2001 Engineering/Finishing \& Converting Conference, TAPPI Press, Atlanta, GA: CD-ROM version (2001).

70. Lai, G., Jirinec, M., Hulsizer, P., "The Properties \& Characteristics of Alloy 625 Overlay Tubing for Recovery Boiler Applications," in Proceedings of the TAPPI 1998 Engineering Conference, TAPPI Press, Atlanta, GA: 417-430 (1998).

71. Lai, G., Hulsizer, P., "Performance of Type 309 SS Overlay in the Lower Furnace of a Black Liquor Recovery Boiler in Proceedings of the TAPPI 2001 Engineering/Finishing \& Converting Conference, TAPPI Press, Atlanta, GA: CD-ROM version (2001).

72. Plumley, A., Henry, J., Jones, A., "Chromium Diffusion Coating-Definitive Protection for Papermill Recovery Boilers," in Proceedings of the TAPPI 1998 Engineering Conference, TAPPI Press, Atlanta, GA: 1073-1078 (1997). 
73. Rivers, K.B., Mackenzie, C.M., Stone, B.B., Lee, D.E., Barna, J.L., "Design and Materials Developments to Improve Recovery Boiler Furnace Reliability, presented at PAPTAC $87^{\text {th }}$ Annual Meeting, Montreal, QC, January 31, 2001.

74. Keiser, J.R., Sarma, G.B., Wang, X-L., Hubbard, C.R., Swideman, R.W., Singbeil, D.L., Singh, P.M., "Why Do Kraft Recovery Boiler Composite Floor Tubes Crack?," in Proceedings of the TAPPI 2000 Engineering Conference, TAPPI Press, Atlanta, GA: CD-ROM version (2000).

75. Keiser, J.R., Singbeil, D.L., Sarma, G.B., Choudhury, K.A., Kish, J.R., Frederick, L.A., Hubbard, C.R., Singh, P.M., "Relationship of Recovery Boiler Parameters and Primary Air Port Cracking, in Proceedings of the TAPPI 2002 Engineering/Pulping Conference, TAPPI Press, Atlanta, GA: CD-ROM version (2002).

76. Odelstam, T., Tran, H.N., Barham, D, Reeve, D.W., Hupa, M., Backman, R., Proceedings of the TAPPI 1987 Engineering Conference, (Atlanta, GA: TAPPI Press, 1987): p. 585.

77. Chiotti, P., Markuszewski, R., J. Chem. Eng. Data 30 (1985): p. 197.

78. Paul. L.D., Barna, J.L., M.J. Danielson, Harper, S.L., "Corrosion Resistant Tube Materials for Extended Life of Openings in Recovery Boilers," in Proceedings of the TAPPI 1992 Engineering Conference, TAPPI Press, Atlanta, GA: 321-330 (1992).

79. Barna, J.L., Byers Rogan, J., "Corrosion of Composite Port Opening Tubes in Recovery Boilers: Appearance and Occurrence," Proceedings of the TAPPI 1986 Engineering Conference, TAPPI Press, Atlanta, GA: 377-385 (1986).

80. Bruno, F., "Primary Air Register Corrosion in Kraft Recovery Boilers," Pulp and Paper Corrosion Problems, Volume 4, Proceedings of the $4^{\text {th }}$ International Symposium on Corrosion in the Pulp \& Paper Industry, p. 68, Swedish Corrosion Institute, Stockholm, Sweden, 1983.

81. Wensley, D.A., "Corrosion of Recovery Boiler Waterwall Composite Tubes," Materials Performance, 26 (11): 53-55 (1987). 



\section{INTERNAL DISTRIBUTION}

1. K. A. Choudhury

2. C. R. Hubbard

3. J. R. Keiser

4. P. J. Maziasz

5. R. D. Ott

6. S. J. Pawel

7. S. M. Robinson
8. G. B. Sarma

9. R. W. Swindeman

10. P. F. Tortorelli

11. D. F. Wilson

12. S. J. Zinkle

13. ORNL Laboratory Records (RC)

\section{EXTERNAL DISTRIBUTION}

14. D. C. Crowe, Acuren Group Inc., 6500 Willow Hollow Lane, Madeira, OH 45243

15. S. A. Dillich, U.S. Department of Energy, EE-2F/Forrestal Building, U.S. Department of Energy, 1000 Independence Ave. S.W., Washington, DC 20585

16. L. A. Frederick, Paprican, 3800 Wesbrook Mall, Vancouver, BC, Canada V6S 2L9

17. J. P. Gorog, Weyerhaeuser Company, Mail Stop WTC 3F38, 32901 Weyerhaeuser Way South, Federal Way, WA 98001

18. M. E. Gorog, Weyerhaeuser Company, Mail Stop WTC 1D41, 32901 Weyerhaeuser Way South, Federal Way, WA 98001

19. F. R. Jetté, Domtar Inc., 395 de Maisonneuve Blvd. West, Montréal QC, Canada H3A 1L6

20. M. C. Jha, U.S. Department of Energy, Golden Field Office, 1617 Cole Boulevard, Golden, CO 80401

21. J. R. Kish, Paprican, 3800 Wesbrook Mall, Vancouver, BC, Canada V6S 2L9

22. J. A. Kulig, Babcock \& Wilcox, 20 S. Van Buren Avenue, Barberton, OH 44203-0351

23. W. B. Sharp, MeadWestvaco Corporation, Alfred H. Nissan Technical Center, 11101 Johns Hopkins Road, Laurel, MD 20723-6006.

24. D. L. Singbeil, Paprican, 3800 Wesbrook Mall, Vancouver, BC, Canada V6S 2L9

25. P. M. Singh, Georgia Institute of Technology, 500 10th Street, N.W., Atlanta, GA 30318-5794

26. J. Yuan, Process Simulations Ltd., \#204, 2386 East Mall, Vancouver, BC, Canada V6T 1Z3 